Representação de coleções de documentos textuais por meio de regras de associação

\author{
Rafael Geraldeli Rossi
}





\title{
Representação de coleções de documentos textuais por meio de regras de associação
}

\author{
Rafael Geraldeli Rossi
}

Orientadora: $\operatorname{Prof}^{a}{ }^{a}{ }^{a}$ Solange Oliveira Rezende

Dissertação apresentada ao Instituto de Ciências Matemáticas e de Computação - ICMC-USP, como parte dos requisitos para obtenção do título de Mestre em Ciências - Ciências de Computação e Matemática Computacional. VERSÃO REVISADA.

USP - São Carlos

Agosto de 2011 
Ficha catalográfica elaborada pela Biblioteca Prof. Achille Bassi e Seção Técnica de Informática, ICMC/USP,

com os dados fornecidos pelo(a) autor(a)

Geraldeli Rossi, Rafael

Representação de coleções de documentos textuais por meio de regras de associação / Rafael Geraldeli Rossi; orientador Solange Oliveira Rezende -- São Carlos, 2011

$133 \mathrm{p}$.

Tese (Doutorado - Programa de Pós-Graduação em Ciências de Computação e Matemática Computacional) Instituto de Ciências Matemáticas e de Computação, Universidade de São Paulo, 2011.

1. Mineração de Textos. 2. Representação de Coleções de Documentos Textuais. I. Oliveira Rezende, Solange, orient. II. Título. 


\section{Agradecimentos}

aos meus pais Nestor e Maria Teresa pela educação dada e por terem me apoiado moralmente e financeiramente em todas as etapas da minha vida;

à minha orientadora Dra . Solange Oliveira Rezende, por me orientar e suportar desde $3^{\circ}$ semestre da graduação em bacharelado em informática até os dias atuais. De antemão já agradeço pelos anos que virão. Agradeço também pela paciência nas dias antecedentes às submissões dos artigos onde extrapolávamos em muito o por do sol;

ao Ricardo Marcacini por ser companheiro de moradia, de trabalho, e de futebol. Sem sua colaboração com certeza o trabalho demoraria muito mais para sair;

aos companheiros do LABIC pela convivência diária e pelas horas de café, que foram de fundamental importância para o desestresse e consequente produtividade;

ao Anandsing Dwarkasing pela enorme contribuição nas correções dos trabalhos escritos em inglês. Os trabalhos se tornaram outros após suas correções;

à todos os amigos e amigas que estiveram ao meu lado, e pessoas especiais que passaram pela minha vida. É graças a eles também que me tornei a pessoa que sou hoje;

à todos do ICMC-USP que contribuíram direta ou indiretamente para a conclusão do mestrado;

e ao CNPq pelo apoio financeiro. 



\section{Resumo}

O número de documentos textuais disponíveis em formato digital tem aumentado incessantemente. Técnicas de Mineração de Textos são cada vez mais utilizadas para organizar e extrair conhecimento de grandes coleções de documentos textuais. Para o uso dessas técnicas é necessário que os documentos textuais estejam representados em um formato apropriado. A maioria das pesquisas de Mineração de Textos utiliza a abordagem bag-of-words para representar os documentos da coleção. Essa representação usa cada palavra presente na coleção de documentos como possível atributo, ignorando a ordem das palavras, informações de pontuação ou estruturais, e é caracterizada pela alta dimensionalidade e por dados esparsos. Por outro lado, a maioria dos conceitos são compostos por mais de uma palavra, como "Inteligência Artificial", "Rede Neural", e "Mineração de Textos". As abordagens que geram atributos compostos por mais de uma palavra apresentam outros problemas além dos apresentados pela representação bag-of-words, como a geração de atributos com pouco significado e uma dimensionalidade muito maior. Neste projeto de mestrado foi proposta uma abordagem para representar documentos textuais nomeada bag-of-related-words. A abordagem proposta gera atributos compostos por palavras relacionadas com o uso de regras de associação. Com as regras de associação, espera-se identificar relações entre palavras de um documento, além de reduzir a dimensionalidade, pois são consideradas apenas as palavras que ocorrem ou que coocorrem acima de uma determinada frequência para gerar as regras. Diferentes maneiras de mapear o documento em transações para possibilitar a geração de regras de associação são analisadas. Diversas medidas de interesse aplicadas às regras de associação para a extração de atributos mais significativos e a redução do número de atributos também são analisadas. Para avaliar o quanto a representação bag-of-related-words pode auxiliar na organização e extração de conhecimento de coleções de documentos textuais, e na interpretabilidade dos resultados, foram realizados três grupos de experimentos: 1) classificação de documentos textuais para avaliar o quanto os atributos da representação bag-of-related-words são bons para distinguir as categorias dos documentos; 2) agrupamento de documentos textuais para avaliar a qualidade dos grupos obtidos com a bag-of-related-words e consequentemente auxiliar na obtenção da estrutura de uma hierarquia de tópicos; e 3) construção e avaliação de hierarquias de tópicos por especialistas de domínio. Todos os resultados e dimensionalidades foram comparados com a representação bag-of-words. Pelos resultados dos experimentos realizados, pode-se verificar que os atributos da representação bag-of-related-words possuem um poder preditivo tão bom quanto os da representação bag-of-words. A qualidade dos agrupamentos de documentos textuais utilizando a representação bag-of-related-words foi tão boa quanto utilizando a representação bag-of-words. Na avaliação de hierarquias de tópicos por especialistas de domínio, a utilização da representação bag-of-related-words apresentou melhores resultados em todos os quesitos analisados. 



\section{Abstract}

The amount of textual documents available in digital format is incredibly large. Text Mining techniques are becoming essentials to manage and extract knowledge in big textual document collections. In order to use these techniques, the textual documents need to be represented in an appropriate format to allow the construction of a model that represents the embedded knowledge in these textual documents. Most of the researches on Text Mining uses the bag-of-words approach to represent textual document collections. This representation uses each word in a collection as feature, ignoring the order of the words, structural information, and it is characterized by the high dimensionality and data sparsity. On the other hand, most of the concepts are compounded by more than one word, such as "Artificial Intelligence", "Neural Network", and "Text Mining". The approaches which generate features compounded by more than one word to solve this problem, suffer from other problems, as the generation of features without meaning and a dimensionality much higher than that of the bag-of-words. An approach to represent textual documents named bag-of-related-words was proposed in this master thesis. The proposed approach generates features compounded by related words using association rules. We hope to identify relationships among words and reduce the dimensionality with the use of association rules, since only the words that occur and cooccur over a frequency threshold will be used to generate rules. Different ways to map the document into transactions to allow the extraction of association rules are analyzed. Different objective interest measures applied to the association rules to generate more meaningful features and to the reduce the feature number are also analyzed. To evaluate how much the textual document representation proposed in this master project can aid the managing and knowledge extraction from textual document collections, and the understanding of the results, three experiments were carried out: 1) textual document classification to analyze the predictive power of the bag-of-related-words features, 2) textual document clustering to analyze the quality of the cluster using the bag-of-related-words representation 3) topic hierarchies building and evaluation by domain experts. All the results and dimensionalities were compared to the bag-of-words representation. The results presented that the features of the bag-of-related-words representation have a predictive power as good as the features of the bag-of-words representation. The quality of the textual document clustering also was as good as the bag-of-words. The evaluation of the topic hierarchies by domain specialists presented better results when using the bag-of-related-words representation in all the questions analyzed. 



\section{Sumário}

Resumo .................................. ii

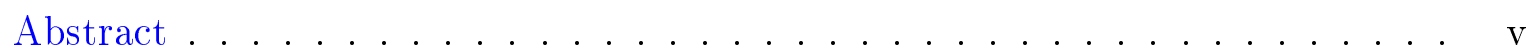

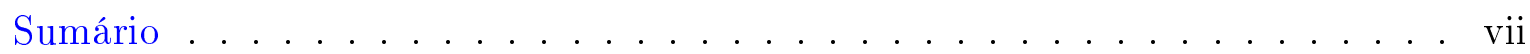

Lista de Figuras . . . . . . . . . . . . . . . . . ix

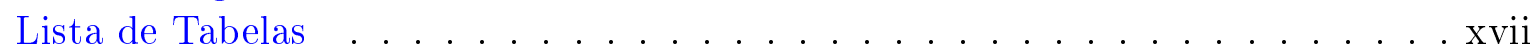

Lista de Algoritmos ...................... . xix

Lista de Abreviaturas $\quad$ xxi

1 Introdução 1

1.1 Objetivos e Hipóteses . . . . . . . . . . . . . . . . . . . 2

1.2 Principais Resultados . . . . . . . . . . . . . . . . 3

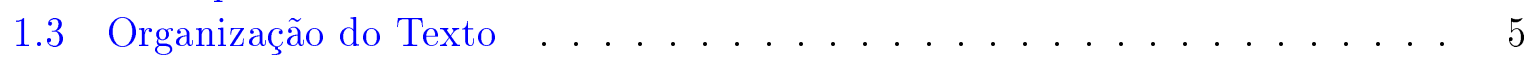

2 Mineração de Textos 7

2.1 Processo de Mineração de Textos . . . . . . . . . . . . . . . . . 7

2.1.1 Identificação do Problema . . . . . . . . . . . . . . . 7

2.1 .2 Pré-Processamento . . . . . . . . . . . . . . . 8

2.1.3 Extração de Padrões . . . . . . . . . . . . . . . . . . . . . . . 11

2.1.4 Pós-Processamento e Utilização do Conhecimento . . . . . . . . . . 11

2.2 Técnicas de Extração de Padrões Utilizadas neste Projeto de Mestrado . . 12

2.2 .1 Regras de Associação . . . . . . . . . . . . . . . . . . . . . . . . 12

2.2 .2 Classificação . . . . . . . . . . . . . . . . . . . . . . 14

2.2.3 Agrupamento . . . . . . . . . . . . . . . . . . . 19

2.3 Representação de Coleções de Documentos Textuais . . . . . . . . . . . . 23

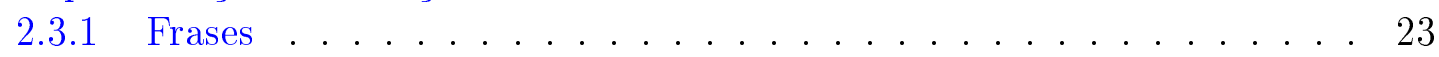

2.3.2 Conjunto de Palavras . . . . . . . . . . . . . . 27

2.3.3 Considerações gerais sobre representação de documentos . . . . . . 30

2.4 Organização e Busca Exploratória em Grandes Coleções de Documentos

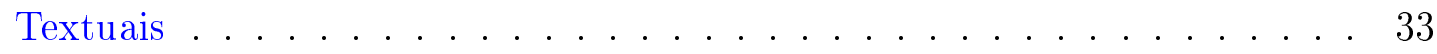

2.5 Considerações Finais . . . . . . . . . . . . . . . . 35

3 Abordagem Proposta para Representação de Coleções de Documentos

Textuais por meio de Regras de Associação $\quad 37$

3.1 Bag-of-Related-Words - Abordagem Proposta para a Representação de Coleções

de Documento Textuais . . . . . . . . . . . . . . . . 37

3.1.1 Mapeando um Documento Textual em Transações . . . . . . . . . . . . 38

3.1 .2 Extraindo Regras de Associação . . . . . . . . . . . . . . . . 41 
3.1.3 Gerando os Atributos e Construindo a Matriz Atributo-Valor . . . . 48

3.2 Síntese das Características da Bag-of-Related-Words . . . . . . . . . . . 48

3.3 Ferramenta Computacional Desenvolvida para a Geração da Representação Bag-of-Related-Words . . . . . . . . . . . . . . . 49

4 Experimentos e Resultados $\quad 53$

4.1 Projeto dos Experimentos . . . . . . . . . . . . . . . 53

4.2 Coleções de Documentos Textuais Utilizadas nos Experimentos . . . . . . 55

4.3 Construção da Bag-of-Related-Words . . . . . . . . . . . . . 55

4.4 Avaliação da Representação Bag-of-Related-Words . . . . . . . . . . . . 58

4.4.1 Avaliação do Poder Preditivo dos Atributos da Bag-of-Related-Words 58

4.4.2 Avaliação da Viabilidade da Representação Bag-of-Related-Words para o Agrupamento de Coleções de Documentos Textuais . . . . . 85

4.4.3 Avaliação de Hierarquias de Tópicos Construídas Utilizando a Representação Bag-of-Related-Words . . . . . . . . . . . . 90

4.5 Considerações Finais Sobre os Experimentos e Resultados Obtidos . . . . . 95

5 Conclusões 97

5.1 Principais Resultados e Contribuições . . . . . . . . . . . . . . . . . . 98

5.2 Limitações . . . . . . . . . . . . . . . . . . . . . . . . . . . . 99

5.3 Trabalhos Futuros . . . . . . . . . . . . . . 100

$\begin{array}{ll}\text { Referências Bibliográficas } & 107\end{array}$

A Pseudocódigos para a geração da representação bag-of-related-words 109

B Tabelas com o Número de Atributos das Coleções Textuais 113

$\begin{array}{lll}\text { C Tabelas com os Resultados de Classificação } & 117\end{array}$

C.1 Naïve Bayes . . . . . . . . . . . . . . . . . . 117

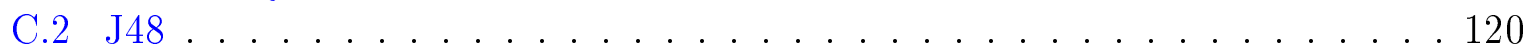

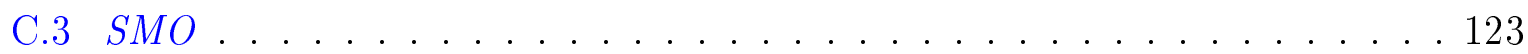

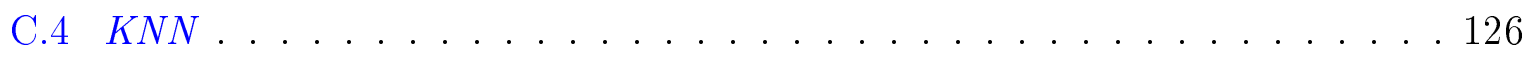

D Tabelas com os Resultados de Agrupamento 131 


\section{Lista de Figuras}

2.1 Etapas do processo de Mineração de Textos (Rezende, 2003). . . . . . . . 8

2.2 Representação da matriz atributo-valor para $N$ documentos e $M$ atributos. 10

2.3 Separação dos dados por hiperplanos perpendiculares aos eixos dos atributos. 17

2.4 Exemplo de uma árvore de decisão obtida por meio dos hiperplanos da Figura 2.3. . . . . . . . . . . . . . . . . . . . . 18

2.5 Exemplo do algoritmo de classificação $K N N$. . . . . . . . . . . . . . 18

2.6 Exemplo dos hiperplanos de decisão e das margens utilizadas pelo algoritmo de classificação $S V M \ldots \ldots \ldots \ldots$. . . . . . . . . . . . . . . 19

2.7 Exemplo de agrupamento de documentos particional. . . . . . . . . . . 21

2.8 Exemplo de um dendrograma obtido por um agrupamento de documentos hierárquico. . . . . . . . . . . . . . . . . . . 21

2.9 Exemplo de organização hierárquica de diretórios relacionado à Mineração de Dados. . . . . . . . . . . . . . . . . . . . 34

3.1 Passos para a geração da representação bag-of-related-words. . . . . . . . . 38

3.2 Frequência das palavras do texto da Tabela 3.2 na representação bag-ofwords e nos mapeamentos para transações analisados. . . . . . . . . . . . 42

3.3 FEATuRE - Tela inicial. . . . . . . . . . . . . . . . . 50

3.4 FEATuRE - Tela para conversão dos documentos textuais em arquivos de transações. . . . . . . . . . . . . . . . . 5 50

3.5 FEATuRE - Tela para conversão dos arquivos de transações em arquivos de regras de associação. . . . . . . . . . . . . . . . . 51

3.6 FEATuRE - Tela para conversão dos arquivos de regras de associação em arquivos de atributos. . . . . . . . . . . . . . 51

3.7 FEATuRE - Tela para conversão dos arquivos de atributos em uma matriz atributos valor. . . . . . . . . . . . . . . . 51

4.1 Desenho Experimental. . . . . . . . . . . . . . . 54

4.2 Número de atributos gerados para as coleções da ACM obtidos pelas diferentes formas de mapeamento com os respectivos valores de suporte mínimo

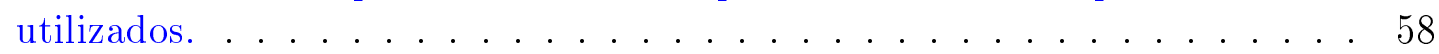

4.3 Número de atributos gerados para as coleções da ACM obtidos pelas representações que utilizaram medidas de interesse objetivas para extrair atributos e os respectivos limiares utilizados. . . . . . . . . . . . . . . 59

4.4 Número de atributos gerados para a coleção Reuters-21578 obtidos pelas representaçõs que utilizaram medidas de interesse objetivas para extrair atributos e os respectivos limiares utilizados. . . . . . . . . . . . . . 60 
4.5 Naïve Bayes - (a) taxas de erro de classificação das representações bagof-related-words com diferentes formas de mapeamento e da representação bag-of-words para as coleções da ACM; (b) taxas de erro de classificação das coleções da ACM para as representações bag-of-related-words com diferentes formas de mapeamento e a representação bag-of-words. . . . . . . . .

4.6 Naïve Bayes - (a) taxas de erro de classificação das representações bag-ofrelated-words com diferentes medidas de interesse objetivas e da representação bag-of-words para as coleções da ACM; (b) taxas de erro de classificação das coleções da ACM para as representações bag-of-related-words com diferentes medidas de interesse objetivas e a representação bag-of-words. 66

4.7 J48 - (a) taxas de erro de classificação das representações bag-of-relatedwords com diferentes formas de mapeamento e da representação bag-ofwords para as coleções da ACM; (b) taxas de erro de classificação das coleções da ACM para as representações bag-of-related-words com diferentes formas de mapeamento e a representação bag-of-words. . . . . . . . . 69

4.8 J48 - (a) taxas de erro de classificação das representações bag-of-relatedwords com diferentes medidas de interesse objetivas e da representação bag-of-words para as coleções da ACM; (b) taxas de erro de classificação das coleções da ACM para as representações bag-of-related-words com diferentes medidas de interesse objetivas e a representação bag-of-words. . . . .

4.9 SMO - (a) taxas de erro de classificação das representações bag-of-relatedwords com diferentes formas de mapeamento e da representação bag-ofwords para as coleções da ACM; (b) taxas de erro de classificação das coleções da ACM para as representações bag-of-related-words com diferentes formas de mapeamento e a representação bag-of-words. . . . . . . . . 78

4.10 SMO - (a) taxas de erro de classificação das representações bag-of-relatedwords com diferentes medidas de interesse objetivas e da representação bag-of-words para as coleções da ACM; (b) taxas de erro de classificação das coleções da ACM para as representações bag-of-related-words com diferentes medidas de interesse objetivas e a representação bag-of-words. . . . .

4.11 KNN - (a) taxas de erro de classificação das representações bag-of-relatedwords com diferentes formas de mapeamento e da representação bag-ofwords para as coleções da ACM; (b) taxas de erro de classificação das coleções da ACM para as representações bag-of-related-words com diferentes formas de mapeamento e a representação bag-of-words. . . . . . . . .

4.12 KNN - (a) taxas de erro de classificação das representações bag-of-relatedwords com diferentes medidas de interesse objetivas e da representação bag-of-words para as coleções da ACM; (b) taxas de erro de classificação das coleções da ACM para as representações bag-of-related-words com diferentes medidas de interesse objetivas e a representação bag-of-words. . . . .

4.13 UPGMA - (A) valores da medida FScore obtida pelas melhores representações utilizando itemsets frequentes e pela representação bag-of-words para as coleções da ACM; (B) valores da medida FScore para as coleções da ACM obtidas pelas melhores representações utilizando itemsets frequentes e a representação bag-of-words. . . . . . . . . . . . . . . . . 
4.14 UPGMA - (A) valores da medida FScore obtidas pelas melhores representações utilizando medidas de interesse objetivas para extrair atributos e pela representação bag-of-words para as coleções da ACM; (B) valores da medida FScore para as coleções da ACM obtidas pelas melhores representações utilizando medidas de interesse objetivas e a representação bag-of-

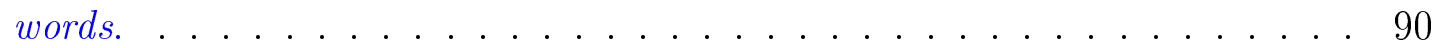

4.15 Segundo nível da hierarquia de tópicos para a coleção ACM-3 utilizando a representação bag-of-related-words (a) e a representação bag-of-words (b). . 93

4.16 Segundo nível da hierarquia de tópicos para a coleção ACM-4 utilizando a representação bag-of-related-words (a) e a representação bag-of-words (b). . 94

4.17 Segundo nível da hierarquia de tópicos para a coleção ACM-8 utilizando a representação bag-of-related-words (a) e a representação bag-of-words (b). . 94 



\section{Lista de Tabelas}

2.1 Matriz de confusão para a categoria $c_{i}$. . . . . . . . . . . . 15

2.2 Síntese das características gerais dos trabalhos que utilizam $n$-gramas como

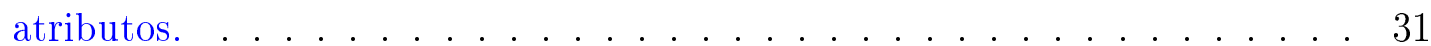

2.3 Síntese das características dos trabalhos que utilizam conjuntos de palavras como atributos. . . . . . . . . . . . . . . . 32

3.1 Texto de exemplo. . . . . . . . . . . . . . . . . . . 39

3.2 Texto da Tabela 3.1 pré-processado. . . . . . . . . . . . . . . . . . 39

3.3 Transações obtidas considerando as sentenças do texto da Tabela 3.2. . . . 40

3.4 Transações obtidas considerando os parágrafos da Tabela 3.2. . . . . . . . . 40

3.5 Transações obtidas considerando um janela deslizante de tamanho 10 do

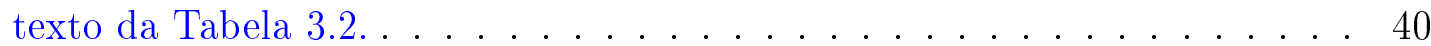

3.6 Número de transações obtidas para o texto da Tabela 3.2 considerando as formas de mapeamento analisadas. . . . . . . . . . . . . . . 41

3.7 Itemsets frequentes obtidos utilizando as diferentes formas de mapeamentos analisadas para o texto da Tabela 3.2. . . . . . . . . . . . . 43

3.8 Medidas de interesse objetivas utilizadas neste projeto. . . . . . . . . . 45

3.9 Propriedades das medidas de interesse objetivas utilizadas neste projeto. $\quad 46$

3.10 Ranking dos atributos segundo as medidas de interesse objetivas utilizadas neste trabalho. . . . . . . . . . . . . . . . . 47

4.1 Descrição das coleções textuais da ACM utilizadas no experimentos. . . . . 56

4.2 Descrição da coleção Reuters 21578 utilizadas no experimentos. . . . . . . 56

4.3 Valores de suporte mínimos utilizados para as formas de mapeamento utilizadas nos experimentos realizados. . . . . . . . . . . . . 57

4.4 Limiares de medidas de interesse objetivas utilizados nos experimentos realizados. . . . . . . . . . . . . . . . 57

4.5 Naïve Bayes - taxas de erro da representação bag-of-words e das representações bag-of-related-words com itemsets frequentes como atributos que obtiveram a menor taxa de erro para as coleções da ACM. . . . . . . . . . 61

4.6 Naïve Bayes - resultado do teste estatístico para avaliar o impacto na taxa de erro de classificação causado pela variação do suporte mínimo para as diferentes formas de mapeamento nas coleções da ACM. . . . . . . . . . . 62

4.7 Naïve Bayes - resultado do teste estatístico para comparar a taxa de erro de classificação nas coleções ACM obtidas pela representação bag-of-words e pelas representações bag-of-related-words com diferentes formas de ma-

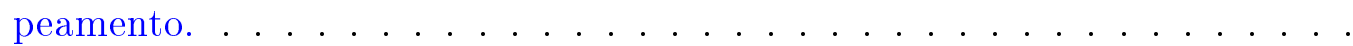


4.8 Naïve Bayes - taxas de erro das representações bag-of-related-words com mapeamento de janela de tamanho 5 e da representação bag-of-words para as coleções da ACM. . . . . . . . . . . . . . . . . . . .

4.9 Naïve Bayes - taxas de erro da representação bag-of-words e das representações bag-of-related-words com medidas de interesse objetivas que obtiveram a menor taxa de erro para as coleções da ACM. . . . . . . . . . . .

4.10 Naïve Bayes - resultado do teste estatístico realizado para avaliar o impacto da variação dos limiares das medidas de interesse objetivas utilizadas na taxa de erro de classificação das coleções ACM. . . . . . . . . . . . .

4.11 Naïve Bayes - resultado do teste estatístico entre as taxas de erro das coleções ACM obtidas pelas representações bag-of-related-words que utilizam medidas de interesse objetivas para extrair atributos e a representação bag-of-words. . . . . . . . . . . . . . . . . . .

4.12 Naïve Bayes - taxas de erro da representação bag-of-words e das representações bag-of-related-words com medidas de interesse objetivas e limiares baseados na média para a coleção Reuters-21578. . . . . . . . . . . . .

4.13 J48 - taxas de erro da representação bag-of-words e das representações bagof-related-words com itemsets frequentes como atributos que obtiveram a menor taxa de erro para as coleções da ACM. . . . . . . . . . . . .

$4.14 \mathrm{~J} 48$ - resultado do teste estatístico para avaliar o impacto na taxa de erro de classificação causado pela variação do suporte mínimo para as diferentes formas de mapeamento nas coleções da ACM. . . . . . . . . . . . .

4.15 J48 - resultado do teste estatístico para comparar a taxa de erro de classificação nas coleções ACM obtidas pela representação bag-of-words e pelas representações bag-of-related-words com diferentes formas de mapeamento.

4.16 Árvores de decisão geradas utilizando as representações [Jan. 5 0,06\%] e [Jan. 30 10\%] para a coleção ACM-3. . . . . . . . . . . . . . . . 70

4.17 J48 - taxas de erro das representações bag-of-related-words com mapeamento de janela de tamanho 5 e da representação bag-of-words para as coleções da ACM. . . . . . . . . . . . . . . . . . .

4.18 J48 - taxas de erro da representação bag-of-words e das representações bagof-related-words com medidas de interesse objetivas que obtiveram a menor taxa de erro para as coleções da ACM. . . . . . . . . . . . . . .

4.19 J48 - resultado do teste estatístico entre as taxas de erro das coleções ACM obtidas pelas representações bag-of-related-words que utilizam medidas de interesse objetivas para extrair atributos e a representação bag-of-words. . .

$4.20 \mathrm{~J} 48$ - taxas de erro da representação bag-of-words e das representações bagof-related-words com medidas de interesse objetivas e limiares baseados na média para a coleção Reuters-21578. . . . . . . . . . . . . . . .

4.21 Ranking da medida Gain Ratio para as coleções ACM-4 e ACM-8 utilizando as representações bag-of-words e [Jan. 5. Aut. Yule's Q $\bar{x}]$. . . . . . . . . 74

4.22 Ranking da medida Gain Ratio para a coleção Reuters 21578 utilizando as representações bag-of-words e [Jan. 5. Aut. Yule's Q $\bar{x}] \ldots \ldots . . . . .75$

4.23 SMO - taxas de erro da representação bag-of-words e das representações bag-of-related-words com itemsets frequentes como atributos que obtiveram a menor taxa de erro para as coleções da ACM. . . . . . . . . . . . .

$4.24 S M O$ - resultado do teste estatístico para avaliar o impacto na taxa de erro de classificação causado pela variação do suporte mínimo para as diferentes formas de mapeamento nas coleções da ACM. 
4.25 SMO - resultado do teste estatístico para comparar a taxa de erro de classificação nas coleções ACM obtidas pela representação bag-of-words e pelas representações bag-of-related-words com diferentes formas de mapeamento.

4.26 SMO - taxas de erro das representações bag-of-related-words com mapeamento de janela de tamanho 5 e da representação bag-of-words para as coleções da ACM. . . . . . . . . . . . . . . . . . . .

4.27 SMO - taxas de erro da representação bag-of-words e das representações bag-of-related-words com medidas de interesse objetivas que obtiveram a menor taxa de erro para as coleções da ACM.

$4.28 S M O$ - taxas de erro da representação bag-of-words e das representações bag-of-related-words com medidas de interesse objetivas e limiares baseados na média para a coleção Reuters-21578. . . . . . . . . . . . . . . .

4.29 KNN - taxas de erro da representação bag-of-words e das representações bag-of-related-words com itemsets frequentes como atributos que obtiveram a menor taxa de erro para as coleções da ACM. . . . . . . . . . . . .

4.30 KNN - resultado do teste estatístico para avaliar o impacto na taxa de erro de classificação causado pela variação do suporte mínimo para as diferentes formas de mapeamento nas coleções da ACM. . . . . . . . . . . . . .

4.31 KNN - resultado do teste estatístico para comparar a taxa de erro de classificação nas coleções ACM obtidas pela representação bag-of-words e pelas representações bag-of-related-words com diferentes formas de mapeamento.

4.32 KNN - taxas de erro das representações bag-of-related-words com mapeamento de janela de tamanho 5 e da representação bag-of-words para as coleções da ACM. . . . . . . . . . . . . . . . . . . .

$4.33 \mathrm{KNN}$ - taxas de erro da representação bag-of-words e das representações bag-of-related-words com medidas de interesse objetivas que obtiveram a menor taxa de erro para as coleções da ACM.

4.34 KNN - taxas de erro da representação bag-of-words e das representações bag-of-related-words com medidas de interesse objetivas e limiares baseados na média para a coleção Reuters-21578. . . . . . . . . . . . .

4.35 UPGMA - resultados da representação bag-of-words e das representações bag-of-related-words com itemsets frequentes como atributos que obtiveram a maior pontuação da medida FScore para as coleções da ACM. . . . . .

4.36 UPGMA - resultados do teste estatístico para avaliar o impacto na pontuação da medida FScore causado pela variação do suporte mínimo para as diferentes formas de mapeamento nas coleções ACM.

4.37UPGMA - resultados dos testes estatísticos para compara o valor da medida FScore nas coleções ACM obtidas pela representação bag-of-words e pelas representações bag-of-related-words com diferentes formas de mapeamento.

4.38 UPGMA - valores da medida FScore obtidos pelas representações bag-ofrelated-words com mapeamento de janela de tamanho 5 e da representação bag-of-words para as coleções da ACM. . . . . . . . . . . . . .

4.39 UPGMA - valores da medida FScore obtidos pela representação bag-ofwords e pelas representações bag-of-related-words com medidas de interesse objetivas que obtiveram o maior valor da medida FScore para as coleções da ACM. . . . . . . . . . . . . . . . . .

4.40 UPGMA - valores da medida FScore obtidos pela representação bag-ofwords e pelas representações bag-of-related-words com medidas de interesse objetivas e limiares baseados na média para a coleção Reuters-21578. . . . 89

4.41 Descrição das classes das coleções textuais da ACM-3, ACM-4, e ACM-8. . 91 
4.42 Matriz de contingência do atributo $t \ldots \ldots . \ldots . \ldots 91$

4.43 Notas dadas pelos especialistas para o primeiro quesito da avaliação subjetiva. 92

4.44 Notas dadas pelos especialistas para o segunda quesito da avaliação subjetiva. 93

B.1 Número de atributos das coleções da ACM obtidos pela representação bagof-words e pelas representações bag-of-related-words que utilizaram itemsets frequentes como atributos. . . . . . . . . . . . . . 114

B.2 Número de atributos das coleções da ACM obtidas pelas representações bag-of-words e bag-of-related-words que utilizaram medidas de interesse objetivas para gerar os atributos. . . . . . . . . . . . . 114

B.3 Número de atributos da coleção Reuters-21578 obtidas pela representação bag-of-words e pelas representações bag-of-related-words que utilizaram medidas interesse objetivas para gerar os atributos. . . . . . . . . . . . 115

C.1 Naïve Bayes - taxas de erro obtidas pelas representações bag-of-relatedwords que utilizaram itemsets frequentes como atributos e pela representação bag-of-words para as coleções da ACM. . . . . . . . . . . . . . 118

C.2 Naïve Bayes - taxas de erro obtidas pelas representações bag-of-relatedwords que utilizaram medidas de interesse objetivas para gerar os atributos e pela representação bag-of-words para as coleções da ACM. . . . . . . . . . 119

C.3 Naïve Bayes - taxas de erro obtidas pelas representações bag-of-relatedwords que utilizaram medidas de interesse objetivas para gerar os atributos e pela representação bag-of-words para a coleção Reuters-21578. . . . . . . 120

C.4 J48 - taxas de erro obtidas pelas representações bag-of-related-words que utilizaram itemsets frequentes como atributos e pela representação bag-ofwords para as coleções da ACM. . . . . . . . . . . . . . . . 121

C.5 J48 - taxas de erro obtidas pelas representações bag-of-related-words que utilizaram medidas de interesse objetivas para gerar os atributos e pela representação bag-of-words para as coleções da ACM. . . . . . . . . . . . . 122

C.6 J48 - taxas de erro obtidas pelas representações bag-of-related-words que utilizaram medidas de interesse objetivas para gerar os atributos e pela representação bag-of-words para a coleção Reuters-21578. . . . . . . . . . . . 123

C.7 SMO - taxas de erro obtidas pelas representações bag-of-related-words que utilizaram itemsets frequentes como atributos e pela representação bag-ofwords para as coleções da ACM. . . . . . . . . . . . . . . . . . 124

C.8 SMO - taxas de erro obtidas pelas representações bag-of-related-words que utilizaram medidas de interesse objetivas para gerar os atributos e pela representação bag-of-words para as coleções da ACM. . . . . . . . . . . . 125

C.9 SMO - taxas de erro obtidas pelas representações bag-of-related-words que utilizaram medidas de interesse objetivas para gerar os atributos e pela representação bag-of-words para a coleção Reuters-21578. . . . . . . . . . 126

C.10 KNN - taxas de erro obtidas pelas representações bag-of-related-words que utilizaram itemsets frequentes como atributos e pela representação bag-ofwords para as coleções da ACM. . . . . . . . . . . . . . . . 127

C.11 KNN - taxas de erro obtidas pelas representações bag-of-related-words que utilizaram medidas de interesse objetivas para gerar os atributos e pela representação bag-of-words para as coleções da ACM. . . . . . . . . . . . 128

C.12 KNN - taxas de erro obtidas pelas representações bag-of-related-words que utilizaram medidas de interesse objetivas para gerar os atributos e pela representação bag-of-words para a coleção Reuters-21578. . . . . . . . . . . 129 
D.1 UPGMA - valores da medida FScore para as coleções da ACM obtidas pelas representações bag-of-related-words que utilizam itemsets frequentes como atributos e pela representação bag-of-words. . . . . . . . . . . . . 132

D.2 UPGMA - valores da medida FScore para as coleções da ACM obtidas pelas representações bag-of-related-words que utilizaram medidas de interesse objetivas para gerar os atributos e pela representação bag-of-words. . . 132

D.3 UPGMA - valores da medida FScore para a coleção Reuters-21578 obtidas pelas representações bag-of-related-words que utilizaram medidas de interesse objetivas para gerar os atributos e pela representação bag-of-words.133 



\section{Lista de Algoritmos}

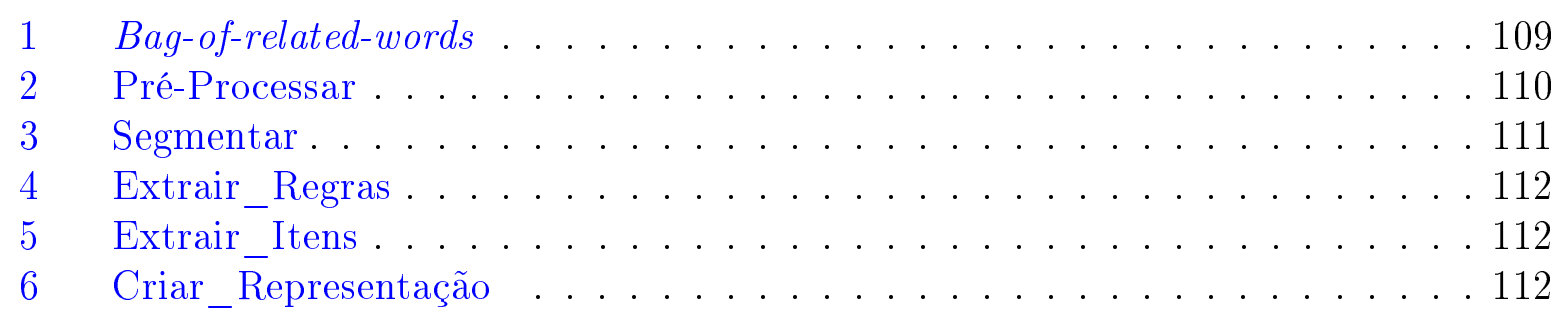





\title{
Lista de Abreviaturas
}

\author{
ACM Association for Computing Machinery \\ BOW Bag-of-words \\ BORW Bag-of-related-words \\ CFWMS Clustering based on Frequent Word Meaning Sequences
}

CFWS Clustering based on Frequent Word Sequences

Conf. Confiança

Conf-min Confiança Mínima

Corr. Correlação

Df document frequency

Idf Inverse document frequency

FIHC Frequent Itemset-based Hierarchical Clustering

FTC Frequent Term-Based Clustering

G.I. Gini Index

HFTC Hierarchical Frequent Term-Based Clustering

I.M. Informação Mútua

INEX Initiative for the Evaluation of XML Retrieval

Jan. Janela

J.M. J-Measure

KNN K-Nearest Neighbors

LHS Left Hand Side

MCV1 Manufacturing Corpus Version 1

Par. Parágrafo

RHS Right Hand Side 
Sent. Sentença

SFM Sequência Frequente Máxima

SMO Sequential Minimal Optimization

Sup-min Suporte mínimo

SVM Support Vector Machine

Tf Term frequency

Tf-idf Term frequency - inverse document frequency

UPGMA Unweighted Pair Group Method with Arithmetic Mean

WPGMA Weighted Pair Group Method with Arithmetic Mean 


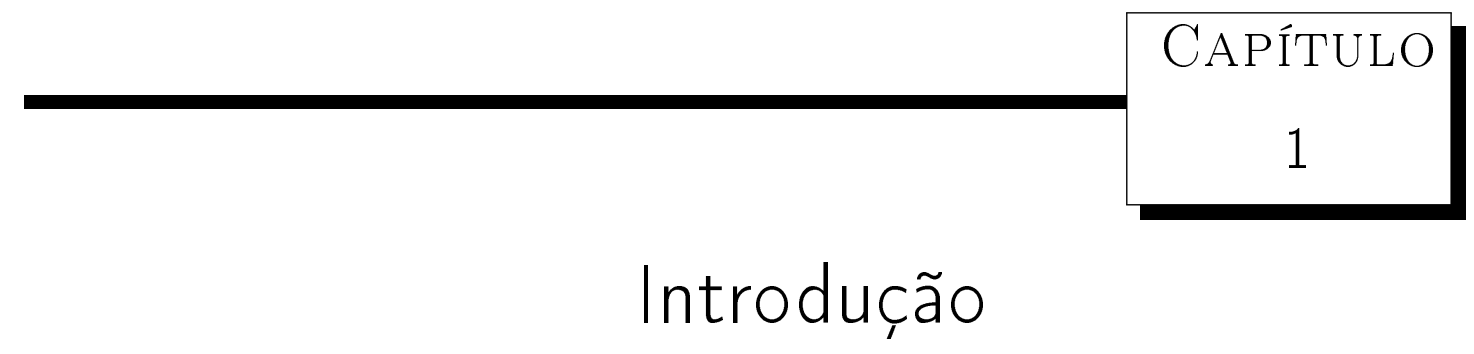

A quantidade de dados disponível em formato digital na rede mundial de computadores tem aumentado incessantemente. De acordo com estimativas realizadas em 2010, somente em 2009 a quantidade de dados armazenada chegou à aproximadamente 800 mil petabytes. A previsão para 2020 é que a quantidade de dados criada e replicada no mundo deve chegar a 35 milhões de petabytes (Gantz e Reinsel, 2010).

Parte dos dados no universo digital estão no formato textual, como e-mails, relatórios, boletins, artigos e conteúdo de páginas de internet. Tais dados podem ter uma grande quantidade de conhecimento embutido. Entretanto, é humanamente impossível analisar, organizar e extrair conhecimento útil de toda essa grande quantidade de dados textuais disponível de forma manual. Consequentemente, o uso de técnicas automáticas para organizar, gerenciar e descobrir conhecimento útil em textos está se tornando cada vez mais importante. Para auxiliar o usuário nessa tarefa, técnicas de Mineração de Textos são fundamentais (Gupta e Lehal, 2009; Feldman e Sanger, 2006).

Para que dados textuais brutos possam tornar-se úteis, é necessário que estes sejam representados de maneira apropriada para a manipulação de algoritmos usados na Mineração de Textos. O modelo espaço vetorial (Salton, 1989) é tipicamente usado na representação de documentos textuais (Song e fang Brook Wu, 2008; Feldman e Sanger, 2006; Ebecken et al., 2003). Neste modelo, cada documento é representado por um vetor, e cada posição desse vetor corresponde a uma dimensão (atributo/termo) da coleção de documentos. Esses atributos geralmente são palavras simples, conjuntos de palavras, ou frases. O valor atribuído a cada dimensão pode indicar a ausência/presença do atributo no documento (0 ou 1), a frequência do atributo no documento, entre outras. O modelo espaço vetorial é simples e permite o uso dos métodos tradicionais que lidam com vetores de atributos numéricos, além de ser construído e computado facilmente (Schenker et al., 2003).

Uma abordagem baseada no modelo espaço vetorial e uma das mais utilizadas na Mineração de Textos é a representação bag-of-words. Nesta abordagem simples, cada palavra encontrada na coleção de documentos pode tornar-se uma dimensão no espaço vetorial. Porém, são ignoradas a ordem das palavras ou as palavras ao redor, informação de pontuação ou estrutural, e assume-se que a ocorrência das palavras em um documento é independente, suposição que não é válida para documentos textuais reais. Este tipo de representação apresenta alta dimensionalidade mesmo após a etapa de pré-processamento (descrito na Seção 2.1.2). Devido à alta dimensionalidade, muitos atributos apresentam valor zero para a frequência e vários algoritmos são computacionalmente ineficientes ao 
lidar com matrizes esparsas e de alta dimensionalidade.

Outro problema encontrado ao utilizar palavras simples como atributos dos documentos textuais é que conceitos normalmente são compostos por duas ou mais palavras, e gerar atributos compostos por mais de uma palavra pode ser útil para o processo de Mineração de Textos. Um exemplo retirado de (Scott e Matwin, 1999) ilustra bem esta situação. Considere a frase "machine learning". Esta frase tem um significado específico que é distinto do significado das palavras "machine" e "learning". Considere também uma situação em que se utiliza um classificador baseado em regras, e as classes a serem aprendidas são "Artificial Intelligence", "Machine Tools" e "Education". É concebível que a frase "machine learning" produz um alto ganho de informação para a classe "Artificial Intelligence", mesmo que cada palavra individual produza um baixo ganho, pois a palavra "machine" pode ocorrer tanto nas classes "Artificial Intelligence" e "Machine Tools", e a palavra "learning" pode ocorrer tanto nas classes "Artificial Intelligence" e "Education". Neste caso, uma regra potencialmente útil como "machine" \& "learning" $\rightarrow$ "Artificial Intelligence" poderia nunca ser aprendida.

A utilização de atributos compostos por mais de uma palavra também pode tornar o conhecimento extraído ou a identificação de documentos mais interpretável ao usuário. Para ilustrar isso, vamos considerar um caso em que se deseja gerar descritores para um documento textual referente a medidas de validação para agrupamentos utilizando o algoritmo $K$-means (Wu et al., 2009). Ao considerar as 10 palavras simples mais frequentes do documento, são extraídos os seguintes descritores: measure, cluster, validation, data, class, normal, k-means, results, sets, distribution. Ao utilizar conjuntos de duas palavras mais frequentes são extraídos os seguintes descritores: cluster_measure, validation_measures, data_sets, measure_normalization, cluster_validation, $k$-means_clustering, results_kmeans, clustering_results, measure_k-means, external_measures, e data_clustering. Pode-se notar que os conjuntos de duas palavras mais frequentes facilitam mais o entendimento do assunto do documento do que as palavras simples mais frequentes.

Essas observações levaram os pesquisadores a desenvolver alternativas para representação de documentos textuais mais ricas que a representação bag-of-words, como as representações baseadas em frases (Carvalho et al., 2010; Carvalho e Cohen, 2006; Fürnkranz, 1998; Mladenic e Grobelnik, 1998; Fagan, 1989) e em conjuntos de palavras (Zhang e Zhu, 2007; Tesar et al., 2006; Bekkerman e Allan, 2004; Yang et al., 2003; Ahonen-Myka et al., 1999). Essas abordagens geralmente adicionam atributos à representação bag-of-words, aumentando ainda mais a dimensionalidade da representação. Algumas abordagens analisam a coleção inteira para gerar os atributos. Isto pode aumentar o custo computacional devido a grande quantidade de dados que precisa ser analisada. Além disso, a maioria das abordagens necessita executar um processo de seleção de atributos supervisionado, requerendo assim coleções textuais rotuladas, o que não é comum em coleções de documentos textuais reais. Portanto, um algoritmo eficiente para gerar esses conjuntos de atributos deve então evitar a geração de uma grande quantidade de atributos para não necessitar de processo de seleção de atributos (Fürnkranz, 1998).

\subsection{Objetivos e Hipóteses}

Considerando os problemas encontrados na literatura para a geração de atributos compostos por mais de uma palavra, o objetivo deste projeto de mestrado é obter uma representação de documentos textuais com atributos que contribuam para os resultados do processo de Mineração de Textos, que facilite a interpretação do conhecimento extraído para o usuário, e que possua um número de atributos menor que a representação bag-of- 
words.

Para atender esses objetivos, neste projeto de mestrado é proposta e desenvolvida uma abordagem para a representação de documentos textuais no modelo espaço vetorial nomeada bag-of-related-words. A abordagem proposta utiliza palavras relacionadas dos documentos da coleção como atributos, é mais compacta, e obtém resultados tão bons quanto os obtidos pela representação bag-of-words.

Para obter os atributos relacionados dos documentos textuais de uma coleção são utilizadas regras de associação, uma técnica tradicional na Mineração de Dados para descobrir relações entre conjuntos de items (Agrawal e Srikant, 1994). Para que se possam extrair as regras de associação de um documento textual, é necessário que o conteúdo desse documento seja mapeado em transações. Para isso, nesse trabalho são avaliados três tipos de mapear um documento textual em transações: considerando as sentenças, os parágrafos, e janelas deslizantes como transações. Após extrair as regras de associação, serão utilizados os itens das regras para compor os atributos. Por exemplo, se for extraída a regra inteligência $\Rightarrow$ artifical, será gerado o atributo inteligência_artificial.

O problema de extrair as relações de palavras de cada documento de uma coleção, e a forma de transformar um documento em transações foi definido desta maneira devido ao fato de que palavras que coocorrem em sentenças, parágrafos ou até mesmo em espaços limitados podem ser mais interpretáveis e fornecerem informações sobre contextos do documento do que simplesmente um conjunto de palavras espalhadas pelos documentos.

Como serão utilizadas apenas as palavras que ocorrem e coocorrem acima de uma determinada frequência no documento para gerar as regras de associação, espera-se que a dimensionalidade seja menor do que a obtida pela representação bag-of-words, mesmo gerando atributos formados por mais de uma palavra. Além disso, a redução da dimensionalidade será realizada sem a necessidade de analisar a representação completa dos documentos. Espera-se que o uso de medidas de interesse aplicadas às regras de associação também possa reduzir ainda mais o número de atributos e manter a qualidade dos resultados.

A representação bag-of-related-words também é independente de conhecimento externo e de língua, não necessitando de técnicas de processamento de língua natural nem de especialistas de domínio ou base de conhecimento.

\subsection{Principais Resultados}

As principais contribuições e resultados alcançados com este projeto de mestrado foram:

- Desenvolvimento de um método para representação de documentos textuais com atributos compostos por mais de uma palavra. A abordagem proposta, nomeada bag-of-related-words, possibilita a representação de coleções de documentos textuais com uma dimensionalidade menor, com uma compreensibilidade dos resultados do processo de Mineração de Textos maior, e com resultados de classificação, agrupamento e construção automática de hierarquias de tópicos tão bons quanto os obtidos pela representação bag-of-words.

- Projeto e desenvolvimento de uma ferramenta que viabiliza gerar a representação de documentos textuais proposta neste projeto de mestrado. A ferramenta FEATuRE (eatures generator based on association rules) está disponível em http://sites. labic.icmc.usp.br:8088/ragero/FEATuRE/feature.zip, e disponibiliza todos os 
passos apresentados no Capítulo 3. A ferramenta também possui outras funcionalidades como visualizar o número de regras geradas para cada documento, comparar os atributos de representações diferentes, verificar quantos atributos são compostos por $x$ palavras, e conversão da uma matriz atributo-valor utilizada na ferramenta FEATuRE (Seção 2.1.2) para o formato arff utilizado na ferramenta Weka (Witten e Frank, 2005).

- Análise de quais formas de mapear um documento textual em transações produzem melhores resultados. Foram analisadas 6 formas de mapeamento na avaliação: sentença, parágrafo, e janela deslizante de tamanhos 5, 10, 20 e 30. Foi verificado que para a maioria das coleções de documentos textuais utilizadas, o mapeamento de janela deslizante de tamanho 5 produziu resultados melhores do que o mapeamento por sentença, parágrafo e janela deslizante de tamanho 10, 20 e 30.

- Análise de medidas de interesse objetivas para redução do número de atributos. Verificou-se que para a maioria das situações os resultados obtidos por diferentes medidas de interesse objetivas são semelhantes para as tarefas de classificação e agrupamento de documentos textuais. $\mathrm{O}$ uso das medidas de interesse objetivas diminuiu o número de atributos e manteve a qualidade para a grande maioria das dos resultados.

- Desenvolvimento de métodos para calcular automaticamente os limiares das medidas de interesse objetivas. Foi proposto um método para calcular automaticamente o valor de suporte mínimo para cada documento da coleção. O método leva em conta a frequência das palavras, o número de palavras no texto, e o número de transações mapeadas. Os resultados obtidos com o uso do valor de suporte mínimo obtido automaticamente foram competitivos com os resultados obtidos utilizando valores de suporte mínimo definido manualmente. Também foi proposto o uso da média dos valores das medidas de interesse objetivas das regras extraídas de cada documento textual como limiar. Os resultados com os limiares baseados na média também foram competitivos com os limiares definidos manualmente.

- Comparação das dimensionalidades das representações bag-of-related-words e bag-ofwords. A representação bag-of-related-words em diversas situações obteve melhores resultados que a representação bag-of-words com um número muito menor de atributos.

- Análise do poder preditivo dos atributos e da qualidade de grupos de documentos utilizando as representações bag-of-related-words e bag-of-words. A representação bag-of-related-words obteve melhores resultados na classificação de documentos textuais utilizando algoritmos que levam em conta uma grande quantidade de atributos para realizar a inferência, como o algoritmo Nä̈ve Bayes e o KNN. Para o agrupamento de documentos textuais a representação bag-of-related-words apresentou melhores resultados quando utilizada em coleções de textos longos.

- Avaliação subjetiva de hierarquias de tópicos construídas utilizando as representações bag-of-related-words e bag-of-words. Os resultados obtidos com a representação bag-of-related-words foram melhores que a bag-of-words para todos os quesitos analisados. 


\subsection{Organização do Texto}

O restante desta dissertação de mestrado está dividido em 4 capítulos.

No Capítulo 2 são apresentadas as etapas do processo de Mineração de Textos. Como o foco deste projeto de mestrado é a representação de documentos textuais, foi criada uma seção neste capítulo para tratar deste assunto. Também foi criada uma seção sobre o uso da Mineração de Texto na organização e busca exploratória em grandes coleções de documentos textuais, tarefas as quais motivaram o desenvolvimento da representação de documentos textuais proposta neste projeto de mestrado.

No Capítulo 3 é apresentada a representação bag-of-related-words, que foi proposta e desenvolvida neste projeto de mestrado. São detalhas as etapas da abordagem e são comparadas suas características com a dos outros métodos para representação de documentos textuais.

No Capítulo 4 são apresentados os resultados obtidos considerando a representação bag-of-related-words e a representação bag-of-words. Foram avaliados o poder preditivo dos atributos das representações, a qualidade dos agrupamentos de documentos textuais e das hierarquias de tópicos obtidas.

Por fim, no Capítulo 5 são feitas as conclusões sobre este projeto de mestrado e são apresentados os trabalhos futuros. 



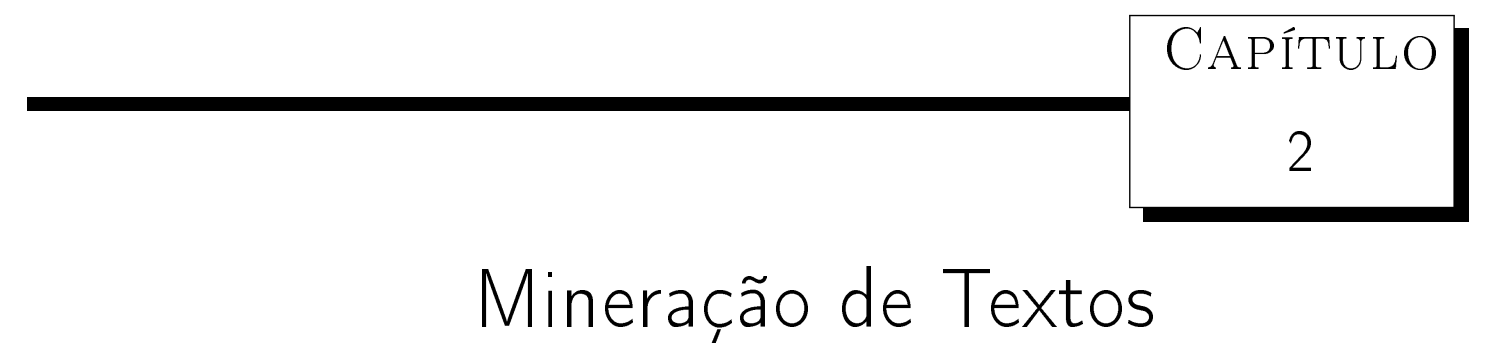

Em um contexto em que grande parte dos dados disponíveis em formato digital encontra-se em formato textual, a Mineração de Textos surge como uma ferramenta de apoio à gestão e organização de conhecimento. Ebecken et al. (2003) definem a Mineração de Textos como "um conjunto de técnicas e processos que descobrem conhecimento inovador nos textos". Nesse sentido, o objetivo da prática de Mineração de Textos centra-se na busca por padrões, tendências e regularidades em documentos escritos em linguagem natural.

A Mineração de Textos é um processo muito semelhante a Mineração de Dados e pode ser considerada uma especialização desta. A principal diferença entre os dois processos é que a Mineração de Textos lida com dados não-estruturados, como e-mails, relatórios e artigos científicos, além de dados semi-estruturados, como páginas HTML ou arquivos XML. Assim, na Mineração de Textos, o primeiro desafio é obter alguma estrutura que represente os documentos textuais.

Neste capítulo são apresentadas as etapas do processo de Mineração de Textos, com foco principalmente: i) na etapa de pré-processamento, onde se encontra a fase de representação de coleções de documentos textuais, e ii) na etapa de extração de padrões, a qual é utilizada na abordagem proposta para geração de atributos e para a etapa de avaliação. Também é apresentado neste capítulo o uso da Mineração de Textos para organização e busca exploratória em grandes coleções de documentos textuais.

\subsection{Processo de Mineração de Textos}

O processo de Mineração de Textos pode ser dividido em cinco grandes etapas: identificação do problema, pré-processamento, extração de padrões, pós-processamento e utilização do conhecimento. Essas etapas formam um ciclo e, ao final deste ciclo, disponibiliza-se o conhecimento descoberto acerca dos textos analisados, como ilustrado na Figura 2.1. Nas próximas subseções serão detalhadas as etapas da Mineração de Textos.

\subsubsection{Identificação do Problema}

Nessa etapa, delimita-se o escopo do problema e o objetivo da aplicação do processo aplicação da Mineração de Textos. Basicamente são definidas as coleções textuais que serão utilizadas, o que se espera obter com o processo de Mineração de Textos, quais 


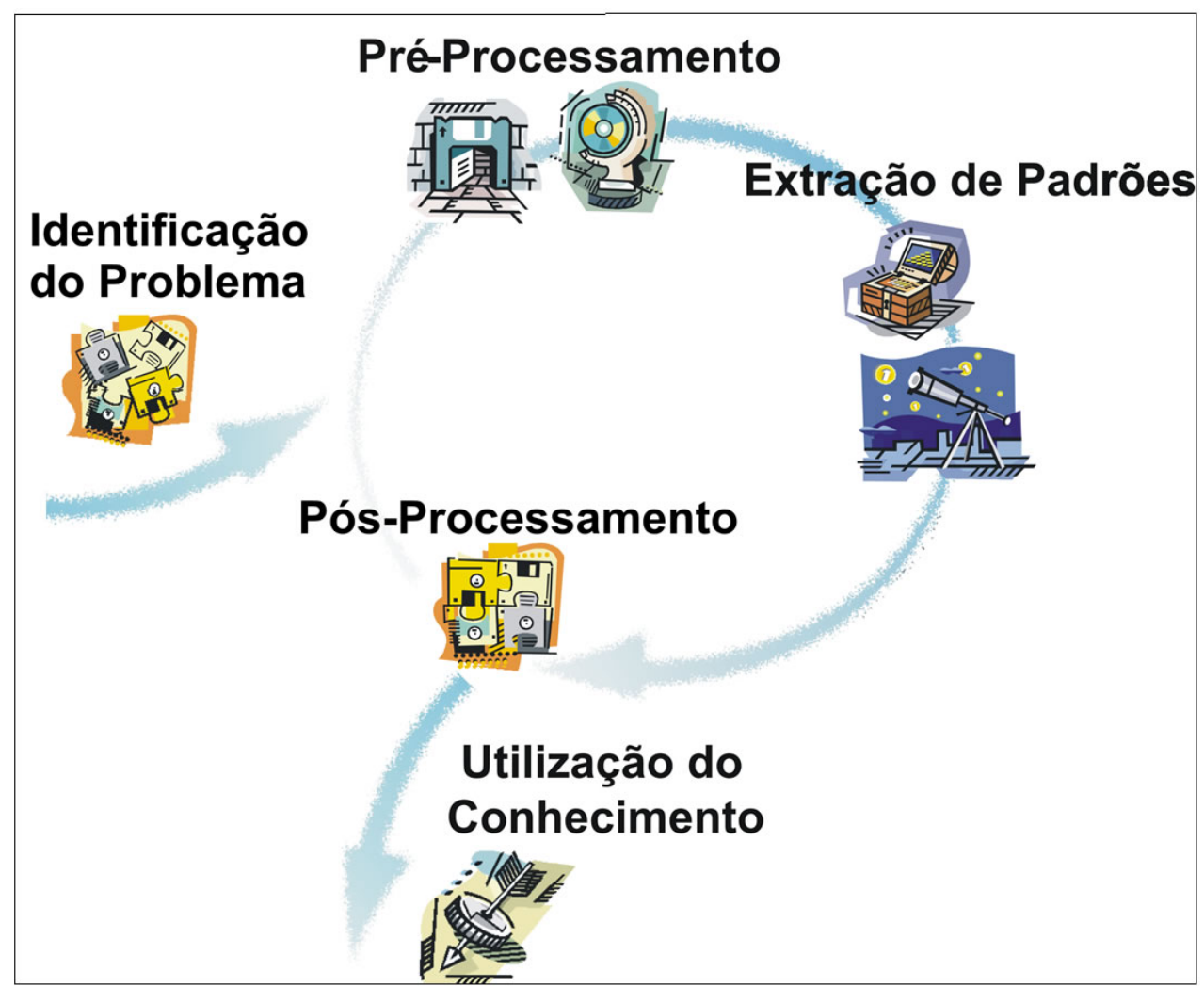

Figura 2.1: Etapas do processo de Mineração de Textos (Rezende, 2003).

técnicas serão utilizadas e como os resultados obtidos serão utilizados. Para isso, (Rezende et al., 2003) definem quatro questões essenciais a serem respondidas nessa etapa:

- Quais são as principais metas do processo?

- Quais critérios são importantes para este problema?

- O conhecimento extraído deve ser compreensível a seres humanos ou um modelo do tipo caixa-preta também é apropriado?

- Qual deve ser a relação entre simplicidade e precisão do modelo extraído?

As respostas a estas questões representam decisões que guiam os próximos passos do processo e têm reflexo no desempenho da aplicação. É importante que, desde essa primeira etapa, as decisões tomadas estejam em concordância com o domínio do problema trabalhado e o objetivo final do processo de extração de conhecimento. Nesse sentido, um ponto importante a ser observado já nessa etapa, é se existe a necessidade de incorporação de conhecimento do domínio para apoiar as tomadas de decisões.

Além disso, os documentos utilizados no processo de extração de conhecimento devem representar o domínio do problema, a fim de que o conhecimento extraído seja representativo e consiga alcançar o objetivo do processo.

\subsubsection{Pré-Processamento}

A principal diferença entre o processo de Mineração de Textos e o processo de Mineração de Dados encontra-se na etapa de pré-processamento. Esta etapa envolve especialmente as atividades de tratamento da coleção de documentos textuais, remoção de caracteres e palavras que não serão utilizadas, geração de atributos, representação dos 
documentos textuais em um formato adequado para a extração de padrões, e redução da dimensionalidade dos atributos.

As atividades de tratamento da coleção de documentos textuais podem compreender a eliminação de documentos repetidos, verificação de uma estrutura prévia nos documentos a fim de utilizar esta informação para atribuição de pesos, análise dos tamanhos e a verificação da necessidade de atribuição de pesos de acordo com o tamanho de cada documento, e remoção de caracteres que não serão utilizados, como números e caracteres não alfabéticos.

A atividade de geração de atributos consiste em extrair características dos documentos. Essas características normalmente são palavras simples, frases, ou conjuntos de palavras.

Muitas vezes, para diminuir a quantidade de atributos gerados e melhorar o resultado obtido ao final do processo de Mineração de Textos, as palavras que compõem os atributos são simplificadas. Este processo de simplificação faz com que palavras que tenham o mesmo significado essencial, mas que se diferenciam pelo tempo verbal, gênero, etc., representem a mesma informação. Isso faz com que palavras como agrupar, agrupamento, e agrupado correspondam a um único atributo e consequentemente sejam representadas e contabilizadas de uma única maneira, por exemplo, agrup. Para a Mineração de Textos, a simplificação de palavras pode ser feita utilizando a radicalização, que reduz cada palavra do texto ao seu radical; a lematização, que agrupa as variantes de um termo em um único lema, ou seja, transforma verbos para sua forma no infinitivo, e substantivos e adjetivos para o masculino singular; ou a substantivação, na qual as palavras passam a exibir um comportamento sintático/semântico semelhante aquele próprio de um nome (Conrado, 2009).

Além da simplificação, as palavras presentes nas coleções textuais podem ser analisadas e tratadas para gerar atributos mais consistentes para representar os documentos. A análise dos atributos pode ser feita segundo duas abordagens: linguística ou estatística. $\mathrm{Na}$ análise linguística, buscam-se as palavras baseadas no seu contexto, utilizando, para isso, técnicas de Processamento de Língua Natural (PLN), sendo, portanto, dependente do idioma. Já na análise estatística, os atributos são avaliados por medidas quantitativas ou qualitativas. As medidas qualitativas correspondem à presença ou ausência do atributo no texto (medidas booleanas). As medidas quantitativas têm sua base na frequência do atributo no documento e, de variações sobre essa medida, por exemplo, frequência relativa na coleção, frequência normalizada em relação à coleção, e frequência relativa no documento.

Outro procedimento para melhorar a qualidade e diminuir a quantidade de atributos consiste na eliminação das stopwords dos documentos da coleção. As stopwords são palavras consideradas irrelevantes para o processo de Mineração de Textos. Normalmente são consideradas como stopwords preposições, pronomes, artigos e interjeições. Além dessas palavras, pode haver palavras que não são úteis apenas para um domínio de aplicação, como por exemplo a palavra "introdução", quando o domínio a ser analisado consiste de artigos científicos. Essas palavras consideradas irrelevantes somente em um domínio específico são denominadas stopwords de domínio.

Uma outra prática adotada na geração de atributos é a adoção de um thesaurus. Nesta situação, um atributo é usado para substituir outros atributos. Por exemplo, supondo um conjunto de documentos sobre notícias de esporte, ao invés de gerar atributos como "futebol", "natação", "vôlei", pode-se gerar apenas o atributo "esporte".

Uma vez gerados os atributos que representam os documentos textuais, é então obtida uma representação estruturada. Quando é feita a representação dos documentos, o modelo espaço vetorial é tipicamente usado (Salton, 1989). No modelo espaço vetorial, cada documento é representado por um vetor $\left(d_{i}\right)$, e cada posição desse vetor corresponde a 
uma dimensão (atributo/termo) do documento $\left(t_{i}\right)$. Ao unir todos os vetores que representam os documentos de uma coleção, forma-se a matriz atributo-valor, apresentada na Figura 2.2. A última coluna dessa matriz corresponde à classe dos documentos $\left(c_{i}\right)$, se estes forem rotulados. Essa coluna não existe caso os documentos não possuam rótulos. O modelo espaço vetorial é simples e permite o uso dos métodos tradicionais de extração de padrões que lidam com vetores de atributos numéricos. Para calcular os valores das células $\left(a_{i j}\right)$ da matriz atributo-valor, diversas medidas foram propostas na literatura. Essas medidas podem ser binárias (0 se o elemento não ocorre no documento, e 1 se o elemento ocorre) e baseadas em frequência, como a frequência do atributo no documento ( $t f$ - term frequency), a quantidade de documentos em que o atributo aparece ( $d f$ - document frequency), a frequência inversa do atributo na coleção de documentos (idf - inverse document frequency), e a combinação da frequência no documento com a frequência inversa na coleção de documento (tf-idf) (Salton, 1989).

\begin{tabular}{|c|c|c|c|c|c|c|}
\hline & $\boldsymbol{t}_{\mathbf{1}}$ & $\boldsymbol{t}_{\mathbf{2}}$ & $\boldsymbol{t}_{\mathbf{3}}$ & $\ldots$ & $\boldsymbol{t}_{\boldsymbol{M}}$ & Classe \\
\hline $\boldsymbol{d}_{\mathbf{1}}$ & $\mathrm{a}_{11}$ & $\mathrm{a}_{12}$ & $\mathrm{a}_{13}$ & $\ldots$ & $\mathrm{a}_{1 \mathrm{M}}$ & $\mathrm{c}_{1}$ \\
\hline $\boldsymbol{d}_{\mathbf{1}}$ & $\mathrm{a}_{21}$ & $\mathrm{a}_{22}$ & $\mathrm{a}_{23}$ & $\ldots$ & $\mathrm{a}_{2 \mathrm{M}}$ & $\mathrm{c}_{2}$ \\
\hline $\boldsymbol{d}_{\mathbf{1}}$ & $\mathrm{a}_{31}$ & $\mathrm{a}_{32}$ & $\mathrm{a}_{33}$ & $\ldots$ & $\mathrm{a}_{3 \mathrm{M}}$ & $\mathrm{c}_{2}$ \\
\hline$\vdots$ & $\vdots$ & $\vdots$ & $\vdots$ & $\ddots$ & $\vdots$ & $\vdots$ \\
\hline $\boldsymbol{d}_{\boldsymbol{N}}$ & $\mathrm{a}_{\mathrm{N} 1}$ & $\mathrm{a}_{\mathrm{N} 2}$ & $\mathrm{a}_{\mathrm{N} 3}$ & $\ldots$ & $\mathrm{a}_{\mathrm{NM}}$ & $\mathrm{c}_{\mathrm{N}}$ \\
\hline
\end{tabular}

Figura 2.2: Representação da matriz atributo-valor para $N$ documentos e $M$ atributos.

A abordagem bag-of-words é uma das formas de representação de documentos textuais baseada no modelo espaço vetorial e uma das mais utilizadas na Mineração de Textos. Cada palavra encontrada na coleção pode tornar-se um atributo nesta representação. Informações como pontuação, a ordem nas quais as palavras aparecem e quais palavras estão relacionas, são descartadas.

A representação bag-of-words tem como características principais a alta dimensionalidade e a alta esparsidade dos dados. A alta dimensionalidade é causada pelo grande número de palavras diferentes contidas em uma coleção de textos. Já a natureza esparsa da matriz é ocasionada pelo fato de que grande parte das palavras ocorre somente em uma pequena parte dos documentos. Devido a esses problemas, vários algoritmos de extração de padrões têm o seu desempenho negativamente afetado. Yu e Liu (2004) destacam que o excesso de atributos pode causar lentidão no processo de Mineração de Textos, bem como decremento na qualidade do conhecimento extraído (overfitting, por exemplo). Além disso, nem todos os atributos gerados são considerados relevantes para a descrição do domínio retratado pela coleção de documentos (Moura, 2009).

Dessa maneira, é de extrema importância a redução do espaço de atributos para otimização dos resultados do processo de Mineração de Textos e melhorar a representatividade dos dados, no sentido de determinar os atributos mais representativos para a modelagem do domínio do problema, como também para atender a aspectos de compreensibilidade e escalabilidade dos modelos resultantes. A ideia é tornar o conjunto de atributos com o qual se trabalha mais conciso, porém não menos representativo em relação ao conjunto original.

Ainda no que se refere aos atributos de uma coleção de documentos textuais, algumas pesquisas mostraram que o uso de atributos compostos por mais de uma palavra de fato melhora a qualidade dos resultados do processo de Mineração de Textos, como no caso da classificação (Carvalho e Cohen, 2006; Tesar et al., 2006; Tan et al., 2002a; Fürnkranz, 
1998; Mladenic e Grobelnik, 1998), do agrupamento de documentos (Beil et al., 2002; Fung et al., 2003), e na recuperação de informação (Koster e Seutter, 2003; Mitra et al., 1997; Fagan, 1989). Além disso, os resultados podem ser interpretados mais facilmente pelo usuário quando são utilizados atributos compostos por mais de uma palavra. Mais detalhes sobre representações que utilizam atributos compostos por mais de uma palavra são apresentados na Seção 2.3

\subsubsection{Extração de Padrões}

Uma vez que os documentos da coleção de documentos textuais foram pré-processados, e tendo obtida uma representação estruturada, a próxima etapa do processo de Mineração de Textos consiste em extrair os padrões. As tarefas a serem realizadas nesse ponto são definidas de acordo com o objetivo do processo de extração de conhecimento que foi estabelecido na etapa de identificação do problema. Assim como na Mineração de Dados, pode-se resumir as principais atividades de extração de padrões em textos em atividades preditivas e atividades descritivas.

As atividades preditivas consistem no uso de algoritmos de aprendizado de máquina supervisionados. Esses algoritmos exigem um conjunto de exemplos de treinamento para os quais o atributo meta tenha valor conhecido. As atividades preditivas são divididas em dois tipos de tarefas: a tarefa de classificação e a tarefa de regressão. A classificação é referente ao processo em que o atributo meta tem valor categórico discreto (rótulos), enquanto que a regressão remete à predição de variáveis com valores contínuos. As atividades preditivas em Mineração de Textos tem como principal aplicação a classificação (categorização) automática de documentos, ou seja, atribuir documentos à categorias pré-definidas. Por exemplo, a partir da seleção de uma coleção de artigos sobre economia e informática, pode-se criar um modelo capaz de inferir se um novo documento pertence a área de economia ou a área de informática.

As atividades descritivas consistem no uso de algoritmos de aprendizado de máquina não-supervisionados. Esses algoritmos detectam comportamentos intrínsecos na coleção de dados, sendo que esses dados não possuem atributos meta. As principais tarefas descritivas em Mineração de Textos são a obtenção de regras de associação, o agrupamento, e a sumarização de coleções documentos.

\subsubsection{Pós-Processamento e Utilização do Conhecimento}

Os padrões extraídos dos documentos precisam ser avaliados para então serem disponibilizados ao usuário. Deve-se avaliar aspectos do conhecimento extraído de acordo com o contexto do problema, como a representatividade do conhecimento obtido, a novidade contida nos resultados e a maneira que o conhecimento deve ser utilizado.

Antes de interpretar os padrões gerados e utilizá-los, deve-se verificar a validade e a aplicabilidade dos padrões de acordo com os objetivos definidos. Por exemplo, em aplicações que envolvam tarefas preditivas, pode-se avaliar os modelos com medidas relativas à erro, precisão, e revocação na predição de dados não vistos. Avaliações repetíveis e com medidas comparáveis são ditas avaliações objetivas. A avaliação de modelos descritivos é um pouco mais complicada, uma vez que o critério de avaliação varia de acordo com o objetivo do processo.

Algumas vezes podem não existir medidas objetivas para avaliar o resultado do processo, ficando a avaliação a cargo de um especialista do domínio, denominada avaliação subjetiva. Vale ressaltar que este tipo de avaliação também pode ser usada em conjunto com a avaliação objetiva para avaliar se o modelo que representa o conhecimento extraído 
condiz com a realidade ou com o conhecimento de um especialista do domínio de aplicação.

Outro aspecto importante refere-se à compreensibilidade do conhecimento. Os algoritmos de extração de padrões podem gerar uma quantidade de padrões muito grande, além de padrões espúrios, dificultando a compreensão por parte do usuário e fazendo necessária a aplicação de mecanismos que forneçam aos usuários apenas os padrões mais interessantes (Silberschatz e Tuzhilin, 1995).

Uma outra tarefa que tem um importante papel no auxílio ao especialista nesse ponto do processo, mas que também pode ser utilizada ao longo das demais etapas, é a visualização dos resultados. Diversos tipos de gráficos e diagramas podem ser utilizados ao longo de todo o processo pelo analista, facilitando a compreensão dos resultados das diversas etapas e auxiliando a tomada de decisão.

Após ter percorrido todas as etapas do processo de Mineração de Textos, e tendo este processo sido validado na etapa de pós-processamento, o conhecimento extraído pode ser utilizado pelo usuário.

De um modo geral, a extração de conhecimento a partir de bases de dados textuais tornou-se um importante aliado às mais diversas corporações, agências de informação e entidades que necessitem gerenciar e extrair conhecimento de grandes coleções de documentos textuais que possam ser úteis para algum processo de tomada de decisão (Marcacini et al., 2007; Souza et al., 2006; Feldman e Sanger, 2006; Liu et al., 2005a).

\subsection{Técnicas de Extração de Padrões Utilizadas neste Projeto de Mestrado}

À seguir serão detalhadas às tarefas de extração de padrões utilizadas neste projeto de mestrado para gerar os atributos e para validar a representação proposta: regras de associação, classificação e agrupamento.

\subsubsection{Regras de Associação}

Uma regra de associação caracteriza o quanto a presença de um conjunto de itens nos registros de uma base de dados implica na presença de algum outro conjunto distinto de itens nos mesmos registros (Agrawal e Srikant, 1994). Desse modo, o objetivo das regras de associação é encontrar tendências que possam ser usadas para entender e explorar padrões de comportamento dos dados. As regras de associação têm sido amplamente discutidas na literatura sobre descoberta de conhecimento direcionada tanto a dados estruturados como dados não estruturados (Adamo, 2001; Feldman e Sanger, 2006).

O formato de uma regra de associação pode ser representado como uma implicação $L H S \Rightarrow R H S$, em que $L H S$ e RHS são respectivamente o lado esquerdo (Left Hand Side) ou corpo da regra, e o lado direito (Right Hand Side) ou cabeça da regra. As regras de associação podem ser definidas como descrito a seguir (Agrawal e Srikant, 1994):

Seja $D$ uma base de dados composta por um conjunto de itens $A=\left\{a_{1}, \ldots, a_{m}\right\}$ ordenados lexicograficamente e por um conjunto de transações $T=\left\{t_{1}, \ldots, t_{n}\right\}$, na qual cada transação $t_{i} \in T$ é composta por um conjunto de itens (itemset) tal que $t_{i} \subseteq A$. A regra de associação é uma implicação na forma $L H S \Rightarrow$ $R H S$, em que $L H S \subset A, R H S \subset A$ e $L H S \cap R H S=\emptyset$.

Existem duas medidas clássicas para gerar uma regra de associação: suporte e confiança. O valor do suporte mede a força de coocorrência entre $L H S$ e $R H S$ e não relaciona 
possíveis dependências de $R H S$ com $L H S$. Por outro lado, a confiança mede a força da implicação descrita pela regra (Zhang e Zhang, 2002). Buscando facilitar a compreensão das medidas, as mesmas são apresentadas a seguir:

- Suporte: quantifica a incidência que um itemset $X$ ou que LHS RHS ocorrem no conjunto de dados. O suporte para um itemset $X$ pode ser representado por:

$$
\sup (X)=\frac{n(X)}{N}
$$

em que $n(X)$ o número de transações nas quais $X$ ocorre, e $N$ o número total de transações consideradas. Portanto, $\sup (X)=P(x)$, ou seja, o suporte do itemset $X$ é a probabilidade do itemset $\mathrm{X}$ ocorrer no conjunto de transações. Já o suporte de uma regra $L H S \Rightarrow R H S$ pode ser representado por:

$$
\sup (L H S \Rightarrow R H S)=\frac{n(L H S \cup R H S)}{N}=P(L H S \cup R H S)
$$

em que $n(L H S \cup R H S)$ é o número de transações nas quais $L H S$ e $R H S$ ocorrem juntos.

- Confiança: indica a incidência com que RHS aparece dado que LHS ocorreu. Do modo como foi definida, a confiança de uma regra $L H S \Rightarrow R H S$ pode ser representada por:

$$
\operatorname{conf}(L H S \Rightarrow R H S)=\frac{\sup (L H S \cup R H S)}{\sup (L H S)}=P(R H S \mid L H S)
$$

Para se obter as regras de associação são necessários dois passos (Agrawal et al., 1993):

1. Encontrar todos os $k$-itemsets (conjunto de $k$ itens) que possuam suporte maior ou igual ao suporte mínimo especificado pelo usuário (sup-min), chamados de itemsets frequentes;

2. Utilizar todos os $k$-itemsets frequentes, com $k \geq 2$, para gerar as regras de associação. Para cada itemset frequente $l \subseteq A$, encontrar todos os subconjuntos $m$ de itens não vazios de $l$. Para cada subconjunto $m \subseteq l$, gerar uma regra na forma $m \Rightarrow(l-m)$ se a confiança da regra for maior ou igual a confiança mínima especificada pelo usuário (conf-min). Por exemplo, com um itemset frequente $l=a, b, c, d$ e $m=a, b$, pode-se gerar uma regra do tipo $a b \Rightarrow c d$, desde que conf $(a b \Rightarrow c d) \geq$ conf-min.

A obtenção de itemsets frequentes para gerar regras de associação pode ser realizada utilizando diversos algoritmos. Um dos mais importantes algoritmos para gerar itemsets frequentes é o algoritmo Apriori (Agrawal et al., 1993). Esse algoritmo se baseia na propriedade do subconjunto frequente: "Todo subconjunto de um conjunto frequente é também frequente". Baseado nesta propriedade, o algoritmo Apriori só irá, por exemplo, formar um 2-itemset composto pelos itens "pão" e "leite", somente se "pão" e "leite" forem por si só itens frequentes.

Vale ressaltar que usualmente, valores de suporte mínimo (sup-min) e confiança mínima (conf-min) são definidos pelo usuário antes da descoberta das regras de associação. Em geral, altos valores para esses parâmetros geram apenas regras triviais, enquanto que 
baixos valores geram um grande volume de conhecimento no formato de regras, dificultando a análise do usuário na etapa de pós-processamento.

Procedimentos adicionais como eliminação de regras redundantes (Ashrafi et al., 2004; Jaroszewicz e Simovici, 2002; Liu et al., 1999) e utilização de outras medidas além de suporte e confiança (Guillet e Hamilton, 2007; Geng e Hamilton, 2006; Tan et al., 2002b), são muitas vezes utilizados para reduzir a grande quantidade de regras de associação geradas.

Na Mineração de Textos, as regras de associação referem-se especificamente às relações diretas entre conceitos e conjuntos de conceitos, ou seja, indica que transações que envolvem uma palavra ou conjunto de palavras $A$ tendem a envolver uma palavra ou conjunto de palavras $B$ em que $A \cap B=\emptyset$ (Feldman e Sanger, 2006).

As regras de associação vêm obtendo bons resultados quando utilizadas na Mineração de Textos devido ao fato de usar a relação de implicação entre conjuntos de palavras. A utilização das regras de associação dá-se para diferentes objetivos, como na descrição de coleções de documentos textuais (Lopes et al., 2007; Cherfi et al., 2006; Feldman et al., 1997), classificação de textos (Liu e Hu, 2007; Antonie e Zaïane, 2002) e criação de thesaurus (Kongthon et al., 2008).

Porém, as características das bases textuais, principalmente quando os documentos são representados pela abordagem $b a g$-of-words, são diferentes daquelas bases de dados de transações de varejo, de maneira que os algoritmos de mineração de regras existentes não podem lidar com bases textuais eficientemente por causa do enorme número de itemsets (conjunto de palavras) que necessitam ser contabilizados. Alguns algoritmos para esses casos vêm sendo desenvolvidos, como em Holt e Chung (2001) e Holt e Chung (2007), mas ainda assim há um alto custo computacional.

\subsubsection{Classificação}

A classificação ou categorização de documentos textuais, como explicado anteriormente, consiste em atribuir um documento textual à uma ou mais categorias. A classificação é uma importante tarefa para o gerenciamento e organização da informação. Algumas de suas aplicações são: recuperação, roteamento, filtragem, organização de arquivos, geração de metadados, desambiguação de palavras e categorização hierárquica de páginas web.

Para classificar um documento, primeiramente constrói-se um modelo de classificação (ou hipótese), que consiste em induzir uma função $M: D \times C \rightarrow\{0,1\}$, em que $D$ é o conjunto de todos os documentos e $C$ é o conjunto de categorias, que melhor se aproxima da função de atribuição de categorias dos documentos de uma coleção $F: D \times C \rightarrow\{0,1\}$, que é desconhecida (Feldman e Sanger, 2006). É atribuído o valor 1 aos documentos que pertencem a uma categoria $c \subset C$. A partir do modelo, é possível atribuir uma categoria a um novo documento utilizando a função induzida $M$.

Tanto para construir como para testar e avaliar um modelo, é necessário definir quais documentos serão utilizados na fase de construção do modelo (conjunto de treinamento) e quais serão utilizados para testar (conjunto de teste). Práticas comuns consistem em utilizar o próprio conjunto de documentos que foi utilizado para construir o modelo para testá-lo, o que pode levar à resultados otimistas, ou utilizar uma parcela do conjunto de documentos para construir o modelo e a outra parcela para testar. Para evitar que a escolha do conjunto de treinamento e teste possam influir nos resultados, um procedimento conhecido por $n$-fold-cross-validation é recomendado. Este procedimento consiste em dividir o conjunto de documentos em $n$ partes, também conhecidas como pastas, realizando-se $n$ iterações, na qual cada iteração utiliza $n-1$ pastas como conjunto de 
treinamento e uma pasta conjunto de teste. A cada iteração o conjunto de pastas utilizado para treinamento e teste são diferentes.

Para cada documento a ser testado, o atributo classe deste documento é oculto, e é obtida a classe por meio do modelo de classificação. A classe obtida é então comparada com a classe oculta para verificar o acerto ou o erro do modelo.

Após testar o modelo de classificação, é possível construir uma matriz de confusão, como apresentado na Tabela 2.1. Observando a matriz de confusão, é possível identificar quais documentos da classe $c_{i}$ foram realmente classificados como pertencendo a classe $c_{i}$ (Verdadeiro Positivos (VP)), quais documentos de $c_{i}$ não foram classificados como $c_{i}$ (Falsos Negativos (FN)), quais documentos que não eram de $c_{i}$ e foram classificados como $c_{i}$ (Falsos Positivos (FP)), e quais documentos que não eram de $c_{i}$ e que não foram classificados como $c_{i}$ (Verdadeiros Negativos (VN)).

Tabela 2.1: Matriz de confusão para a categoria $c_{i}$.

\begin{tabular}{|c|c|c|c|}
\hline \multicolumn{2}{|c|}{ Categoria $c_{i}$} & \multicolumn{2}{c|}{ Classe Real } \\
\cline { 3 - 4 } Classe Predita & Positivo & Negativo \\
\cline { 2 - 4 } & Negativo & $V P_{i}$ & $F P_{i}$ \\
\hline \multirow{2}{*}{ Clive } & $F N_{i}$ \\
\hline
\end{tabular}

Uma vez construída a matriz de confusão, é possível avaliar o modelo de classificação. Duas medidas muitos comuns para avaliar o modelo são a acurácia $(\hat{A})$ e o erro $(\hat{E})$ dadas pelas seguintes fórmulas:

$$
\begin{gathered}
\hat{A}=\frac{V P+V N}{V P+V N+F P+F N} \\
\hat{E}=\frac{V P+F N}{V P+V N+F P+F N} \text { ou } \hat{E}=1-\hat{A}
\end{gathered}
$$

Além dessas, são comuns a utilização de outras medidas referentes a recuperação de informação, como a precisão $(\pi)$, a revocação $(\rho)$, e a medida $F_{\beta}$, dadas pelas seguintes fórmulas:

$$
\begin{gathered}
\pi_{i}=\frac{V P_{i}}{V P_{i}+F P_{i}} \\
\rho=\frac{V P_{i}}{V P_{i}+F N_{i}} \\
F_{\beta_{i}}=\frac{\left(\beta^{2}+1\right) \pi_{i} \rho_{i}}{\beta^{2} \pi_{i}+\rho_{i}}
\end{gathered}
$$

A precisão avalia os acertos para a classe $c_{i}$ em relação a todos os documentos que o modelo de classificação considerou como sendo da classe $c_{i}$. Já a revocação avalia os acertos para a classe $c_{i}$ em relação a todos os documentos que realmente eram da classe $c_{i}$. A medida $F_{\beta}$ é uma média harmônica entre precisão e revocação, na qual $\beta$ define o grau de importância dado a $\pi$ e consequentemente a $\rho$. Usualmente $\beta$ é definido em 1.

Para obter as estimativas de precisão, revocação e demais outras medidas de avaliação para todas as classes da coleção utilizada, dois métodos diferentes podem ser adotados (Sebastiani, 2002): 
- microaveraging $(\mu)$ : realiza a soma de todas as medidas individualmente para cada classe $c_{i}$.

$$
\begin{aligned}
\pi^{\mu} & =\frac{\sum_{i=1}^{|C|} V P_{i}}{\sum_{i=1}^{|C|}\left(V P_{i}+F P_{i}\right)} \\
\rho^{\mu} & =\frac{\sum_{i=1}^{|C|} V P_{i}}{\sum_{i=1}^{|C|}\left(V P_{i}+F N_{i}\right)}
\end{aligned}
$$

- macroaveraging $(M)$ : pondera as medidas obtidas para cada classe pelo número de classes.

$$
\begin{aligned}
& \pi^{M}=\frac{\sum_{i=1}^{|C|} \hat{\pi}_{i}}{|C|} \\
& \rho^{M}=\frac{\sum_{i=1}^{|C|} \rho_{i}}{|C|}
\end{aligned}
$$

Sendo a classificação uma área do Aprendizado de Máquina, podem haver algoritmos de classificação baseados em diferentes paradigmas. Para avaliar o comportamento da representação de documentos textuais proposta frente a diferentes paradigmas, neste trabalho foram utilizados algoritmos de classificação de 4 paradigmas diferentes (probabilístico, simbólico, baseado em instâncias, e estatístico) (Feldman e Sanger, 2006; Sebastiani, 2002):

- Paradigma Probabilístico: calcula a probabilidade de um vetor de características de um documento $d_{j}=\left\langle w_{1 j}, w_{2 j}, \ldots w_{|T| j}\right\rangle$, em que $w_{x j}$ é o peso do atributo $x$ no documento $d_{j}$, pertencer à classe $c_{i}$ utilizando o teorema de Bayes:

$$
P\left(c_{i} \mid d_{j}\right)=\frac{P\left(c_{i}\right) P\left(d_{j} \mid c_{i}\right)}{P\left(d_{j}\right)}
$$

O algoritmo baseado no paradigma probabilístico utilizado neste trabalho é o Naïve Bayes. Neste algoritmo, no cálculo de $P\left(d_{j} \mid c i\right)$ assume-se que todos os atributos são independentes e portanto,

$$
P\left(d_{j} \mid c_{i}\right)=\prod_{k=1}^{|T|} P\left(w_{k j} \mid c_{i}\right)
$$

Para atributos categóricos ou binários, $P\left(w_{k j} \mid c_{i}\right)$ é estimado pela fração de exemplos de treinamento da classe $c_{i}$ que possuem uma valor particular do atributo $k$.

No caso de atributos contínuos, para a estimativa de $P\left(w_{k j} \mid c_{i}\right)$ pode-se assumir uma forma de distribuição de probabilidades, como a distribuição gaussiana. Considerando isso, $P\left(w_{k j} \mid c_{i}\right)$ pode ser estimado utilizando a seguinte fórmula:

$$
P\left(w_{k j} \mid c_{i}\right)=\frac{1}{\sqrt{2 \pi} \sigma_{k i}} \exp ^{-\frac{\left(w_{k j}-\mu_{k i}\right)^{2}}{2 \sigma_{k i}^{2}}}
$$

em que $\mu_{k i}$ é a média dos valores do atributo $k$ para a classe $c_{i}$, e $\sigma^{2}$ é a variância dos valores do atributo $k$ para a classe $c_{i}$. 
- Paradigma Simbólico: os classificadores baseados no paradigma simbólico produzem modelos facilmente interpretáveis. Uma classe de algoritmos do paradigma simbólico amplamente utilizado nas áreas de Aprendizado de Máquina, Mineração de Dados e Textos, são as árvores de decisão. Uma árvore de decisão é uma árvore na qual os nós internos são rotulados com os atributos da coleção, as arestas são rotulados com testes sobre os atributos, e os nós folhas são rotulados com as classes.

Um dos métodos mais comuns para se construir uma árvore de decisão consiste na estratégia de "divisão e conquista", na qual a cada passo é escolhido um atributo que melhor divide os exemplos de acordo com suas classes. Normalmente essa escolha é feita seguindo uma medida de informação, como a entropia ou o ganho de informação. Após a escolha do atributo é também escolhido um respectivo teste, e são verificados se todos os exemplos de treinamento após este teste pertencem à uma mesma classe. Caso não haja a separação, para cada teste da árvore é realizado uma nova escolha e um novo teste. Esses passos se repetem até que os exemplos separados pelo teste pertençam à uma mesma classe ou até que um critério predefinido seja atingido.

Na Figura 2.3 é ilustrada a separação dos dados por hiperplanos perpendiculares aos eixos, que possibilitam a geração de uma árvore de decisão. Na Figura 2.4 é ilustrada uma árvore de decisão utilizando os hiperplanos da Figura 2.3.

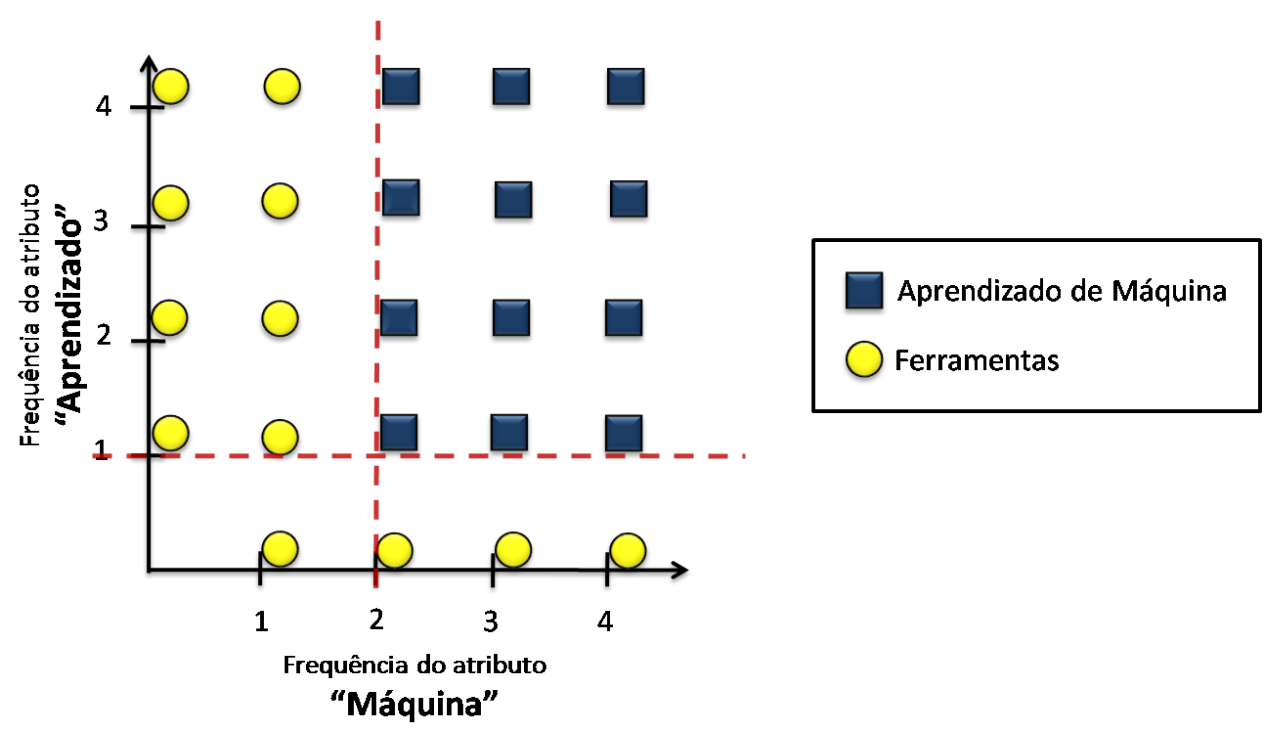

Figura 2.3: Separação dos dados por hiperplanos perpendiculares aos eixos dos atributos.

Para classificar um novo documento, a árvore é percorrida de acordo os valores dos atributos desse documento até alcançar um nó folha. O novo documento será então classificado de acordo com a classe do nó folha alcançado.

- Paradigma Baseado em Instâncias: os classificadores baseados em instâncias não constroem um modelo como uma tabela de probabilidades ou uma árvore de decisão. Ao invés disso, os classificadores baseados em instâncias medem a semelhança entre o exemplo a ser classificado e cada exemplo de treinamento para determinar a classe. 


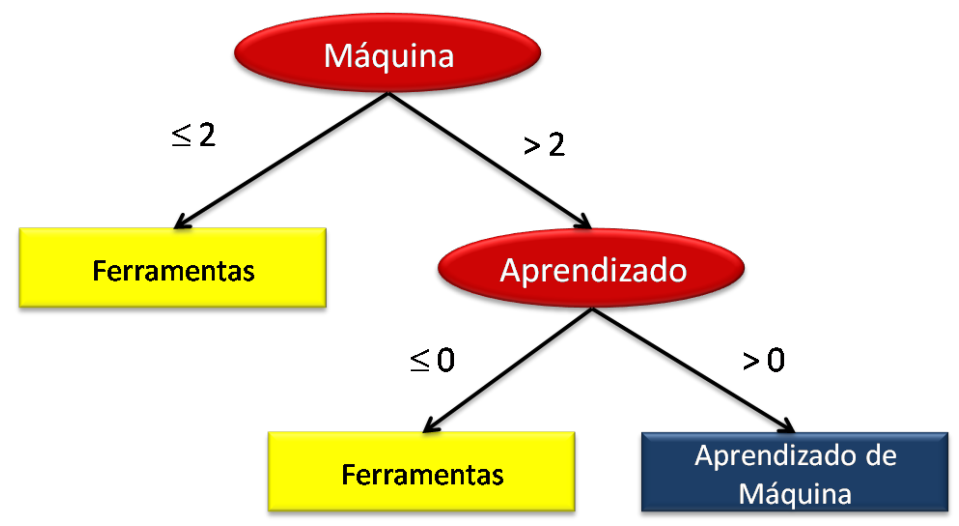

Figura 2.4: Exemplo de uma árvore de decisão obtida por meio dos hiperplanos da Figura 2.3.

Um dos classificadores baseados em instâncias mais utilizados é o KNN ( $k$ Nearest Neighbors). Para definir a classe de um documento $d_{j}$ segundo este algoritmo, é calculada a semelhança para todos os outros documentos da base de treinamento. Então, são retornados os $k$ documentos mais semelhantes, e a classe do documento $d$ será a classe majoritária dos $k$ exemplos retornados. Na Figura 2.5 é ilustrado o $K N N$ com $k=4$. Neste exemplo, o novo documento é classificado como "Aprendizado de Máquina" uma vez que 3 dos 4 vizinhos mais próximos pertencem a esta classe.

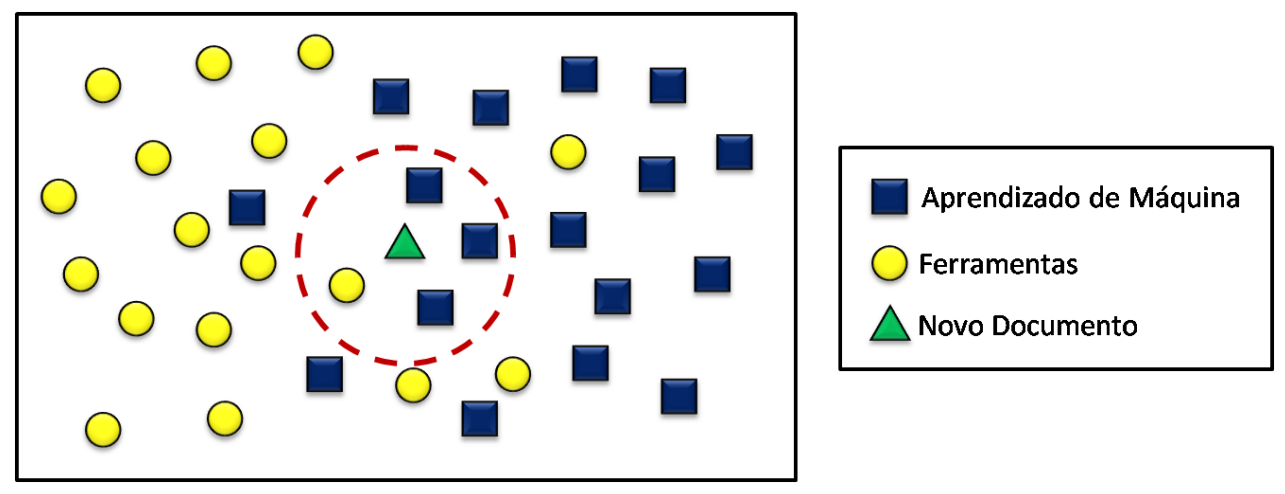

Figura 2.5: Exemplo do algoritmo de classificação $K N N$.

As semelhanças entre os documentos podem ser obtidas utilizando medidas de (dis)similaridades, como a distância Manhatan, Euclidiana, Cosseno, e Jaccard (Tan et al., 2005).

- Paradigma Estatístico: o método de aprendizado supervisionado escolhido para classificação neste trabalho foi o SVM (Support Vector Machines). Basicamente o $S V M$ tenta encontrar um hiperplano com maior margem de separação entre exemplos de classes distintas. Na Figura 2.6 são ilustrados documentos de duas classes e dois hiperplanos $\left(h_{1}\right.$ e $\left.h_{2}\right)$ dentre vários possíveis hiperplanos que poderiam ser utilizados para separar os documentos das duas classes. Neste exemplo, o hiperplano escolhido para separar os documentos das duas classe é $h_{1}$, uma vez que sua margem de separação é maior entre todos os hiperplanos. Os hiperplanos podem ser determinados por um subconjunto de exemplos de treinamento, que são chamados de vetores de suporte. O método $S V M$ é imune à remoção de algum padrão que não seja um vetor de suporte. 


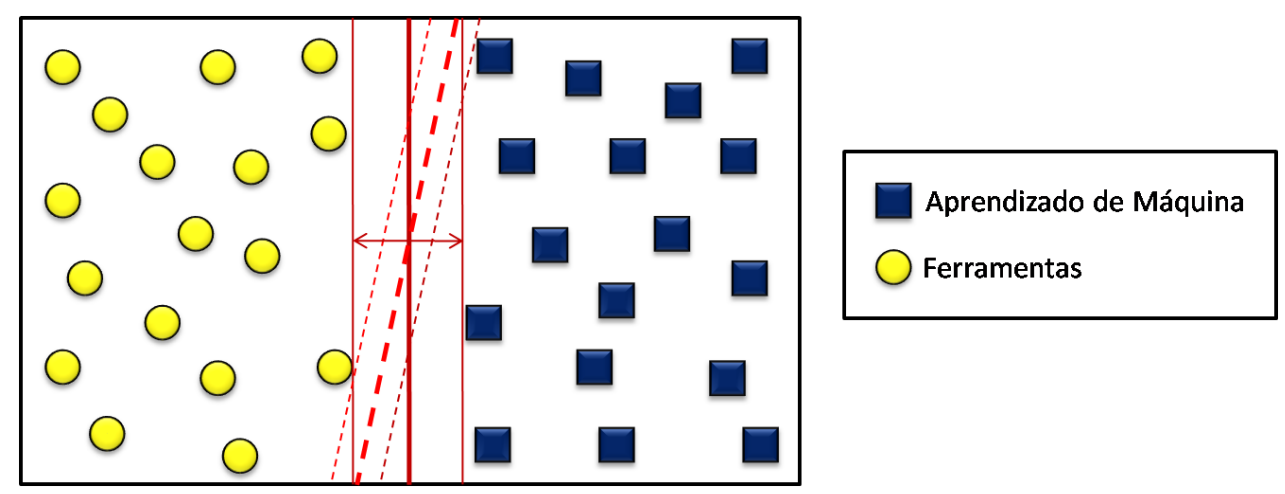

Figura 2.6: Exemplo dos hiperplanos de decisão e das margens utilizadas pelo algoritmo de classificação SVM.

O método $S V M$ não é utilizado somente para casos linearmente separáveis. Pode-se fazer uso de um método conhecido por soft margin o qual permite que o hiperplano de separação de classes escolhidos possa tolerar erros, como no caso da ocorrência de ruídos. Neste caso, é preciso definir um parâmetro $C$ que determinará a penalidade para os exemplos separados incorretamente pelo hiperplano nesse tipo de situação. Além disso, em casos não linearmente separáveis, pode-se mapear o espaço de dados em um novo espaço para que se possa criar um hiperplano de separação linear. Vale ressaltar que o novo espaço de atributos pode ser muito maior que a dimensão do espaço original.

Muitas vezes o mapeamento do espaço necessário não é conhecido. Porém, nesta situação pode-se utilizar o kernel trick, que consiste em criar uma matriz de produto vetorial dos padrões, também conhecida por kernel. Dois exemplos de kernel muitos utilizados são o polinomial e o radio basis function (RBF) (Tan et al., 2005).

O $S V M$ é utilizado somente para problemas com atributos numéricos e é um classificador binário, necessitando ser adaptado para casos de múltiplas classes. A qualidade do modelo de classificação do algoritmo de classificação $S V M$ depende da escolha do kernel, e do parâmetro $C$.

Vale ressaltar que para classificar documentos textuais corretamente, além de um algoritmo de classificação de textos apropriado, é de fundamental importância uma representação de documentos textuais apropriada.

\subsubsection{Agrupamento}

O agrupamento de documentos textuais consiste em criar grupos significativos de documentos, ou seja, reunir em um mesmo grupo documentos de assuntos/tópicos semelhantes. Diferentemente da classificação, no agrupamento não há informações relacionadas às categorias ou tópicos dos documentos.

O agrupamento é uma importante tarefa na sumarização de resultados de busca, e no auxílio à navegação em grandes coleções de documentos. Por exemplo, suponha que um usuário realize uma consulta utilizando a frase "Inteligência Artificial". O resultado desta consulta poderia retornar uma vasta quantidade de documentos dada a diversidade da área. Uma técnica de agrupamento poderia, por exemplo, retornar uma pequena quantidade de grupos/tópicos encontrados durante a busca, como "agentes inteligentes", 
"aprendizado de máquina", "resolução de problemas por meio de busca" e "representação de conhecimento".

Outro exemplo retirado de Feldman e Sanger (2006) também ilustra a utilidade do agrupamento de documentos na recuperação de informação. Suponha uma consulta dada pela palavra "carro". "Carros" muitas vezes podem ser referidos como "automóveis" e uma busca por "carro" poderia não recuperar os documentos contendo "automóvel". Entretanto, as palavras contidas nos textos de ambos podem fazer com que estes sejam similares. Utilizando uma técnica de agrupamento, esta pode recuperar documentos que não contém a exata palavra da consulta, mas um grupo de documentos relacionados à consulta.

Para realizar o agrupamento de documentos representados no espaço vetorial, é necessário calcular a (dis)similaridade entre os vetores de atributos dos documentos, de maneira a deixar os documentos mais semelhantes em um mesmo grupo, e os mais distintos em grupos separados. Normalmente os vetores que representam os documentos são esparsos, ou seja, possuem poucos atributos cujo valor é diferente de zero. Portanto, ao medir a similaridade entre dois vetores que representam os documentos, esta não deve levar em conta os atributos que não ocorrem nos documentos. Atendendo a esses requisitos, a medida de similaridade mais utilizada na Mineração de Textos é a medida cosseno. Essa medida não considera os 0's dos vetores de atributos, nem a magnitude dos pesos dos atributos dos vetores. É considerado apenas o ângulo formado entre os vetores. A medida cosseno varia entre $[0,1]$, sendo que 1 indica que o ângulo entre dois documentos $d_{i}$ e $d_{j}$ é de $0^{\circ}$, ou seja, $d_{i}$ e $d_{j}$ são similares. A fórmula da medida cosseno é a seguinte:

$$
\cos \left(d_{i}, d_{j}\right)=\frac{d_{i} \cdot d_{j}}{\left\|d_{i}\right\|\left\|d_{j}\right\|}
$$

em que $d_{i} \cdot d_{j}$ é o produto dos vetores dos documento $d_{i}$ e $d_{j}$, e $\left\|d_{i}\right\|$ e $\left\|d_{i}\right\|$ são as normas dos vetores dos documentos $d_{i}$ e $d_{j}$ respectivamente.

Uma maneira simples de classificar os algoritmos de agrupamento é separando-os em algoritmos particionais, em que cada documento pertence a um único grupo e os grupos não são sobrepostos (Figura 2.7), e algoritmos hierárquicos, na qual podem haver grupos e subgrupos, gerando uma série encadeada de partições (Figura 2.8). Segundo Zhao e Karypis (2002), as hierarquias de grupos obtidas utilizando algoritmos de agrupamento hierárquicos provêm uma visão dos documentos em diferentes níveis de granularidade, o que facilita a visualização e a interação ao explorar uma grande quantidade de documentos. Dados esses motivos e o fato de que o usuário necessita especificar o número de grupos para os algoritmos particionais, que é uma tarefa difícil quando não há conhecimento suficiente sobre a coleção de textos a ser analisada, o foco deste projeto de mestrado será na utilização de algoritmos de agrupamento hierárquicos para avaliar a qualidades dos agrupamentos de documentos textuais obtidos utilizando a representação de coleções de documentos textuais proposta.

Os algoritmos de agrupamentos hierárquicos podem ser divididos em aglomerativos ou divisivos. Nos algoritmos de agrupamento hierárquico divisivos, inicialmente todos os objetos estão contidos em um único grupo, e a partir daí, são realizadas sucessivas divisões nas partições até que se tenha um objeto por grupo ou até que um critério de parada seja atingido. Já os algoritmos de agrupamento hierárquicos aglomerativos, inicialmente cada objeto corresponde a um grupo. A partir disso, são aglomerados pares de grupos de acordo com algum critério de similaridade até que se tenha um único grupo. O resultado de um algoritmo de agrupamento hierárquico é uma representação denominada dendrograma, apresentada na Figura 2.8. Essa representação provê os grupos e subgrupos obtidos pelo algoritmo de agrupamento, e a similaridade entre os grupos da hierarquia. 


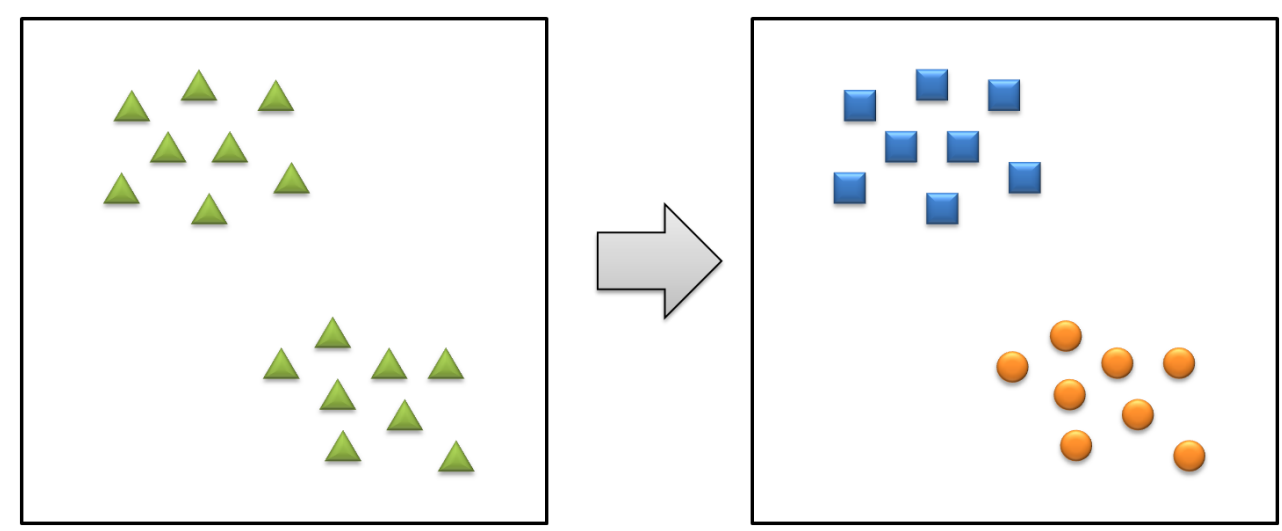

Figura 2.7: Exemplo de agrupamento de documentos particional.

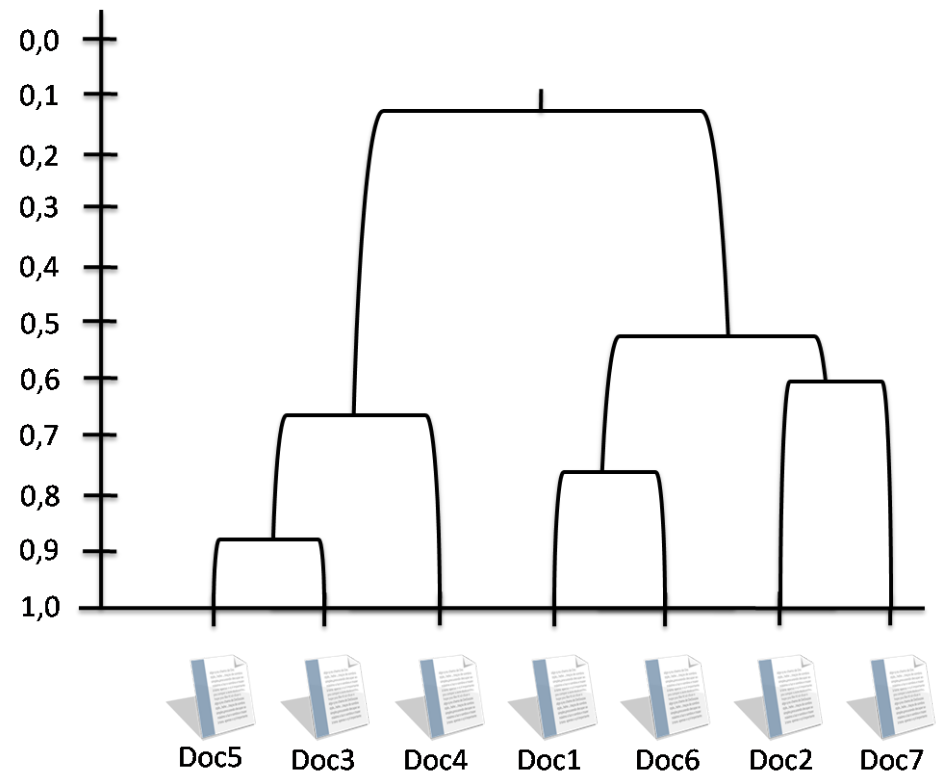

Figura 2.8: Exemplo de um dendrograma obtido por um agrupamento de documentos hierárquico.

Ambos os algoritmos de agrupamento hierárquicos (divisivos e aglomerativos) produzem bons resultados (Zhao e Karypis, 2002). Porém, no caso do agrupamento hierárquico divisivo, é necessário selecionar as sementes para dividir os grupos. A escolha das sementes pode afetar o resultado final, e muitas vezes é necessário escolher diversas sementes para realizar a divisão de um grupo. Por esse motivo, este projeto irá focar nos algoritmos de agrupamento hierárquicos aglomerativos.

Diferentes variações para determinar a similaridade entre grupos de objetos do agrupamento hierárquico aglomerativo foram desenvolvidas. As mais comuns são o single link, complete link, e average link. No método single link, a similaridade entre os grupos se dá pela maior similaridade entre quaisquer pares de objetos de cada grupo. No método complete link, a similaridade entre os grupos se dá pela menor similaridade entre quaisquer pares de objetos de cada grupo. No caso do método average link, é feita a média das similaridades entre todos os pares de objetos de cada grupo, podendo ou não ser considerado o tamanho do grupo como peso para calcular a similaridade. Os algoritmos mais comuns para o average link são o UPGMA (Unweighted Pair Group Method with 
Arithmetic Mean), e o WPGMA (Weighted Pair Group Method with Arithmetic Mean). O UPGMA considera o tamanho dos grupos no cálculo da similaridade, enquanto o WPGMA dá o mesmo peso no cálculo aos grupos independentemente do tamanho.

Para verificar a qualidade dos grupos gerados pelas técnicas de agrupamento, pode-se fazer uso de medidas de avaliação internas e externas. As medidas de avaliação internas informam qual algoritmo teve o melhor desempenho em um problema particular, como a separabilidade entre os grupos e compactação dos grupos. As medidas de avaliação externas comparam os grupos obtidos com informações fornecidas à respeito do que deveriam ser os grupos.

Uma medida de avaliação externa amplamente utilizada nos algoritmos de agrupamento hierárquico é a medida FScore (Fung et al., 2003; Zhao e Karypis, 2002; Beil et al., 2002; Larsen e Aone, 1999). Essa medida analisa a hierarquia de grupos e compara os grupos obtidos com as classes de documentos previamente rotulados. Essa medida é a mesma medida $F_{\beta} \operatorname{com} \beta=1$ apresentada anteriormente, mas agora aplicada ao contexto de agrupamento. Para entender a medida FScore são necessárias as seguintes considerações (Zhao e Karypis, 2002):

- $L_{c}$ : representa uma classe $c$ da coleção;

- $n_{c}$ : representa o número de documentos da classe $c$;

- $S_{i}$ : representa um subgrupo $i$ do agrupamento obtido;

- $n_{i}$ : representa o número de documentos do grupo $i$;

- $n_{c i}$ : representa o número de documentos do grupo $S i$ que pertence à classe $L_{c}$.

Assim como na classificação, a medida FScore é uma média harmônica entre precisão $(\pi)$ e revocação $(\rho)$. Para avaliar o agrupamento, a precisão e revocação para uma classe $L_{c}$ e um grupo $S_{i}$ são definidas da seguinte forma:

$$
\begin{aligned}
& \pi\left(L_{c}, S_{i}\right)=\frac{n_{c i}}{n_{i}} \\
& \rho\left(L_{c}, S_{i}\right)=\frac{n_{c i}}{n_{c}}
\end{aligned}
$$

Uma vez obtida a FScore para as classes com os respectivos grupos, a medida FScore para uma classe $L_{c}$ é o maior valor da FScore obtida para aquela classe em qualquer grupo da hierarquia $T$, ou seja:

$$
F\left(L_{c}\right)=\max _{S_{i} \in T} F\left(L_{c}, S_{i}\right)
$$

A medida FScore para todo o agrupamento é dado pela soma das medidas FScore obtidas para todas as classes $(c)$ ponderada pelo tamanho de cada classe. A media FScore para o agrupamento é dada pela seguinte fórmula:

$$
F \text { Score }=\sum_{r=1}^{c} \frac{n_{r}}{n} F\left(L_{r}\right)
$$

A medida FScore varia entre $[0,1]$ e quanto mais próximo de 1 , maior a qualidade do agrupamento.

Assim como na classificação, para o agrupamento de documentos textuais, não somente um algoritmo apropriado, mas também uma representação apropriada deve ser levada em conta para se obter bons resultados. 


\subsection{Representação de Coleções de Documentos Textuais}

A representação de documentos textuais é fundamental para o processo de Mineração de Textos. Pesquisadores de Mineração de Textos e de Recuperação de Informação têm expressado problemas e insatisfação com a representação bag-of-words, e têm tentado gerar atributos que sejam ao mesmo tempo ricos semanticamente, viáveis tecnicamente, e que melhorem a qualidade dos padrões extraídos.

Além da representação bag-of-words (apresentada na Seção 2.1.2) que utiliza apenas palavras simples para compor os atributos, muitas representações de documentos textuais utilizam atributos compostos por mais de uma palavra. Usualmente esses atributos podem ser compostos por frases ou conjuntos de palavras. Nas próximas seções são apresentados trabalhos relacionados à este tipo de representação.

\subsubsection{Frases}

Segundo o dicionário Michaelis", uma frase é "uma palavra ou grupo de palavras que concorre para exprimir uma ideia ou conjunto de ideias".

As frases são mais úteis para identificar conceitos do que palavras individuais. $\mathrm{O}$ termo frase tem sido utilizado tanto para denotar atributos compostos por mais de uma palavra que foram extraídos por métodos linguísticos, quanto aqueles extraídos por métodos estatísticos. As definições desses dois tipos de frases segundo Mitra et al. (1997) são:

- Frases estatísticas: qualquer sequência de $n$ palavras que ocorrem em um corpus após realizada a etapa de pré-processamento. As frases estatísticas também são conhecidas como $\boldsymbol{n}$-gramas;

- Frases sintáticas: qualquer conjunto de palavras que satisfaçam certas relações sintáticas ou que constituem estruturas sintáticas específicas. Pode-se especificar, por exemplo, que uma frase pode ser constituída por um substantivo seguido por um adjetivo, por exemplo "performance eficiente".

Algumas pesquisas investigaram as diferenças obtidas pelo uso destes dois tipos de frases, como Mitra et al. (1997) e Fagan (1989). Em ambos os trabalhos, as diferenças obtidas pelas abordagens foram insignificantes, além de haver uma grande sobreposição das frases identificadas por ambas as abordagens.

As frases estatísticas apresentam vantagens em relação às frases obtidas por métodos linguísticos. Entre elas pode-se citar (Caropreso et al., 2001):

- Podem ser reconhecidas por meios mais robustos e com um custo computacional menor;

- O efeito de variantes sintaticamente irrelevantes pode ser eliminado, como por exemplo, exemplo de classificação e exemplo classificado.

Dado estas vantagens e a natureza desse projeto de mestrado, o foco deste projeto são os $n$-gramas.

Uma característica da representação por frases estatísticas é a necessidade de definir o número de palavras que irão compor o atributo $(n)$. Porém, mesmo para pequenos valores

\footnotetext{
${ }^{1}$ http://michaelis.uol.com.br/moderno/portugues/index.php?lingua=portuguesportugues\&palavra $=$ frase
} 
de $n$, o número de diferentes atributos que podem ser gerados aumenta monotonicamente com $n$. Para cada $n$-grama há ao menos um $n+1$-grama que tem o $n$-grama como sequência inicial. Além disso, o número de ocorrências da maioria dos n-gramas irá decair com o crescimento de $n$.

Existem duas abordagens principais para utilizar n-gramas na representação de documentos (Bekkerman e Allan, 2004): a primeira utiliza $n$-gramas junto com unigramas, enquanto a segunda exclui unigramas da representação e baseia-se somente em $n$-gramas, com $n \geq 2$. A segunda abordagem em muitos casos piora os resultados em comparação com a abordagem bag-of-words, enquanto a primeira pode potencialmente melhorar os resultados. A seguir são listados alguns trabalhos que envolvem a utilização de $n$-gramas para a representação de documentos textuais.

Em Fagan (1989) foi avaliada a efetividade de frases estatísticas na recuperação de informação em cinco coleções textuais experimentais (CACM, INSPEC, CRAN, MED, e CISI). Neste trabalho, uma frase é composta por dois elementos: a cabeça, palavra principal, e o corpo, palavras que coocorrem com a cabeça. Este método possui seis parâmetros: 1) Dominio, que define qual o limite em que as palavras podem coocorrer na coleção, podendo ser este limite as sentenças, os parágrafos, ou o próprio documento; 2) Proximidade, utilizado para delimitar a distância máxima entre as palavras de uma frase; 3) Df-frase, utilizado para especificar o limite mínimo de ocorrência da frase na coleção de documentos; 4) Df-cabeça, que é o limiar de frequência da cabeça da frase na coleção de documentos; 5) Df-comp, que é o limiar de frequência na coleção de documentos para os componentes da frase; e 6) Comprimento, que limita o número de palavras em uma frase. Nos experimentos realizados, as frases foram definidas com o comprimento 2 e foram variados os demais parâmetros. O método proposto neste trabalho obteve melhoras com diferenças estatisticamente significantes em relação à representação bag-of-words para as bases CACM, INSPEC, CRAN, e MED. A base CISI obteve melhoras em seus resultados, mas não foram estatisticamente significantes. Não foram obtidas diferenças significativas nos resultados com a remoção de frases com baixa e alta frequência, e variações dos limites de proximidade e frequência da cabeça e dos componentes. Além disso, os resultados foram competitivos ou melhores quando comparados com métodos de extração de frases sintáticas. Vale ressaltar que para diferentes coleções, diferentes estratégias para seleção de frases foram utilizadas para obter os melhores resultados.

No trabalho de Mitra et al. (1997) foram comparadas as frases obtidas por métodos estatísticos e as obtidas por métodos linguísticos para a tarefa de recuperação de informação. Foram considerados como frases estatísticas todos os pares de palavras que ocorrem de maneira contígua em ao menos 25 documentos da coleção TREC-Disco 1. Cada palavra que constitui o atributo é radicalizada e o par de palavras é ordenado lexicograficamente. Já para a identificação de frases sintáticas, cada palavra do documento foi marcada por meio da execução de um part-of-speech tagging, e foram extraídas somente as frases nominais $^{2}$. Devido ao custo computacional dos métodos linguísticos para a extração de frases sintáticas, foram extraídos atributos utilizando esta abordagem apenas em uma parcela dos documentos da coleção utilizada. Os resultados obtidos mostraram que o uso de frases não tem efeito nas posições mais altas dos rankings de documentos obtidos por um processo de recuperação, mas têm influência nas posições mais baixas do ranking. Também foi mostrado neste trabalho que as frases obtidas por métodos linguísticos ou estatísticos obtém resultados semelhantes.

Em Mladenic e Grobelnik (1998) é feito o enriquecimento da abordagem bag-of-words com atributos $n$-gramas de diferentes tamanhos. O processo de geração de atributos é realizado em passadas sobre os documentos de uma coleção, na qual $n$-gramas são gerados

\footnotetext{
${ }^{2}$ Frases nominais não frases que não possuem verbos, ou seja, constituídas apenas por nomes.
} 
na $n$-ésima passada utilizando atributos de tamanho $n-1$ gerados no passo anterior. Este processo é semelhante à geração dos k-itemsets frequentes para a extração de regras de associação (Agrawal e Srikant, 1994). Após a geração dos atributos é realizada uma seleção para detectar os melhores atributos. A avaliação é feita na classificação automática de documentos com a hierarquia de textos do Yahoo. Foi utilizada a medida de seleção de atributos odds ratio e foi utilizado o algoritmo de classificação Naïve Bayes. Os resultados foram melhores quando utilizadas sequências de palavras próximas a 3 do que palavras simples, enquanto que sequências longas não têm influência na performance.

No trabalho de Fürnkranz (1998) foi utilizado o algoritmo APRIORITID (Agrawal et al., 1996), que é um algoritmo para gerar itemsets frequentes, para extrair $n$-gramas das coleções textuais. A ideia é bastante similar ao trabalho de Mladenic e Grobelnik (1998). Os atributos $n$-gramas são gerados por $n$ diferentes passadas sobre os documentos. Em cada passo, o número de ocorrências de cada atributo é contado, e um limiar especificado pelo usuário é usado para podar os atributos menos frequentes. O usuário também pode definir uma frequência mínima de documentos. Foram utilizadas as bases Reuters-21578 e 20 Newsgroups, e o algoritmo de aprendizado de regras RIPPER. Para a base 20 Newsgroups, foi utilizado o procedimento 5-fold cross-validation para obter a taxa de erro. Os melhores resultados foram obtidos com cortes moderados na frequência do atributo $(t f)$ e na frequência do documento $d f$ ( 5 para $t f$ e 3 para $d f$ ) e com o uso de sequência de palavras de tamanho 3. De forma geral, o uso de $n$-gramas melhorou os resultados, obtendo uma diferença na taxa de erro de 2,02\%. Para a base Reuters-21578 foram analisadas a precisão, a revocação, a medida $F_{1}$, e a acurácia. Em todas as representações o uso de bigramas resultou nas maiores revocações e nas menores precisões. Já para a medida $F_{1}$ e a acurácia, bigramas apresentaram vantagens nos cortes moderados, enquanto os unigramas apresentaram vantagens considerando cortes mais pesados. As maiores diferenças obtidas pelo método em relação a bag-of-words foram de 3,36\% para a revocação, 0,57\% para a precisão, $1,26 \%$ para a $F_{1}$ e $0,01 \%$ para a acurácia.

Em Caropreso et al. (2001), os autores definiram $n$-grama como uma sequência de palavras radicalizadas, consecutivas, e ordenadas alfabeticamente em uma sentença (após a remoção das stopwords). Os autores usaram unigramas e bigramas como atributos do documento. Foram extraídos os atributos melhores ranqueados utilizando os métodos de seleção de atributos ganho de informação, chi-quadrado, odds ratio, e pela frequência do atributo nos documentos. Os resultados obtidos utilizando a base Reuters-21578 mostram que bigramas extraídos seguindo esse método nem sempre contribuem para a efetividade da classificação de documentos utilizando o algoritmo de classificação Rocchio. Além disso, quando bigramas trazem melhora na performance, é raramente significante (a melhora máxima foi de $2,8 \%$ para a medida macroaveraged $F_{1}$ ).

No trabalho de Tan et al. (2002a), os bigramas foram gerados utilizando o seguinte método: primeiro, as palavras com maior frequência em seus documentos foram ordenadas por frequência e foram consideradas somente as palavras com maior frequência $(U)$. Então foram extraídos bigramas de tal forma que ao menos um de seus componentes pertença a $U$. Depois disso, os autores filtraram os bigramas de acordo com seu $t f$ - $i d f$ e informação mútua. Os autores obtiveram um conjunto de bigramas correspondente a $2 \%$ do número total de unigramas considerados. Os resultados para as medidas $F_{1}$ e $B E P$ foram estatisticamente significantes em relação ao uso de unigramas utilizando o classificador Naïve Bayes.

No trabalho de Zhang e Lee (2003), os autores definem $n$-grama como todas as sequências de palavras. Foram realizados experimentos para classificar questões. Para cada questão foram extraídos dois tipos de atributos: bag-of-words e $n$-gramas. Os resultados referentes ao número de questões classificadas incorretamente utilizando o algoritmo de 
classificação $S V M$ mostraram que os resultados obtidos utilizando os $n$-gramas foram essencialmente os mesmos para a representação bag-of-words.

Em Carvalho e Cohen (2006), foram utilizados $n$-gramas para classificar as intenções dos e-mails, como propor uma reunião, ou submeter uma tarefa. Foi mostrado que explorar a informação contextual nas mensagens, ou seja, utilizar sequências de palavras que aparecem nas mensagens, pode melhorar as classificações das ações embutidas nos e-mails, uma vez que sequências de palavras estão inerentemente associadas com a intenção da mensagem de e-mail. Os atributos foram gerados considerando todas as possíveis sequências de tamanho 1, 2, 3, 4 ou 5 palavras. Foi obtida uma taxa de erro de classificação em média 26,4\% menor que o trabalho semelhante de Cohen et al. (2004) que utilizava apenas atributos compostos por uma palavra. As menores taxas de erro obtidas foram alcançadas utilizando a combinação de 1-grama, 2-gramas e 3-gramas.

No trabalho de Li et al. (2008) foram propostos dois algoritmos para o agrupamento de documentos: o CFWS (Clustering based on Frequent Word Sequences) que realiza o agrupamento apenas baseado em sequências de palavras frequentes, e o CFWMS (Clustering based on Frequent Word Meaning Sequences) que realiza o agrupamento baseando-se em um conjunto de significados de palavras frequentes. Sequências de (significados de) palavras frequentes são aquelas que ocorrem acima de uma certa porcentagem nos documentos de uma coleção. Nesta abordagem cada documento é tratado como uma sequência de palavras. Os significados das palavras são incorporados por meio de relações como a sinonímia e hiponímia/hiperonímia utilizando a Wordnet (Fellbaum, 1998). Os grupos são obtidos de forma semelhante aos métodos FIHC (Fung et al., 2003) e HFTC (Beil et al., 2002) em que um candidato a grupo é um conjunto de documentos textuais que possui o mesmo conjunto de palavras frequentes. Foram realizados experimentos na base Reuters-21578, CISI e no corpus HARD da TREC. Os resultados obtidos utilizando a medida FScore e puridade mostraram que o $C F W M S$ teve maior acurácia do que o $C F W S$ e que ambos tem maior acurácia de agrupamento do que o bisecting k-means e o FIHC em todos as coleções utilizadas.

No trabalho de Carvalho et al. (2010) é investigado o impacto da adição dos $n$-gramas detectados automaticamente em um sistema de recuperação de informação para diversos conjuntos de dados. O trabalho é focado na geração de bigramas. Primeiramente, são extraídos todos os bigramas da coleção de documentos. Após isso, é construído um modelo de classificação utilizando o método $S V M$ em uma base de bigramas rotulados como válidos e não-válidos. Após a obtenção do modelo, são selecionados os $n$-gramas obtidos na primeira etapa. A técnica não necessita de processamento de linguagem natural, porém, para alguns domínios é necessária a intervenção de um especialista para criar uma base de bigramas válidos e não-válidos. Além disso, há um custo adicional de criar um modelo de classificação do algoritmo $S V M$, que pode ser custoso computacionalmente. Nos experimentos, os resultados mostraram que esta abordagem pode ser eficaz para detectar automaticamente os n-gramas, além de poder melhorar a recuperação de informação, aumentando em algumas situações a precisão em até $50 \%$.

Diante dos trabalhos apresentados, vale ressaltar que a mera ocorrência de palavras em sequência no texto não garante que estas se referem a um conceito específico. Por exemplo, do seguinte texto retirado do Wikipedia " "mineração de dados é o processo de explorar grandes quantidades de dados à procura de padrões consistentes", seriam extraídos os seguintes bigramas após a remoção de stopwords: mineracao_dados, dados_processo, processo_explorar, explorar_grandes, grandes_quantidades, quantidades_dados, dados_procura, procura_padroes, padroes_consistentes. Muitos dos n-gramas extraídos não fazem sentido e podem não ser úteis a um processo de extração de padrões, como explorar_grandes,

${ }^{3}$ http://pt.wikipedia.org/wiki/Mineração_de_dados (24 de Novembro de 2010) 
dados_procura e quantidades_dados.

Fica claro que o uso de $n$-gramas para a representação de coleções de documentos textuais é viável quando é utilizado somente na presença de um método para filtrar os $n$-gramas interessantes. O filtro também é necessário porque o número de diferentes $n$-gramas que ocorrem ao menos uma ou poucas vezes na coleção é muito alto.

\subsubsection{Conjunto de Palavras}

Além de utilizar sequências de palavras como atributos, pode-se utilizar também conjuntos de palavras, uma vez que muitos conceitos podem ser expressos não somente por palavras em sequência, mas por palavras que aparecem próximas ou que se repetem em vários documentos de uma coleção. Alguns autores afirmam que as informações do documento são apenas parcialmente representadas por palavras simples ou $n$-gramas. Atributos compostos por mais de uma palavra, que podem ser úteis para implicar uma classe, podem aparecem em posições longe uma das outras por causa da gramática ou algum outro motivo de escrita. Um exemplo retirado de (Yang et al., 2003) ilustra bem esta situação. Suponha que um atributo é constituído apenas pela palavra mineração. Este atributo pode ser insuficiente para distinguir documentos das classes Mineração de Dados e Mineração de Carvão. Entretanto, se a palavra classificação aparecer próximo ou em um mesmo documento que a palavra mineração, esta informação pode ser suficiente para distinguir as duas classes.

Os atributos que contém conjuntos de palavras são mais livres, mais descritivos, e podem ser reconhecidos como uma expansão do $n$-gramas. Porém, o mesmo problema que ocorre ao utilizar $n$-gramas como atributos ocorre ao utilizar conjuntos de palavras: o número de diferentes atributos que podem ser extraídos em uma coleção de documentos pode ser muito maior que o da representação bag-of-words. A seguir são listados alguns trabalhos que envolvem a utilização de conjuntos de palavras para a representação de documentos textuais.

Em Ahonen-Myka et al. (1999) foi proposto o uso de sequências frequentes máximas (SFMs) para representar as características dos documentos de uma coleção. Entretanto, é permitido um intervalo entre as palavras da sequência. Primeiramente são extraídas as SFMs das coleções, ou seja, sequências de palavras frequentes na coleção e que não estão contidas em nenhuma outra sequência maior. Posteriormente, para reduzir o número de SFMs em grandes coleções de documentos, são criadas as classes de equivalência, que consistem em unir as SFMs que aparecem em quase os mesmos documentos. A abordagem foi testada na coleção Reuters e foram obtidos atributos representativos para a descoberta de tendências e eventos.

No trabalho de Beil et al. (2002) foram utilizados conjuntos de palavras frequentes para o agrupamento de textos. Conjuntos de palavras frequentes são conjuntos de palavras que coocorrem acima de uma determinada quantidade de documentos em uma coleção. A principal ideia deste trabalho é obter o agrupamento de documentos evitando a alta dimensionalidade da bag-of-words, considerando somente a dimensionalidade obtida pelo conjunto de palavras frequentes que em geral é mais baixa que a dimensionalidade da bag-of-words. Um grupo nesta abordagem corresponde a um conjunto de documentos que contenham os mesmos conjuntos de palavras frequentes. Neste trabalho são propostos dois algoritmos: o FTC (Frequent Term-Based Clustering) para agrupamento particional, e o HFTC (Hierarchical Frequent Term-Based Clustering) para agrupamento hierárquico. O algoritmo FTC inicia com um conjunto vazio, e continua selecionando um descritor de grupo do conjuntos de palavras até que sejam cobertos todos os documentos da coleção. Para o algoritmo HFTC, o algoritmo FTC é aplicado utilizando um conjunto de um 
único nível, isto é, nos conjuntos de palavras frequentes de tamanho $k$ com $k=1$. Os grupos resultantes são então particionados aplicando o $F T C$ nos conjuntos de atributos frequentes do próximo nível, isto é, utilizando os conjuntos compostos por $k+1$ palavras que contenham o conjunto de $k$ palavras como descritor do grupo. Portanto, o algoritmo HFTC descobre uma hierarquia de agrupamento com um conjunto de palavras vazio na raiz, utilizando conjuntos de uma palavra frequentes no primeiro nível, 2 no segundo nível, e assim por diante, parando quando não existem mais conjuntos de palavras frequentes de próximo nível. O FTC e o HFTC foram avaliados nas bases de textos Classic3, Reuters, e WAP. Foram utilizados os algoritmos bisecting k-means e $k$-secting $k$-means, e as medidas de avaliação entropia para o FTC, e FScore para o HFTC. O FTC apresentou os melhores resultados para a base Classic3, e piores porém próximos para as demais bases em relação ao bisecting e o 9-secting k-means. O HFTC alcançou valores similares ao 9-secting $k$ means mas o bisecting $k$-means apresentou resultados significativamente melhores.

Em Fung et al. (2003) foi proposto o algoritmo FIHC (Frequent Itemset-Based Hierarchical Clustering) para a construção de agrupamentos hierárquicos. Da mesma forma que o trabalho de Beil et al. (2002), também foi utilizada somente a baixa dimensionalidade dos conjuntos de palavras (itemsets) frequentes. Inicialmente são construídos grupos para cada itemset frequente. O grupo é formado pelos documentos que contenham o itemset frequente. Os grupos iniciais não são disjuntos pois um documentos podem contér vários itemsets frequentes. A partir daí, é identificado o melhor grupo para cada documento, de forma que os itemsets frequentes da coleção que o documento contém são também itemsets frequentes do grupo. Para construir a árvore de grupos a partir dos grupos identificados, é utilizado um processo bottom-up, ou seja é escolhido um nó pai no nível $k-1$ a partir do filho no nível $k$. Para escolher o pai, são analisados os descritores dos grupos. Se um grupo possui $k$ descritores (nível $k$ da árvore), será analisado e escolhido o melhor nó pai com $k-1$ descritores. Esse processo continua até atingir o nível 0 da árvore (raiz) que é preenchido com o rótulo nulo. O algoritmo $F I H C$ foi comparado com a versão UPGMA (Unweighted Pair Group Method with Arithmetic Mean) do algoritmo de agrupamento hierárquico complete-link, com o bisecting k-means, e com o HFTC. A medida de avaliação utilizada foi a FScore e as bases utilizadas foram a Reuters, San Jose Mercury Newspaper, páginas web da hierarquia do Yahoo, e Classic4. O UPGMA e o bisecting k-means foram melhores que o FIHC em algumas situações mas o FIHC superou os dois na maioria do casos e o HFTC em todas as situações.

No trabalho de Yang et al. (2003) os autores definiram os "atributos de associação". Estes atributos não levam em consideração onde as palavras ocorrem em um documento textual. Para extraí-los, os documentos são representados por uma bag-of-words, e um processo de extração de itemsets frequentes (apresentados na Subseção 2.2.1) é utilizado para obter as palavras que coocorrem na coleção. Os atributos associados, ou os conjuntos de palavras extraídos por essa abordagem, são adicionados à representação bag-of-words. Também está incluso na abordagem algoritmos para eliminação de redundâncias e para seleção de atributos. Os resultados obtidos para a base Reuters utilizando o classificador Naïve Bayes apresentaram melhoras com os conjuntos de palavras obtidos pela abordagem proposta, podendo chegar a aproximadamente $20 \%$ na medida $F_{1}$ microaveraged, $25 \%$ na precisão macroaveraged, e $35 \%$ na revocação macroaveraged. Também foi mostrado que os resultados se tornam mais estáveis com a variação do número de atributos compostos por palavras simples.

Em Bekkerman e Allan (2004), os autores propuseram a geração de atributos baseado na distribuição de agrupamentos de bigramas e unigramas. A ideia do agrupamento distribucional de atributos é representar cada atributo como uma distribuição sobre as categorias dos documentos na base de dados e então agrupar essas distribuições de modo 
que as distribuições similares caiam no mesmo grupo. Cada documento é então representado como uma distribuição sobre os centróides dos agrupamentos de atributos. Neste método, primeiramente são ordenados todos os unigramas de acordo com a medida de informação mútua para cada categoria. Então, são extraídos os $k_{u}$ unigramas do topo do ranking (detonado por $U$ ). Estes são os candidatos para construir os bigramas. São então gerados os bigramas de modo que ambos os componentes são unigramas de $U$. Novamente são ordenados os atributos de acordo com a medida de informação mútua com respeito a cada categoria e são extraídos $k_{b}$ de forma que a pontuação da medida desses bigramas é maior do que a pontuação de ambos os seus componentes (denotado por $B$ ). O novo conjunto de atributos é o conjunto $U$ e o conjunto $B$. Os resultados obtidos para a base 20 Newsgroups utilizando o classificador $S V M$ foi $91,8 \pm 0,4 \%$ enquanto o baseline do agrupamento distribucional utilizando apenas a representação bag-of-words é $91,3 \pm 0,4 \%$. Vale ressaltar que o número de atributos obtidos utilizando esta abordagem foi duas ordens de magnitude menor.

No trabalho de Doucet e Ahonen-Myka (2004) também foram utilizadas as sequências frequentes máximas (SFM) (Ahonen-Myka et al., 1999) na representação de documentos textuais juntamente com a bag-of-words. É permitido um intervalo em duas palavras nos documentos que formam as sequências. Foram realizados experimentos na base INEX (Initiative for the Evaluation of XML Retrieval), e foram obtidas representações de documentos textuais utilizando a bag-of-words e frases estatísticas segundo a abordagem de (Mitra et al., 1997). Foram extraídas 674.257 sequências frequentes máximas, 4.941.051 frases estatísticas e 156.723 palavras simples. Nos experimentos referentes à recuperação de informação foi considerada a precisão média dos $r$ primeiros retornos em relação à referência principal para cada consulta realizada. Obteve-se uma melhoria na precisão média com $r=100$ de $26,6 \%$ em relação à palavras simples e $9,7 \%$ em relação à palavras simples adicionadas à frases estatísticas.

O trabalho de Tesar et al. (2006) foi focado na análise de bigramas e 2-itemsets. Para extrair os $n$-gramas, primeiramente é criada uma árvore de sufixo que contém palavras na ordem em que elas ocorrem. Cada nó da árvore de sufixo representa uma palavra e o nó raiz é uma palavra nula. Portanto, cada caminho representa um $n$-grama que contém as palavras que rotulam os nós atravessados. Para extrair os 2-itemsets, primeiramente é formada uma lista de palavras únicas do documento. Dessa lista de palavras únicas são formadas todas as combinações de palavras do documento. Este processo é realizado para cada documento de uma coleção. Como o número de 2-itemsets com esta abordagem torna-se extremamente grande, são consideradas apenas as palavras com uma frequência maior que um limiar, da mesma forma que acontece na geração dos itemsets frequentes das regras de associação. Foi comparada a melhora do enriquecimento da representação em termos de acurácia de classificação utilizando o algoritmo de classificação Multinomial Naïve Bayes nas coleções Reuters-21578 e 20 Newsgroups. Os resultados mostraram uma melhora com diferença estatisticamente significante quando os bigramas e também 2-itemsets são incorporados.

Em Zhang e Zhu (2007), foram definidos os loose n-grams, que são palavras que coocorrem em um espaço limitado, como em sentenças, ou em sequências de palavras (janelas). As posições relativas das palavras não são consideradas. No processo de geração de atributos, somente são consideradas as palavras que ocorram acima de um determinado número de documentos. Após isso, é feita uma seleção de palavras simples, de forma que se uma palavra simples já possui um bom poder discriminativo, esta não precisa ser expandida, ou seja, não é necessário verificar e extrair palavras que coocorrem com esta. Após isso, são analisadas as coocorrências com as demais palavras que não foram selecionadas na etapa anterior. Os novos atributos obtidos são novamente filtrados. Foram realizados testes 
com as bases Reuters-21578 e TREC-2005 utilizando o classificador libsvm com kernel linear. A medida de avaliação utilizada foi a $F_{1}$. A melhora para a base Reuters não foi muito notável, chegando apenas a $0,6 \%$, enquanto para a base $T R E C$-2005 a medida $F_{1}$ foi $1,2 \%$ melhor.

No trabalho de Lie et al. (2007) foi proposto o uso de sequências frequentes máximas (SFMs) (Ahonen-Myka et al., 1999) extraídas das sentenças de um documento. O documento é representado pelas SFMs extraídas e pelas palavras frequentes do mesmo. Esta representação foi avaliada na construção de hierarquias de tópicos. É necessário definir o suporte e o intervalo entre palavras de uma sequência. Segundo os autores, as MFSs encontradas no nível de sentença em um documento podem prover mais informações com relação ao tema do documento. A coleção de documentos textuais utilizada foi a MCV1 (Manufacturing Corpus Version 1) e a medida de avaliação foi a FScore. Utilizando algoritmos de agrupamento hierárquico aglomerativo para a construção de uma hierarquia de tópicos e utilizando um limiar de distância entre palavras definido em 1, os resultados obtidos utilizando a representação com as SFMs foram melhores do que utilizando a representação bag-of-words. Foram obtidas melhoras no resultado da medida FScore de aproximadamente $8 \%$ para o algoritmo single-link, $15,50 \%$ para o algoritmo complete-link, e $18,50 \%$ para o algoritmo average-link.

Os trabalhos apresentados mostram que utilizar conjuntos de palavras como atributos pode ser de grande utilidade para o processo de Mineração de Textos e para a área recuperação de informação. Porém, este tipo de representação pode apresentar os mesmos problemas das abordagens que utilizam frases: a enorme quantidade de atributos gerados. Novamente, são necessários métodos para filtrar os atributos, além de em muitas situações haver a necessidade de analisar a alta dimensionalidade da coleção de documentos para realizar a geração de atributos.

\subsubsection{Considerações gerais sobre representação de documentos}

A maneira de representar os documentos textuais é de fundamental importância para os resultados do processo de Mineração de Textos. Além da maneira mais comum de representar os documentos textuais, que considera cada palavra individualmente como possível atributo, outras formas de representar os documentos textuais, que não consideram apenas palavras simples, mas que fazem uso de uma sequência ou um conjunto de palavras, foram apresentadas. Nas Tabelas 2.2 e 2.3 são apresentadas uma síntese das características dos trabalhos que utilizam $n$-gramas e conjuntos de palavras como atributos respectivamente.

Esses tipos de atributos podem ser benéficos tanto para o processo de Mineração de Textos, no que se refere a qualidade dos resultados, quanto para o usuário, no que se refere à interpretação do conhecimento extraído. Porém, as representações de coleções de documentos textuais que utilizam estes tipos de atributos apresentam uma dimensionalidade ainda maior do que a apresentadas pela representação bag-of-words. Devido a isso, a maioria dos trabalhos necessita selecionar os atributos mais significativos para serem mantidos na representação da coleção de documentos. Portanto, é necessário analisar toda a representação da coleção de documentos para selecionar os atributos. Este processo pode apresentar sérias dificuldades devido a própria alta dimensionalidade das coleções textuais, e pelo fato de muitas coleções não serem rotuladas, necessitando assim do uso de métodos de seleção atributos não supervisionados.

Além disso, algumas abordagem representam a coleção de documentos com uma bagof-words para então gerar os conjuntos de palavras. Com isso, a geração de conjuntos de palavras pode não apresentar sucesso perante coleções de documentos desbalanceadas. 
Tabela 2.2: Síntese das características gerais dos trabalhos que utilizam $n$-gramas como atributos.

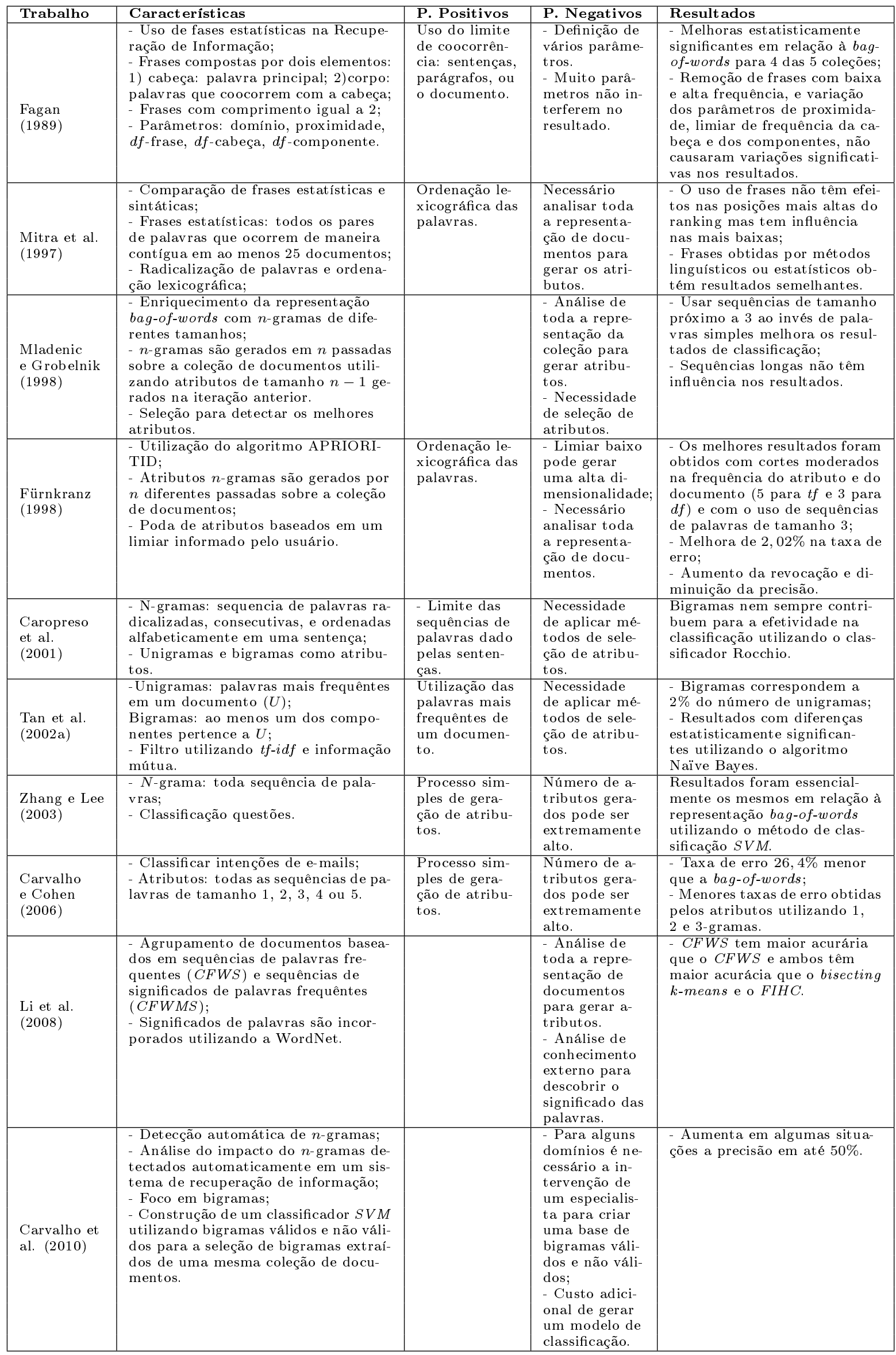


Tabela 2.3: Síntese das características dos trabalhos que utilizam conjuntos de palavras como atributos.

\begin{tabular}{|c|c|c|c|c|}
\hline Trabalho & Caracteristicas & P. Positivos & P. Negativos & Resultados \\
\hline $\begin{array}{l}\text { Ahonen- } \\
\text { Myka et al. } \\
(1999)\end{array}$ & $\begin{array}{l}\text { - Uso de sequências frequentes máxi- } \\
\text { mas (SFMs) como atributos; } \\
\text { - Classes de equivalência. }\end{array}$ & $\begin{array}{l}\text { Uso de classes } \\
\text { de equivalên- } \\
\text { cia para redu- } \\
\text { zir o número } \\
\text { de SFMs. }\end{array}$ & $\begin{array}{l}\text { Análise de to- } \\
\text { da a represen- } \\
\text { tação de docu- } \\
\text { mentos para } \\
\text { gerar os atri- } \\
\text { butos. }\end{array}$ & $\begin{array}{l}\text { Os atribots descobertos foram } \\
\text { representativos para a desco- } \\
\text { berta de tendências e eventos. }\end{array}$ \\
\hline $\begin{array}{l}\text { Beil et al. } \\
(2002)\end{array}$ & $\begin{array}{l}\text { - Conjuntos de palavras frequentes } \\
\text { para o agrupamento de textos; } \\
\text { - Dois algorimtos: FTC (Frequent } \\
\text { Term-Based Clustering) e HFTC } \\
\text { (Hierarchical Frequente Term-Based } \\
\text { Clustering). }\end{array}$ & $\begin{array}{l}\text { Uso da baixa } \\
\text { dimensionali- } \\
\text { dade do con- } \\
\text { junto de pala- } \\
\text { vras frequen- } \\
\text { tes para rea- } \\
\text { lizar o agru- } \\
\text { pamento. }\end{array}$ & $\begin{array}{l}\text { Análise de to- } \\
\text { da a represen- } \\
\text { tação de docu- } \\
\text { mentos para } \\
\text { gerar os atri- } \\
\text { butos. }\end{array}$ & $\begin{array}{l}\text { - FTC apresentou resultados } \\
\text { próximos ao estado da arte; } \\
\text { - HFTC alcançou resultados } \\
\text { similares ao } 9 \text {-secting } k- \\
\text { means, mas o bisecting } k \text { - } \\
\text { means apresentou resultados } \\
\text { significativamente melhores. }\end{array}$ \\
\hline $\begin{array}{l}\text { Fung et al. } \\
(2003)\end{array}$ & $\begin{array}{l}\text { - Conjuntos de palavras frequentes } \\
\text { para o agrupamento de textos; } \\
\text { - FIHC (Frequent Itemset-Based Hie- } \\
\text { rarchical Clustering); }\end{array}$ & $\begin{array}{l}\text { Uso da baixa } \\
\text { dimensionali- } \\
\text { dade do con- } \\
\text { junto de pala- } \\
\text { vras frequen- } \\
\text { tes para rea- } \\
\text { lizar o agru- } \\
\text { pamento. }\end{array}$ & $\begin{array}{l}\text { Análise de to- } \\
\text { da a represen- } \\
\text { tação de docu- } \\
\text { mentos para } \\
\text { gerar os atri- } \\
\text { butos. }\end{array}$ & $\begin{array}{l}\text { - O FIHC superou o bisecting } \\
k \text {-means e o UPGMA na mai- } \\
\text { oria das situações, e o HFTC } \\
\text { em todas as situações. }\end{array}$ \\
\hline $\begin{array}{l}\text { Yang et al. } \\
(2003)\end{array}$ & $\begin{array}{l}\text { - "Atributos de associação"; } \\
\text { - Extração dos atributos de associa- } \\
\text { ção utilizando a representação bag- } \\
\text { of-words; } \\
\text { - Adição dos atributos de associação } \\
\text { à representação bag-of-words. }\end{array}$ & & $\begin{array}{l}\text { - Extração dos } \\
\text { dos conjuntos } \\
\text { de palavras u- } \\
\text { tilizando uma } \\
\text { representação } \\
\text { bag-of-words; } \\
\text { - Aumento da } \\
\text { dimensionali- } \\
\text { dade da repre- } \\
\text { sentação bag- } \\
\text { of-words. }\end{array}$ & $\begin{array}{l}\text { - Melhora nos resultados che- } \\
\text { garam à } 20 \% \text { na } F_{1} \text { microaver- } \\
\text { aged, } 25 \% \text { na precisão micro- } \\
\text { averaged, e } 35 \% \text { na revocação } \\
\text { macroaveraged. }\end{array}$ \\
\hline $\begin{array}{l}\text { Bekkerman } \\
\text { e Allan } \\
(2004)\end{array}$ & $\begin{array}{l}\text { - Geração de atributos baseado na dis- } \\
\text { tribuição de agrupamentos de bigra- } \\
\text { mas e unigramas; } \\
\text { - Agrupamento das distribuições de } \\
\text { modo que as distribuições similares } \\
\text { caiam no mesmo grupo; } \\
\text { - Uso dos melhores unigramas }(U) \text { pa- } \\
\text { ra a geração dos bigramas; } \\
\text { - Representação Final }>U+B \text { (melho- } \\
\text { res bigramas). }\end{array}$ & $\begin{array}{l}\text { Número de } \\
\text { atributos duas } \\
\text { ordens de } \\
\text { magnitude } \\
\text { menor. }\end{array}$ & $\begin{array}{l}\text { - Análise e a- } \\
\text { grupamento de } \\
\text { todas as pala- } \\
\text { vras da cole- } \\
\text { ção. } \\
\text { - Necessidade } \\
\text { de aplicação } \\
\text { de métodos de } \\
\text { seleção de a- } \\
\text { tributos. }\end{array}$ & $\begin{array}{l}\text { Taxa de erro } 0,5 \% \text { menor uti- } \\
\text { lizando o método de classifica- } \\
\text { ção } S V M \text {. }\end{array}$ \\
\hline $\begin{array}{l}\text { Doucet e } \\
\text { Ahonen- } \\
\text { Myka } \\
(2004)\end{array}$ & $\begin{array}{l}\text { - Utilização das sequências frequentes } \\
\text { máximas juntamente com a bag-of- } \\
\text { words; } \\
\text { - É permitido um intervalo de duas pa- } \\
\text { lavras nas sequências. }\end{array}$ & $\begin{array}{l}\text { Intervalos nas } \\
\text { sequências de } \\
\text { palavras. }\end{array}$ & $\begin{array}{l}\text { Aumento da } \\
\text { dimensionali- } \\
\text { dade da repre- } \\
\text { sentação bag- } \\
\text { of-words. }\end{array}$ & $\begin{array}{l}\text { Foi obtida uma melhoria na } \\
\text { precisão média com } n=100 \text { de } \\
26,6 \% \text { em relação às palavras } \\
\text { simples, e } 9,7 \% \text { em relação às } \\
\text { palavras simples adicionadas } \\
\text { às frases estatísticas. }\end{array}$ \\
\hline $\begin{array}{l}\text { Tesar et al. } \\
(2006)\end{array}$ & $\begin{array}{l}\text { - Análise de bigramas e 2-itemsets; } \\
\text { - } N \text {-gramas são obtidos por meio de } \\
\text { uma árvore de sufixo; } \\
\text { - Itemsets frequentes são todas as } \\
\text { combinações de palavras que coocor- } \\
\text { rem acima de uma determinada } \\
\text { frequência em um documento. }\end{array}$ & & $\begin{array}{l}\text { Alta custo } \\
\text { computacional } \\
\text { para combinar } \\
\text { todas as pala- } \\
\text { vras de cada } \\
\text { documento da } \\
\text { coleção. }\end{array}$ & $\begin{array}{l}\text { Melhoras estatisticamente sig- } \\
\text { nificantes quando são utiliza- } \\
\text { dos os bigramas e os 2-itemsets } \\
\text { frequentes com o Multinomial } \\
\text { Naïve Bayes para as coleções } \\
\text { Reuters-21578 e } 20 \text { News- } \\
\text { group. }\end{array}$ \\
\hline $\begin{array}{l}\text { Zhang e Zhu } \\
(2007)\end{array}$ & $\begin{array}{l}\text { - Loose n-grams: palavras que coocor- } \\
\text { rem em espaços limitados como sen- } \\
\text { tenças ou janelas; } \\
\text { - São utilizadas as palavras que não } \\
\text { possuem um bom poder discriminati- } \\
\text { vo para gerar os atributos compostos } \\
\text { por conjuntos de palavras; } \\
\text { - São consideradas palavras que ocor- } \\
\text { ram acima de um determinado número } \\
\text { de documentos. }\end{array}$ & $\begin{array}{l}\text { Não gera com- } \\
\text { binações de } \\
\text { palavras que } \\
\text { estão espalha- } \\
\text { das pelo do- } \\
\text { cumento. }\end{array}$ & $\begin{array}{l}\text { Necessidade } \\
\text { de analisar to- } \\
\text { da a coleção de } \\
\text { documentos } \\
\text { para verificar } \\
\text { o poder discri- } \\
\text { minativo e re- } \\
\text { duzir o núme- } \\
\text { ro de atribu- } \\
\text { tos. }\end{array}$ & $\begin{array}{l}\text { Melhora de } 0,6 \% \text { para a Reu- } \\
\text { ters- } 21578 \text { e } 1,2 \% \text { para a } \\
\text { TREC- } 2005 \text { considerando a } \\
\text { medida } F_{1} \text { para o classificador } \\
\text { libsvm com kernel linear. }\end{array}$ \\
\hline $\begin{array}{l}\text { Liu et al. } \\
(2007)\end{array}$ & $\begin{array}{l}\text { - Uso de sequencias frequentes máxi- } \\
\text { mas (SFMs) extraídas das sentenças } \\
\text { de cada documento da coleção; } \\
\text { - Mostrar os temas dos documentos; } \\
\text { - Necessário definir o suporte e o inter- } \\
\text { valo entre palavras de uma sequência; }\end{array}$ & $\begin{array}{l}\text { As SFMs en- } \\
\text { cotradas no } \\
\text { nível de sen- } \\
\text { tenças em um } \\
\text { documento } \\
\text { podem prover } \\
\text { mais informa- } \\
\text { ções com rela- } \\
\text { ção ao tema } \\
\text { do documento. }\end{array}$ & $\begin{array}{l}\text { Aumento da } \\
\text { dimensionali- } \\
\text { dade da repre- } \\
\text { sentação bag- } \\
\text { of-words. }\end{array}$ & $\begin{array}{l}\text { Melhora nos resultados da me- } \\
\text { dida FScore em } 8 \% \text { para o al- } \\
\text { goritmo single-link, } 15,50 \% \\
\text { para o algoritmo complete- } \\
\text { link, e } 18,50 \% \text { para o algorimo } \\
\text { average-link. }\end{array}$ \\
\hline
\end{tabular}

Por exemplo, suponha um coleção de documentos textuais onde há uma grande quantidade de documentos com vocabulário $X$, e uma pequena quantidade de documentos com vocabulário $Y$. Ao tentar extrair conjuntos de palavras de vocabulário $Y$, pode ser extraído uma enorme quantidade de conjuntos de palavras de vocabulário $X$, e ao ten- 
tar extrair poucos conjuntos de palavras de vocabulário $X$, podem ser extraídas poucos ou nenhum conjunto de palavras de vocabulário $X$. Isso acontece devido ao fato que é necessário a definição de limiares de coocorrência para extrair os conjuntos de palavras, ou seja, as palavras devem coocorr em um número mínimo de documentos.

Vale ressaltar também que a interpretabilidade dos atributos muitas vezes podem ser afetadas quando se modelam os documentos como uma bag-of-words para a geração de atributos. Nesta situação, palavras que aparecem muito longe uma das outras, ou que não estão relacionadas, ou ainda que não contribuem para o processo de Mineração de Textos, podem coocorrer acima de um limiar nos documentos de uma coleção e com isso serem utilizados como atributos. Por exemplo, em uma coleção de documentos sobre técnicas de mineração de dados no apoio à tomada de decisão, poderia ser extraído o atributo "classificação_apoio", uma vez que estas duas palavras mesmo aparecendo distantes no documento, podem coocorrer em vários documentos da coleção.

Os trabalhos relacionados apresentaram alguns pontos considerados interessantes e que serviram como base da proposta deste projeto de mestrado. Estes pontos são a geração de conjuntos de palavras quando um dos ou todos os componente do conjunto são frequentes, e a geração de conjunto de palavras que coocorrem em espaços limitados em cada documento de uma coleção.

Além dessas formas de representação de documentos textuais baseadas no modelo espaço vetorial, existem outras formas de representação como as baseadas em grafo (Solé et al., 2010), baseadas em suffix trees (Zamir e Etzioni, 1998), e baseadas em tensor (Liu et al., 2005b). Essas outras formas de representação, por não estarem diretamente relacionados ao foco da proposta deste mestrado e pelo fato de que os algoritmos de extrações existentes que em sua maioria utilizam o modelo de espaço vetorial, não serão detalhadas.

\subsection{Organização e Busca Exploratória em Grandes Coleções de Documentos Textuais}

Muitos trabalhos utilizando Mineração de Textos para a organização de informações e extração de conhecimento visam a melhoria do processo de busca e recuperação em grandes coleções de documentos textuais. Em muitas situações que se desejam recuperar documentos relevantes, organizar coleções de documentos, e auxiliar o usuário na busca exploratória em grandes coleções de documento textuais, técnicas de agrupamento e a classificação de documentos são muito utilizadas.

A classificação de documentos textuais pede ser útil para documentos pertencentes à determinada categoria, ou organizar documentos de acordo com suas categorias. Quando não há informações sobre as categorias dos documentos, o agrupamento de documentos pode ser utilizado para separar os documentos por grupos, exibindo ao usuário apenas uma grande quantidade de grupos ao invés de uma vasta coleção de documentos. Essa técnica pode seu muito útil quando é retornada uma grande quantidade de documentos de vários tópicos por um mecanismo de busca e o usuário está interessado em apenas um tópico. Além disso, ao encontrar um documentos de interesse, o usuário pode também estar interessado em documentos semelhantes a esse, ou seja, em documentos do mesmo grupo/tópico do documento de interesse.

Deve-se considerar que muitas vezes o usuário pode não estar interessado em informar uma consulta específica a um sistema de recuperação de informação, ou ter um interesse que não está definido. Ao invés disso, ele pode querer explorar os documentos textuais de uma coleção. Por exemplo, suponha um graduando que está no início de sua iniciação 
científica e que utilizará regras de associação no seu projeto. Supondo que o usuário não tenha experiência prévia nesta área, este não vai saber, por exemplo, que existem artigos de regras de associação envolvendo medidas de interesse objetivas, extração de itemsets frequentes, eliminação de redundância, generalização, dentre outros. Nesta situação, um mecanismo que disponibilizasse de forma concisa toda a grande quantidade de informação disponível sobre regras de associação, separada por suas especificidades ou tópicos, seria muito útil.

Uma maneira intuitiva para navegar em grandes coleções de documentos textuais, é organizar os documentos desta coleção em formas de diretórios, onde cada diretório contém um determinado tópico. Estes diretórios podem inclusive estar organizados de maneira hierárquica. Na Figura 2.9 é apresentado um exemplo de uma organização hierárquica de diretórios de documentos sobre Mineração de Dados. Este tipo de organização permite ao usuário, à partir de conceitos mais gerais, como Regras de Associação, encontrar documentos de tópicos específicos, como Medidas de Interesse Objetivas.

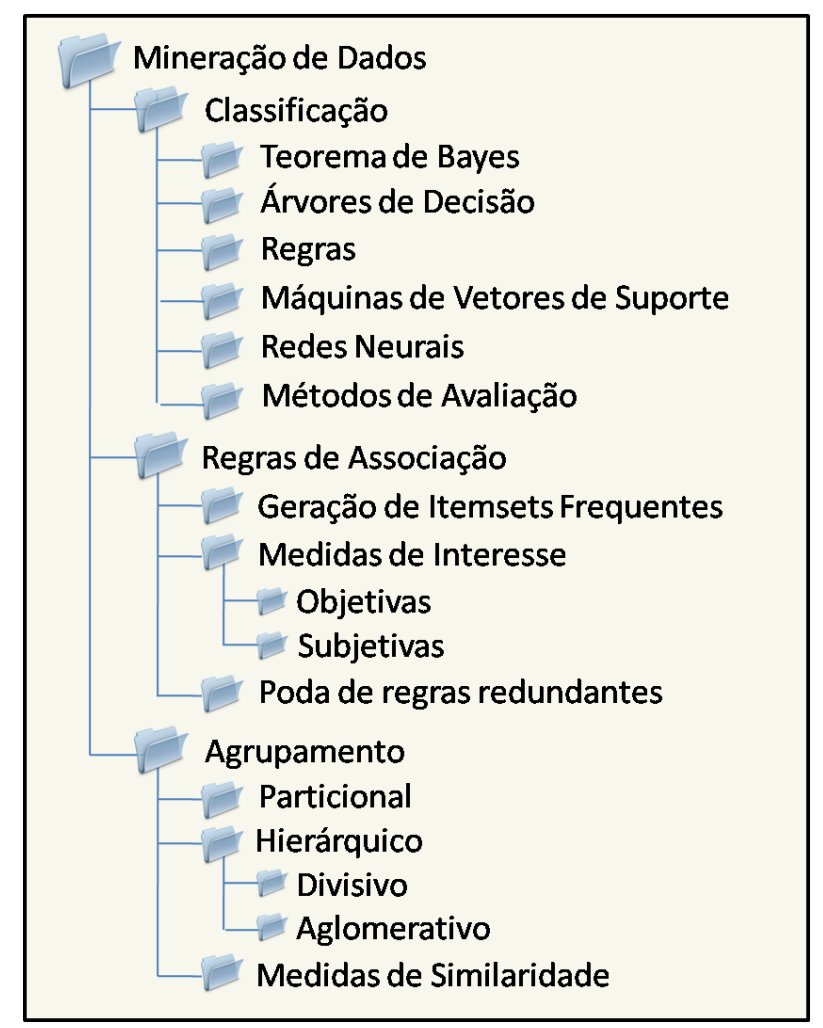

Figura 2.9: Exemplo de organização hierárquica de diretórios relacionado à Mineração de Dados.

Porém, a organização manual de uma grande coleção de documentos em diretórios, como acontece nos diretórios do Google ${ }^{4}$ e Yahoo $^{5}$, pode ser uma tarefa muito árdua e demandar muito tempo. Uma maneira de construir esse tipo de organização de maneira automática pode ser realizada por meio de uma hierarquia de tópicos obtida automaticamente de uma coleção de documentos (Moura, 2009; Bae et al., 2008; Kashyap et al., 2005).

A hierarquia de tópicos viabiliza a organização da coleção de documentos em uma estrutura de tópicos que facilita a navegação e a busca por documentos relevantes em

\footnotetext{
${ }^{4}$ http://dir.google.com/

${ }^{5}$ http://dir.yahoo.com/
} 
grandes coleções de documentos textuais. Na hierarquia de tópicos o conhecimento mais genérico está presente nos nós mais altos da hierarquia, enquanto que os conhecimentos mais específicos encontram-se nos níveis mais baixos. Cada nó da hierarquia corresponde a um tópico do domínio de conhecimento e contém documentos textuais relacionados ao mesmo.

A obtenção de forma automática da estrutura hierárquica pode ser realizada por meio de um algoritmo de agrupamento hierárquico, que como já apresentado na Seção 2.2.3, fornece uma visão em diversos níveis de granularidade. Porém, ao executar um algoritmo de agrupamento hierárquico na coleção de documentos, é obtido o dendrograma, que fornece apenas a informação de grupos, subgrupos e (dis)similaridades entre estes. É necessário então identificar os tópicos por meio da extração de descritores dos grupos e subgrupos (Moura, 2009; Zhang et al., 2009; Ienco e Meo, 2008; Kashyap et al., 2005; Larsen e Aone, 1999).

$\mathrm{Na}$ fase de geração dos descritores dos grupos e subgrupos da hierarquia, a forma como os documentos estão representados têm grande importância. No exemplo retirado de Bekkerman e Allan (2004) fica claro esta situação. Dado um documento que ocorre o nome do empresário "Bill Gates", a representação bag-of-words iria considerar as palavras "bill" e "gates" de forma separada, e um usuário ao ver os descritores "bill" e "gates" separadamente podeira entender que o documento ou o conjunto de documentos trata de contabilidade ou gastos com jardinagem.

Para avaliar o quanto a representação proposta para a representação de documentos textuais pode auxiliar na organização e busca exploratória em coleções de documentos textuais, serão construidas e avaliadas hierarquias de tópicos. Serão avaliadas objetivamente a qualidade dos atributos da representação por meio de algoritmos de classificação, a estrutura hierárquica da taxonomia com algoritmos de agrupamento, e por fim uma avaliação subjetiva da hierarquia de tópicos por especialistas de domínio.

\subsection{Considerações Finais}

Neste capítulo foi apresentado o processo de Mineração de Textos, no qual a representação de documentos é fundamental para a extração de padrões e consequentemente para a organização de informações e extração de conhecimento de coleções de documentos textuais. Foram apresentadas duas abordagens para representação de documentos textuais cujos atributos são compostos por mais de uma palavra: atributos compostos por frases, e atributos compostos por conjuntos de palavras. Pôde-se identificar que dependendo da forma com que estas representações são construídas, a alta dimensionalidade e a presença de atributos que muitas vezes só aparecem em um ou poucos documentos da coleção, pode prejudicar a extração de padrões. Além disso, os atributos podem não contribuir para o processo de Mineração de Textos ou para a interpretação dos resultados por parte do usuário.

Neste capítulo também foram apresentadas as técnicas de extração de padrões que serão utilizadas no decorrer deste projeto de mestrado: classificação, agrupamento e regras de associação. A classificação de documentos textuais será utilizada para verificar o poder preditivo dos atributos extraídos utilizando a abordagem proposta. O agrupamento de documentos textuais será utilizado para ver o quão bom a representação proposta neste projeto pode ajudar no agrupamento de documentos textuais e consequentemente na geração da estrutura hierárquica de uma taxonomia de tópicos. As regras de associação serão utilizadas para descobrir palavras relacionadas nos documentos de uma coleção e com isso gerar os atributos documentos textuais. No próximo capítulo serão apresentados 
2.5. Considerações Finais

os detalhes da abordagem proposta para representação de documentos textuais. 
CAPÍTUlo

\section{Abordagem Proposta para Representação de Coleções de Documentos Textuais por meio de Regras de Associação}

Nos capítulos anteriores, foi salientado que utilizar atributos compostos por mais de uma palavra pode ser útil para melhorar os resultados obtidos com a Mineração de Textos. Entretanto, representar coleções de documentos textuais com esse tipo de atributo pode ser muito custoso, tanto para gerar os atributos, quanto para extrair padrões da representação de alta dimensionalidade gerada. Nesse contexto, é proposto neste projeto de mestrado uma representação de coleções de documentos textuais mais compacta, que gera atributos compostos por palavras relacionadas, e capaz de extrair padrões tão bons quanto a representação bag-of-words.

Nas próximas seções serão detalhados os passos para a geração da representação dos documentos textuais de uma coleção utilizando a abordagem proposta neste projeto.

\subsection{Bag-of-Related-Words - Abordagem Proposta para a Repre- sentação de Coleções de Documento Textuais}

Neste projeto de mestrado, é proposta uma abordagem para gerar atributos compostos por palavras relacionadas de cada documento textual, nomeada bag-of-related-words. Para extrair as relações entre as palavras são utilizadas regras de associação (apresentadas na Seção 2.2.1).

O objetivo da representação bag-of-related-words é utilizar como atributos palavras relacionadas que se repetem, em espaços limitados, ao longo de um documento. Espera-se que estes atributos auxiliem a extração de padrões, e sejam mais significativos aos usuários do processo de Mineração de Textos.

Vale ressaltar que os mecanismos provenientes das regras de associação viabilizam a redução da dimensionalidade, pois, ao invés de utilizar todas as possíveis palavras e combinações de palavras para representar um documento, só serão extraídas palavras e relações entre palavras que tenham uma frequência maior que um limiar fornecido pelo usuário (suporte mínimo). Com isso, a abordagem proposta busca encontrar os melhores atributos diretamente, ou seja, encontrando relações entre as palavras mais frequentes no 
3.1. Bag-of-Related-Words - Abordagem Proposta para a Representação de Coleções de Documento Textuais

documento.

Os quatro passos principais para a construção da representação bag-of-related-words são:

1. Mapear o documento textual em transações;

2. Extrair regras de associação das transações;

3. Utilizar os itens das regras para compor os atributos;

4. Utilizar os atributos para construir a matriz atributo-valor;

Uma ilustração geral desses 4 passos é apresentado na Figura 3.1. Nas próximas seções serão detalhados os passos para a geração da representação bag-of-related-words.

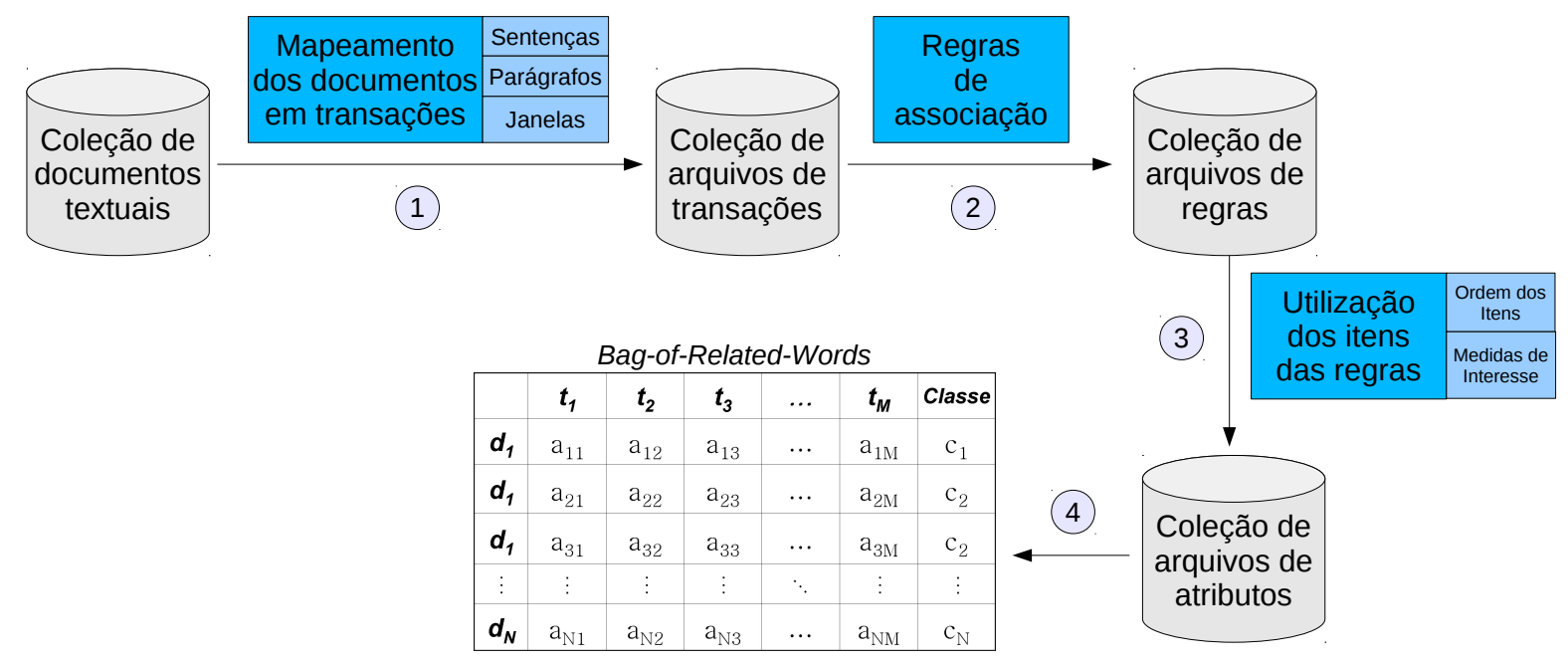

Figura 3.1: Passos para a geração da representação bag-of-related-words.

\subsubsection{Mapeando um Documento Textual em Transações}

Para que se possam extrair as regras de associação de um único documento, é necessário mapear esse documento em um conjunto de transações. Neste trabalho foram consideradas três formas de realizar este mapeamento: utilizando as sentenças do documento como transações, utilizando parágrafos como transações, e utilizando janelas deslizantes como transações. Como as transações correspondem a "pedaços" do documento textual, intuitivamente serão extraídos conjuntos de palavras que realmente estão relacionados em um contexto específico do documento, e não conjuntos de palavras que aparecem espalhadas em um mesmo documento ou em vários documentos de uma coleção.

Foram consideradas como sentenças neste projeto, todas as palavras entre os sinais ".", "!", ou "?". Como parágrafos, são consideradas as palavras entre os sinais de pontuação “.", "!", ou "?" que são seguidos por uma quebra de linha.

Pode haver erros ao extrair as sentenças de um documento textual. Por exemplo, em ocasiões em que são utilizadas abreviações em que aparecem o sinal de ponto final ("."), o método irá considerar como sendo o final de uma sentença. Além disso, em textos curtos, com poucas sentenças ou parágrafos, são mapeadas poucas transações, fazendo como que praticamente todas as coocorrências sejam frequentes. Por estes motivos foram consideradas também como formas de mapeamento as janelas deslizante. Com este tipo 
de mapeamento pode-se também limitar a distância máxima em que duas palavras devem aparecer no texto para que seja considerada sua coocorrência.

No mapeamento de janelas deslizantes, a primeira transação contém apenas a primeira palavra do documento, a segunda contém as duas primeiras palavras, e assim por diante, até que a janela contenha o número de palavras igual ao tamanho definido para a janela $(d)^{1}$. Após isso, a janela desliza uma palavra e considera as próximas $d$ palavras do documento. Considerando que o documento tenha sido mapeado em $l$ transações, a transação $l-d$ irá conter as $d$ últimas palavras, a transação $l-d+1$ as $d-1$ palavras, e assim por diante, até que a última transação contenha apenas uma palavra. O mapeamento de janelas deslizantes foi definido desta forma para que todas as palavras do texto estejam contidas o mesmo número de vezes na janela deslizante.

Para ilustrar a etapa de mapeamento do documento textual em transações, considere o texto de exemplo sobre Data Mining ${ }^{2}$ apresentado na Tabela 3.1.

\title{
Tabela 3.1: Texto de exemplo.
}

\begin{abstract}
Data mining is the process of extracting patterns from data. Data mining is becoming an increasingly important tool to transform this data into information. It is commonly used in a wide range of profiling practices, such as marketing, surveillance, fraud detection and scientific discovery.

Data mining can be used to uncover patterns in data but is often carried out only on samples of data. The mining process will be ineffective if the samples are not a good representation of the larger body of data. Data mining cannot discover patterns that may be present in the larger body of data if those patterns are not present in the sample being "mined". Inability to find patterns may become a cause for some disputes between customers and service providers. Therefore data mining is not foolproof but may be useful if sufficiently representative data samples are collected. The discovery of a particular pattern in a particular set of data does not necessarily mean that a pattern is found elsewhere in the larger data from which that sample was drawn. An important part of the process is the verification and validation of patterns on other samples of data.
\end{abstract}

Para cada documento, o pré-processamento comumente utilizado na Mineração de Textos, como padronização de caixas, remoção de stopwords e radicalização das palavras, pode ser aplicado. O resultado do pré-processamento realizado no texto da Tabela 3.1 é apresentado na Tabela 3.2.

Tabela 3.2: Texto da Tabela 3.1 pré-processado.

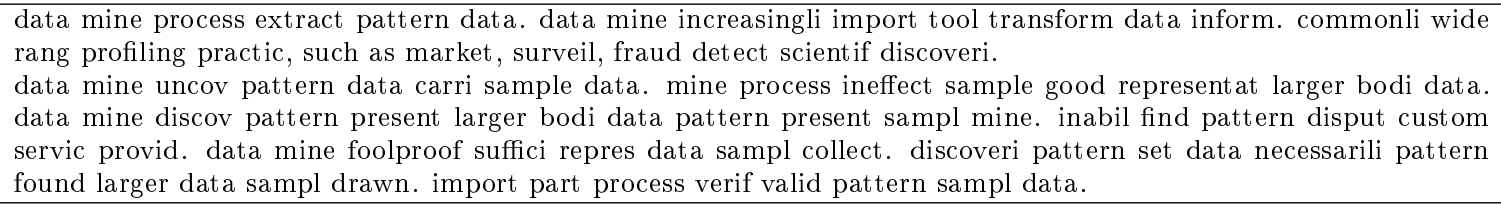

Com o documento textual pré-processado, pode-se então mapeá-lo em um conjunto de transações. Nas Tabelas 3.3, 3.4, e 3.5, são apresentadas as transações mapeadas do texto da Tabela 3.2 considerando sentenças, parágrafos e uma janela deslizante de tamanho 10 respectivamente.

Vale ressaltar que as tarefas de pré-processamento aplicadas nesta etapa são opcionais e vão de acordo com a intenção do usuário. Por exemplo, ao simplificar as palavras de um texto e remover as stopwords, pode-se fazer com que "conjunto de dados" e "conjuntos de dados" sejam contabilizados igualmente, aumentando então a ocorrência de "conjunt dad". Além disso, como o processo de extração de regras de associação não leva em conta a ordem dos itens nas transações, caso seja realizado o pré-processamento no texto, frases

\footnotetext{
${ }^{1}$ As janelas deslizantes com seus respectivos tamanhos serão expressos por "janela Tamanho". Por exemplo, uma janela deslizante de tamanho 5 será expressa por "janela 5".

${ }^{2}$ http://en.wikipedia.org/wiki/Data_mining (Acessado em 13 de Maio de 2010)
} 
Tabela 3.3: Transações obtidas considerando as sentenças do texto da Tabela 3.2.

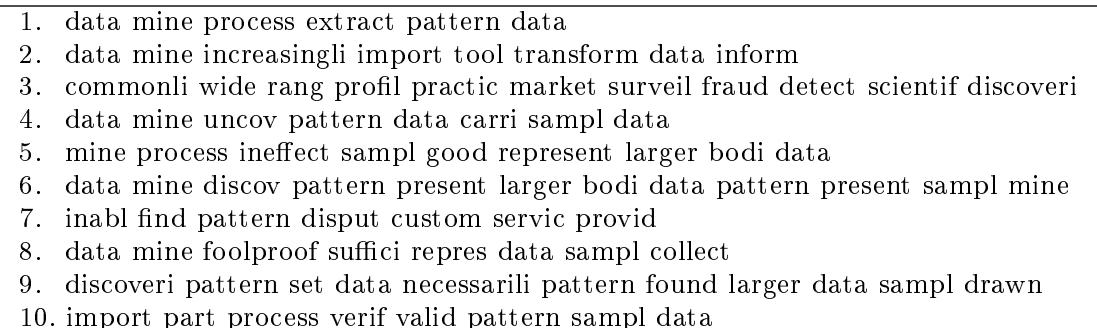

Tabela 3.4: Transações obtidas considerando os parágrafos da Tabela 3.2.

1. data mine process extract pattern data data mine increasingli import tool transform data inform commonli
wide rang profil practic market surveil fraud detect scientif discoveri
2. data mine uncov pattern data carri sampl
data mine process ineffect sampl good represent larger bodi data data mine discov
pattern present larger bodi data pattern present sampl mine inabl find pattern disput custom servic provid
data minefoolproof suffici repres data sampl collect discoveri pattern set data necessarili pattern found larger
data sampl drawn import part process verif valid pattern sampl data

Tabela 3.5: Transações obtidas considerando um janela deslizante de tamanho 10 do texto da Tabela 3.2.

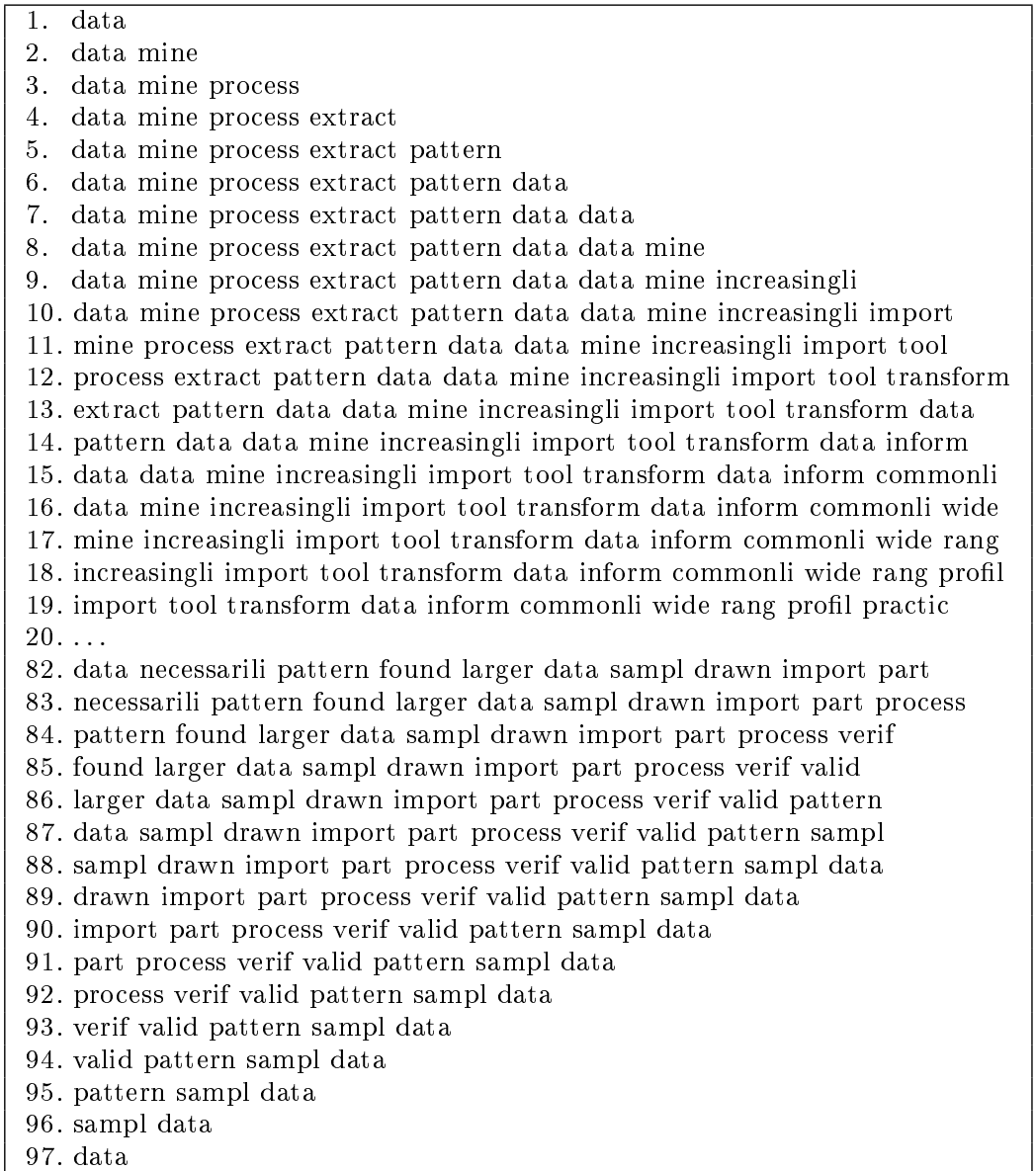

como "mineração dos textos" e "textos para mineração" serão contabilizadas juntas sob a forma "min text". O pré-processamento faz com que frases com variações sintáticas ou semânticas, mas que em geral representam o mesmo conceito, sejam agregadas no cálculo das frequências.

A forma de modelar o documento em transações pode interferir tanto na frequência das 
palavras como em suas coocorrências. A frequências das palavras é definida pelo número de ocorrências de uma palavra em uma mesma transação. Por exemplo, a palavra "data" ocorre 15 vezes no texto da Tabela 3.2. Ao considerar parágrafos como transações do texto da Tabela 3.2, a palavra "data" ocorreu 11 vezes na transação $\mathrm{n}^{0} 2$, sendo contabilizada apenas uma vez nesta transação, e ocorreu em todas as transações, tendo sua frequência igual a 2 e suporte de $100 \%$. Já ao considerar as sentenças como transações, a palavra "data" apareceu no máximo 3 vezes em uma mesma transação, e ocorreu em 7 das 10 transações, tendo sua frequência igual a 7 e suporte de $70 \%$.

Ao utilizar um mapeamento considerando janelas deslizantes de tamanho pequeno como transações, a distribuição de frequências terá um comportamento semelhante ao da bag-of-words. Isso se dá pelo fato que dificilmente uma mesma palavra se repetirá em uma transação modelada por uma janela de tamanho pequeno. Já ao utilizar janelas grandes, uma mesma palavra, principalmente as palavras mais frequentes no documento, tendem a aparecer mais de uma vez em uma mesma transação, fazendo assim com que as diferenças relativas entre as palavras mais frequentes diminuam em relação às demais palavras. Na Figura 3.2 são comparadas as frequências das palavras ao representar o texto por uma bag-of-words (a), e por mapear os texto em transações considerando sentenças (b), parágrafos (c), janelas 5 (d), janela 10 (e), janela 20 (f), e janela 30 (g).

As coocorrências das palavras são alteradas conforme o tipo de mapeamento muda. Por exemplo, o mapeamento considerando os parágrafos faz com que as palavras coocorram com mais palavras do que o mapeamento por sentenças. O mesmo ocorre ao utilizar janelas de tamanhos maiores em relação à janelas de tamanhos menores.

A forma de mapeamento também irá influir no número de transações. Na Tabela 3.6 é apresentado o número de transações obtidas para cada forma de mapeamento analisada para o texto da Tabela 3.2. Pode-se notar uma grande disparidade no número de transações obtidas pelo mapeamento de parágrafos em relação às sentenças, e uma disparidade ainda maior das janelas deslizantes que geraram cerca de $800 \%$ a mais de transações em relação às sentenças. Portanto, o tipo de mapeamento pode influir no tempo de extração das regras de associação.

Tabela 3.6: Número de transações obtidas para o texto da Tabela 3.2 considerando as formas de mapeamento analisadas.

\begin{tabular}{|l|c|}
\hline Mapeamento & N $^{\mathbf{o}}$ de transações \\
\hline Sentenças & 10 \\
\hline Parágrafos & 2 \\
\hline Janela 5 & 92 \\
\hline Janela 10 & 97 \\
\hline Janela 20 & 107 \\
\hline Janela 30 & 117 \\
\hline
\end{tabular}

\subsubsection{Extraindo Regras de Associação}

O tipo de mapeamento do documento textual em transações pode alterar a distribuição de frequências das palavras, suas coocorrências, o número de transações, e o valor de suporte mínimo. Assim, as relações entre palavras são influenciadas pelo tipo de mapeamento.

Para ilustrar o impacto das formas de mapeamento na geração dos itemsets frequentes e consequentemente nas regras de associação, na Tabela 3.7 são apresentados os itemsets extraídos considerando os seguintes mapeamentos e valores de suporte mínimo: 30,0\% 


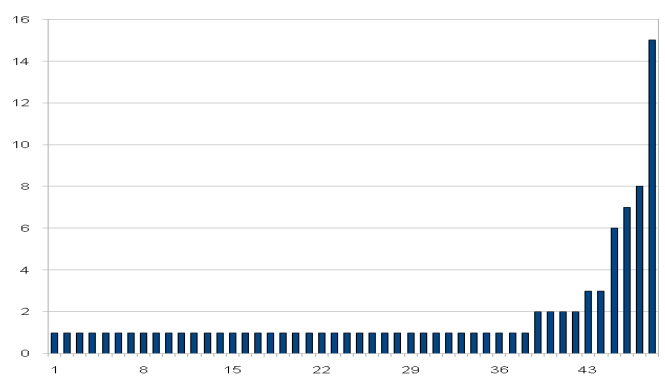

(a) Bag-of-words.

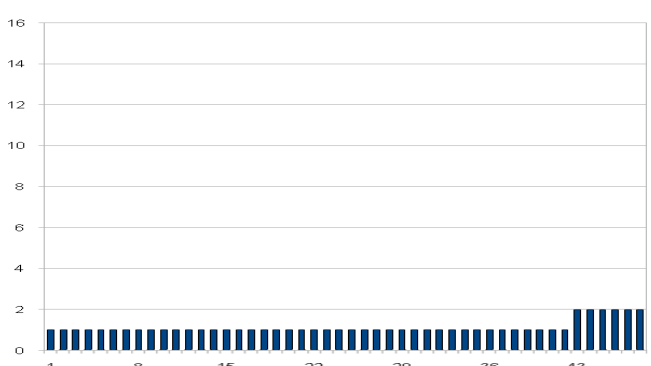

(c) Parágrafo

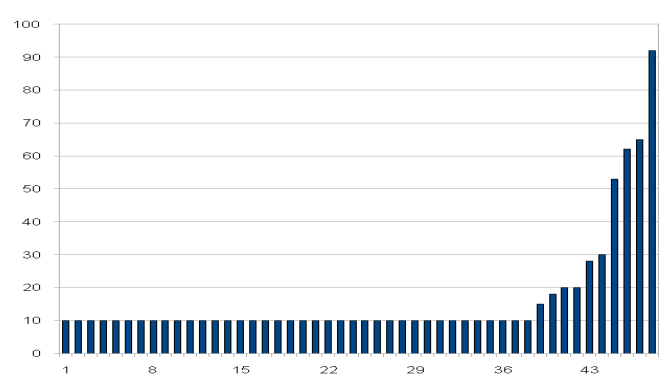

(e) Janela de tamanho 10 .

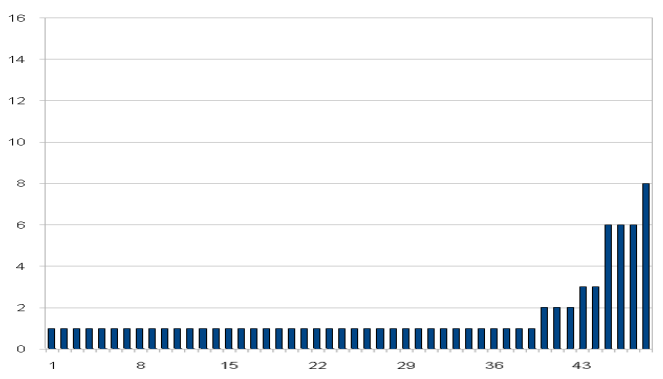

(b) Sentença

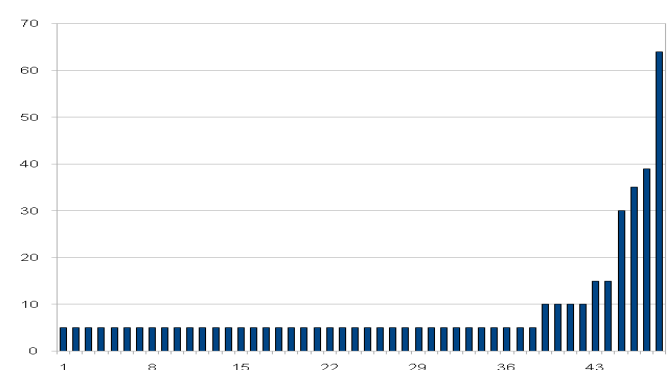

(d) Janela de tamanho 5 .

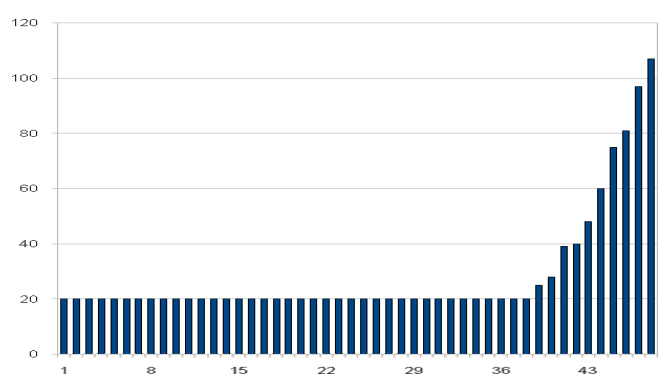

(f) Janela de tamanho 20 .

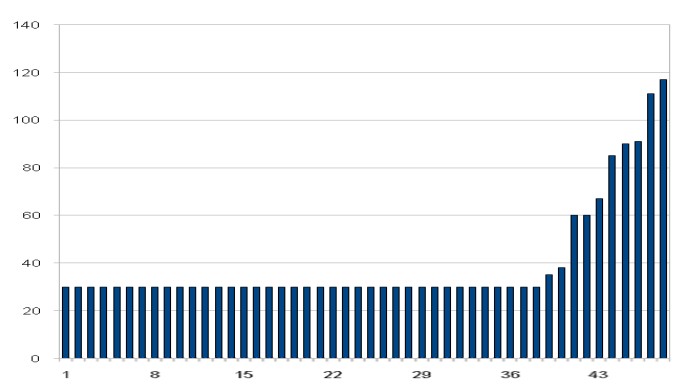

(g) Janela de tamanho 30 .

Figura 3.2: Frequência das palavras do texto da Tabela 3.2 na representação bag-of-words e nos mapeamentos para transações analisados.

para o mapeamento de sentença, 100,0\% para parágrafo, 10, $0 \%$ para janela $5,21,0 \%$ para janela $10,47,0 \%$ para janela 20 , e $58,0 \%$ para janela 30 . Esses valores de suporte mínimo foram definidos de forma a gerar o número mais próximo possível de itemsets frequentes em todas as formas de mapeamento.

Pode-se notar que alguns itemsets importantes para identificar o texto da Tabela 3.1 aparecem em todos os tipos de mapeamento, como "process", "mine", "pattern", "data", "mine_pattern", "data_mine", "data_pattern", e "data_mine_pattern" (assinalados em 
Tabela 3.7: Itemsets frequentes obtidos utilizando as diferentes formas de mapeamentos analisadas para o texto da Tabela 3.2 .

Sentença
\begin{tabular}{|l|l|}
\hline Itemsets & Suporte \\
\hline process & $30,00 \%$ \\
\hline larger & $30,00 \%$ \\
\hline mine & $60,00 \%$ \\
\hline pattern & $60,00 \%$ \\
\hline sampl & $60,00 \%$ \\
\hline data & $80,00 \%$ \\
\hline data process & $30,00 \%$ \\
\hline larger sampl & $30,00 \%$ \\
\hline data larger & $30,00 \%$ \\
\hline mine pattern & $30,00 \%$ \\
\hline mine sampl & $40,00 \%$ \\
\hline data mine & $60,00 \%$ \\
\hline pattern sampl & $40,00 \%$ \\
\hline data pattern & $50,00 \%$ \\
\hline data sampl & $60,00 \%$ \\
\hline data larger sampl & $30,00 \%$ \\
\hline data mine pattern & $30,00 \%$ \\
\hline data mine sampl & $40,00 \%$ \\
\hline data pattern sampl & $40,00 \%$ \\
\hline- & - \\
\hline
\end{tabular}

\begin{tabular}{|c|c|}
\hline \multicolumn{2}{|l|}{ Janela 10} \\
\hline Itemsets & Suporte \\
\hline process & $30,90 \%$ \\
\hline larger & $28,90 \%$ \\
\hline sampl & $54,60 \%$ \\
\hline mine & $63,90 \%$ \\
\hline pattern & $67,00 \%$ \\
\hline data & $94,80 \%$ \\
\hline pattern process & $21,60 \%$ \\
\hline data process & $30,90 \%$ \\
\hline larger sampl & $21,60 \%$ \\
\hline larger pattern & $21,60 \%$ \\
\hline data larger & $28,90 \%$ \\
\hline mine sampl & $30,90 \%$ \\
\hline pattern sampl & $42,30 \%$ \\
\hline data sampl & $52,60 \%$ \\
\hline mine pattern & $44,30 \%$ \\
\hline data mine & $61,90 \%$ \\
\hline data pattern & $64,90 \%$ \\
\hline data pattern process & $21,60 \%$ \\
\hline data larger sampl & $21,60 \%$ \\
\hline data larger pattern & $21,60 \%$ \\
\hline data mine sampl & $28,90 \%$ \\
\hline data pattern sampl & $40,20 \%$ \\
\hline data mine pattern & $42,30 \%$ \\
\hline
\end{tabular}

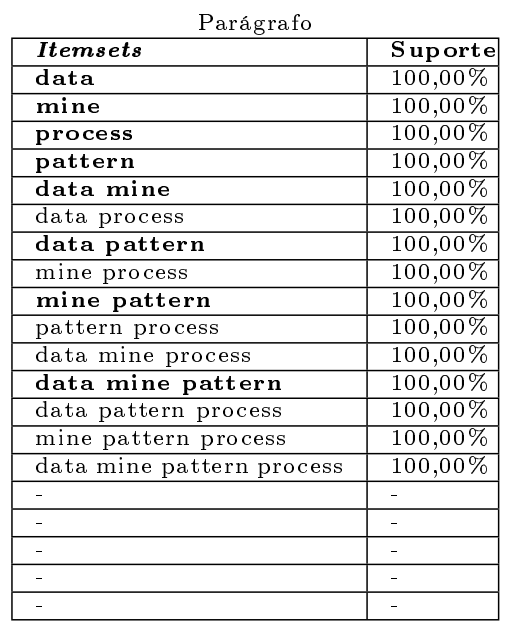

Janela 20

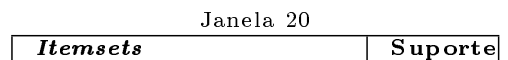

\begin{tabular}{|l|l|}
\hline Itemsets & Suporte \\
\hline proces & $56,10 \%$ \\
\hline sampl & $70,10 \%$ \\
\hline mine & $75,70 \%$ \\
\hline pattern & $90,70 \%$ \\
\hline data & $100,00 \%$ \\
\hline pattern process & $54,20 \%$ \\
\hline data process & $56,10 \%$ \\
\hline mine sampl & $47,70 \%$ \\
\hline pattern sampl & $69,20 \%$ \\
\hline data sampl & $70,10 \%$ \\
\hline mine pattern & $69,20 \%$ \\
\hline data mine & $75,70 \%$ \\
\hline data pattern & $90,70 \%$ \\
\hline data pattern process & $54,20 \%$ \\
\hline mine pattern sampl & $47,70 \%$ \\
\hline data mine sampl & $47,70 \%$ \\
\hline data pattern sampl & $69,20 \%$ \\
\hline data mine pattern & $69,20 \%$ \\
\hline data mine pattern sampl & $47,70 \%$ \\
\hline- & - \\
\hline- & - \\
\hline- & - \\
\hline- & - \\
\hline
\end{tabular}

Janela 5

\begin{tabular}{|c|c|}
\hline Itemsets & Suporte \\
\hline bodi & $10,90 \%$ \\
\hline import & $10,90 \%$ \\
\hline present & $10,90 \%$ \\
\hline discoveri & $10,90 \%$ \\
\hline process & $16,30 \%$ \\
\hline larger & $16,30 \%$ \\
\hline sampl & $32,60 \%$ \\
\hline mine & $38,00 \%$ \\
\hline pattern & $42,40 \%$ \\
\hline data & $69,60 \%$ \\
\hline pattern present & $9,80 \%$ \\
\hline data larger & $12,00 \%$ \\
\hline mine sampl & $9,80 \%$ \\
\hline pattern sampl & $14,10 \%$ \\
\hline data sampl & $21,70 \%$ \\
\hline mine pattern & $15,20 \%$ \\
\hline data mine & $30,40 \%$ \\
\hline data pattern & $30,40 \%$ \\
\hline data pattern sampl & $9,80 \%$ \\
\hline data mine pattern & $10,90 \%$ \\
\hline
\end{tabular}

Janela 30

Janela 30
\begin{tabular}{|l|l|}
\hline Itemsets & Suporte \\
\hline process & $76,90 \%$ \\
\hline sampl & $72,60 \%$ \\
\hline mine & $77,80 \%$ \\
\hline pattern & $94,90 \%$ \\
\hline data & $100,00 \%$ \\
\hline mine process & $59,80 \%$ \\
\hline pattern process & $75,20 \%$ \\
\hline data process & $76,90 \%$ \\
\hline pattern sampl & $71,80 \%$ \\
\hline data sampl & $72,60 \%$ \\
\hline mine pattern & $75,20 \%$ \\
\hline data mine & $77,80 \%$ \\
\hline data pattern & $94,90 \%$ \\
\hline mine pattern process & $58,10 \%$ \\
\hline data mine process & $59,80 \%$ \\
\hline data pattern process & $75,20 \%$ \\
\hline data pattern sampl & $71,80 \%$ \\
\hline data mine pattern & $75,20 \%$ \\
\hline data mine pattern process & $58,10 \%$ \\
\hline- & - \\
\hline- & - \\
\hline- & - \\
\hline- & - \\
\hline
\end{tabular}

negrito na Tabela 3.7). Alguns itemsets possivelmente úteis para representar o texto não aparecem em todos os mapeamentos, como "mine_sampl" (apenas na sentença, janela 5, janela 10, e janela 20), "pattern_sampl" (só não aparece no mapeamento de parágrafo), "data_mine_sampl" (apenas na sentença, janela 10, e janela 20), "data_mine_process" (apenas no parágrafo e janela 30), "mine_pattern_process" (apenas no parágrafo e janela 30), e "data_mine_pattern_process" (apenas no mapeamento de janela 30). Dado as diferenças obtidas, neste projeto será avaliado qual forma de mapeamento pode produzir melhores resultados para a classificação e o agrupamento de documentos textuais.

Pode-se notar pelo exemplo da Tabela 3.7 que o suporte mínimo utilizado varia de acordo com o número de transações, o número de itens nas transações, e a frequência dos itens. Todos esses fatores que fazem com que o valor de suporte mínimo varie, dificultam a definição do valor de suporte mínimo por parte do usuário. Nesse projeto de mestrado é proposta uma forma para calcular o suporte mínimo automaticamente de cada documento da coleção. Para isso, foram consideradas três premissas:

1. Dado que a frequência total das palavras seja fixa, quanto menor o número de palavras diferentes, maior deve ser o valor de suporte.

2. Dado que o número de transações seja fixo, se a frequência média das palavras aumenta, o suporte deve aumentar. 
3. Dado que a frequência média das palavras é fixa, quanto maior o número de transações, menor deve ser o suporte.

Com base nessas 3 premissas, a equação proposta para o cálculo automático do suporte mínimo é a seguinte:

$$
\sup \_a u t\left(d_{i}\right)=\frac{\left(\sum_{\forall a \in A} \operatorname{freq}(a)\right) /|A|}{|T|}
$$

na qual $A$ é o conjunto de atributos do documento $d_{i}$, freq $(a)$ é a frenquência do atributo $a \in A,|A|$ é o número total de atributos e $|T|$ é o número total de transações do documento $d_{i}$.

O numerador da Equação 3.1 atende às duas primeiras premissas, ou seja, se o número de palavras diferentes aumentar, o suporte irá diminuir, uma vez que há uma ponderação pelo número de palavras diferentes $(|A|)$. Se a frequência média das palavras aumenta, o valor de suporte também aumenta, uma vez que o numerador da Equação 3.1 refere-se a frequência média. Já o numerador desta equação atende à terceira premissa, ou seja, quanto maior o número de transações, menor será o valor de suporte, uma vez que há uma ponderação pelo número de transações $(|\mathrm{T}|)$.

O suporte mínimo automático isenta o usuário de conhecer as características do documento ou da coleção de documentos. Além disso, evita-se que o usuário defina um valor de suporte mínimo baixo de forma a gerar uma grande quantidade de regras, já que a fórmula para o cálculo do suporte mínimo leva em consideração a frequência média das palavras nas transações.

Embora as medidas de suporte e confiança sejam as mais comuns na extração de regras de associação, em muitos casos as regras obtidas utilizando somente essas medidas podem não apresentar relacionamentos interessantes, mesmo com altos valores de confiança. Isto acontece principalmente quando o valor de suporte do antecedente é baixo e o valor de suporte do consequente é alto. Neste caso, os itens que mais ocorrerem nas transações compõem a maioria das regras. Por exemplo, suponha um texto mapeado em 10 transações, e que foi extraída a regra stemming $\rightarrow$ clustering, cujo suporte de stemming é $10,0 \%$, de clusterging é $90,0 \%$ e de clustering $\cup$ stemming é $10 \%$. Neste caso, a confiança da regra stemming $\rightarrow$ clustering seria de 100,0\%, mesmo que a palavra stemming tenha aparecido uma única vez e que nesta vez tenha coocorrido com a palavra clustering.

Ainda há casos em que os itemsets das regras podem ser independentes, ou seja, a presença de um itemset não aumenta nem diminui as chances de ocorrência de um outro itemset. Por exemplo, suponha novamente um texto mapeado em 10 transações, e que foi extraída a regra information $\rightarrow$ categorization, cujo suporte de information é $50,0 \%$, de categorization é $80,0 \%$, e de categorization $\cup$ information é $40 \%$. Neste caso, a confiança da regra information $\rightarrow$ categorization seria de $80,0 \%$, que é o mesmo valor do suporte do item categorizatioin, ou seja, a probabilidade de ocorrer categorization dado que information ocorreu é a mesma de ocorrer somente categorization.

Além das medidas de suporte e confiança, outras medidas, conhecidas como medidas de interesse, podem ser utilizadas na extração de regras de associação. Em geral, o objetivo das medidas de interesse é identificar regras não triviais, relevantes, e úteis ao usuário, pois capturam diferentes relações entre itens que não são capturadas pelas medidas suporte e confiança. As medidas de interesse podem ser classificadas como objetivas, que consideram somente o conjunto de dados para calcular o valor de uma regra, ou subjetivas, que analisam os dados e se baseiam no conhecimento de um especialista do 
domínio de aplicação. Essas medidas são normalmente utilizadas para ranquear e podar as regras de associação.

Como a abordagem proposta não visa utilizar conhecimento de domínio, serão utilizadas medidas de interesse objetivas para podar as regras de associação, e com isso obter atributos mais significativos e diminuir ainda mais a dimensionalidade da representação obtida. As medidas de interesse objetivas são originárias de várias áreas, como estatística, teoria da informação, e recuperação de informação (Guillet e Hamilton, 2007). Neste trabalho foram utilizadas as seguintes medidas de interesse objetivas: Suporte, Confiança, Lift, Yules'Q, Coeficiente de Correlação Linear, Informação Mútua, Gini Index, Kappa, e J-Measure. Na Tabela 3.8 são apresentadas as fórmulas das medidas de interesse objetivas utilizadas neste projeto definidas em termos de probabilidade, na qual $A$ significa os itens do corpo da regra e $B$ os itens da cabeça da regra (Guillet e Hamilton, 2007; Geng e Hamilton, 2006; Blanchard et al., 2005; Tan et al., 2002b).

Tabela 3.8: Medidas de interesse objetivas utilizadas neste projeto.

\begin{tabular}{|l|l|}
\hline Medida & Fórmula \\
\hline Suporte & $P(A B)$ \\
\hline Confiança & $P(B \mid A)$ \\
\hline Lift & $P(B \mid A) / P(B)$ ou $P(A B) / P(A) P(B)$ \\
\hline Yule's Q & $\frac{P(A B) P(\neg A \neg B)-P(A \neg B)(P(\neg A B)}{P(A B)(P \neg A \neg B)+P(A \neg B) P(\neg A B)}$ \\
\hline Coeficiente de Correlação Linear & $\frac{P(A B)-P(A) P(B)}{\sqrt{P(A) P(B) P(\neg A) P(\neg B)}}$ \\
\hline Informação Mútua & $\begin{array}{l}P(A B) \log _{2}\left(\frac{P(A B)}{P(A) P(B)}\right)+P(A \neg B) \log _{2}\left(\frac{P(A \neg B)}{P(A) P(\neg B)}\right)+ \\
P(\neg A B) \log _{2}\left(\frac{P(\neg A B)}{P(\neg A) P(B)}\right)+P(\neg A \neg B) \log _{2}\left(\frac{P(\neg A \neg B)}{P(\neg A) P(\neg B)}\right)\end{array}$ \\
\hline Gini Index & $\begin{array}{l}P(A) *\left\{P(B \mid A)^{2}+P(\neg B \mid A)^{2}\right\}+ \\
P(\neg A) *\left\{P(B \mid \neg A)^{2}+P(\neg B \mid \neg A)^{2}\right\}-P(B)^{2}-P(\neg B)^{2}\end{array}$ \\
\hline Kappa & $\frac{P(A B)+P(\neg A \neg B)-P(A) P(B)-P(\neg A)(P \neg B)}{1-P(A) P(B)-P(\neg A) P(\neg B)}$ \\
\hline J-Measure & $P(A B) \log \frac{P(B \mid A)}{P(B)}+P(A \neg B) \log \frac{P(\neg B \mid A)}{P(\neg B)}$ \\
\hline
\end{tabular}

O intervalo dos possíveis valores da medida Lift varia entre 0 e $\infty$, sendo então difícil estabelecer um limiar para esta medida. Assim, neste trabalho foi utilizado a medida Lift padronizada, cujo limite de valores varia entre 0 e 1. A padronização foi realizada baseada na fórmula proposta em McNicholas et al. (2008):

$$
\operatorname{lift}(A \Rightarrow B)=\frac{\operatorname{lift}(A \Rightarrow B)-\lambda}{v-\lambda}
$$

na qual

$$
\lambda=\frac{4 s}{(1+\text { sup_min })^{2}}
$$

e

$$
v=\frac{1}{\text { sup_min }}
$$

são os limites inferior e superir da medida lift dado o suporte mínimo utilizado. 
Para selecionar uma medida objetiva $F$, foram considerados os seguintes quesitos retirados de Lenca et al. (2007); Tan et al. (2002b); Piatetsky-Shapiro (1991):

- Q1: $F=0$ se $A$ e $B$ são estatisticamente independentes, isto, é, $P(A B)=P(A) P(B)$;

- Q2: $F$ aumenta monotonicamente com $P(A B)$ quando $P(A)$ e $P(B)$ permanecem os mesmos;

- Q3: $F$ diminui monotonicamente com $P(A)$ (ou $P(B)$ ) quando $P(A B)$ e $P(B)$ (ou $P(A)$ ) permanecem os mesmos;

- Q4: $F$ deve ser simétrico à permutação de variáveis;

- Q5: $F$ deve ser o mesmo quando as linhas e as colunas são multiplicadas por um valor positivo;

- Q6: $F$ deve tornar-se $-F$ se as colunas ou linhas são permutadas;

- Q7: $F$ deve permanecer a mesma se ambas as linhas e colunas forem permutadas;

- Q8: $F$ não deve ter relação com a contagem dos registros que não contém $A$ ou $B$;

- Q9: F é constante se não existe contra exemplo para a regra;

Na Tabela 3.9 são apresentados os quesitos que as medidas de interesse objetivas utilizadas neste projeto de mestrado atendem. Foram selecionadas para esse projeto medidas de interesse objetivas cujo conjunto de quesitos cobertos por elas fossem diferentes.

Tabela 3.9: Propriedades das medidas de interesse objetivas utilizadas neste projeto.

\begin{tabular}{|l|c|c|c|c|c|c|c|c|c|c|}
\hline Medida & Intervalo & Q1 & Q2 & Q3 & Q4 & Q5 & Q6 & Q7 & Q8 & Q9 \\
\hline Suporte & $0 \ldots 1$ & & X & & X & & & & & \\
\hline Confiança & $0 \ldots 1$ & & X & & & & & & & X \\
\hline Lift & $0 \ldots 1 \ldots \infty$ & & X & X & X & & & & & \\
\hline Yule's Q & $-1 \ldots 0 \ldots 1$ & X & X & X & X & X & X & X & & X \\
\hline Coeficiente de Correlação Linear & $-1 \ldots 0 \ldots 1$ & $\mathrm{X}$ & $\mathrm{X}$ & $\mathrm{X}$ & $\mathrm{X}$ & & $\mathrm{X}$ & $\mathrm{X}$ & & \\
\hline Informação Mútua & $0 \ldots 1$ & $\mathrm{X}$ & $\mathrm{X}$ & $\mathrm{X}$ & & & & $\mathrm{X}$ & & \\
\hline Gini Index & $0 \ldots 1$ & $\mathrm{X}$ & & & & & & $\mathrm{X}$ & & \\
\hline Kappa & $-1 \ldots 0 \ldots 1$ & $\mathrm{X}$ & & & $\mathrm{X}$ & & & $\mathrm{X}$ & & \\
\hline J-Measure & $0 \ldots 1$ & $\mathrm{X}$ & & & & & & & & $\mathrm{X}$ \\
\hline
\end{tabular}

De acordo com suas características, as medidas de interesse objetivas podem ser conflitantes quanto ao ranqueamento e consequentemente na poda das regras. Algumas medidas de interesse objetivas podem ser melhores para alguns domínios de aplicação do que outras. Entretanto, pode haver situações em que as medidas podem ser consistentes umas com as outras. Para ilustrar essas situações, na Tabela 3.10 são apresentados os rankings de 25 atributos extraídos de um texto sobre medidas de validação de agrupamento de dados (Wu et al., 2009) gerados pelas medidas de interesse objetivas utilizadas neste projeto.

Pode-se notar que as medidas derivadas da estatística e que medem a dependência entre os itens da regra, como Lift, Yule's Q e Correlação, obtiveram a maior pontuação para o itemset "contig matrix". Já as medidas baseadas em teoria da informação, como Informação Mútua e J-Measure, obtiveram a maior pontuação para o itemset "data set".

Ao comparar o ranking obtido pelas medidas Informação Mútua e J-Measure na Tabela 3.10, ambas originárias da teoria da informação, pode-se notar uma grande semelhança entre os itens que compõem o ranking. Ao todo são 23 itens dos 25 itens em 
Tabela 3.10: Ranking dos atributos segundo as medidas de interesse objetivas utilizadas neste trabalho.

\begin{tabular}{|c|c|c|}
\hline \multicolumn{3}{|c|}{ Suporte } \\
\hline Rank & Atributos & Score \\
\hline $1^{\circ}$ & measur valid & 0,073 \\
\hline $2^{\circ}$ & data set & 0,055 \\
\hline $3^{\circ}$ & cluster measur & 0,053 \\
\hline $4^{\circ}$ & measur normal & 0,050 \\
\hline $5^{\circ}$ & cluster valid & 0,046 \\
\hline $6^{\circ}$ & cluster mean & 0,039 \\
\hline $7^{\circ}$ & cluster result & 0,036 \\
\hline $8^{\circ}$ & measur properti & 0,027 \\
\hline $9^{\circ}$ & class cluster & 0,025 \\
\hline $10^{\circ}$ & cluster measur valid & 0,024 \\
\hline $11^{\circ}$ & data sampl & 0,020 \\
\hline $12^{\circ}$ & extern measur & 0,020 \\
\hline $13^{\circ}$ & mean measur & 0,020 \\
\hline $14^{\circ}$ & effect uniform & 0,019 \\
\hline $15^{\circ}$ & extern valid & 0,019 \\
\hline $16^{\circ}$ & conting matrix & 0,018 \\
\hline $17^{\circ}$ & result valid & 0,018 \\
\hline $18^{\circ}$ & cluster evalu & 0,017 \\
\hline $19^{\circ}$ & class data & 0,017 \\
\hline $20^{\circ}$ & entropi measur & 0,016 \\
\hline $21^{\circ}$ & cluster number & 0,016 \\
\hline $22^{\circ}$ & bound upper & 0,015 \\
\hline $23^{\circ}$ & effect mean & 0,015 \\
\hline $24^{\circ}$ & evalu measur & 0,015 \\
\hline $25^{\circ}$ & class distribut & 0,015 \\
\hline
\end{tabular}

\begin{tabular}{|l|l|l|}
\hline Rank & Atributos & Score \\
\hline $1^{\circ}$ & conting matrix & 0,998 \\
\hline $2^{\circ}$ & bound upper & 0,995 \\
\hline $3^{\circ}$ & inform mutual & 0,991 \\
\hline $4^{\circ}$ & effect uniform & 0,990 \\
\hline $5^{\circ}$ & rand statist & 0,982 \\
\hline $6^{\circ}$ & data set & 0,965 \\
\hline $7^{\circ}$ & data imbalanc & 0,956 \\
\hline $8^{\circ}$ & data simul & 0,952 \\
\hline $9^{\circ}$ & data sampl & 0,947 \\
\hline $10^{\circ}$ & effect mean uniform & 0,919 \\
\hline $11^{\circ}$ & defect measur & 0,917 \\
\hline $12^{\circ}$ & data sampl set & 0,913 \\
\hline $13^{\circ}$ & sampl set & 0,893 \\
\hline $14^{\circ}$ & effect mean & 0,886 \\
\hline $15^{\circ}$ & class size & 0,860 \\
\hline $16^{\circ}$ & mean uniform & 0,859 \\
\hline $17^{\circ}$ & extern valid & 0,856 \\
\hline $18^{\circ}$ & class distribut & 0,757 \\
\hline $19^{\circ}$ & measur section & 0,750 \\
\hline $20^{\circ}$ & measur valid & 0,686 \\
\hline $21^{\circ}$ & extern measur valid & 0,670 \\
\hline $22^{\circ}$ & measur properti & 0,669 \\
\hline $23^{\circ}$ & cluster evalu & 0,654 \\
\hline $24^{\circ}$ & cluster result & 0,650 \\
\hline $25^{\circ}$ & measur puriti & 0,646 \\
\hline & & \\
\hline
\end{tabular}

Gini Index

\begin{tabular}{|c|c|c|}
\hline \multicolumn{3}{|c|}{ Gini Index } \\
\hline Rank & Atributos & Score \\
\hline $1^{\circ}$ & data set & 0,066 \\
\hline $2^{\circ}$ & measur valid & 0,030 \\
\hline $3^{\circ}$ & conting matrix & 0,029 \\
\hline $4^{\circ}$ & effect uniform & 0,024 \\
\hline $5^{\circ}$ & data sampl & 0,023 \\
\hline $6^{\circ}$ & bound upper & 0,023 \\
\hline $7^{\circ}$ & inform mutual & 0,020 \\
\hline $8^{\circ}$ & effect mean uniform & 0,019 \\
\hline $9^{\circ}$ & data sampl set & 0,019 \\
\hline $10^{\circ}$ & data imbalanc & 0,016 \\
\hline $11^{\circ}$ & data simul & 0,014 \\
\hline $12^{\circ}$ & extern valid & 0,014 \\
\hline $13^{\circ}$ & cluster result & 0,014 \\
\hline $14^{\circ}$ & rand statist & 0,014 \\
\hline $15^{\circ}$ & cluster measur valid & 0,013 \\
\hline $16^{\circ}$ & cluster mean & 0,012 \\
\hline $17^{\circ}$ & effect mean & 0,012 \\
\hline $18^{\circ}$ & extern measur valid & 0,011 \\
\hline $19^{\circ}$ & sampl set & 0,011 \\
\hline $20^{\circ}$ & measur properti & 0,011 \\
\hline $21^{\circ}$ & mean uniform & 0,009 \\
\hline $22^{\circ}$ & class size & 0,009 \\
\hline $23^{\circ}$ & cluster valid & 0,008 \\
\hline $24^{\circ}$ & measur normal & 0,008 \\
\hline $25^{\circ}$ & defect measur & 0,008 \\
\hline
\end{tabular}

Confiança

Confiança
\begin{tabular}{|l|l|l|}
\hline Rank & Atributos & Score \\
\hline $1^{\circ}$ & conting matrix & 0,766 \\
\hline $2^{\circ}$ & effect uniform & 0,663 \\
\hline $3^{\circ}$ & effect mean uniform & 0,600 \\
\hline $4^{\circ}$ & bound upper & 0,562 \\
\hline $5^{\circ}$ & data set & 0,552 \\
\hline $6^{\circ}$ & cluster measur valid & 0,336 \\
\hline $7^{\circ}$ & inform mutual & 0,331 \\
\hline $8^{\circ}$ & rand statist & 0,271 \\
\hline $9^{\circ}$ & measur valid & 0,237 \\
\hline $10^{\circ}$ & data sampl set & 0,226 \\
\hline $11^{\circ}$ & cluster valid & 0,207 \\
\hline $12^{\circ}$ & cluster mean measur & 0,203 \\
\hline $13^{\circ}$ & data sampl & 0,199 \\
\hline $14^{\circ}$ & effect mean & 0,198 \\
\hline $15^{\circ}$ & sampl set & 0,189 \\
\hline $16^{\circ}$ & extern measur valid & 0,184 \\
\hline $17^{\circ}$ & mean uniform & 0,179 \\
\hline $18^{\circ}$ & class distribut & 0,179 \\
\hline $19^{\circ}$ & cluster mean & 0,175 \\
\hline $20^{\circ}$ & class data & 0,172 \\
\hline $21^{\circ}$ & cluster measur & 0,172 \\
\hline $22^{\circ}$ & extern valid & 0,171 \\
\hline $23^{\circ}$ & result valid & 0,166 \\
\hline $24^{\circ}$ & measur normal & 0,162 \\
\hline $25^{\circ}$ & class set & 0,161 \\
\hline
\end{tabular}

\section{Correlação}

\begin{tabular}{|c|c|c|}
\hline \multicolumn{3}{|c|}{ Correlação } \\
\hline Rank & Atributos & Score \\
\hline $1^{\circ}$ & conting matrix & 0,814 \\
\hline $2^{\circ}$ & bound upper & 0,673 \\
\hline $3^{\circ}$ & effect uniform & 0,657 \\
\hline $4^{\circ}$ & data set & 0,606 \\
\hline $5^{\circ}$ & inform mutual & 0,520 \\
\hline $6^{\circ}$ & rand statist & 0,438 \\
\hline $7^{\circ}$ & data sampl & 0,364 \\
\hline $8^{\circ}$ & data sampl set & 0,329 \\
\hline $9^{\circ}$ & data imbalanc & 0,302 \\
\hline $10^{\circ}$ & sampl set & 0,289 \\
\hline $11^{\circ}$ & effect mean & 0,289 \\
\hline $12^{\circ}$ & data simul & 0,287 \\
\hline $13^{\circ}$ & effect mean uniform & 0,287 \\
\hline $14^{\circ}$ & extern valid & 0,273 \\
\hline $15^{\circ}$ & measur valid & 0,268 \\
\hline $16^{\circ}$ & mean uniform & 0,260 \\
\hline $17^{\circ}$ & class size & 0,250 \\
\hline $18^{\circ}$ & class distribut & 0,208 \\
\hline $19^{\circ}$ & cluster result & 0,204 \\
\hline $20^{\circ}$ & cluster mean & 0,191 \\
\hline $21^{\circ}$ & measur properti & 0,162 \\
\hline $22^{\circ}$ & cluster valid & 0,160 \\
\hline $23^{\circ}$ & cluster evalu & 0,143 \\
\hline $24^{\circ}$ & measur normal & 0,139 \\
\hline $25^{\circ}$ & defect measur & 0,137 \\
\hline
\end{tabular}

Kappa
\begin{tabular}{|l|l|l|}
\hline Rank & Atributos & Score \\
\hline $1^{\circ}$ & measur valid & 0,427 \\
\hline $2^{\circ}$ & measur normal & 0,384 \\
\hline $3^{\circ}$ & cluster measur & 0,361 \\
\hline $4^{\circ}$ & measur properti & 0,351 \\
\hline $5^{\circ}$ & extern measur & 0,339 \\
\hline $6^{\circ}$ & entropi measur & 0,333 \\
\hline $7^{\circ}$ & evalu measur & 0,330 \\
\hline $8^{\circ}$ & mean measur & 0,329 \\
\hline $9^{\circ}$ & measur select & 0,328 \\
\hline $10^{\circ}$ & cluster valid & 0,328 \\
\hline $11^{\circ}$ & consist measur & 0,327 \\
\hline $12^{\circ}$ & measur section & 0,327 \\
\hline $13^{\circ}$ & measur puriti & 0,326 \\
\hline $14^{\circ}$ & defect measur & 0,324 \\
\hline $15^{\circ}$ & equival measur & 0,323 \\
\hline $16^{\circ}$ & measur result & 0,321 \\
\hline $17^{\circ}$ & inform measur & 0,319 \\
\hline $18^{\circ}$ & cluster mean & 0,310 \\
\hline $19^{\circ}$ & cluster result & 0,303 \\
\hline $20^{\circ}$ & class cluster & 0,283 \\
\hline $21^{\circ}$ & cluster evalu & 0,262 \\
\hline $22^{\circ}$ & cluster data & 0,261 \\
\hline $23^{\circ}$ & cluster number & 0,259 \\
\hline $24^{\circ}$ & data set & 0,254 \\
\hline $25^{\circ}$ & cluster set & 0,254 \\
\hline & & \\
\hline
\end{tabular}

Lift

\begin{tabular}{|l|l|l|}
\hline Rank & Atributos & Score \\
\hline $1^{\circ}$ & conting matrix & 37,267 \\
\hline $2^{\circ}$ & bound upper & 30,864 \\
\hline $3^{\circ}$ & effect uniform & 23,399 \\
\hline $4^{\circ}$ & inform mutual & 21,666 \\
\hline $5^{\circ}$ & rand statist & 20,242 \\
\hline $6^{\circ}$ & data sampl set & 8,783 \\
\hline $7^{\circ}$ & data imbalanc & 8,125 \\
\hline $8^{\circ}$ & effect mean uniform & 8,097 \\
\hline $9^{\circ}$ & data simul & 8,000 \\
\hline $10^{\circ}$ & data sampl & 7,692 \\
\hline $11^{\circ}$ & data set & 7,432 \\
\hline $12^{\circ}$ & sampl set & 7,276 \\
\hline $13^{\circ}$ & effect mean & 6,868 \\
\hline $14^{\circ}$ & mean uniform & 6,189 \\
\hline $15^{\circ}$ & class size & 6,172 \\
\hline $16^{\circ}$ & extern valid & 5,187 \\
\hline $17^{\circ}$ & class distribut & 4,306 \\
\hline $18^{\circ}$ & defect measur & 2,961 \\
\hline $19^{\circ}$ & data distribut & 2,558 \\
\hline $20^{\circ}$ & cluster evalu & 2,518 \\
\hline $21^{\circ}$ & result valid & 2,457 \\
\hline $22^{\circ}$ & cluster number & 2,452 \\
\hline $23^{\circ}$ & measur section & 2,443 \\
\hline $24^{\circ}$ & cluster result & 2,424 \\
\hline $25^{\circ}$ & cluster perform & 2,311 \\
\hline
\end{tabular}

Informação Mútua

\begin{tabular}{|c|c|c|}
\hline Rank & Atributos & Score \\
\hline $1^{\circ}$ & data set & 0,148 \\
\hline $2^{\circ}$ & conting matrix & 0,100 \\
\hline $3^{\circ}$ & effect uniform & 0,083 \\
\hline $4^{\circ}$ & bound upper & 0,073 \\
\hline $5^{\circ}$ & inform mutual & 0,055 \\
\hline $6^{\circ}$ & data sampl & 0,049 \\
\hline $7^{\circ}$ & measur valid & 0,047 \\
\hline $8^{\circ}$ & rand statist & 0,039 \\
\hline $9^{\circ}$ & data imbalanc & 0,033 \\
\hline $10^{\circ}$ & extern valid & 0,032 \\
\hline $11^{\circ}$ & data sampl set & 0,031 \\
\hline $12^{\circ}$ & effect mean & 0,030 \\
\hline $13^{\circ}$ & data simul & 0,030 \\
\hline $14^{\circ}$ & sampl set & 0,029 \\
\hline $15^{\circ}$ & effect mean uniform & 0,028 \\
\hline $16^{\circ}$ & mean uniform & 0,025 \\
\hline $17^{\circ}$ & cluster result & 0,024 \\
\hline $18^{\circ}$ & class size & 0,023 \\
\hline $19^{\circ}$ & cluster mean & 0,022 \\
\hline $20^{\circ}$ & class distribut & 0,019 \\
\hline $21^{\circ}$ & measur properti & 0,017 \\
\hline $22^{\circ}$ & cluster valid & 0,016 \\
\hline $23^{\circ}$ & measur normal & 0,013 \\
\hline $24^{\circ}$ & defect measur & 0,012 \\
\hline $25^{\circ}$ & cluster evalu & 0,012 \\
\hline
\end{tabular}

J-Measure

\begin{tabular}{|c|c|c|}
\hline \multicolumn{3}{|c|}{$\mathrm{J}$-Measure } \\
\hline Rank & Atributos & Score \\
\hline $1^{\circ}$ & data set & 0.124 \\
\hline $2^{\circ}$ & conting matrix & 0.085 \\
\hline $3^{\circ}$ & effect uniform & 0.072 \\
\hline $4^{\circ}$ & bound upper & 0.066 \\
\hline $5^{\circ}$ & inform mutual & 0.051 \\
\hline $6^{\circ}$ & data sampl & 0.047 \\
\hline $7^{\circ}$ & effect mean uniform & 0.046 \\
\hline $8^{\circ}$ & measur valid & 0.041 \\
\hline $9^{\circ}$ & rand statist & 0.037 \\
\hline $10^{\circ}$ & data imbalanc & 0.032 \\
\hline $11^{\circ}$ & extern valid & 0.030 \\
\hline $12^{\circ}$ & data simul & 0.029 \\
\hline $13^{\circ}$ & data sampl set & 0.029 \\
\hline $14^{\circ}$ & effect mean & 0.028 \\
\hline $15^{\circ}$ & sampl set & 0.028 \\
\hline $16^{\circ}$ & cluster measur valid & 0.024 \\
\hline $17^{\circ}$ & mean uniform & 0.024 \\
\hline $18^{\circ}$ & cluster result & 0.022 \\
\hline $19^{\circ}$ & class size & 0.022 \\
\hline $20^{\circ}$ & cluster mean & 0.020 \\
\hline $21^{\circ}$ & extern measur valid & 0.019 \\
\hline $22^{\circ}$ & class distribut & 0.017 \\
\hline $23^{\circ}$ & measur properti & 0.016 \\
\hline $24^{\circ}$ & cluster valid & 0.014 \\
\hline $25^{\circ}$ & defect measur & 0.012 \\
\hline
\end{tabular}

comum. Porém, alguns elementos, como effect_mean_uniform, aparecem em posições diferentes do ranking. Além disso, atributos importantes como measur_norm e cluster_evalu só apareceram no ranking da medida Informação Mútua, enquanto que cluster_measur_valid e extern_measur_valid só apareceram no ranking da medida J-Measure. 
De maneira semelhante, ao analisar as medidas Yule's Q e Correlação na Tabela 3.10, alguns atributos como defect_measur aparecem em posições distantes no ranking de cada medida. Atributos importantes como extern_measur_valid, e measur_puriti só apareceram no ranking da medida Yule's Q, enquanto que atributos como cluster_valid e measur_normal só apareceram no ranking da medida Correlação.

Já ao comparar medidas como a Confiança, que analisa a força da implicação da regra, e a medida Lift, que analisa as dependências dos itens da regra, pode-se notar uma grande diferença dos atributos e das posições do ranking. Dado as diferenças obtidas ao utilizar diferentes medidas de interesse objetivas, neste projeto será avaliado qual medida objetiva obtém melhores resultados nos processos de agrupamento e classificação de documentos textuais.

\subsubsection{Gerando os Atributos e Construindo a Matriz Atributo-Valor}

Para gerar os atributos da representação bag-of-related-words são utilizados os itemsets das regras de associação extraídas. Por exemplo, se fosse extraída a regra data $\rightarrow$ mine, seria gerado o atributo "data_mine".

Para evitar situações em que regras diferentes compostas pelos mesmos itemsets como mine $\rightarrow$ data e data $\rightarrow$ mine gerem atributos diferentes, pode-se ordenar os itens em ordem lexicográfica ou na ordem em que eles aparecem no texto.

$\mathrm{Na}$ abordagem proposta, não é feito o enriquecimento da abordagem bag-of-relatedwords, mas são utilizados os 1-itemsets frequentes como atributos compostos por palavras simples. Isso se dá pelo fato de que trabalhos relacionados, apresentados na Seção 2.3, afirmarem que somente o uso de conjuntos de $n$ palavras, com $n \geq 2$ degradam os resultados. Além disso, experimentos realizados com a abordagem proposta sem a incorporação dos 1-itemsets frequentes na representação também causaram degradação nos resultados.

Uma vez gerados os atributos dos documentos utilizando as regras extraídas, é possível construir a matriz atributo-valor. Os pesos dos atributos na matriz podem ser os mesmos utilizados comumente na Mineração de Textos (Seção 2.1.2) ou pode-se utilizar o suporte da regra que foi utilizada para gerar o atributo.

\subsection{Síntese das Características da Bag-of-Related-Words}

A abordagem proposta neste projeto de mestrado evita muitos dos problemas encontrados ao gerar conjuntos de palavras como atributos das coleções de documentos textuais. A abordagem evita analisar toda a coleção de documentos para extrair palavras relacionadas, uma vez que as coleções de documentos apresentam um número de atributos extremamente elevado, sendo muito custoso e muitas vezes impossível fazer esse tipo de análise (Li et al., 2008; Tesar et al., 2006; Yang et al., 2003; Fung et al., 2003; Ahonen-Myka et al., 1999; Fürnkranz, 1998; Fagan, 1989). A abordagem proposta analisa documentos da coleção individualmente, onde o número de palavras diferentes de um único documento pode ser ordens de grandeza menor do que o da coleção de documentos.

Além disso, analisar toda a coleção de documentos pode apresentar problemas quando esta apresenta tópicos desbalanceados. Por exemplo, suponha uma coleção de documentos textuais com 5000 documentos da área de química e 20 de informática. Suponha ainda que nos documentos pertencentes à categoria informática, palavras apareçam no máximo em 5 documentos diferentes. Neste caso, para um suporte maior que 0,001, não seriam obtidos conjuntos de palavras referentes aos documentos de informática. Ademais, com um suporte muito baixo, pode-se gerar uma quantidade de relações extremamente elevada, podendo ser muito maior que a alta dimensionalidade da representação bag-of-words. Esse 
problema não ocorre com a abordagem proposta uma vez que os atributos são extraídos analisando individualmente cada documento da coleção.

Um outro problema apresentado pelas abordagens que analisam toda a coleção de documentos para obter atributos compostos por mais de uma palavra, é que muitas das relações obtidas, apesar de válidas, podem não ser significativas aos usuários, ou não contribuir com o processo de Mineração de Textos. Por exemplo, supondo uma coleção textual de artigos científicos, uma regra possível de ser gerada é $\{$ Introdução $\} \rightarrow\{$ Conclusão\}, uma vez que os atributos "Introdução" e "Conclusão" irão coocorrer em vários documentos da coleção. Mesmo extraindo atributos de um artigo científico, a abordagem proposta não irá extrair a regra $\{$ Introdução $\} \rightarrow\{$ Conclusão $\}$ uma vez que essas duas palavras só aparecerão uma ou poucas vezes em um artigo científico e provavelmente distantes uma da outra.

Pode-se notar também que muitos trabalhos adicionam os atributos compostos por mais de uma palavra à bag-of-words, o que aumenta ainda mais o problema da alta dimensionalidade. Com isso, torna-se imprescindível aplicar métodos de seleção de atributos na representação obtida, que pode ser ineficiente devido a própria alta dimensionalidade, ou difícil definição de parâmetros caso os documentos não possuam classe, tendo em geral que aplicar métodos de seleção de atributos supervisionados (Zhang e Zhu, 2007; Bekkerman e Allan, 2004; Yang et al., 2003; Tan et al., 2002a; Caropreso et al., 2001; Fürnkranz, 1998; Mladenic e Grobelnik, 1998). Mesmo extraindo conjuntos de palavras como atributos mais a incorporação dos 1-itemsets frequentes, a dimensionalidade obtida pela bag-of-related-words pode ser muito menor do que a representação bag-of-words. Ademais, uma vez a coleção de documentos estando representada no espaço vetorial, métodos de seleção de atributos podem ser aplicados à representação bag-of-related-words. Vale ressaltar que não é necessário definir o número de palavras que irão compor os atributos, uma vez que o número de itens nas regras será incrementado até que o superte mínimo e outro valor de medida objetiva estejam acima de um limiar especificado.

A abordagem proposta pode ser aplicada em contextos dinâmicos, já que não necessita analisar toda a coleção de documentos para gerar os atributos, uma vez que neste tipo de situação é inviável que a cada documento novo pertencente a coleção, realize-se algum tipo de processamento envolvendo toda a representação de documentos textuais. Além disso, esta abordagem proposta é independente de língua ou conhecimento externo, não necessitando assim de técnicas de processamento de linguagem natural, que são custosas computacionalmente, nem da interferência de um especialista ou de bases de conhecimento.

\subsection{Ferramenta Computacional Desenvolvida para a Geração da Representação Bag-of-Related-Words}

No decorrer do projeto de mestrado foi desenvolvida a ferramenta FEATuRE (Features gEnerator based on AsssociaTion $\underline{\text { RulEs }) ~ p a r a ~ a p o i a r ~ t o d o s ~ o s ~ p a s s o s ~ d a ~ g e r a c ̧ a ̃ o ~ d a ~ r e p-~}$ resentação bag-of-related-words. A ferramenta foi desenvolvida na linguagem de programação Java e implementa todos os passos apresentados no Capítulo 3. Na Figura 3.3 é apresentada a tela inicial da ferramenta desenvolvida. A ferramenta FEATuRE apresenta as seguintes funcionalidades:

1. Mapear o documento textual em transações - Figura 3.4. São realizadas a remoção de stopwords, radicalização das palavras utilizando o algoritmo de Porter (Porter, 1980), e o mapeamento do documento textual em um arquivo de transações. Também é possível nesta etapa, utilizar a palavra mais frequente na coleção no lugar do 


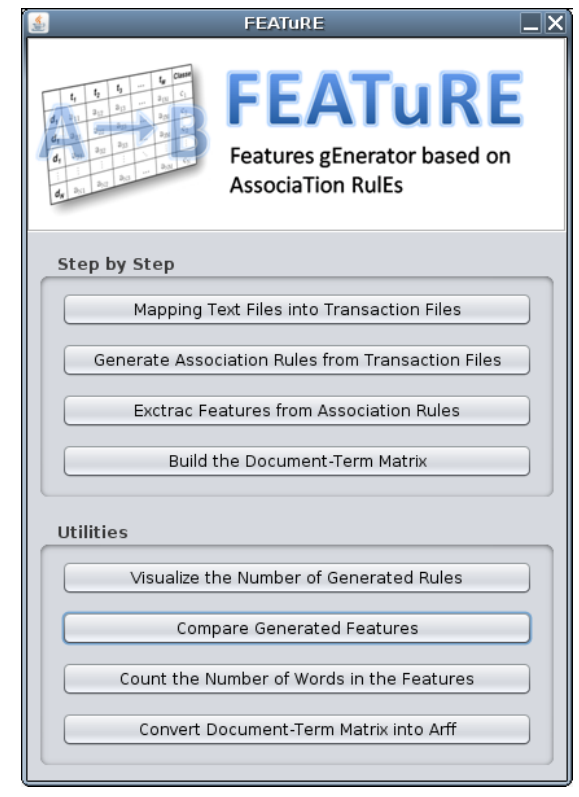

Figura 3.3: FEATuRE - Tela inicial.

radical gerado pela mesma. Para cada documento textual é gerado um arquivo de transações correspondente.

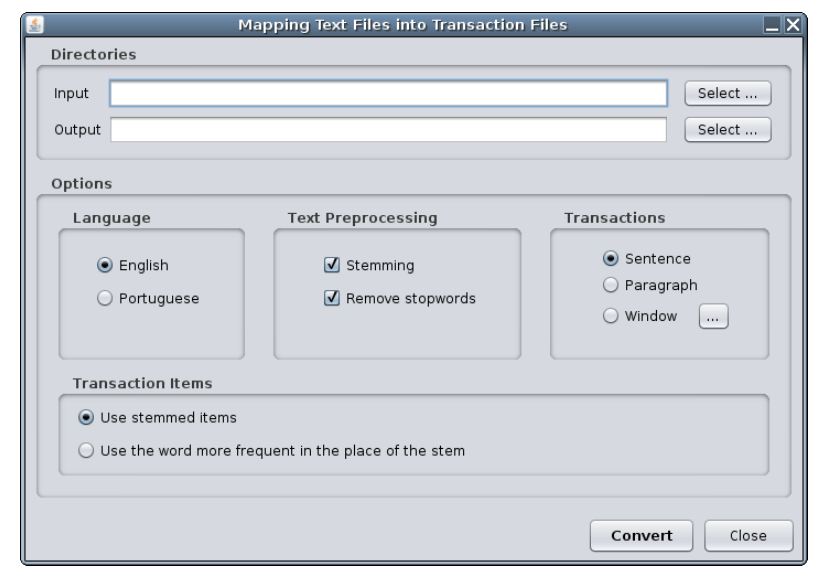

Figura 3.4: FEATuRE - Tela para conversão dos documentos textuais em arquivos de transações.

2. Extrair regras de associação das transações - Figura 3.5. São extraídas as regras de associação dos arquivos de transações gerados no passo anterior. Foi utilizada a implementação do algoritmo APRIORI desenvolvida por (Borgelt, 2004). Nesta etapa é definido o valor do limiar de suporte, podendo este ser definido manualmente ou pela fórmula do suporte automático apresentado na Equação 3.1. Também é possível definir nesta etapa um valor de um multiplicador $(\alpha)$ para aumentar ou diminuir o valor de limiar gerado pelo suporte automático.

3. Utilizar os itens das regras para compor os atributos - Figura 3.6. São definidas quais medidas objetivas serão utilizadas para gerar os atributos. Além disso, são definidos os limiares das medidas objetivas, e pode-se definir um novo limiar de suporte caso o usuário queira diminuir ainda mais o número de atributos. Também é definido nesta etapa o peso do atributo na matriz atributo-valor. Para cada arquivo de regras é gerado um arquivo correspondente de atributos. 


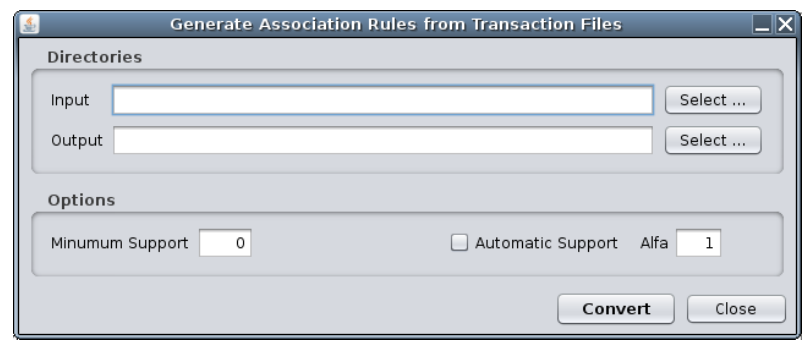

Figura 3.5: FEATuRE - Tela para conversão dos arquivos de transações em arquivos de regras de associação.

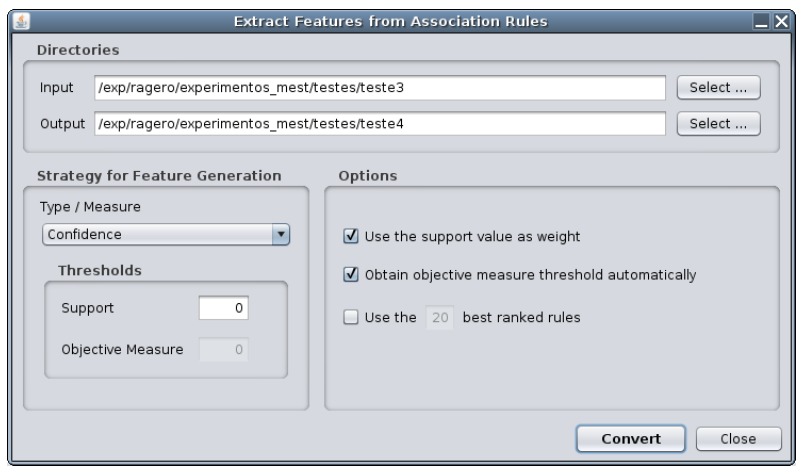

Figura 3.6: FEATuRE - Tela para conversão dos arquivos de regras de associação em arquivos de atributos.

4. Utilizar os atributos para construir a matriz atributo-valor - Figura 3.7. Os arquivos de atributos são utilizados para construir a matriz atributo-valor. Caso estes arquivos estejam separados em pastas e o usuário opte por utilizar a informação da classe na matriz, as pastas serão consideradas como classes.

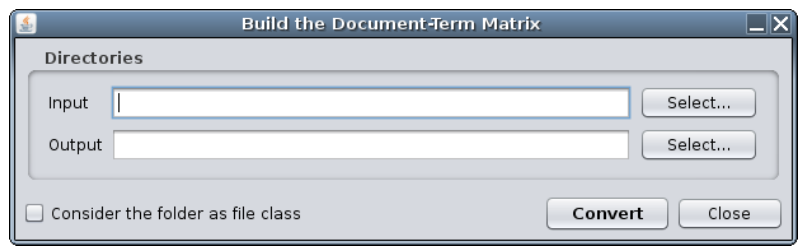

Figura 3.7: FEATuRE - Tela para conversão dos arquivos de atributos em uma matriz atributos valor.

Os pseudocódigos para estas 4 etapas são apresentados no Apêndice A.

Ainda há uma série de outros utilitários implementados na ferramenta FEATuRE, como a visualização do número de regras em um documento, comparação dos atributos de diferentes representações, contagem de quanto atributos são compostos por $n$ palavras, e conversão da uma matriz atributo-valor utilizada na ferramenta FEATuRE para o formato arff utilizado na ferramenta Weka (Witten e Frank, 2005). A ferramenta FEATuRE está disponível em http://sites.labic.icmc.usp.br:8088/ragero/feature/ feature.zip. 



\section{Experimentos e Resultados}

Para avaliar a adequação da representação bag-of-related-words com os objetivos esperados deste projeto de mestrado, foram realizados 3 experimentos. O primeiro experimento consiste em verificar o poder preditivo dos atributos. No segundo experimento é analisada a qualidade dos agrupamentos hierárquicos de documentos textuais e consequentemente a capacidade de auxiliar na construção das hierarquias de tópicos. O terceiro experimento consiste na construção automática de hierarquia de tópicos e na avaliação de especialistas do domínio das coleções textuais utilizadas. Todos os resultados e as dimensionalidades obtidas foram comparados com a representação bag-of-words.

Nas próximas seções são detalhados os experimentos realizados, as coleções de documentos textuais utilizadas, e os resultados obtidos.

\subsection{Projeto dos Experimentos}

O objetivo principal dos experimentos é avaliar as formas de mapear os textos em transações, e quais medidas de interesse objetivas podem produzir os melhores resultados para as tarefas de classificação, agrupamento e construção de hierarquias de tópicos de coleções de documentos textuais. Além disso, também serão comparadas as dimensionalidades das representações bag-of-related-words e bag-of-words.

Foram utilizadas as seguintes ferramentas para a realização dos experimentos:

- FEATuRE: ferramenta desenvolvida neste projeto de mestrado para gerar as representações bag-of-related-words;

- Pretext (Soares et al., 2008): gerar a representação bag-of-words;

- Weka (Witten e Frank, 2005): executar e avaliar algoritmos de classificação;

- TaxTools (Marcacini e Rezende, 2008): executar e avaliar algoritmos de agrupamento hierárquico;

- Torch (Marcacini e Rezende, 2010): construir automaticamente hierarquia de tópicos.

Foram utilizados 4 algoritmos de classificação: Naïve Bayes, J48, $S M O$, e $K N N$. Para avaliar os modelos de classificação de documentos textuais obtidos pelas representações 
utilizadas nos experimentos, é utilizado o procedimento 10-fold-cross-validation para a coleção da ACM, e a divisão de treinamento e teste para a coleção Reuters-21578. A métrica de avaliação é a taxa de erro de classificação.

Nos experimentos referentes ao agrupamento de documentos textuais, são gerados agrupamentos hierárquicos aglomerativos do tipo average-link utilizando o algoritmo UPGMA. A métrica de avaliação é a medida FScore (Larsen e Aone, 1999; Steinbach et al., 2000).

Para as hierarquias de tópicos, são realizadas avaliações subjetivas com especialistas dos domínios das coleções de documentos textuais utilizadas. A métrica de comparação são as notas dadas aos quesitos apresentados na Seção 4.4.3. Na Figura 4.1 são ilustrados os passos utilizados nos experimentos.

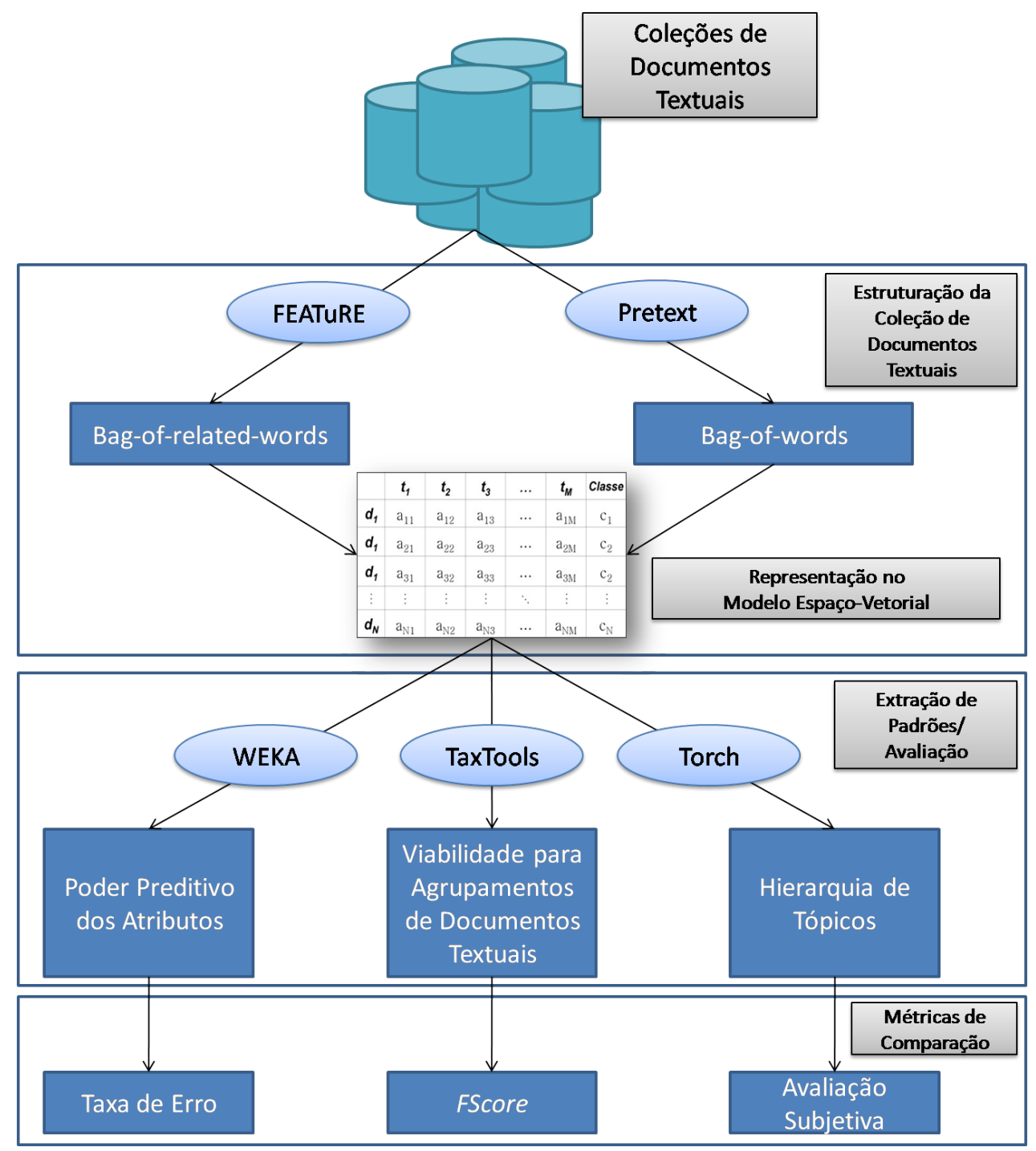

Figura 4.1: Desenho Experimental.

Inicialmente são realizados experimentos apenas avaliando os itemsets frequentes como atributos da representação bag-of-related-words, ou seja, utilizando apenas a medida suporte para obter relações entre itens. A idéia dos experimentos iniciais é avaliar o impacto das diversas formas de mapeamento de documentos textuais em transações nos resultados de classificação e agrupamento de documentos textuais, sem a influência das medidas de interesse objetivas. Inicialmente foram avaliados os diversos mapeamentos e limiares de suporte mínimo nas coleções da ACM e posteriormente foi utilizada a melhor forma de mapeamento verificada na coleção da Reuters-21578. 
Com base nos resultados obtidos utilizando somente a medida suporte, são testadas as demais medidas de interesse objetivas. Além dos limiares definidos empiricamente, também foi utilizada a média das medidas de interesse objetivas obtidas por todas as regras de um documento como limiar. O limiar baseado na média será tratado pelo símbolo $\bar{x}$.

Para todas as representações, são removidas as stopwords utilizando a lista de palavras da ferramenta Pretext (Soares et al., 2008), as palavras são simplificadas utilizando o algoritmo de radicalização de Porter (Porter, 1980), e são utilizados pesos binários para os atributos. Optou-se por utilizar os pesos binários para dar a mesma importância a todos os atributos e evitar a influência dos pesos nos resultados de determinada representação.

$\mathrm{Na}$ análise das formas de mapeamentos, medidas de interesse objetivas e limiares utilizados, os resultados da coleção Reuters são diretamente comparados. Para as coleções da ACM é utilizado o teste de Friedman com pós-teste de Dunn (Kanji, 2006) para verificar diferenças estatísticas significativas nos resultados obtidos para as 8 coleções. O nível de confiança utilizado no teste foi de $95 \%$. Este teste foi escolhido pois os resultados obtidos nos experimentos advém das mesmas amostras, e não se assume conhecimento da forma de distribuição dos dados. Neste trabalho serão utilizados os símbolos ( $\mathbf{\Delta})$ e ( $\mathbf{\nabla})$ para representar, respectivamente, os resultados que foram melhores ou piores com diferenças estatisticamente significantes, e o símbolo $(\bullet)$ quando não houve diferença estatisticamente significante. As tabelas que apresentam os testes mostram o resultado do teste da representação da linha em relação à representação da coluna.

Nas próximas seções são apresentados os detalhes das coleções de documentos textuais utilizadas nos experimentos.

\subsection{Coleções de Documentos Textuais Utilizadas nos Experimentos}

Os experimentos foram realizados utilizando duas coleções textuais: proceedings da biblioteca digital da $\mathrm{ACM}^{1}$ (Association for Computing Machinery), e a Reuters-21578 ${ }^{2}$.

A coleção ACM foi divida em 8 coleções de documentos textuais, com 5 classes para cada coleção e aproximadamente 90 documentos por classe, como apresentado na Tabela 4.1. Cada uma dessas coleções será tratada por ACM-Número. O intuito de utilizar as coleções de proceedings da ACM é que como são textos longos, normalmente 10 páginas, pode-se gerar um grande número de transações para todas as formas de mapeamento utilizadas neste projeto.

Na coleção Reuters-21578 foram utilizados somente o conteúdo das tags TITLE e $B O D Y$. Além disso, foram considerados somente documentos que apresentavam um único tópico e cuja divisão LEWISSPLIT foi definida como "TRAIN" ou "TEST". A partir daí foram utilizadas as 15 classes mais frequentes, sendo ao todo 2537 documentos para treinamento e 952 documentos para teste. Na Tabela 4.2 são apresentados o número de documentos de treinamento e teste das classes utilizadas nos experimentos. A utilização da base Reuters tem como objetivo principal verificar a adequabilidade da abordagem proposta também para textos curtos.

\subsection{Construção da Bag-of-Related-Words}

Foram geradas representações de documentos textuais segundo a abordagem proposta considerando como transações as sentenças, parágrafos e janelas de tamanho 10, 20 e 30

\footnotetext{
${ }^{1}$ http://sites.labic.icmc.usp.br:8088/ragero/Acm-Collection/

${ }^{2}$ http://www.daviddlewis.com/resources/testcollections/reuters21578/
} 
Tabela 4.1: Descrição das coleções textuais da ACM utilizadas no experimentos.

\begin{tabular}{|c|c|c|c|}
\hline Coleção & Evento (Periodo) & $\mathbf{N}^{\circ}$ Docs. & Total \\
\hline \multirow{5}{*}{ ACM-1 } & 3D technologies for the World Wide Web (2002-2008) & 91 & \multirow{5}{*}{401} \\
\hline & IEEE Visualization $(2002-2008)$ & 72 & \\
\hline & International Workshop on Wireless Mobile Multimedia $(2002-2006)$ & 82 & \\
\hline & ACM Symposium on Solid and Physical Modeling $(2004-2008)$ & 74 & \\
\hline & Foundations of Software Engineering $(2002-2008)$ & 82 & \\
\hline \multirow{5}{*}{$\mathrm{ACM}-2$} & Theoretical Aspects Of Rationality And Knowledge (1998-2007) & 86 & \multirow{5}{*}{411} \\
\hline & Winter Simulation Conference (2006) & 84 & \\
\hline & Symposium on Software Reusability $(1995-2001)$ & 72 & \\
\hline & Virtual Reality Software and Technology $(2006-2008)$ & 83 & \\
\hline & Web Intelligence (2007) & 86 & \\
\hline \multirow{5}{*}{$\mathrm{ACM}-3$} & Workshop on Computer Architecture Education (1997 - 2007) & 78 & \multirow{5}{*}{424} \\
\hline & Symposium on Architecture for Networking And Communications Systems $(2005-2008)$ & 75 & \\
\hline & Workshop on Privacy in the Electronic Society $(2002-2007)$ & 98 & \\
\hline & Workshop on Software and Performance $(2005-2008)$ & 81 & \\
\hline & Workshop on Web Information and Data Management $(2003-2008)$ & 92 & \\
\hline \multirow{5}{*}{$\mathrm{ACM}-4$} & Conference on Embedded Networked Sensor Systems $(2003-2004)$ & 50 & \multirow{5}{*}{394} \\
\hline & Annual ACM Conference on Research and Development in Information Retrieval (2009) & 71 & \\
\hline & ACM Symposium on Parallel Algorithms and Architectures $(2003-2004)$ & 98 & \\
\hline & Symposium on Volume Visualization $(1989-2002)$ & 104 & \\
\hline & International Cross-Disciplinary Conference on Web Accessibility $(2004-2009)$ & 71 & \\
\hline \multirow{5}{*}{$\mathrm{ACM}-5$} & Tangible and Embedded Interaction $(2007-2009)$ & $\overline{81}$ & \multirow{5}{*}{471} \\
\hline & International Conference on Management of Data $(2008-2009)$ & 96 & \\
\hline & Symposium on User Interface Software and Technology $(2005-2008)$ & 104 & \\
\hline & Conference on Information Technology Education $(2006-2008)$ & 87 & \\
\hline & Annual ACM Symposium on Theory of Computing $(2007-2009)$ & 103 & \\
\hline \multirow{5}{*}{$\mathrm{ACM}-6$} & Annual Symposium on Computational Geometry $(2008-2009)$ & 89 & \multirow{5}{*}{439} \\
\hline & Symposium on Access Control Models and Technologies $(2006-2009)$ & 90 & \\
\hline & Annual Conference on Research in Computational Molecular Biology $(2002-2004)$ & 71 & \\
\hline & Principles and Practice of Parallel Programming $(2006-2009)$ & 96 & \\
\hline & Annual Symposium on Integrated Circuits and System Design $(2007-2008)$ & 93 & \\
\hline \multirow{5}{*}{ ACM-7 } & Symposium on Principles of Database Systems $(2006-2009)$ & 104 & \multirow{5}{*}{471} \\
\hline & Int. Conference on Principles and Practice of Declarative Programming $(2004-2008)$ & 101 & \\
\hline & Workshop on Parallel and Distributed Simulation $(2005-2009)$ & 98 & \\
\hline & International Conference on Mobile Systems, Applications and Services (2005 - 2009) & 95 & \\
\hline & Workshop on Network and System Support for Games $(2005-2008)$ & 73 & \\
\hline \multirow{5}{*}{ ACM-8 } & International Symposium on Mobile Ad Hoc Networking \& Computing (2007 - 2009) & 90 & \multirow{5}{*}{495} \\
\hline & International Conference on Knowledge Discovery and Data Mining (2009) & 105 & \\
\hline & Language, Compiler and Tool Support for Embedded Systems $(2004-2009)$ & 102 & \\
\hline & Conference on Hypertext and Hypermedia $(2006-2009)$ & 93 & \\
\hline & International Symposium on Microarchitecture $(2006-2008)$ & 105 & \\
\hline
\end{tabular}

Tabela 4.2: Descrição da coleção Reuters 21578 utilizadas no experimentos.

\begin{tabular}{|l|c|c|}
\hline Classe & $\mathbf{N}^{\text {o de Doc. } \mathbf{p} / \text { Treino }}$ & $\mathbf{N}^{\text {o }}$ de Doc. $\mathbf{p} /$ Teste \\
\hline Acq & 450 & 200 \\
\hline Cocoa & 46 & 15 \\
\hline Coffee & 90 & 22 \\
\hline Cpi & 54 & 17 \\
\hline Crude & 253 & 121 \\
\hline Earn & 500 & 200 \\
\hline Gnp & 58 & 15 \\
\hline Gold & 70 & 20 \\
\hline Grain & 41 & 10 \\
\hline Interest & 190 & 81 \\
\hline Money-fx & 206 & 87 \\
\hline Money-supply & 123 & 28 \\
\hline Ship & 108 & 36 \\
\hline Sugar & 97 & 25 \\
\hline Trade & 251 & 75 \\
\hline
\end{tabular}

para as coleções da ACM. Foram analisados quais tipos de mapeamento produziram melhores resultados para estas coleções. Verificou-se janela de tamanho 5 obteve os melhores resultados para a coleção ACM. O mapeamento de janela de tamanho 5 foi então utilizado para a coleção Reuters-21578, uma vez que além de obter os melhores resultados para as coleções da ACM, os textos dessa coleção não possuem muitas sentenças ou parágrafos. 
Como não há uma regra para definir valores de parâmetros que possam ser efetivos nos resultados tanto na classificação quanto no agrupamento de documentos para diferentes coleções de documentos, foram definidos valores de parâmetros de maneira empírica para cada coleção de documentos textuais. A base para a definição dos parâmetros foi o número de atributos gerados. Na Tabela 4.3 são apresentados os limiares de suporte utilizados nos experimentos para as coleções ACM e Reuters-21578, e na Figura 4.2 são apresentados os números de atributos obtidos para os diversos mapeamentos utilizando os itemsets frequentes como atributos para as coleções da ACM.

Tabela 4.3: Valores de suporte mínimos utilizados para as formas de mapeamento utilizadas nos experimentos realizados.

\begin{tabular}{|l|l|l|}
\hline Tipo de Transação & ACM & Reuters \\
\hline Sentença & $2 \% ; 3 \% ; 4 \% ; 5 \% ; 6 \%$ & - \\
\hline Parágrafo & $9 \% ; 10 \% ; 11 \% ; 12 \% ; 13 \%$ & - \\
\hline Janela - 5 & $0,6 \% ; 0,8 \% ; 1 \% ; 2 \% ; 3 \% ;$ Automático & Automático \\
\hline Janela - 10 & $2 \% ; 3 \% ; 4 \% ; 5 \% ; 6 \%$ & - \\
\hline Janela - 20 & $6 \% ; 7 \% ; 8 \% ; 9 \% ; 10 \%$ & - \\
\hline Janela - 30 & $10 \% ; 11 \% ; 12 \% ; 13 \% ; 14 \%$ & - \\
\hline
\end{tabular}

Posteriormente, foram testadas as demais medidas de interesse objetivas. Além dos limiares definidos empiricamente, também foi utilizada a média das medidas de interesse objetivas obtidas por todas as regras de um documento como limiar de poda $(\bar{x})$. Todos os limiares foram aplicados às regras extraídas utilizando um mapeamento de janela deslizante de tamanho 5 com o uso do suporte calculado automaticamente. Este tipo de mapeamento foi escolhido devido à janela de tamanho 5 obter os melhores resultados e o suporte automático obter resultados tão bons quanto os valores de suporte definidos manualmente.

Na Tabela 4.4 são apresentados os limiares das medidas de interesse objetivas utilizados nos experimentos. O número de atributos obtidos estão representados na Figura 4.3 para a coleção da ACM e na Figura 4.4 para a coleção da Reuters-21578.

Tabela 4.4: Limiares de medidas de interesse objetivas utilizados nos experimentos realizados.

\begin{tabular}{|l|l|l|}
\hline Medida & ACM & Reuters \\
\hline Confiança & 0,$25 ; 0,50 ; \bar{x}$ & 0,$25 ; 0,50 ; \bar{x}$ \\
\hline Lift & 0,$10 ; 0,20 ; \bar{x}$ & 0,$10 ; 0,20 ; \bar{x}$ \\
\hline Yule's Q & 0,$50 ; 0,75 ; \bar{x}$ & 0,$50 ; 0,75 ; \bar{x}$ \\
\hline Correlação & 0,$25 ; 0,50 ; \bar{x}$ & 0,$25 ; 0,50 ; \bar{x}$ \\
\hline Informação Mútua & 0,$005 ; 0,01 ; \bar{x}$ & 0,$01 ; 0,05 ; \bar{x}$ \\
\hline Gini Index & 0,$005 ; 0,01 ; \bar{x}$ & 0,$01 ; 0,04 ; \bar{x}$ \\
\hline Kappa & 0,$15 ; 0,20 ; \bar{x}$ & 0,$30 ; 0,50 ; \bar{x}$ \\
\hline J-Measure & 0,$01 ; 0,02 ; \bar{x}$ & 0,$02 ; 0,05 ; \bar{x}$ \\
\hline
\end{tabular}

O número de atributo obtidos por todas as representações utilizadas neste projeto de mestrado é apresentado no Apêndice B. Nas próximas seções serão apresentados os resultados dos 3 grupos de experimentos realizados para avaliação da abordagem proposta. Para facilitar o entendimento, as representações bag-of-related-words serão escritas da seguinte forma: [Tipo_de_Mapeamento Valor_de_Sup-mín Medida_Objetiva Limiar_Medida_Objetiva]. Por exemplo, a representação que utiliza o mapeamento de sentenças com suporte mínimo de $2 \%$ será representada por [Sent. $2 \%$ ]. Já a representação 


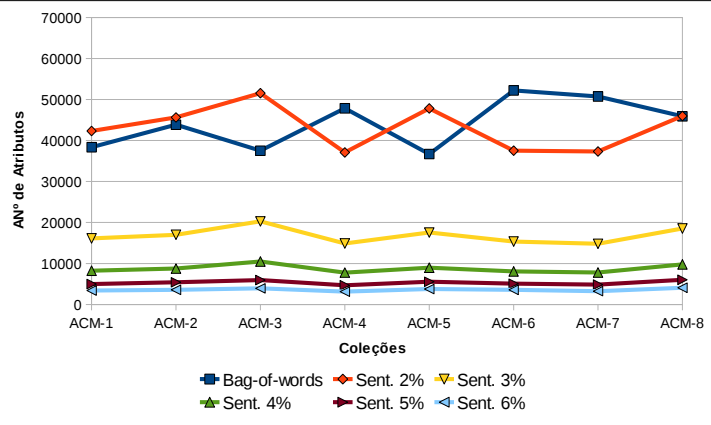

(a) Sentença

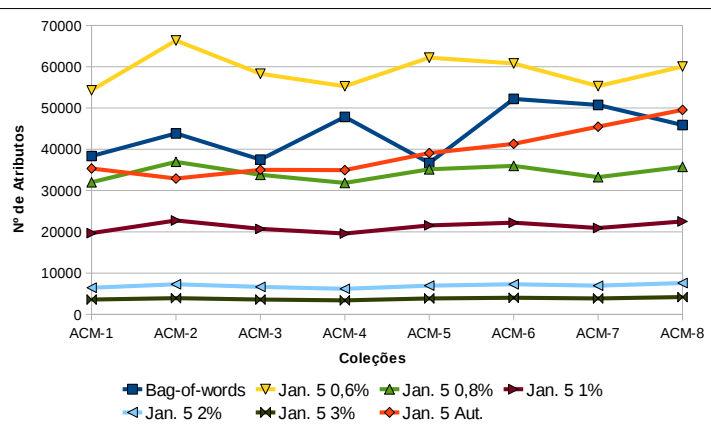

(c) Janela 5

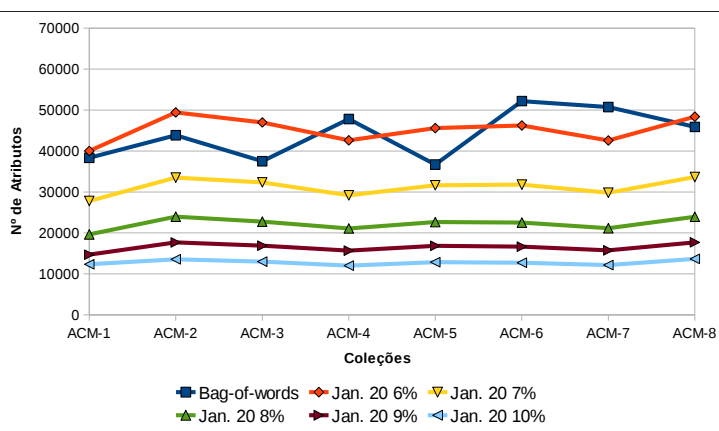

(e) Janela 20

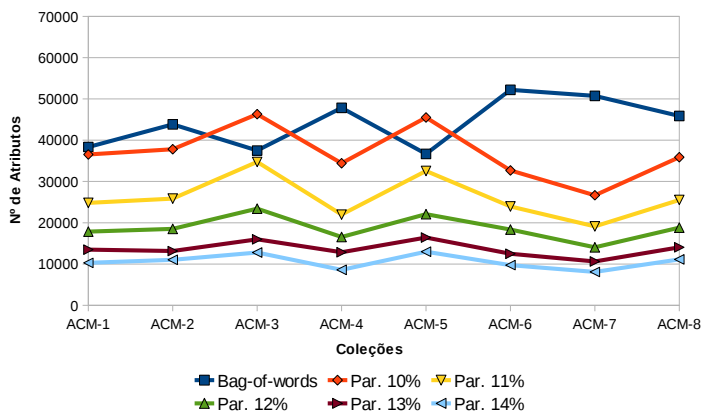

(b) Parágrafo

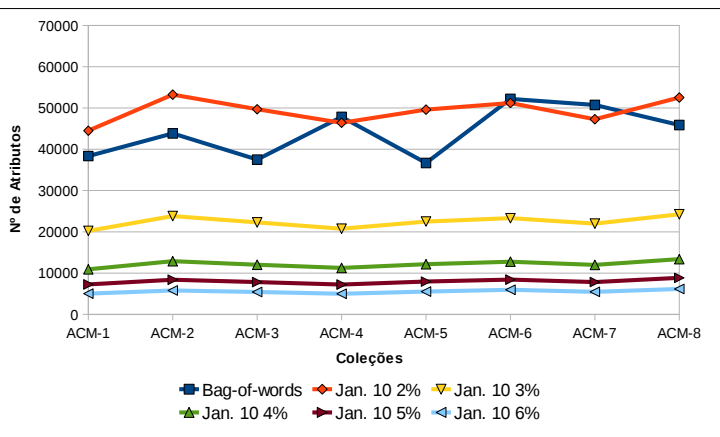

(d) Janela 10

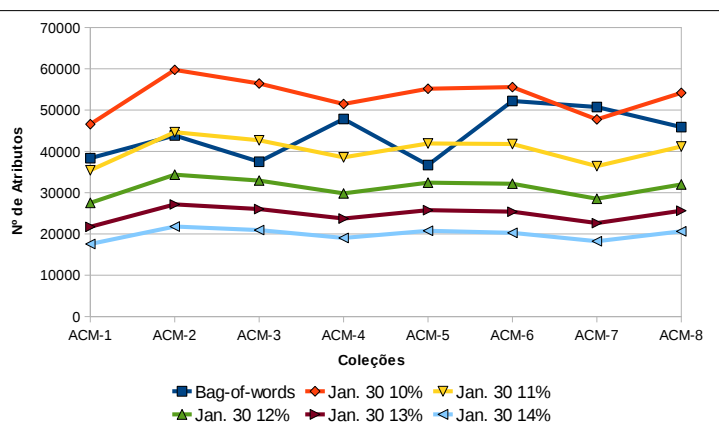

(f) Janela 30

Figura 4.2: Número de atributos gerados para as coleções da ACM obtidos pelas diferentes formas de mapeamento com os respectivos valores de suporte mínimo utilizados.

que utiliza o mapeamento de janelas de tamanho 5 com suporte obtido automaticamente, e a medida Lift com um limiar de 0,5, será representada por [Jan. 5 Aut. Lift 0,5].

\subsection{Avaliação da Representação Bag-of-Related-Words}

Nas próximas seções são apresentados os resultados da avaliação da representação bagof-related-words para as tarefas de classificação, agrupamento, e construção automática de hierarquias de tópicos.

\subsubsection{Avaliação do Poder Preditivo dos Atributos da Bag-of-Related-Words}

Para avaliar o poder preditivo dos atributos gerados pela abordagem proposta frente a representação bag-of-words, foram utilizados 4 algoritmos de classificação: i) Naïve 


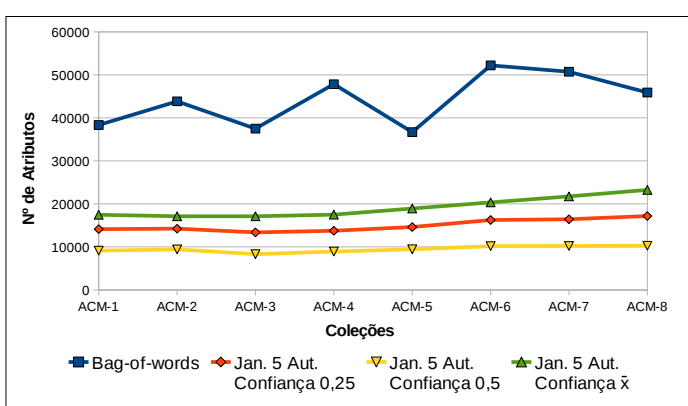

(a) Confiança

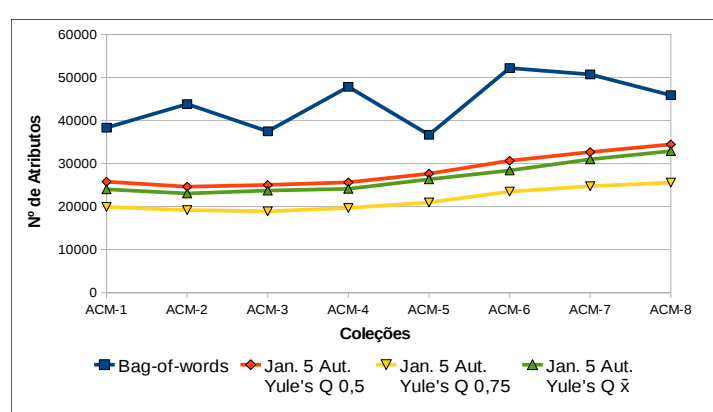

(c) Yule's Q

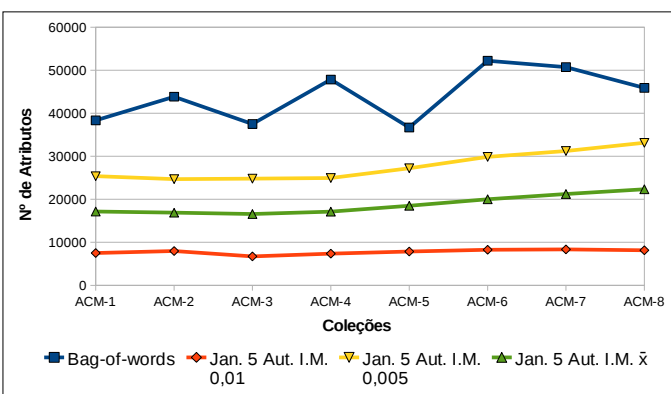

(e) Informação Mútua

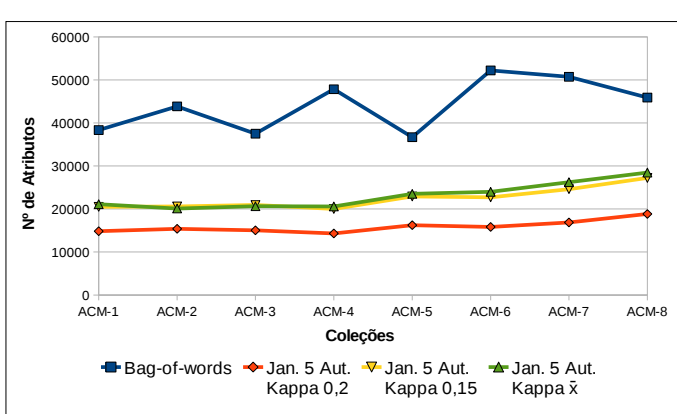

(g) Kappa

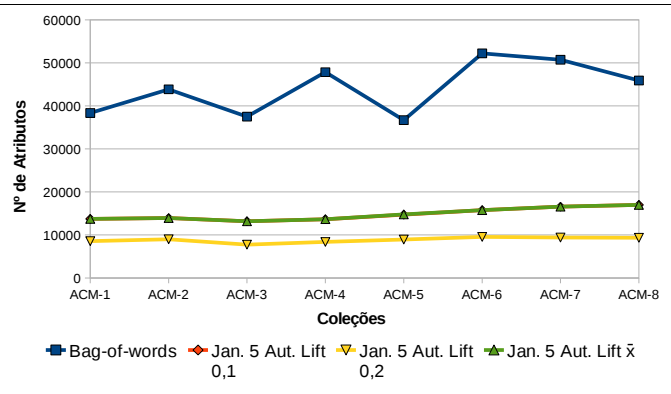

(b) Lift

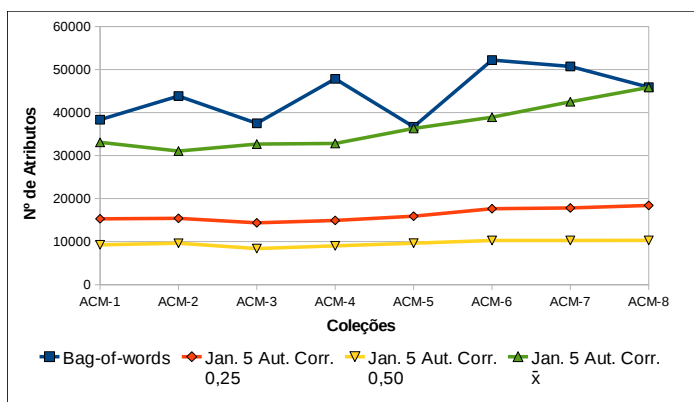

(d) Correlação

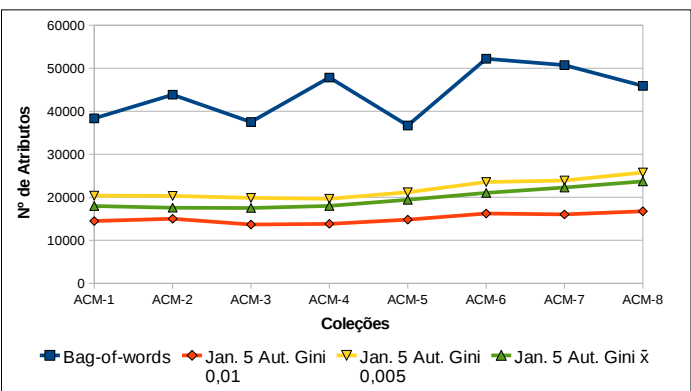

(f) Gini Index

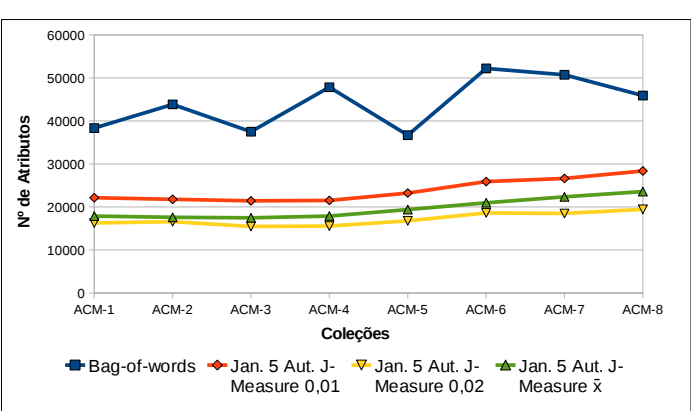

(h) J-Measure

Figura 4.3: Número de atributos gerados para as coleções da ACM obtidos pelas representações que utilizaram medidas de interesse objetivas para extrair atributos e os respectivos limiares utilizados.

Bayes, aprendizado probabilístico; ii) $\mathrm{J}_{4} 8^{3}$, aprendizado simbólico; iii) $S M O$, aprendizado estatístico; e iv) $K N N$, aprendizado baseado em instâncias.

Para todos os algoritmos de classificação foram utilizadas as opções padrões da ferramenta Weka. A métrica usada para comparar os resultados foi a taxa de erro de classificação. Por simplicidade, para as coleções ACM são apresentados somente os resultados das representações que obtiveram a menor taxa de erro para pelo menos uma das

\footnotetext{
${ }^{3}$ J48 é a implementação do algoritmo de classificação C4.5 no Weka.
} 


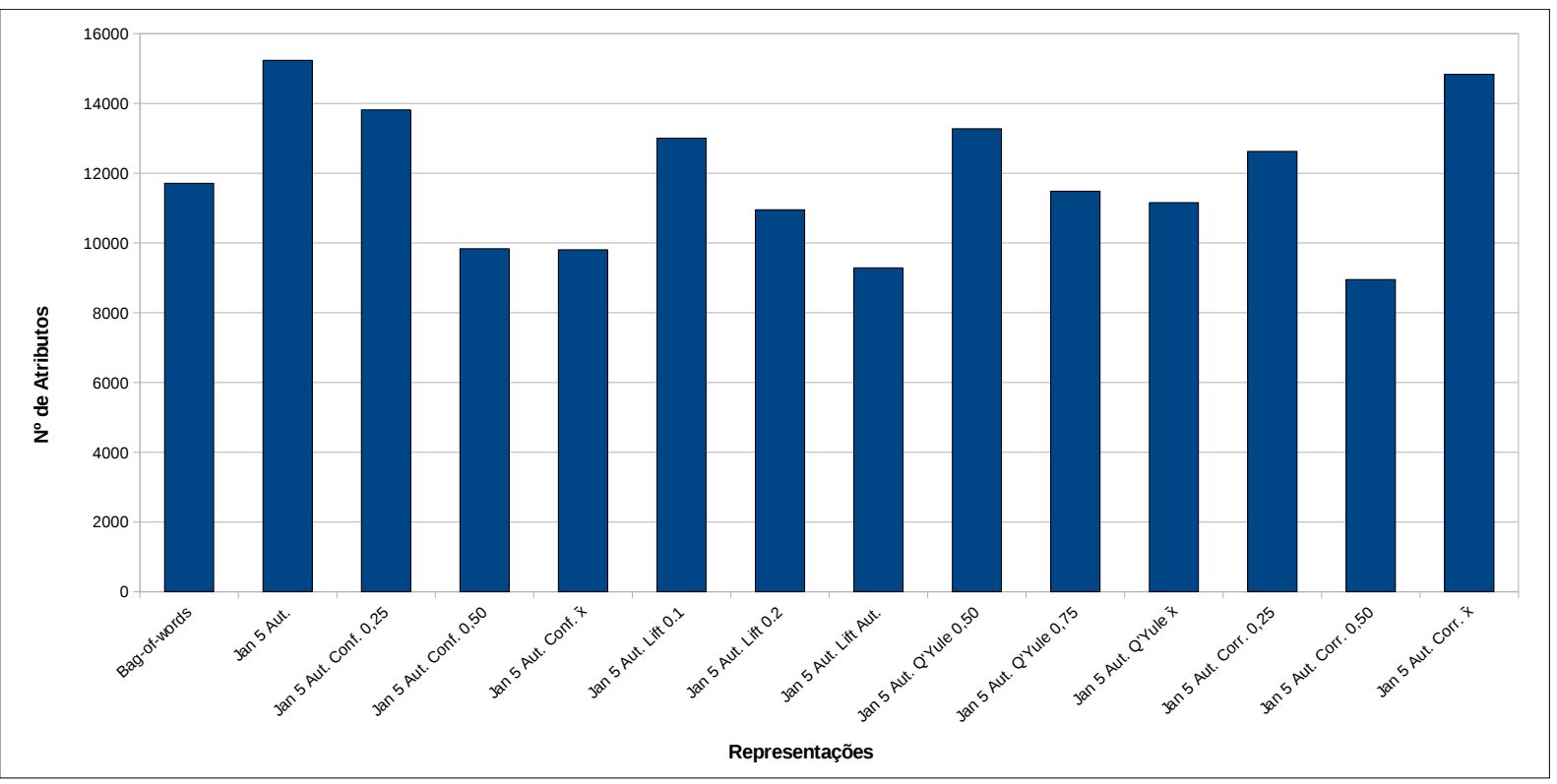

(a)

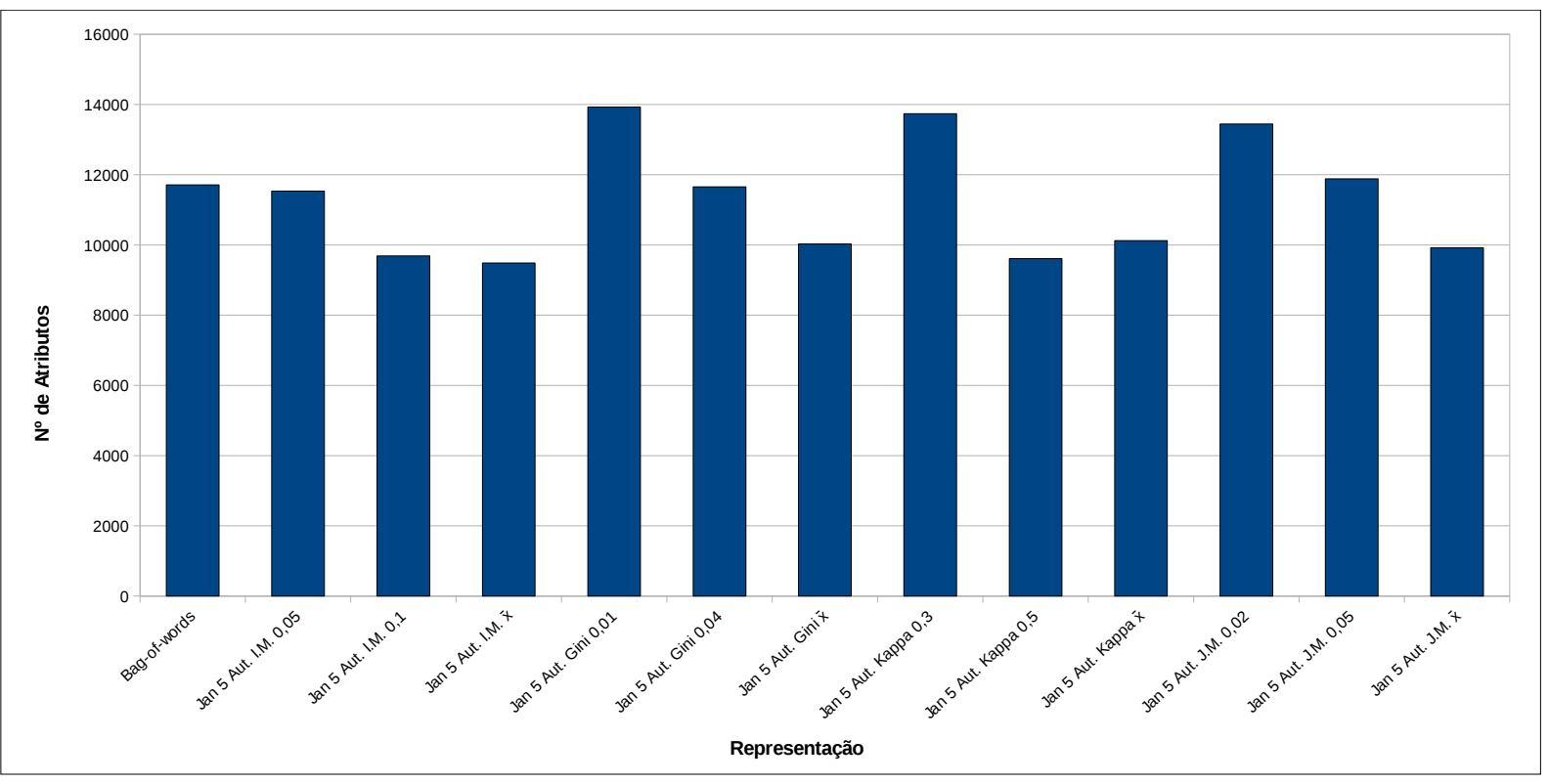

(b)

Figura 4.4: Número de atributos gerados para a coleção Reuters-21578 obtidos pelas representaçõs que utilizaram medidas de interesse objetivas para extrair atributos e os respectivos limiares utilizados.

coleções. Para a coleção Reuters-21578 são apresentação os resultados das representações com limiares obtidos automaticamente e a representação bag-of-words. Os resultados de classificação obtidos por todas as representações utilizadas nos experimentos são apresentados no Apêndice C.

Nas próximas subseções serão apresentados os resultados obtidos para cada algoritmo de classificação utilizado neste trabalho.

\section{Naïve Bayes}

Nesta seção são apresentados alguns dos resultados obtidos pelo algoritmo de classificação Naïve Bayes utilizando as representações bag-of-related-words e bag-of-words. Na Tabela 4.5 são apresentados os resultados da representação bag-of-words e das represen- 
tações bag-of-related-words com diferentes formas de mapeamento que obtiveram a menor taxa de erro para ao menos uma das coleções da ACM. Foram considerados apenas os itemsets frequentes como atributos das representações bag-of-related-words. Em 5 das 8 coleções (ACM-2, ACM-3, ACM-4, ACM-6, ACM-7), a menor taxa de erro foi obtida por uma representação bag-of-related-words com uma diferença de aproximadamente $5 \%$ em relação à bag-of-words para a maioria das coleções.

Tabela 4.5: Naïve Bayes - taxas de erro da representação bag-of-words e das representações bag-of-relatedwords com itemsets frequentes como atributos que obtiveram a menor taxa de erro para as coleções da ACM.

\begin{tabular}{|l|c|c|c|c|c|c|c|c|}
\cline { 2 - 9 } \multicolumn{1}{c|}{} & \multicolumn{9}{c|}{ Taxa de Erro } \\
\hline Representação & ACM-1 & ACM-2 & ACM-3 & ACM-4 & ACM-5 & ACM-6 & ACM-7 & ACM-8 \\
\hline \multirow{2}{*}{ Bag-of-words } & $\boldsymbol{*} \mathbf{5 , 5 1}$ & 7,80 & 7,55 & 11,42 & $\boldsymbol{*} \mathbf{2 , 7 6}$ & 7,29 & 7,89 & $\boldsymbol{*} \mathbf{5 , 8 6}$ \\
& $\pm 0,14$ & $\pm 0,10$ & $\pm 0,14$ & $\pm 0,08$ & $\pm 0,09$ & $\pm 0,10$ & $\pm 0,10$ & $\pm 0,14$ \\
\hline \multirow{2}{*}{ Jan. 50,6\% } & 8,27 & 3,66 & 4,09 & $\boldsymbol{*} \mathbf{0 , 5 1}$ & 2,97 & $\boldsymbol{*} \mathbf{2 , 5 2}$ & $\boldsymbol{*} \mathbf{2 , 9 9}$ & 7,47 \\
& $\pm 0,18$ & $\pm 0,12$ & $\pm 0,12$ & $\pm 0,05$ & $\pm 0,11$ & $\pm 0,10$ & $\pm 0,11$ & $\pm 0,17$ \\
\hline \multirow{2}{*}{ Jan. 50,8\% } & 9,77 & $\boldsymbol{* 2 , 9 3}$ & 3,37 & 0,76 & 5,31 & 2,97 & 4,90 & 6,46 \\
& $\pm 0,19$ & $\pm 0,11$ & $\pm 0,12$ & $\pm 0,06$ & $\pm 0,14$ & $\pm 0,11$ & $\pm 0,14$ & $\pm 0,16$ \\
\hline \multirow{2}{*}{ Jan. 5 Aut. } & 9,27 & 3,90 & $\boldsymbol{*} \mathbf{3 , 1 3}$ & 1,52 & 3,61 & 3,66 & 4,26 & 6,67 \\
& $\pm 0,18$ & $\pm 0,12$ & $\pm 0,11$ & $\pm 0,07$ & $\pm 0,11$ & $\pm 0,12$ & $\pm 0,12$ & $\pm 0,16$ \\
\hline
\end{tabular}

A representação [Jan. 5 0,6\%] foi melhor em 3 coleções enquanto que as representações [Jan. 5 0,8\%] e [Jan. 5 Aut.] foram melhores em uma coleção cada. Para as coleções ACM-3 e ACM-6, apenas uma representação apresentou a taxa de erro maior que a bagof-words ([Sent. 6\%] e [Par. 14\%] respectivamente), e para a coleção ACM-7 apenas duas representações apresentaram a taxa de erro maior que a bag-of-words ([Sent. 6\%] e [Par. $14 \%]$ ). Em alguns casos, a abordagem proposta obteve uma taxa de erro menor com um número de atributos aproximadamente 12 vezes menor em relação à bag-of-words.

As representações que utilizaram uma janela de tamanho 5 obtiveram os melhores resultados em relação às demais representações bag-of-related-words com diferentes tipos de mapeamento. Ao comparar os atributos da coleção ACM-8 obtidos pelas representações [Jan. 5 1\%] e [Jan. 20 8\%], que geraram um número de atributos semelhante, pode-se notar que a representação [Jan. 5 1\%] gerou alguns atributos importantes para o cálculo das probabilidades que não foram obtidos pela representação [Jan. 20 8\%]. Por exemplo, alguns atributos importantes para o cálculo das probabilidades para a classe "Data Mining" obtidos pela representação [Jan. 5 1\%] foram: "build_classif", "classif_perform", "cluster_size", "data_dimension", "data_imbalance", "data_reduc", e "data_geometr_structr". Mesmo comparando com os atributos da representação [Sent. $2 \%$ ], a qual possui 23453 atributos à mais que a representação [Jan. 5 1\%], alguns atributos que influenciam o cálculo das probabilidades aparecem somente na representação [Jan. 5 1\%], como "accuraci_rate", "categori_probabl", "chromosom", "classif_error", "cluster_interpret", "cluster_purit", e "data_imbalanc".

Para verificar o efeito da variação do suporte mínimo nos resultados para as diversas formas de mapeamento, foi aplicado o teste de Friedman considerando os resultados das 8 coleções da ACM. Na Tabela 4.6 são apresentados os resultados dos testes estatísticos, onde são camparadas as representações das linhas em relação às representações das colunas. De um modo geral, foram verificadas diferenças estatisticamente significantes nos resultados obtidos pelo uso de um suporte mínimo menor em relação a um suporte mínimo maior, ou seja, uma poda excessiva no número de atributos pode degradar significativamente os resultados. A exceção se dá pelas janelas de tamanho 20 e 30 na qual as diferenças dos resultados obtidos variando o suporte mínimo não foram estatisticamente significantes.

Para comparar com a representação bag-of-words e analisar as diversas formas de mapeamento, foram escolhidos os melhores valores de suporte mínimo para cada forma 
Tabela 4.6: Naïve Bayes - resultado do teste estatístico para avaliar o impacto na taxa de erro de classificação causado pela variação do suporte mínimo para as diferentes formas de mapeamento nas coleções da ACM.

\begin{tabular}{|c|c|c|c|c|c|}
\cline { 2 - 6 } \multicolumn{1}{c|}{} & $2 \%$ & $3 \%$ & $4 \%$ & $5 \%$ & $6 \%$ \\
\hline $2 \%$ & - & $\bullet$ & $\bullet$ & $\boldsymbol{\Delta}$ & $\boldsymbol{\Delta}$ \\
\hline $3 \%$ & $\bullet$ & - & $\bullet$ & $\boldsymbol{\Delta}$ & $\boldsymbol{\Delta}$ \\
\hline $4 \%$ & $\bullet$ & $\bullet$ & - & $\boldsymbol{\Delta}$ & $\boldsymbol{\Delta}$ \\
\hline $5 \%$ & $\mathbf{\nabla}$ & $\mathbf{\nabla}$ & $\mathbf{\nabla}$ & - & $\boldsymbol{\Delta}$ \\
\hline $6 \%$ & $\mathbf{\nabla}$ & $\mathbf{\nabla}$ & $\mathbf{\nabla}$ & $\mathbf{\nabla}$ & - \\
\hline
\end{tabular}

Janela 5

\begin{tabular}{|c|c|c|c|c|c|}
\multicolumn{1}{c|}{} & Janela 5 \\
\cline { 2 - 6 } \multicolumn{1}{c|}{} & $0,6 \%$ & $0,8 \%$ & $1 \%$ & $2 \%$ & $3 \%$ \\
\hline $0,6 \%$ & - & $\bullet$ & $\bullet$ & $\boldsymbol{\Delta}$ & $\mathbf{\Delta}$ \\
\hline $0,8 \%$ & $\bullet$ & - & $\bullet$ & $\boldsymbol{\Delta}$ & $\boldsymbol{\Delta}$ \\
\hline $1 \%$ & $\bullet$ & $\bullet$ & - & $\boldsymbol{\Delta}$ & $\boldsymbol{\Delta}$ \\
\hline $2 \%$ & $\mathbf{\nabla}$ & $\mathbf{\nabla}$ & $\mathbf{\nabla}$ & - & $\bullet$ \\
\hline $3 \%$ & $\mathbf{\nabla}$ & $\mathbf{\nabla}$ & $\mathbf{\nabla}$ & $\bullet$ & - \\
\hline
\end{tabular}

\begin{tabular}{|c|c|c|c|c|c|}
\cline { 2 - 6 } \multicolumn{1}{c|}{} & $6 \%$ & $7 \%$ & $8 \%$ & $9 \%$ & $10 \%$ \\
\hline $6 \%$ & - & $\bullet$ & $\bullet$ & $\bullet$ & $\bullet$ \\
\hline $7 \%$ & $\bullet$ & - & $\bullet$ & $\bullet$ & $\bullet$ \\
\hline $8 \%$ & $\bullet$ & $\bullet$ & - & $\bullet$ & $\bullet$ \\
\hline $9 \%$ & $\bullet$ & $\bullet$ & $\bullet$ & - & $\bullet$ \\
\hline $10 \%$ & $\bullet$ & $\bullet$ & $\bullet$ & $\bullet$ & - \\
\hline
\end{tabular}

\begin{tabular}{|c|c|c|c|c|c|}
\cline { 2 - 6 } \multicolumn{1}{c|}{} & $10 \%$ & $11 \%$ & $12 \%$ & $13 \%$ & $14 \%$ \\
\hline $10 \%$ & - & $\bullet$ & $\bullet$ & $\bullet$ & $\Delta$ \\
\hline $11 \%$ & $\bullet$ & - & $\bullet$ & $\bullet$ & $\Delta$ \\
\hline $12 \%$ & $\bullet$ & $\bullet$ & - & $\bullet$ & $\Delta$ \\
\hline $13 \%$ & $\bullet$ & $\bullet$ & $\bullet$ & - & $\bullet$ \\
\hline $14 \%$ & $\mathbf{\nabla}$ & $\mathbf{\nabla}$ & $\mathbf{\nabla}$ & $\bullet$ & - \\
\hline
\end{tabular}

\begin{tabular}{|c|c|c|c|c|c|}
\cline { 2 - 6 } \multicolumn{1}{c|}{} & $2 \%$ & $3 \%$ & $4 \%$ & $5 \%$ & $6 \%$ \\
\hline $2 \%$ & - & $\Delta$ & $\bullet$ & $\Delta$ & $\Delta$ \\
\hline $3 \%$ & $\bullet$ & - & $\bullet$ & $\bullet$ & $\Delta$ \\
\hline $4 \%$ & $\bullet$ & $\bullet$ & - & $\bullet$ & $\Delta$ \\
\hline $5 \%$ & $\bullet$ & $\bullet$ & $\bullet$ & - & $\Delta$ \\
\hline $6 \%$ & $\mathbf{\nabla}$ & $\bullet$ & $\mathbf{\nabla}$ & $\mathbf{\nabla}$ & - \\
\hline
\end{tabular}

Janela 30

\begin{tabular}{|c|c|c|c|c|c|}
\multicolumn{7}{c}{ Janela 30} \\
\cline { 2 - 6 } \multicolumn{1}{c|}{} & $10 \%$ & $11 \%$ & $12 \%$ & $13 \%$ & $14 \%$ \\
\hline $10 \%$ & - & $\bullet$ & $\bullet$ & $\bullet$ & $\bullet$ \\
\hline $11 \%$ & $\bullet$ & - & $\bullet$ & $\bullet$ & $\bullet$ \\
\hline $12 \%$ & $\bullet$ & $\bullet$ & - & $\bullet$ & $\bullet$ \\
\hline $13 \%$ & $\bullet$ & $\bullet$ & $\bullet$ & - & $\bullet$ \\
\hline $14 \%$ & $\bullet$ & $\bullet$ & $\bullet$ & $\bullet$ & - \\
\hline
\end{tabular}

de mapeamento, ou seja, limiares de suporte cujos resultados apresentaram diferenças estatisticamente significantes em relação a outros limiares no mesmo tipo de mapeamento. Nas situações que não foi encontrada diferença, foi escolhido o limiar de suporte com menor média na taxa de erro de classificação das 8 coleções da ACM. As representações selecionadas foram: [Sent. 3\%], [Par. 11\%], [Jan. 5 0,6\%], [Jan. 10 2\%], [Jan. 20 9\%], [Jan. 30 10\%].

Na Tabela 4.7 são apresentados os resultados dos testes estatísticos com os melhores limiares de suporte para cada tipo de mapeamento e a representação bag-of-words. Podese notar que todas as representações da abordagem proposta não obtiveram diferenças estatisticamente significantes em relação à bag-of-words. Portanto, mesmo utilizando somente os itemsets frequentes como atributos, é possível obter resultados tão bons quanto os da bag-of-words.

Vale ressaltar que muitas representações bag-of-related-words como [Sent. 3\%], e [Jan. 20 9\%], têm um número de atributos muito menor comparado com a bag-of-words, chegando a uma redução do número de atributos em aproximadamente $71 \%$ e $69 \%$ respectivamente para algumas coleções.

Tabela 4.7: Naïve Bayes - resultado do teste estatístico para comparar a taxa de erro de classificação nas coleções ACM obtidas pela representação bag-of-words e pelas representações bag-of-related-words com diferentes formas de mapeamento.

\begin{tabular}{|c|c|c|c|c|c|c|c|}
\cline { 2 - 8 } \multicolumn{1}{c|}{} & Bag-of-words & Sent. 3\% & Par. 11\% & Jan. 5 0,6\% & Jan. $102 \%$ & Jan. 20 9\% & Jan. 30 10\% \\
\hline Bag-of-words & - & $\bullet$ & $\bullet$ & $\bullet$ & $\bullet$ & $\bullet$ & $\bullet$ \\
\hline Sent. 3\% & $\bullet$ & - & $\bullet$ & $\bullet$ & $\bullet$ & $\bullet$ & $\bullet$ \\
\hline Par. 11\% & $\bullet$ & $\bullet$ & - & $\bullet$ & $\bullet$ & $\bullet$ & $\bullet$ \\
\hline Jan. 50,6\% & $\bullet$ & $\bullet$ & $\bullet$ & - & $\bullet$ & $\bullet$ & $\bullet$ \\
\hline Jan. 102\% & $\bullet$ & $\bullet$ & $\bullet$ & $\bullet$ & - & $\bullet$ & $\bullet$ \\
\hline Jan. 20 9\% & $\bullet$ & $\bullet$ & $\bullet$ & $\bullet$ & $\bullet$ & - & $\bullet$ \\
\hline Jan. 3010\% & $\bullet$ & $\bullet$ & $\bullet$ & $\bullet$ & $\bullet$ & $\bullet$ & - \\
\hline
\end{tabular}

Na Figura 4.5 é apresentada uma comparação gráfica das taxas de erro obtidas pelas representações bag-of-related-words com diferentes tipos de mapeamento selecionadas para 
a comparação com a bag-of-words. Analisando a Figura 4.5(a), pode-se notar que os diversos tipos de mapeamento têm um comportamento similar em relação à taxa de erro de classificação e obtém resultados melhores que a bag-of-words para a maioria das coleções. Pela Figura 4.5(b) pode-se observar que há um aumento da taxa de erro obtido pelo mapeamento de parágrafos em relação ao mapeamento de sentenças, e um aumento da taxa de erro conforme o tamanho da janela deslizante aumenta para a maioria das coleções.

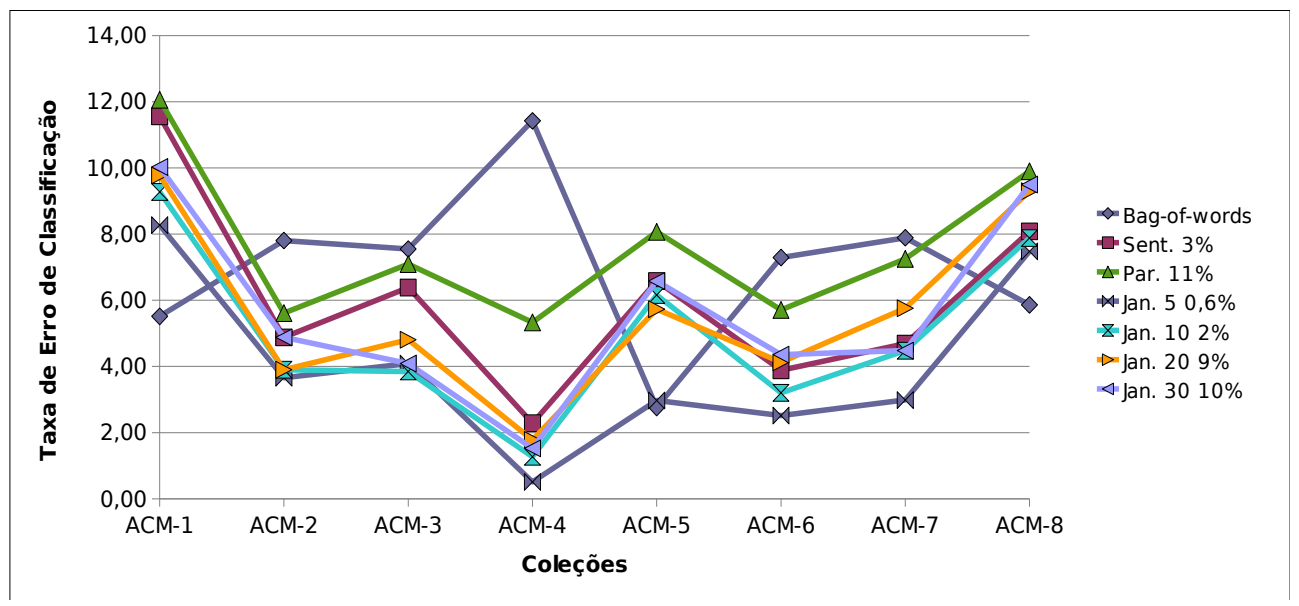

(a)

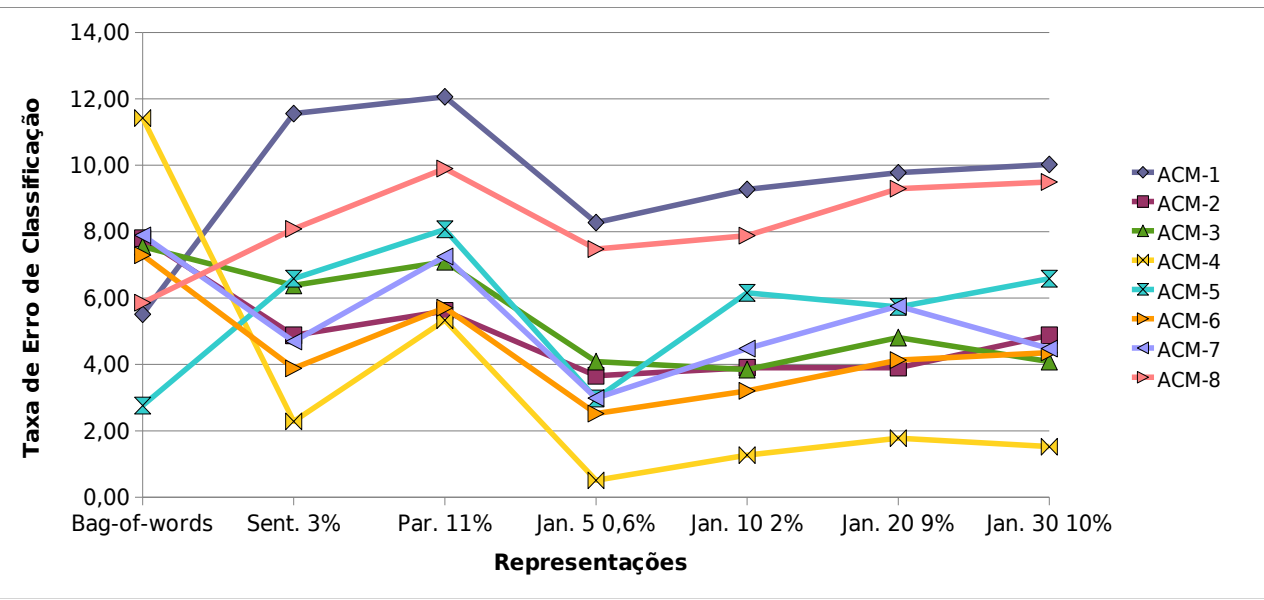

(b)

Figura 4.5: Naïve Bayes - (a) taxas de erro de classificação das representações bag-of-related-words com diferentes formas de mapeamento e da representação bag-of-words para as coleções da ACM; (b) taxas de erro de classificação das coleções da ACM para as representações bag-of-related-words com diferentes formas de mapeamento e a representação bag-of-words.

Como as representações baseadas em janelas de tamanho 5 apresentaram os melhores resultados, decidiu-se verificar o uso do suporte automático neste tipo de mapeamento. Na Tabela 4.8 são apresentados os resultados das representações bag-of-related-words com mapeamento de janela 5 e da representação bag-of-words. Pode-se observar que os resultados obtidos utilizando o suporte automático foram tão bons quanto os obtidos utilizando valores de suporte mínimos definidos manualmente. Dado isso, foram então utilizadas as medidas de interesse objetivas no mapeamento de janela deslizante de tamanho 5 com suporte mínimo automático para as coleções da ACM e da Reuters-21578.

Na Tabela 4.9 são apresentados os resultados da representação bag-of-words e das representações bag-of-related-words em que o uso das medidas de interesse objetivas com a representações [Jan. 5 Aut.], obteve menores taxas de erro de classificação para ao menos uma das coleções da ACM. As representações bag-of-related-words com medidas 
Tabela 4.8: Naïve Bayes - taxas de erro das representações bag-of-related-words com mapeamento de janela de tamanho 5 e da representação bag-of-words para as coleções da ACM.

\begin{tabular}{|c|c|c|c|c|c|c|c|c|}
\hline & \multicolumn{8}{|c|}{ Taxa de Erro } \\
\hline Representação & ACM-1 & ACM-2 & ACM-3 & ACM-4 & ACM-5 & ACM-6 & ACM-7 & ACM-8 \\
\hline Bag-of-words & $\begin{array}{l}\boldsymbol{*} \mathbf{5 , 5 1} \\
\pm 0,14\end{array}$ & $\begin{array}{c}7,80 \\
\pm 0,10\end{array}$ & $\begin{array}{c}7,55 \\
\pm 0,14\end{array}$ & $\begin{array}{c}11,42 \\
\pm 0,08\end{array}$ & $\begin{array}{l}* \mathbf{2}, \mathbf{7 6} \\
\pm 0,09\end{array}$ & $\begin{array}{c}7,29 \\
\pm 0,10\end{array}$ & $\begin{array}{c}7,89 \\
\pm 0,10\end{array}$ & $\begin{array}{r}\boldsymbol{*}^{\mathbf{5}, \mathbf{8 6}} \\
\pm 0,14\end{array}$ \\
\hline Jan. 5 Aut. & $\begin{array}{c}9,27 \\
\pm 0,18\end{array}$ & $\begin{array}{c}3,90 \\
\pm 0,12\end{array}$ & $\begin{array}{c}\boldsymbol{*} \mathbf{3}, \mathbf{1 3} \\
\pm 0,11\end{array}$ & $\begin{array}{c}1,52 \\
\pm 0,07\end{array}$ & $\begin{array}{c}3,61 \\
\pm 0,11\end{array}$ & $\begin{array}{c}3,66 \\
\pm 0,12\end{array}$ & $\begin{array}{c}4,26 \\
\pm 0,12\end{array}$ & $\begin{array}{c}6,67 \\
\pm 0,16\end{array}$ \\
\hline Jan. $50,6 \%$ & $\begin{array}{c}8,27 \\
\pm 0,18\end{array}$ & $\begin{array}{c}3,66 \\
\pm 0,12\end{array}$ & $\begin{array}{c}4,09 \\
\pm 0,12\end{array}$ & $\begin{array}{l}\boldsymbol{*}_{\mathbf{0}, \mathbf{5 1}} \\
\pm 0,05\end{array}$ & $\begin{array}{c}2,97 \\
\pm 0,11\end{array}$ & $\begin{array}{l}\boldsymbol{*}_{\mathbf{2}, \mathbf{5 2}} \\
\pm 0,10\end{array}$ & $\begin{array}{c}\boldsymbol{*}_{\mathbf{2}, \mathbf{9 9}} \\
\pm 0,11\end{array}$ & $\begin{array}{l}7,47 \\
\pm 0,17\end{array}$ \\
\hline Jan. $50,8 \%$ & $\begin{array}{c}9,77 \\
\pm 0,19\end{array}$ & $\begin{array}{l}* \mathbf{2}, \mathbf{9 3} \\
\pm 0,11\end{array}$ & $\begin{array}{c}3,37 \\
\pm 0,12\end{array}$ & $\begin{array}{c}0,76 \\
\pm 0,06\end{array}$ & $\begin{array}{c}5,31 \\
\pm 0,14\end{array}$ & $\begin{array}{c}2,97 \\
\pm 0,11\end{array}$ & $\begin{array}{c}4,90 \\
\pm 0,14\end{array}$ & $\begin{array}{c}6,46 \\
\pm 0,16\end{array}$ \\
\hline Jan. $51 \%$ & $\begin{array}{c}10,03 \\
\pm 0,19\end{array}$ & $\begin{array}{c}4,15 \\
\pm 0,13\end{array}$ & $\begin{array}{c}4,09 \\
\pm 0,13\end{array}$ & $\begin{array}{c}0,76 \\
\pm 0,06\end{array}$ & $\begin{array}{c}5,31 \\
\pm 0,14\end{array}$ & $\begin{array}{c}3,20 \\
\pm 0,11\end{array}$ & $\begin{array}{c}5,33 \\
\pm 0,14\end{array}$ & $\begin{array}{c}6,67 \\
\pm 0,16\end{array}$ \\
\hline Jan. $52 \%$ & $\begin{array}{c}9,77 \\
\pm 0,19\end{array}$ & $\begin{array}{c}5,37 \\
\pm 0,14\end{array}$ & $\begin{array}{c}4,33 \\
\pm 0,13\end{array}$ & $\begin{array}{c}1,27 \\
\pm 0,07\end{array}$ & $\begin{array}{c}7,01 \\
\pm 0,16\end{array}$ & $\begin{array}{c}3,43 \\
\pm 0,12\end{array}$ & $\begin{array}{c}5,33 \\
\pm 0,14\end{array}$ & $\begin{array}{l}11,31 \\
\pm 0,20\end{array}$ \\
\hline Jan. $53 \%$ & $\begin{array}{c}11,28 \\
\pm 0,20\end{array}$ & $\begin{array}{c}5,37 \\
\pm 0,14\end{array}$ & $\begin{array}{c}6,73 \\
\pm 0,15\end{array}$ & $\begin{array}{c}2,28 \\
\pm 0,09\end{array}$ & $\begin{array}{c}7,01 \\
\pm 0,16\end{array}$ & $\begin{array}{c}4,12 \\
\pm 0,12\end{array}$ & $\begin{array}{c}5,76 \\
\pm 0,15\end{array}$ & $\begin{array}{c}9,90 \\
\pm 0,19\end{array}$ \\
\hline
\end{tabular}

de interesse objetivas foram melhores novamente em 5 das 8 coleções (ACM-2, ACM3, ACM-4, ACM-6 e ACM-7). Para as coleções ACM-2, ACM-6, ACM-7 e ACM-8, as medidas de interesse objetivas melhoram os resultados obtidos pela janela de tamanho 5 com suporte automático. Para as coleções ACM-1, ACM-3, ACM-4 e ACM-5, em diversas situações os resultados foram mantidos com o uso das medidas de interesse objetivas.

Tabela 4.9: Naïve Bayes - taxas de erro da representação bag-of-words e das representações bag-of-relatedwords com medidas de interesse objetivas que obtiveram a menor taxa de erro para as coleções da ACM.

\begin{tabular}{|c|c|c|c|c|c|c|c|c|}
\hline & \multicolumn{8}{|c|}{ Taxa de Erro } \\
\hline Representação & ACM-1 & ACM-2 & ACM-3 & ACM-4 & ACM-5 & ACM-6 & ACM-7 & ACM-8 \\
\hline \multirow{2}{*}{ Bag-of-words } & $* \mathbf{5 , 5 1}$ & 7,80 & 7,55 & 11,42 & $* 2,76$ & 7,29 & 7,89 & $* 5,86$ \\
\hline & $\pm 0,14$ & $\pm 0,10$ & $\pm 0,14$ & $\pm 0,08$ & $\pm 0,09$ & $\pm 0,10$ & $\pm 0,10$ & $\pm 0,14$ \\
\hline \multirow{2}{*}{ Jan. 5 Aut. Corr. $\bar{x}$} & 9,27 & $* 3,66$ & $* 3,13$ & 1,78 & 3,40 & 3,66 & 4,48 & 6,46 \\
\hline & $\pm 0,19$ & $\pm 0,12$ & $\pm 0,11$ & $\pm 0,08$ & $\pm 0,12$ & $\pm 0,12$ & $\pm 0,13$ & $\pm 0,16$ \\
\hline \multirow{2}{*}{ Jan. 5 Aut. I.M. 0,005 } & 9,27 & 3,90 & 3,37 & $* 1,52$ & 3,61 & 3,66 & 5,33 & 6,87 \\
\hline & $\pm 0,19$ & $\pm 0,12$ & $\pm 0,12$ & $\pm 0,08$ & $\pm 0,12$ & $\pm 0,12$ & $\pm 0,14$ & $\pm 0,17$ \\
\hline \multirow{2}{*}{ Jan. 5 Aut. Kappa 0,15} & 9,77 & 4,39 & 3,85 & $* 1,52$ & 3,61 & 3,89 & 4,69 & 7,27 \\
\hline & $\pm 0,20$ & $\pm 0,13$ & $\pm 0,12$ & $\pm 0,08$ & $\pm 0,12$ & $\pm 0,12$ & $\pm 0,13$ & $\pm 0,17$ \\
\hline \multirow{2}{*}{ Jan. 5 Aut. Kappa $\bar{x}$} & 9,52 & 4,15 & 3,85 & 1,78 & 3,61 & 3,66 & $* 4,05$ & 7,47 \\
\hline & $\pm 0,20$ & $\pm 0,13$ & $\pm 0,12$ & $\pm 0,08$ & $\pm 0,12$ & $\pm 0,12$ & $\pm 0,13$ & $\pm 0,17$ \\
\hline \multirow{2}{*}{ Jan. 5 Aut. J.M. 0,02 } & 9,77 & 4,15 & 3,85 & 2,28 & 3,61 & $* 3,43$ & 5,76 & 7,47 \\
\hline & $\pm 0,20$ & $\pm 0,12$ & $\pm 0,12$ & $\pm 0,10$ & $\pm 0,12$ & $\pm 0,12$ & $\pm 0,15$ & $\pm 0,17$ \\
\hline
\end{tabular}

Vale ressaltar que algumas medidas de interesse objetivas com seus respectivos limiares obtiveram a menor taxa de erro de classificação e reduziram consideravelmente o número de atributos. Por exemplo, o uso da medida J-Measure com limiar de 0,02, obteve o melhor resultado para a coleção ACM-6 e reduziu em $55 \%$ o número de atributos em relação à representação [Jan. 5 Aut] e $65 \%$ em relação à bag-of-words. Já para a coleção ACM-7, o uso da medida Kappa com limiar automático obteve o melhor resultado e reduziu em $43 \%$ o número de atributos em relação a [Jan. 5 Aut.] e $49 \%$ em relação à bag-of-words.

Para verificar se os limiares das medidas de interesse objetivas utilizadas causaram diferenças significativas nas taxas de erro obtidas pelo algoritmo Naïve Bayes, foi aplicado o teste de Friedman para cada medida objetiva considerando as 8 coleções da ACM. Na Tabela 4.10 são apresentados os resultados do teste estatístico aplicado. Pode-se notar que a variação dos limiares para a maioria das medidas de interesse objetivas não apresentou diferenças estatisticamente significantes em relação à taxa de erro para a maioria das medidas. Foram observadas diferenças estatísticas nas variações dos limiares das medidas Correlação, Informação Mútua, e Gini. Pode-se notar também que não foram obtidas diferenças estatisticamente significantes em relação aos limiares baseados na média. Inclusive, na medida Correlação, o uso da média apresentou melhores resultados com 
diferenças estatisticamente significantes em relação aos outros limiares utilizados.

Tabela 4.10: Naïve Bayes - resultado do teste estatístico realizado para avaliar o impacto da variação dos limiares das medidas de interesse objetivas utilizadas na taxa de erro de classificação das coleções ACM.

\begin{tabular}{|c|c|c|c|}
\multicolumn{4}{c}{ Conf. } \\
\cline { 2 - 4 } \multicolumn{1}{c|}{} & 0,25 & 0,50 & $\bar{x}$ \\
\hline 0,25 & - & $\bullet$ & $\bullet$ \\
\hline 0,50 & $\bullet$ & - & $\bullet$ \\
\hline $\bar{x}$ & $\bullet$ & $\bullet$ & - \\
\hline
\end{tabular}

\begin{tabular}{|c|c|c|c|}
\multicolumn{4}{c|}{ Corr. } \\
\cline { 2 - 4 } \multicolumn{1}{c|}{} & 0,25 & 0,50 & $\bar{x}$ \\
\hline 0,25 & - & $\bullet$ & $\mathbf{\nabla}$ \\
\hline 0,50 & $\bullet$ & - & $\mathbf{\nabla}$ \\
\hline $\bar{x}$ & $\boldsymbol{\Delta}$ & $\mathbf{\Delta}$ & - \\
\hline
\end{tabular}

\begin{tabular}{|c|c|c|c|}
\multicolumn{4}{c}{ Kappa } \\
\cline { 2 - 4 } \multicolumn{1}{c|}{} & 0,15 & 0,20 & $\bar{x}$ \\
\hline 0,15 & - & $\bullet$ & $\bullet$ \\
\hline 0,20 & $\bullet$ & - & $\bullet$ \\
\hline $\bar{x}$ & $\bullet$ & $\bullet$ & - \\
\hline
\end{tabular}
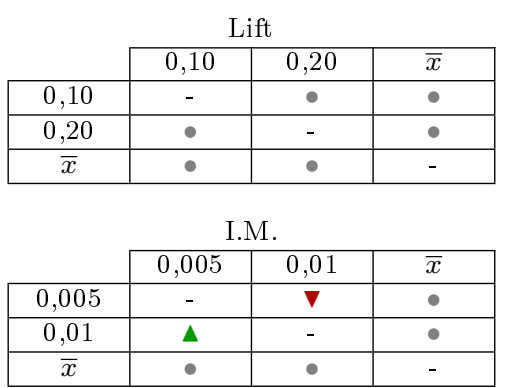

\begin{tabular}{|c|c|c|c|}
\multicolumn{4}{c}{} \\
\cline { 2 - 4 } \multicolumn{1}{c|}{ J.M. } \\
\hline 0,01 & 0,01 & 0,02 & $\bar{x}$ \\
\hline 0,02 & - & $\bullet$ & $\bullet$ \\
\hline $\bar{x}$ & $\bullet$ & - & $\bullet$ \\
\hline
\end{tabular}

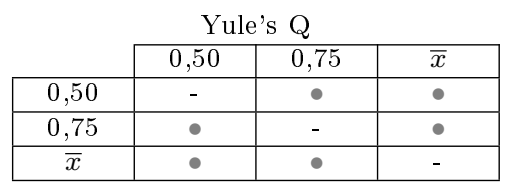

\begin{tabular}{|c|c|c|c|}
\multicolumn{4}{c}{} \\
\cline { 2 - 4 } \multicolumn{1}{c|}{} \\
\cline { 2 - 4 } \multicolumn{1}{c|}{} & 0,005 & 0,01 & $\bar{x}$ \\
\hline 0,005 & - & $\nabla$ & $\bullet$ \\
\hline 0,01 & $\Delta$ & - & $\bullet$ \\
\hline $\bar{x}$ & $\bullet$ & $\bullet$ & - \\
\hline
\end{tabular}

Como não houve diferenças estatisticamente significantes nos resultados obtidos pelos diferentes limiares das medidas de interesse objetivas, foram comparadas as representações bag-of-related-words com medidas de interesse objetivas com limiares baseados na média e a representação bag-of-words. Na Tabela 4.11 são apresentados os resultados do teste estatístico. Pode-se notar que a maioria das medidas de interesse objetivas não apresentou diferenças estatisticamente significantes entre si. Somente a medida Correlação foi melhor com diferença estatisticamente significante em relação às medidas Confiança e Lift. Na Figura 4.6 é apresentada uma comparação gráfica das taxas de erro entre as medidas de interesse objetivas com limiares baseados na média e a representação bag-of-words. Pode-se observar pela Figura 4.6(a) um comportamento similar das medidas de interesse objetivas para as coleções da ACM, com exceção da coleção ACM-7, em que as medidas Kappa e Correlação se destacam das demais. Pela Figura 4.6(b) pode-se observar que a taxa de erro normalmente cai ao utilizar as medidas Correlação e Kappa para a Maioria das Coleções.

Tabela 4.11: Naïve Bayes - resultado do teste estatístico entre as taxas de erro das coleções ACM obtidas pelas representações bag-of-related-words que utilizam medidas de interesse objetivas para extrair atributos e a representação bag-of-words.

\begin{tabular}{|c|c|c|c|c|c|c|c|c|c|}
\cline { 2 - 10 } \multicolumn{1}{c|}{} & $B O W$ & Conf. & Lift & Yule's Q & Corr. & I.M. & Gini & Kappa & J.M. \\
\hline$B O W$ & - & $\bullet$ & $\bullet$ & $\bullet$ & $\bullet$ & $\bullet$ & $\bullet$ & $\bullet$ & $\bullet$ \\
\hline Conf. & $\bullet$ & - & $\bullet$ & $\bullet$ & $\mathbf{}$ & $\bullet$ & $\bullet$ & $\bullet$ & $\bullet$ \\
\hline Lift & $\bullet$ & $\bullet$ & - & $\bullet$ & $\mathbf{v}$ & $\bullet$ & $\bullet$ & $\bullet$ & $\bullet$ \\
\hline Yule's Q & $\bullet$ & $\bullet$ & $\bullet$ & - & $\bullet$ & $\bullet$ & $\bullet$ & $\bullet$ & $\bullet$ \\
\hline Corr. & $\bullet$ & $\bullet$ & $\bullet$ & $\bullet$ & - & $\bullet$ & $\bullet$ & $\bullet$ & $\bullet$ \\
\hline I.M. & $\bullet$ & $\bullet$ & $\bullet$ & $\bullet$ & $\bullet$ & - & $\bullet$ & $\bullet$ & $\bullet$ \\
\hline Gini & $\bullet$ & $\bullet$ & $\bullet$ & $\bullet$ & $\bullet$ & $\bullet$ & - & $\bullet$ & $\bullet$ \\
\hline Kappa & $\bullet$ & $\bullet$ & $\bullet$ & $\bullet$ & $\bullet$ & $\bullet$ & $\bullet$ & - & $\bullet$ \\
\hline J.M. & $\bullet$ & $\bullet$ & $\bullet$ & $\bullet$ & $\bullet$ & $\bullet$ & $\bullet$ & $\bullet$ & - \\
\hline
\end{tabular}

Para a coleção Reuters-21578, todas as representações bag-of-related-words obtiveram taxas de erro menores que a bag-of-words. Na Tabela 4.12 são apresentados os resultados obtidos pela representação bag-of-words e pelas representações bag-of-related-words utilizando limiares de medidas obtivas baseados na média. A menor taxa de erro foi obtida utilizando a representação [Jan. 5 Aut. Kappa $\bar{x}$ ], obtendo uma taxa de erro de $24.05 \%$, sendo $3,89 \%$ menor que a bag-of-words. Vale ressaltar que representações como a [Jan. 


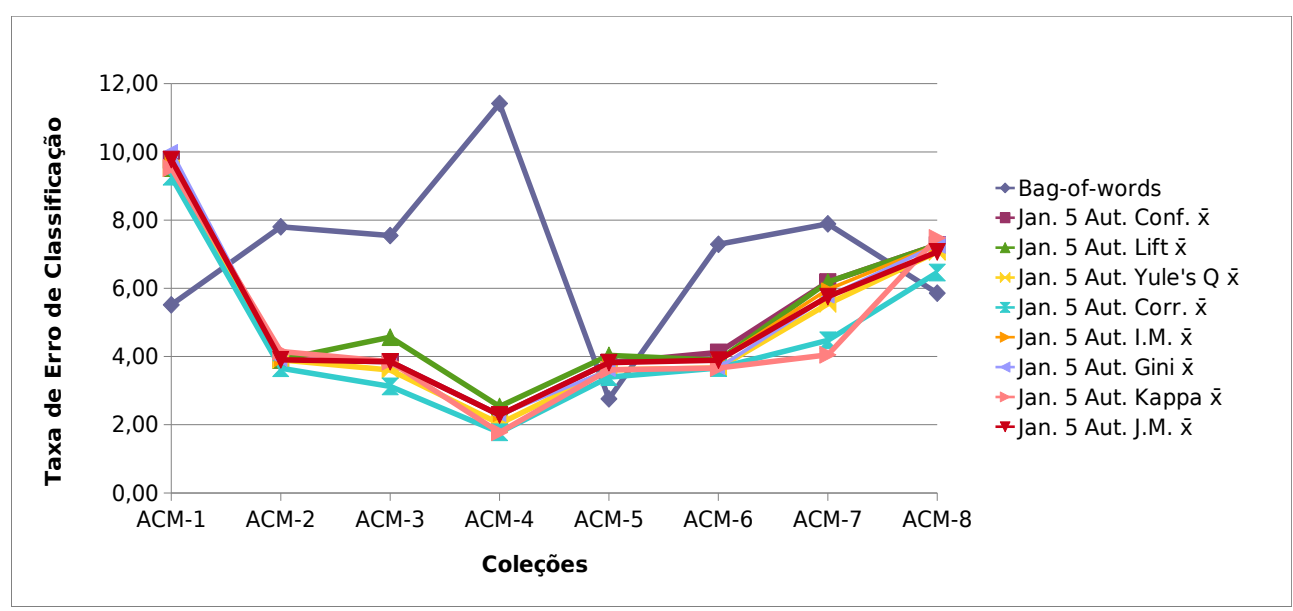

(a)

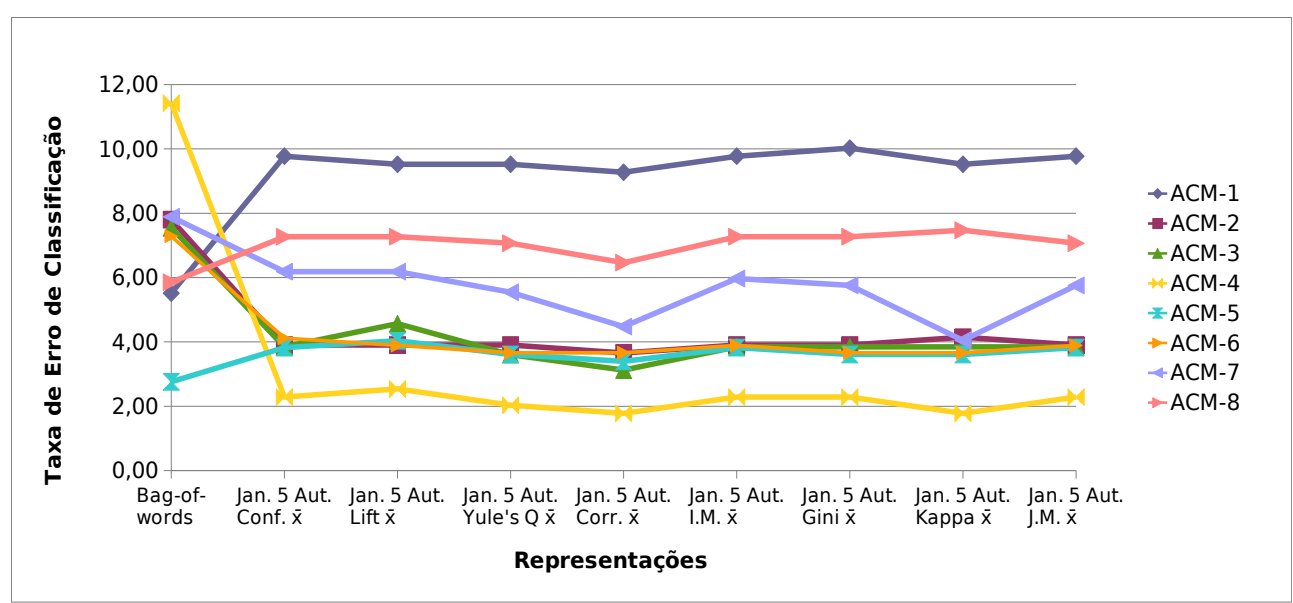

(b)

Figura 4.6: Naïve Bayes - (a) taxas de erro de classificação das representações bag-of-related-words com diferentes medidas de interesse objetivas e da representação bag-of-words para as coleções da ACM; (b) taxas de erro de classificação das coleções da ACM para as representações bag-of-related-words com diferentes medidas de interesse objetivas e a representação bag-of-words.

5 Aut. I.M. 0,2\%] obtiveram uma taxa de erro menor com um número de atributos $38 \%$ menor em relação à bag-of-words.

Tabela 4.12: Naïve Bayes - taxas de erro da representação bag-of-words e das representações bag-of-relatedwords com medidas de interesse objetivas e limiares baseados na média para a coleção Reuters-21578.

\begin{tabular}{|l|r|}
\hline Representação & Taxa de Erro \\
\hline Bag-of-words & 27,94 \\
\hline Jan. 5 Aut. & 24,26 \\
\hline Jan. 5 Aut. Lift $\bar{x}$ & 24,90 \\
\hline Jan. 5 Aut. Conf. $\bar{x}$ & 25,00 \\
\hline Jan. 5 Aut. Yule's Q $\bar{x}$ & 24,79 \\
\hline Jan. 5 Aut. Corr. $\bar{x}$ & 24,26 \\
\hline Jan. 5 Aut. I.M. $\bar{x}$ & 24,90 \\
\hline Jan. 5 Aut. Gini $\bar{x}$ & 24,79 \\
\hline Jan. 5 Aut. Kappa $\bar{x}$ & 24,05 \\
\hline Jan. 5 Aut. J.M. $\bar{x}$ & 25,00 \\
\hline
\end{tabular}

Os resultados mostram que a abordagem proposta é adequada para o algoritmo de classificação Naïve Bayes, uma vez que foram obtidos melhores resultados para a maio- 
ria das coleções e com um número de atributos muito menor, mesmo tendo os atributos representados por conjuntos de palavras. Pode-se observar que todas as formas de mapeamento obtiveram bons resultados para este algoritmo de classificação, destacando o mapeamento por janelas de tamanho 5 que obteve os melhores resultados. Além disso, o uso de medidas de interesse objetivas atendeu aos objetivos de reduzir o número de atributos e manter a qualidade dos resultados.

Nesta seção são apresentados alguns dos resultados obtidos pelo algoritmo de classificação J48 utilizando as representações bag-of-related-words e bag-of-words. Na Tabela 4.13 são apresentados os resultados da representação bag-of-words e das representações bag-ofrelated-words com diferentes formas de mapeamento que obtiveram a menor taxa de erro para ao menos uma das coleções da ACM. Foram considerados apenas os itemsets frequentes como atributos das representações bag-of-related-words e foram obtidas a menor taxa de erro de classificação em 3 de 8 coleções (ACM-3, ACM-6, ACM-7).

Tabela 4.13: J48 - taxas de erro da representação bag-of-words e das representações bag-of-related-words com itemsets frequentes como atributos que obtiveram a menor taxa de erro para as coleções da ACM.

\begin{tabular}{|c|c|c|c|c|c|c|c|c|}
\hline & \multicolumn{8}{|c|}{ Taxa de Erro } \\
\hline Representação & ACM-1 & ACM-2 & ACM-3 & ACM-4 & ACM-5 & ACM-6 & ACM-7 & ACM-8 \\
\hline Bag-of-words & $\begin{array}{c}\boldsymbol{*}_{\mathbf{1 1}, \mathbf{5 3}} \\
\pm 0,22\end{array}$ & $\begin{array}{l}* \mathbf{7}, \mathbf{0 7} \\
\pm 0,19\end{array}$ & $\begin{array}{c}12,97 \\
\pm 0,22\end{array}$ & $\begin{array}{l}\boldsymbol{*}_{\mathbf{6}, \mathbf{0 9}} \\
\pm 0,13\end{array}$ & $\begin{array}{c}* \mathbf{1 4}, \mathbf{0 1} \\
\pm 0,22\end{array}$ & $\begin{array}{l}11,62 \\
\pm 0,20\end{array}$ & $\begin{array}{l}11,30 \\
\pm 0,20\end{array}$ & $\begin{array}{c}* \mathbf{1 0 , 3 0} \\
\pm 0,20\end{array}$ \\
\hline Jan. $50,6 \%$ & $\begin{array}{c}14,79 \\
\pm 0,24 \\
\end{array}$ & $\begin{array}{c}14,88 \\
\pm 0,24 \\
\end{array}$ & $\begin{array}{l}* \mathbf{9 , 6 2} \\
\pm 0,19 \\
\end{array}$ & $\begin{array}{c}6,60 \\
\pm 0,16 \\
\end{array}$ & $\begin{array}{l}15,71 \\
\pm 0,25\end{array}$ & $\begin{array}{l}* \mathbf{7 , 5 5} \\
\pm 0,17\end{array}$ & $\begin{array}{c}13,01 \\
\pm 0,22\end{array}$ & $\begin{array}{l}17,17 \\
\pm 0,26\end{array}$ \\
\hline Jan. $3010 \%$ & $\begin{array}{l}19,80 \\
\pm 0,27\end{array}$ & $\begin{array}{c}13,17 \\
\pm 0,22\end{array}$ & $\begin{array}{c}14,42 \\
\pm 0,23 \\
\end{array}$ & $\begin{array}{c}10,41 \\
\pm 0,20\end{array}$ & $\begin{array}{l}20,17 \\
\pm 0,27\end{array}$ & $\begin{array}{c}18,12 \\
\pm 0,26 \\
\end{array}$ & $\begin{array}{l}\mathbf{* 8 , 9 6} \\
\pm 0,18\end{array}$ & $\begin{array}{l}26,26 \\
\pm 0,31\end{array}$ \\
\hline
\end{tabular}

Ao analisar as árvores de decisão geradas utilizando as representações bag-of-words e bag-of-related-words, pode-se observar que a característica da coleção, que possui atributos relacionados com locais de eventos ou nomes de autores, fizeram com que a representação bag-of-words obtivesse melhores resultados. Por exemplo, alguns nós da árvore de decisão obtidos na coleção ACM-8 utilizando a representação bag-of-words são:

- "hawaii > 0: Hypertext_Hypermedia"

- "jaschk > 0: Hypertext_Hypermedia"

- "piezzo > 0: Embedded_Systems"

- "rajwar > 0: Microarchtecture"

Pode-se notar que os atributos escolhidos como nós da árvore são nomes de autores de alguma área ou local de conferência. Utilizando a representação [Jan. 5 0,6\%], alguns dos nós da árvore de decisão para a coleção ACM-8 são:

- "number_vertice > 0: Hypertext_Hypermedia"

- "system_time $>0$ : Embedded_Systems"

- "architecture_ comput $>0$ : Microarchitecture"

- "packet_process > 0: Embedded_Systems"

- "address_fetch >0: Microarchitecture" 
Intuitivamente, as regras geradas pela representação bag-of-related-words trazem mais conhecimento e são mais interpretáveis do que as que são obtidas utilizando a representação bag-of-words. Além disso, em situações em que não há autores ou locais que apareçam em vários documentos de uma classe, a representação bag-of-related-words pode obter melhores resultados do que a bag-of-words.

Para verificar o efeito nos resultados do algoritmo J48 provocado pela variação do limiar de suporte nas diferentes formas de mapeamento, foi aplicado o teste de Friedman considerando as 8 coleções da ACM. Na Tabela 4.14 são apresentados os resultados dos testes estatísticos. Pode-se notar que os menores limiares de suporte obtiveram resultados estatisticamente melhores em relação aos maiores valores de suporte mínimo, ou seja, para o algoritmo de classificação J48, a abordagem proposta é melhor quando se utilizam mais atributos.

Tabela 4.14: J48 - resultado do teste estatístico para avaliar o impacto na taxa de erro de classificação causado pela variação do suporte mínimo para as diferentes formas de mapeamento nas coleções da ACM.

\begin{tabular}{|c|c|c|c|c|c|}
\cline { 2 - 6 } \multicolumn{1}{c|}{} & $2 \%$ & $3 \%$ & $4 \%$ & $5 \%$ & $6 \%$ \\
\hline $2 \%$ & - & $\Delta$ & $\Delta$ & $\Delta$ & $\Delta$ \\
\hline $3 \%$ & $\boldsymbol{\nabla}$ & - & $\bullet$ & $\boldsymbol{\Delta}$ & $\boldsymbol{\Delta}$ \\
\hline $4 \%$ & $\mathbf{V}$ & $\bullet$ & - & $\bullet$ & $\boldsymbol{\Delta}$ \\
\hline $5 \%$ & $\mathbf{\nabla}$ & $\mathbf{\nabla}$ & $\bullet$ & - & $\bullet$ \\
\hline $6 \%$ & $\mathbf{\nabla}$ & $\mathbf{\nabla}$ & $\mathbf{\nabla}$ & $\bullet$ & - \\
\hline
\end{tabular}

Janela 5

\begin{tabular}{|c|c|c|c|c|c|}
\multicolumn{1}{c|}{ Janela 5} \\
\cline { 2 - 6 } \multicolumn{1}{c|}{} & $0,6 \%$ & $0,8 \%$ & $1 \%$ & $2 \%$ & $3 \%$ \\
\hline $0,6 \%$ & - & $\bullet$ & $\bullet$ & $\Delta$ & $\mathbf{\Delta}$ \\
\hline $0,8 \%$ & $\bullet$ & - & $\bullet$ & $\bullet$ & $\boldsymbol{\Delta}$ \\
\hline $1 \%$ & $\bullet$ & $\bullet$ & - & $\bullet$ & $\boldsymbol{\Delta}$ \\
\hline $2 \%$ & $\bullet$ & $\bullet$ & $\bullet$ & - & $\bullet$ \\
\hline $3 \%$ & $\mathbf{\nabla}$ & $\mathbf{\nabla}$ & $\mathbf{\nabla}$ & $\bullet$ & - \\
\hline
\end{tabular}

Janela 20

\begin{tabular}{|c|c|c|c|c|c|}
\cline { 2 - 6 } \multicolumn{1}{c|}{} & $6 \%$ & $7 \%$ & $8 \%$ & $9 \%$ & $10 \%$ \\
\hline $6 \%$ & - & $\bullet$ & $\bullet$ & $\bullet$ & $\boldsymbol{\Delta}$ \\
\hline $7 \%$ & $\bullet$ & - & $\boldsymbol{\Delta}$ & $\boldsymbol{\Delta}$ & $\boldsymbol{\Delta}$ \\
\hline $8 \%$ & $\mathbf{\nabla}$ & $\bullet$ & - & $\bullet$ & $\bullet$ \\
\hline $9 \%$ & $\mathbf{\nabla}$ & $\bullet$ & $\bullet$ & - & $\bullet$ \\
\hline $10 \%$ & $\mathbf{V}$ & $\mathbf{\nabla}$ & $\bullet$ & $\bullet$ & - \\
\hline
\end{tabular}

\begin{tabular}{|c|c|c|c|c|c|}
\cline { 2 - 6 } \multicolumn{1}{c|}{} & $10 \%$ & $11 \%$ & $12 \%$ & $13 \%$ & $14 \%$ \\
\hline $10 \%$ & - & $\bullet$ & $\Delta$ & $\Delta$ & $\Delta$ \\
\hline $11 \%$ & $\bullet$ & - & $\bullet$ & $\bullet$ & $\Delta$ \\
\hline $12 \%$ & $\mathbf{V}$ & $\bullet$ & - & $\bullet$ & $\bullet$ \\
\hline $13 \%$ & $\mathbf{\nabla}$ & $\bullet$ & $\bullet$ & - & $\bullet$ \\
\hline $14 \%$ & $\mathbf{\nabla}$ & $\mathbf{\nabla}$ & $\bullet$ & $\bullet$ & - \\
\hline
\end{tabular}

\begin{tabular}{|c|c|c|c|c|c|}
\cline { 2 - 6 } \multicolumn{1}{c|}{} & $2 \%$ & $3 \%$ & $4 \%$ & $5 \%$ & $6 \%$ \\
\hline $2 \%$ & - & $\boldsymbol{\Delta}$ & $\boldsymbol{\Delta}$ & $\boldsymbol{\Delta}$ & $\boldsymbol{\Delta}$ \\
\hline $3 \%$ & $\mathbf{\nabla}$ & - & $\bullet$ & $\bullet$ & $\boldsymbol{\Delta}$ \\
\hline $4 \%$ & $\mathbf{\nabla}$ & $\bullet$ & - & $\bullet$ & $\boldsymbol{\Delta}$ \\
\hline $5 \%$ & $\mathbf{\nabla}$ & $\bullet$ & $\bullet$ & - & $\boldsymbol{\Delta}$ \\
\hline $6 \%$ & $\mathbf{\nabla}$ & $\mathbf{\nabla}$ & $\mathbf{\nabla}$ & $\mathbf{\nabla}$ & - \\
\hline
\end{tabular}

\begin{tabular}{|c|c|c|c|c|c|}
\cline { 2 - 6 } \multicolumn{1}{c|}{} & $10 \%$ & $11 \%$ & $12 \%$ & $13 \%$ & $14 \%$ \\
\hline $10 \%$ & - & $\bullet$ & $\boldsymbol{\Delta}$ & $\boldsymbol{\Delta}$ & $\boldsymbol{\Delta}$ \\
\hline $11 \%$ & $\bullet$ & - & $\bullet$ & $\bullet$ & $\bullet$ \\
\hline $12 \%$ & $\mathbf{V}$ & $\bullet$ & - & $\bullet$ & $\bullet$ \\
\hline $13 \%$ & $\mathbf{\nabla}$ & $\bullet$ & $\bullet$ & - & $\bullet$ \\
\hline $14 \%$ & $\mathbf{V}$ & $\bullet$ & $\bullet$ & $\bullet$ & - \\
\hline
\end{tabular}

Para analisar os diferentes tipos de mapeamento e comparar com a bag-of-words, novamente foram escolhidos os melhores valores de suporte mínimo para cada tipo de mapeamento. As representações selecionadas para a comparação foram: [Sent. 2\%], [Par. 10\%], [Jan. 5 0,6\%], [Jan. 10 2\%], [Jan. 20 7\%], e [Jan. 30 10\%]. Na Tabela 4.15 são apresentados os resultados dos testes estatísticos utilizando estas representações. Pode-se notar que a bag-of-words foi estatisticamente superior em relação à maiorias das janelas deslizantes, com exceção da janela deslizante de tamanho 5. Além disso, o uso de parágrafos como transações apresentaram os piores resultados, enquanto que a janela de tamanho 5 foi melhor que os outros tipo de mapeamento, obtendo resultados melhores com diferenças estatisticamente significantes em relação às janelas de tamanho 20 e 30.

Na Figura 4.7 é apresentada uma comparação gráfica das taxas de erros obtidas pelas representações bag-of-related-words com diferentes tipos de mapeamento selecionadas para a comparação com a bag-of-words. Analisando a Figura 4.7(a), pode-se notar que os diversos tipos de mapeamento têm um comportamento semelhante em relação à taxa de erro de classificação, com exceção da janela de tamanho 5 que teve um comportamento diferente em duas situações (ACM-2 e ACM-7). Pela Figura 4.7(b), pode-se observar várias situações em que há um aumento da taxa de erro obtido pelo mapeamento de parágrafos em relação ao mapeamento de sentenças, e um aumento da taxa de erro conforme 
Tabela 4.15: J48 - resultado do teste estatístico para comparar a taxa de erro de classificação nas coleções ACM obtidas pela representação bag-of-words e pelas representações bag-of-related-words com diferentes formas de mapeamento.

\begin{tabular}{|c|c|c|c|c|c|c|c|}
\hline & Bag-of-words & Sent. $2 \%$ & Par. 10\% & Jan. $50,6 \%$ & Jan. $102 \%$ & Jan. $207 \%$ & Jan. $3010 \%$ \\
\hline Bag-of-words & -2 & $\bullet$ & $\Delta$ & $\bullet$ & $\Delta$ & $\Delta$ & $\Delta$ \\
\hline Sent. $2 \%$ & $\bullet$ & - & $\Delta$ & $\bullet$ & $\bullet$ & $\bullet$ & $\bullet$ \\
\hline Par. $10 \%$ & $\nabla$ & $\nabla$ & - & $\nabla$ & $\nabla$ & $\bullet$ & $\bullet$ \\
\hline Jan. $50,6 \%$ & $\bullet$ & $\bullet$ & $\Delta$ & - & $\bullet$ & $\Delta$ & $\Delta$ \\
\hline Jan. $102 \%$ & $\boldsymbol{\nabla}$ & $\bullet$ & $\Delta$ & $\bullet$ & - & $\bullet$ & $\bullet$ \\
\hline Jan. $207 \%$ & $\nabla$ & $\bullet$ & $\bullet$ & $\nabla$ & $\bullet$ & - & $\bullet$ \\
\hline Jan. $3010 \%$ & $\nabla$ & $\bullet$ & 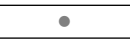 & $\nabla$ & $\bullet$ & & - \\
\hline
\end{tabular}

o tamanho da janela deslizante aumenta.

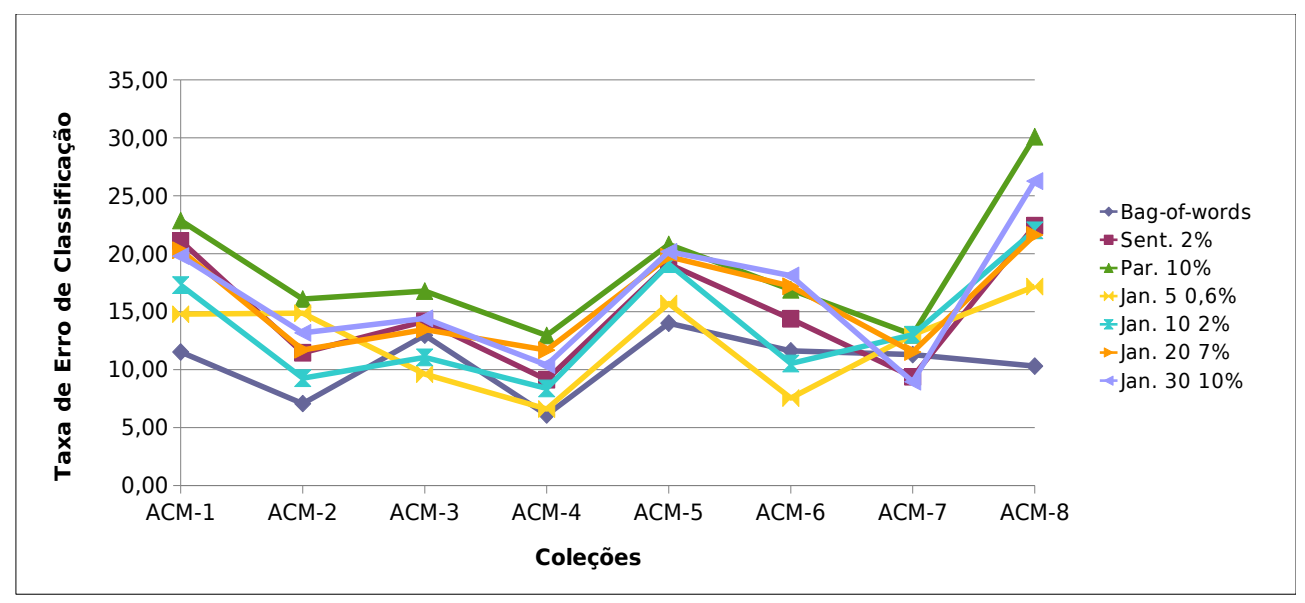

(a)

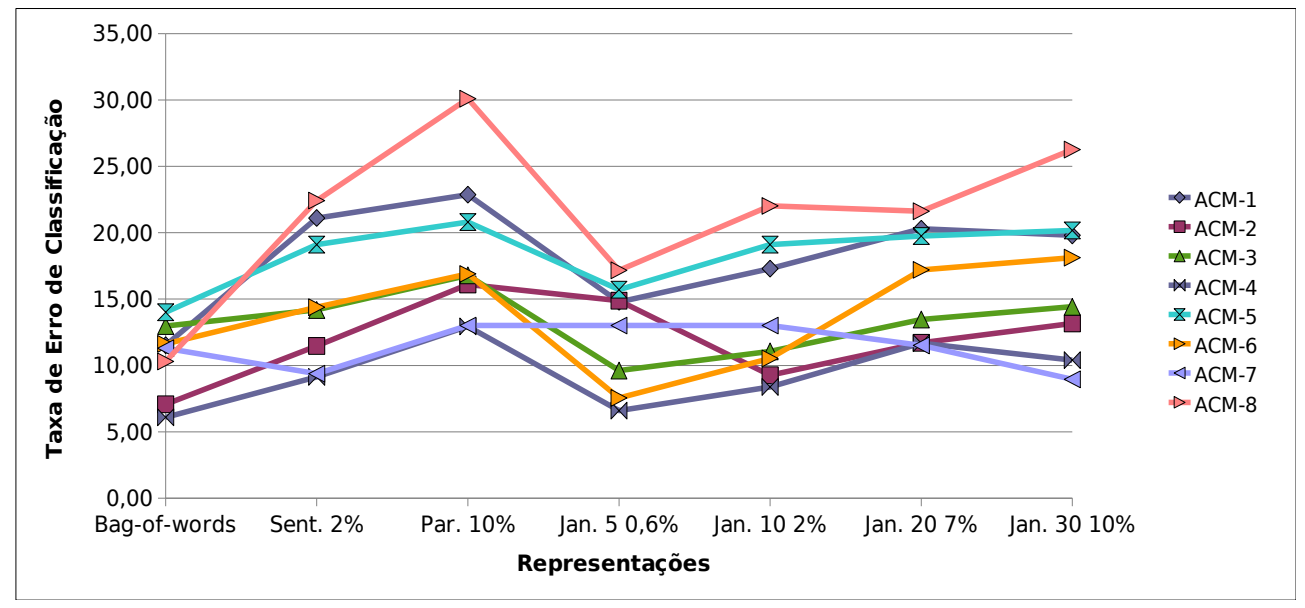

(b)

Figura 4.7: J48 - (a) taxas de erro de classificação das representações bag-of-related-words com diferentes formas de mapeamento e da representação bag-of-words para as coleções da ACM; (b) taxas de erro de classificação das coleções da ACM para as representações bag-of-related-words com diferentes formas de mapeamento e a representação bag-of-words.

Para verificar as causas desse comportamento, foram comparadas as árvores geradas pelas representações [Jan. 5 0,06\%] e [Jan. 30 10\%], apresentadas na Tabela 4.16. Pode-se notar uma diferença dos nós da raiz e de outros nós de decisão. São apenas 4 atributos em comuns nos nós de decisão: "encrypt", "layer_network", "privaci", e softwar. Além dos atributos diferentes nos nós das árvores de decisão, foi verificada uma diferença do valor da medida gain ratio (utilizada na escolha de nós da árvore de decisão) de alguns 
atributos ao aumentar o tamanho da janela deslizante. Por exemplo, o atributo "privaci", que é o melhor atributo ranqueado segundo a medida gain ratio utilizando a representação [Jan. 5 0,06], obtém o valor de 0,8416 , enquanto que o mesmo atributo obtém o valor de 0,6322 utilizando a representação [Jan. 30 10\%], sendo apenas o terceiro atributo melhor ranqueado.

Tabela 4.16: Árvores de decisão geradas utilizando as representações [Jan. 5 0,06\%] e [Jan. 30 10\%] para a coleção ACM-3.

\begin{tabular}{|c|c|}
\hline [Jan. $50,06 \%$ ] & [Jan. 30 10\%] \\
\hline 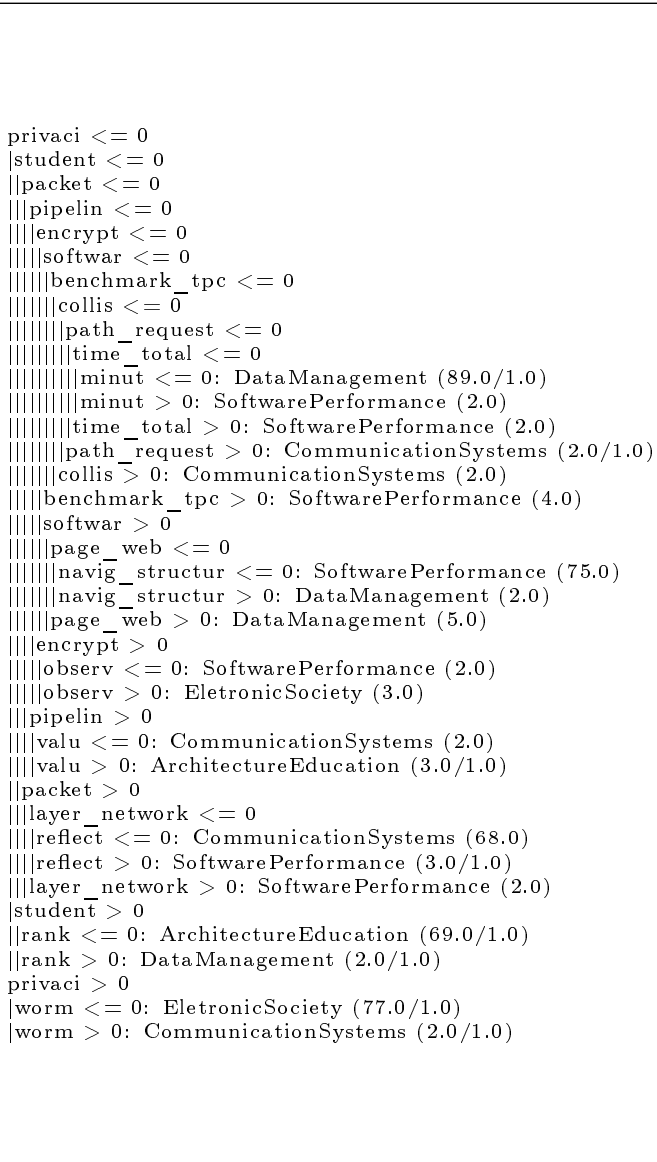 & 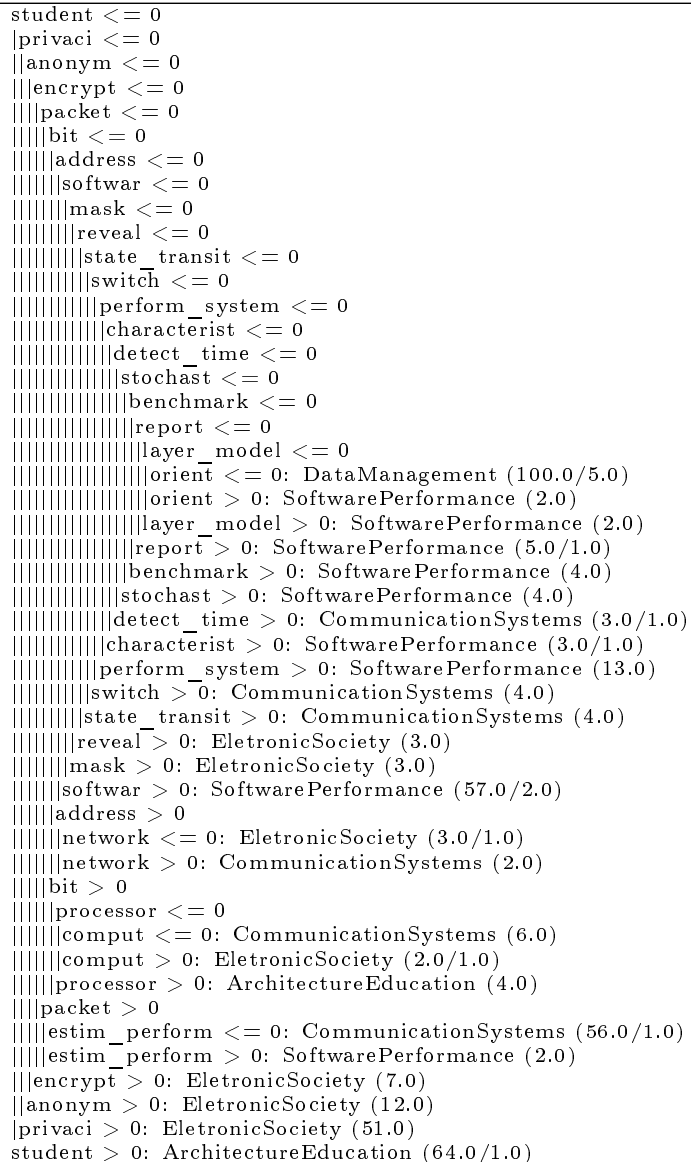 \\
\hline
\end{tabular}

Como as representações baseadas em janelas de tamanho 5 novamente apresentaram os melhores resultados, foram analisados os resultados obtidos pelo uso do suporte automático neste tipo de mapeamento. Na Tabela 4.17 são apresentados os resultados das representações bag-of-related-words com mapeamento de janela 5 e da representação bagof-words. Pode-se observar que os resultados obtidos com o suporte automático novamente foram tão bons quanto os obtidos utilizando valores de suporte mínimos definidos manualmente. Foram então utilizadas as demais medidas de interesse objetivas utilizando uma janela de tamanho 5 com suporte mínimo automático para as coleções da ACM e Reuters-21578.

Na Tabela 4.18 são apresentados os resultados da representação bag-of-words e das representações bag-of-related-words em que o uso das medidas de interesse objetivas, com o mapeamento de janelas de tamanho 5 e suporte mínimo automático, obteve as menores taxas de erro de classificação para ao menos uma das coleções da ACM. As representações bag-of-related-words com medidas de interesse objetivas obtiveram a menor taxa de erro em 2 de 8 coleções (ACM-3 e ACM-6). Pode-se notar que para as coleções ACM-2, ACM4, ACM-5, ACM-6 e ACM-8, as medidas de interesse objetivas diminuíram a taxa de erro em diversas situações em relação ao erro obtido pela representação [Jan. 5 Aut.], além de 
Tabela 4.17: J48 - taxas de erro das representações bag-of-related-words com mapeamento de janela de tamanho 5 e da representação bag-of-words para as coleções da ACM.

\begin{tabular}{|c|c|c|c|c|c|c|c|c|}
\hline & \multicolumn{8}{|c|}{ Taxa de Erro } \\
\hline Representação & ACM-1 & ACM-2 & ACM-3 & ACM-4 & ACM-5 & ACM-6 & ACM-7 & ACM-8 \\
\hline Bag-of-words & $\begin{array}{c}* \mathbf{1 1}, \mathbf{5 3} \\
\pm 0,22\end{array}$ & $\begin{array}{l}* \mathbf{*}, \mathbf{0 7} \\
\pm 0,19\end{array}$ & $\begin{array}{l}12,97 \\
\pm 0,22\end{array}$ & $\begin{array}{l}\boldsymbol{*}_{\mathbf{6}, \mathbf{0 9}} \\
\pm 0,13\end{array}$ & $\begin{array}{c}* \mathbf{1 4}, \mathbf{0 1} \\
\pm 0,22\end{array}$ & $\begin{array}{l}11,62 \\
\pm 0,20\end{array}$ & $\begin{array}{l}11,30 \\
\pm 0,20\end{array}$ & $\begin{array}{c}* \mathbf{1 0 , 3 0} \\
\pm 0,20\end{array}$ \\
\hline Jan. 5 Aut. & $\begin{array}{l}14,29 \\
\pm 0,23\end{array}$ & $\begin{array}{l}13,90 \\
\pm 0,22\end{array}$ & $\begin{array}{l}* \mathbf{9 , 6 2} \\
\pm 0,18\end{array}$ & $\begin{array}{c}8,88 \\
\pm 0,18\end{array}$ & $\begin{array}{l}18,26 \\
\pm 0,26\end{array}$ & $\begin{array}{c}8,24 \\
\pm 0,17\end{array}$ & $\begin{array}{l}16,63 \\
\pm 0,24\end{array}$ & $\begin{array}{l}17,37 \\
\pm 0,25\end{array}$ \\
\hline Jan. $50,6 \%$ & $\begin{array}{l}14,79 \\
\pm 0,24\end{array}$ & $\begin{array}{r}14,88 \\
\pm 0,24\end{array}$ & $\begin{array}{l}* \mathbf{9}, \mathbf{6 2} \\
\pm 0,19\end{array}$ & $\begin{array}{c}6,60 \\
\pm 0,16\end{array}$ & $\begin{array}{l}15,71 \\
\pm 0,25\end{array}$ & $\begin{array}{l}* \mathbf{*}, \mathbf{5 5} \\
\pm 0,17\end{array}$ & $\begin{array}{l}13,01 \\
\pm 0,22\end{array}$ & $\begin{array}{l}17,17 \\
\pm 0,26\end{array}$ \\
\hline Jan. $50,8 \%$ & $\begin{array}{l}17,04 \\
\pm 0,25\end{array}$ & $\begin{array}{l}10,24 \\
\pm 0,20\end{array}$ & $\begin{array}{l}10,34 \\
\pm 0,20\end{array}$ & $\begin{array}{c}7,61 \\
\pm 0,17\end{array}$ & $\begin{array}{l}20,17 \\
\pm 0,27\end{array}$ & $\begin{array}{l}11,90 \\
\pm 0,21\end{array}$ & $\begin{array}{l}13,86 \\
\pm 0,23\end{array}$ & $\begin{array}{l}20,00 \\
\pm 0,27\end{array}$ \\
\hline Jan. $51 \%$ & $\begin{array}{l}16,29 \\
\pm 0,25\end{array}$ & $\begin{array}{c}9,27 \\
\pm 0,19\end{array}$ & $\begin{array}{l}11,78 \\
\pm 0,21\end{array}$ & $\begin{array}{l}10,41 \\
\pm 0,20\end{array}$ & $\begin{array}{l}19,32 \\
\pm 0,27\end{array}$ & $\begin{array}{l}11,67 \\
\pm 0,21\end{array}$ & $\begin{array}{l}13,43 \\
\pm 0,22\end{array}$ & $\begin{array}{l}24,85 \\
\pm 0,30\end{array}$ \\
\hline Jan. $52 \%$ & $\begin{array}{l}21,80 \\
\pm 0,28\end{array}$ & $\begin{array}{l}12,44 \\
\pm 0,22\end{array}$ & $\begin{array}{c}14,18 \\
\pm 0,22\end{array}$ & $\begin{array}{c}8,63 \\
\pm 0,18\end{array}$ & $\begin{array}{l}19,53 \\
\pm 0,27\end{array}$ & $\begin{array}{l}14,87 \\
\pm 0,24\end{array}$ & $\begin{array}{l}11,30 \\
\pm 0,21\end{array}$ & $\begin{array}{l}27,88 \\
\pm 0,32\end{array}$ \\
\hline Jan. $53 \%$ & $\begin{array}{l}23,31 \\
\pm 0,29\end{array}$ & $\begin{array}{c}15,12 \\
\pm 0,23\end{array}$ & $\begin{array}{c}18,03 \\
\pm 0,25\end{array}$ & $\begin{array}{l}12,44 \\
\pm 0,21\end{array}$ & $\begin{array}{l}25,27 \\
\pm 0,30\end{array}$ & $\begin{array}{r}16,25 \\
\pm 0,25\end{array}$ & $\begin{array}{r}* \mathbf{9}, \mathbf{5 9} \\
\pm 0,19\end{array}$ & $\begin{array}{l}28,48 \\
\pm 0,32\end{array}$ \\
\hline
\end{tabular}

diminuir o número de atributos. Por exemplo, o uso da medida objetiva Lift com limiar de 0,1 diminuiu o erro de classificação em $0,23 \%$ e o número de atributos em $62 \%$.

Tabela 4.18: J48 - taxas de erro da representação bag-of-words e das representações bag-of-related-words com medidas de interesse objetivas que obtiveram a menor taxa de erro para as coleções da ACM.

\begin{tabular}{|c|c|c|c|c|c|c|c|c|}
\hline Representação & ACM-1 & ACM-2 & ACM-3 & ACM-4 & ACM-5 & ACM-6 & ACM-7 & ACM-8 \\
\hline \multirow{2}{*}{ Bag-of-words } & $* 11,53$ & $* 7,07$ & 12,97 & $* 6,09$ & $* 14,01$ & 11,62 & $* 11,30$ & $* 10,30$ \\
\hline & $\pm 0,22$ & $\pm 0,19$ & $\pm 0,22$ & $\pm 0,13$ & $\pm 0,22$ & $\pm 0,20$ & $\pm 0,20$ & $\pm 0,20$ \\
\hline \multirow{2}{*}{ Jan. 5 Aut. Lift 0,1} & 14,79 & 13,66 & 11,54 & 9,39 & 18,47 & $* 8,01$ & 18,55 & 16,97 \\
\hline & $\pm 0,24$ & $\pm 0,23$ & $\pm 0,21$ & $\pm 0,19$ & $\pm 0,26$ & $\pm 0,18$ & $\pm 0,26$ & $\pm 0,25$ \\
\hline \multirow{2}{*}{ Jan. 5 Aut. Lift 0,2} & 15,04 & 13,17 & $* 9,86$ & 8,12 & 17,41 & 10,53 & 18,55 & 19,39 \\
\hline & $\pm 0,24$ & $\pm 0,22$ & $\pm 0,19$ & $\pm 0,18$ & $\pm 0,26$ & $\pm 0,2$ & $\pm 0,26$ & $\pm 0,27$ \\
\hline \multirow{2}{*}{ Jan. 5 Aut. Lift $\bar{x}$} & 14,79 & 13,66 & 11,54 & 9,39 & 18,47 & $* 8,01$ & 18,55 & 16,97 \\
\hline & $\pm 0,24$ & $\pm 0,23$ & $\pm 0,21$ & $\pm 0,19$ & $\pm 0,26$ & $\pm 0,18$ & $\pm 0,26$ & $\pm 0,25$ \\
\hline \multirow{2}{*}{ Jan. 5 Aut. Yule's Q 0,5} & 14,04 & 13,41 & 11,06 & 10,15 & 17,41 & $* 8,01$ & 18,98 & 18,59 \\
\hline & $\pm 0,23$ & $\pm 0,23$ & $\pm 0,2$ & $\pm 0,2$ & $\pm 0,26$ & $\pm 0,17$ & $\pm 0,26$ & $\pm 0,26$ \\
\hline \multirow{2}{*}{ Jan. 5 Aut. Yule's Q $\bar{x}$} & 14,54 & 13,90 & 10,10 & 9,39 & 17,41 & $* 8,01$ & 18,55 & 18,38 \\
\hline & $\pm 0,24$ & $\pm 0,23$ & $\pm 0,19$ & $\pm 0,18$ & $\pm 0,26$ & $\pm 0,17$ & $\pm 0,26$ & $\pm 0,26$ \\
\hline
\end{tabular}

Para verificar a influência dos limiares das medidas de interesse objetivas nas taxas de erro obtidas pelo algoritmo J48, foi aplicado o teste de Friedman para as representações bag-of-related-words de cada medida objetiva considerando as 8 coleções da ACM. Diferente do ocorrido com o algoritmo de classificação Naïve Bayes, não foi obtida nenhuma diferença estatisticamente significante entre as taxas de erro de classificação.

Tabela 4.19: J48 - resultado do teste estatístico entre as taxas de erro das coleções ACM obtidas pelas representações bag-of-related-words que utilizam medidas de interesse objetivas para extrair atributos e a representação bag-of-words.

\begin{tabular}{|c|c|c|c|c|c|c|c|c|c|}
\cline { 2 - 10 } \multicolumn{1}{c|}{} & $B O W$ & Conf. & Lift & Yule's Q & Corr. & I.M. & Gini & Kappa & J.M. \\
\hline$B O W$ & - & $\bullet$ & $\bullet$ & $\bullet$ & $\bullet$ & $\bullet$ & $\bullet$ & $\bullet$ & $\bullet$ \\
\hline Conf. & $\bullet$ & - & $\bullet$ & $\bullet$ & $\bullet$ & $\bullet$ & $\bullet$ & $\bullet$ & $\bullet$ \\
\hline Lift & $\bullet$ & $\bullet$ & - & $\bullet$ & $\bullet$ & $\bullet$ & $\bullet$ & $\bullet$ & $\bullet$ \\
\hline Yule's Q & $\bullet$ & $\bullet$ & $\bullet$ & - & $\bullet$ & $\bullet$ & $\bullet$ & $\bullet$ & $\bullet$ \\
\hline Corr. & $\bullet$ & $\bullet$ & $\bullet$ & $\bullet$ & - & $\bullet$ & $\bullet$ & $\bullet$ & $\bullet$ \\
\hline I.M. & $\bullet$ & $\bullet$ & $\bullet$ & $\bullet$ & $\bullet$ & - & $\bullet$ & $\bullet$ & $\bullet$ \\
\hline Gini & $\bullet$ & $\bullet$ & $\bullet$ & $\bullet$ & $\bullet$ & $\bullet$ & - & $\bullet$ & $\bullet$ \\
\hline Kappa & $\bullet$ & $\bullet$ & $\bullet$ & $\bullet$ & $\bullet$ & $\bullet$ & $\bullet$ & - & $\bullet$ \\
\hline J.M. & $\bullet$ & $\bullet$ & $\bullet$ & $\bullet$ & $\bullet$ & $\bullet$ & $\bullet$ & $\bullet$ & - \\
\hline
\end{tabular}

Como não houve diferenças estatisticamente significantes nos resultados obtidos pelos diferentes limiares das medidas de interesse objetivas, foram selecionadas as representações com limiares baseados na média para comparar as representações com diferentes medidas 
de interesse objetivas e a bag-of-words. Na Tabela 4.19 são apresentados os resultados do teste estatístico utilizando estas representações. Pode-se notar pela Tabela 4.19 que nenhuma das representações, inclusive a representação bag-of-words, que obteve a menor taxa de erro em 6 das 8 coleções, apresentou resultados com diferenças estatisticamente significantes.

Na Figura 4.8 é apresentada uma comparação gráfica das taxas de erro das representações que utilizam medidas de interesse objetivas com limiares baseados na média e a representação bag-of-words. De acordo com o gráfico da Figura 4.8(a), todas as medidas apresentaram comportamento semelhante quanto à taxa de erro, com exceção da medida objetiva Lift na coleção ACM-8, que obteve uma taxa de erro bem abaixo das demais medidas de interesse objetivas. Pela Figura 4.8(b) pode-se observar que a taxa de erro não varia muito para as representações utilizando medidas de interesse objetivas.

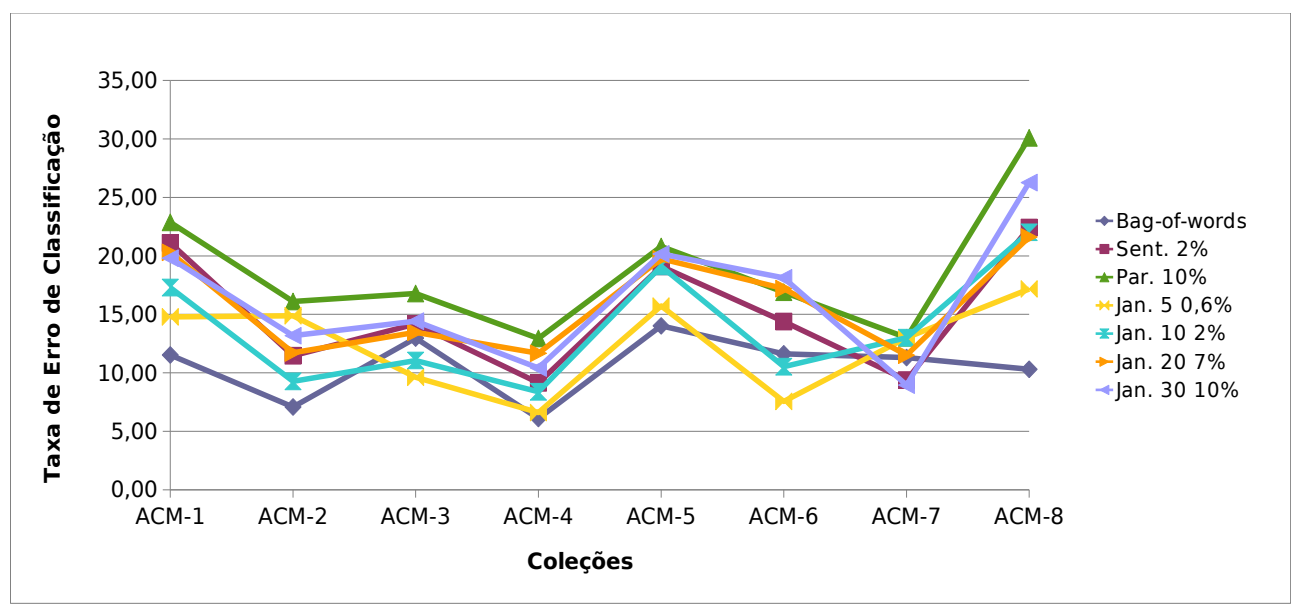

(a)

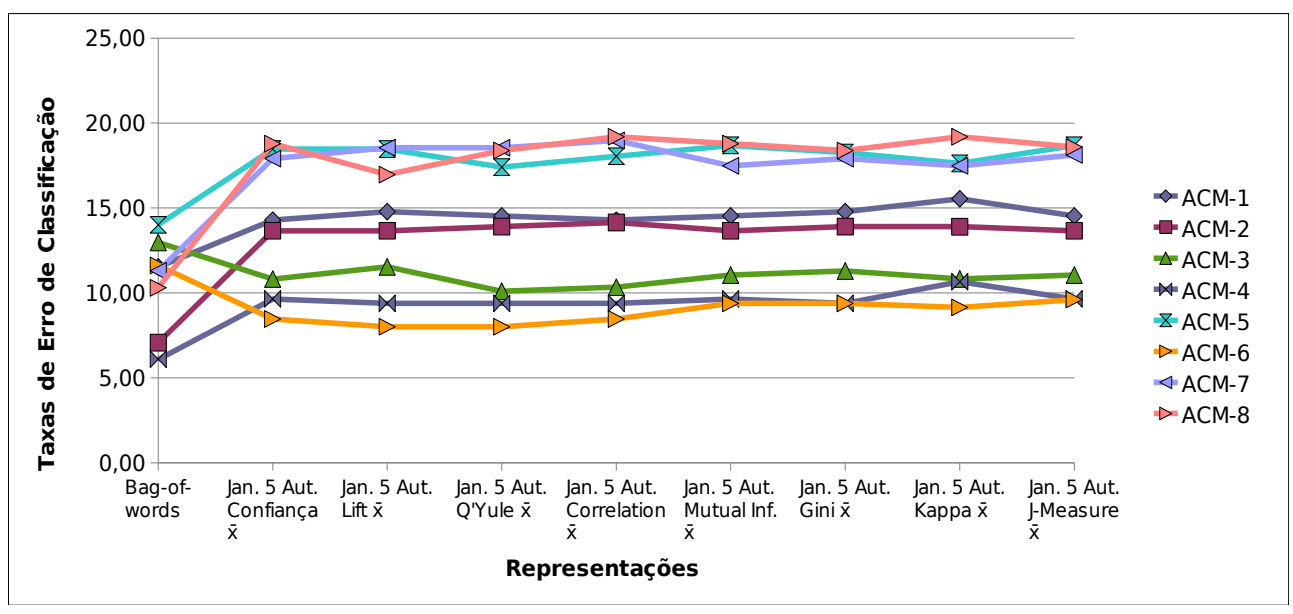

(b)

Figura 4.8: J48 - (a) taxas de erro de classificação das representações bag-of-related-words com diferentes medidas de interesse objetivas e da representação bag-of-words para as coleções da ACM; (b) taxas de erro de classificação das coleções da ACM para as representações bag-of-related-words com diferentes medidas de interesse objetivas e a representação bag-of-words.

Para a coleção Reuters-21578, todas as representações bag-of-related-words obtiveram taxas de erro menores que a bag-of-words. Na Tabela 4.20 são apresentados os resultados da representação bag-of-words e das representações bag-of-related-words com medidas de interesse objetivas e limiares baseados na média. A menor taxa de erro foi de $28,89 \%$, sendo 2,83\% menor que a representação bag-of-words, e foi obtida pelas representações [Jan. 5 I.M. 0,05], [Jan. 5 Gini 0,01] e [Jan. 5 J.M. 0,02]. Algumas representações como a 
[Jan. 5 Aut. I.M. 0,2\%] obtiveram taxas de erros menores com uma redução de até $38 \%$ no número de atributos.

Tabela 4.20: J48 - taxas de erro da representação bag-of-words e das representações bag-of-related-words com medidas de interesse objetivas e limiares baseados na média para a coleção Reuters-21578.

\begin{tabular}{|l|r|}
\hline Representação & Taxa de Erro \\
\hline Bag-of-words & 31,72 \\
\hline Jan. 5 Aut. & 29,62 \\
\hline Jan. 5 Aut. Lift $\bar{x}$ & 30,04 \\
\hline Jan. 5 Aut. Conf. $\bar{x}$ & 30,36 \\
\hline Jan. 5 Aut. Yule's Q $\bar{x}$ & 29,52 \\
\hline Jan. 5 Aut. Corr. $\bar{x}$ & 29,62 \\
\hline Jan. 5 Aut. I.M. $\bar{x}$ & 30,04 \\
\hline Jan. 5 Aut. Gini $\bar{x}$ & 30,57 \\
\hline Jan. 5 Aut. Kappa $\bar{x}$ & 29,73 \\
\hline Jan. 5 Aut. J.M. $\bar{x}$ & 29,83 \\
\hline
\end{tabular}

Ao analisar os resultados observou-se que apesar da representação bag-of-words obter uma menor taxa de erro para a maioria das coleções da ACM, não houve indícios que as diferenças do resultados fossem significantes para a representação bag-of-related-words. Além disso, as regras geradas pela representação proposta são mais significativas do que as obtidas pela bag-of-words. O fato de não obter as menores taxas de erro de classificação também se deve à característica da base.

Foi analisado o ranking de atributos da representação bag-of-related-words e bag-ofwords utilizando a medida gain ratio para verificar se os atributos da representação bagof-related-words ficavam bem ranqueados e se havia alteração no valor da medida para o mesmo atributo nas diferentes representações. Foi observado que muitos dos atributos melhores ranqueados são semelhantes, e muitos os atributos gerados pela abordagem proposta são bem ranqueados seguindo a medida gain ratio. Na Tabela 4.21 são apresentados as 50 primeiras posições do ranking dos atributos para as coleções ACM-4 e ACM-8 utilizando as representações [Jan. 5. Aut. Yule's Q $\bar{x}$ ] e bag-of-words. Estão marcados em itálico os atributos que são comuns aos dois rankings e em negrito os atributos considerados importantes e que aparecem somente no ranking utilizando a representação [Jan. 5. Aut. Yule's Q $\bar{x}$.

Muitos dos atributos entre os 50 melhores ranqueados são comuns às duas abordagens de representação. Na coleção ACM-4 são 20 atributos em comum e na coleção ACM-8 são 18 atributos em comum. Também, muitos atributos compostos por mais de uma palavra aparecem bem ranqueados e são relacionados às classes das coleções, como "network_sensor", "comput_graphic", "render_volum", "network_wireless", "render_volum", "inform_retriev", e "acess_web", para a coleção ACM-4, e "ad-hoc_network", "network_wireless", "node_transmit", e "data_mine" para a coleção ACM-8.

Muitos atributos formados por palavras simples aparecem no ranking utilizando a representação [Jan. 5. Aut. Yule's $Q \bar{x}$ ] e não aparecem no ranking da representação bag-of-words. Por exemplo, os atributos "wireless", "surfac", "usabl", e "retriev", para a coleção ACM-4, e "embed", "architectur", "web", "memori", "bechmark", "dataset", "hyperlink", "folksonomi", e "transistor" para a coleção ACM-8, só aparecem no ranking obtido utilizando a representação [Jan. 5. Aut. Yule's Q $\bar{x}$ ].

Pode-se observar também na Tabela 4.21 que alguns atributos formados por palavras simples obtém uma pontuação maior para a medida gain ratio utilizando a representação bag-of-related-words do que utilizando a bag-of-words. Por exemplo, para a coleção ACM4, o atributo "sensor" obtém uma pontuação de 0,80 utilizando a representação [Jan. 5 
Tabela 4.21: Ranking da medida Gain Ratio para as coleções ACM-4 e ACM-8 utilizando as representações bag-of-words e [Jan. 5. Aut. Yule's Q $\bar{x}$.

\begin{tabular}{|c|c|c|c|}
\hline \multicolumn{4}{|c|}{$\mathrm{ACM}-4$} \\
\hline \multicolumn{2}{|c|}{ Bag-of-words } & \multicolumn{2}{|r|}{ [Jan. 5. Aut. Yule's Q $\bar{x}$ ] } \\
\hline Val. & Átributo & Val. & Atributo \\
\hline 0,82 & sigir & 0,82 & network sensor \\
\hline 0,72 & voxel & 0,80 & sensor \\
\hline 0,71 & mote & 0,79 & volum \\
\hline 0,69 & estrin & 0,74 & graphic \\
\hline 0,69 & mica & 0,72 & web \\
\hline 0,69 & $\mathrm{rai}$ & 0,72 & render \\
\hline 0,67 & browser & 0,66 & org \\
\hline 0,65 & heidemann & 0,66 & comput graphic \\
\hline 0,63 & sensor & 0,65 & wireless \\
\hline 0,62 & descriptor & 0,62 & voxel \\
\hline 0,62 & szewczyk & 0,62 & disabl \\
\hline 0,61 & classroom & 0,62 & sigir \\
\hline 0,61 & volumetr & 0,62 & html \\
\hline 0,61 & score & 0,61 & document \\
\hline 0,60 & siggraph & 0,61 & $\mathrm{rai}$ \\
\hline 0,59 & graphic & 0,60 & render volum \\
\hline 0,59 & guidelin & 0,60 & text \\
\hline 0,58 & trec & 0,60 & sensor wireless \\
\hline 0,58 & levoi & 0,59 & guidelin \\
\hline 0,57 & habitat & 0,58 & usabl \\
\hline 0,57 & pister & 0,58 & http www \\
\hline 0,57 & wcag & 0,58 & surfac \\
\hline 0,57 & $w e b$ & 0,57 & tini \\
\hline 0,56 & $\mathrm{kbp}$ & 0,57 & mote \\
\hline 0,56 & redistribut & 0,57 & score \\
\hline 0,56 & govindan & 0,56 & radio \\
\hline 0,56 & culler & 0,55 & rank \\
\hline 0,56 & ucla & 0,55 & hop \\
\hline 0,55 & pixel & 0,54 & mica \\
\hline 0,55 & bear & 0,54 & estrin \\
\hline 0,55 & cikm & 0,54 & packet \\
\hline 0,55 & markup & 0,54 & network wireless \\
\hline 0,54 & alt & 0,53 & browser \\
\hline 0,54 & $\operatorname{css}$ & 0,53 & deploy \\
\hline 0,54 & hanrahan & 0,52 & inform retriev \\
\hline 0,53 & ganesan & 0,52 & technolog \\
\hline 0,53 & person & 0,52 & topic \\
\hline 0,53 & croft & 0,51 & retriev \\
\hline 0,53 & $\operatorname{rank}$ & 0,51 & www \\
\hline 0,53 & $i m a g$ & 0,51 & trec \\
\hline 0,52 & post & 0,51 & peopl \\
\hline 0,52 & text & 0,51 & org www \\
\hline 0,52 & elson & 0,50 & visual \\
\hline 0,52 & hollar & 0,50 & network sensor wireless \\
\hline 0,52 & mainwar & 0,50 & $i m a g$ \\
\hline 0,52 & polastr & 0,49 & pixel \\
\hline 0,52 & packet & 0,49 & reader screen \\
\hline 0,52 & blind & 0,49 & berkelei \\
\hline 0,52 & render & 0,49 & reader \\
\hline 0,51 & impair & 0,47 & access web \\
\hline 0,51 & disabl & 0,47 & Temma \\
\hline
\end{tabular}

\begin{tabular}{|c|c|c|c|}
\hline \multicolumn{4}{|c|}{ ACM- 8} \\
\hline \multicolumn{2}{|c|}{ Bag-of-words } & \multicolumn{2}{|c|}{ [Jan. 5. Aut. Yule's Q $\bar{x}]$} \\
\hline Val. & Atributo & Val. & Atributo \\
\hline 0,88 & descriptor & 0,75 & wireless \\
\hline 0,84 & classroom & 0,65 & network wireless \\
\hline 0,81 & fee & 0,63 & processor \\
\hline 0,80 & redistribut & 0,59 & hypertext \\
\hline 0,76 & processor & 0,54 & hoc network \\
\hline 0,76 & bear & 0,53 & execut \\
\hline 0,74 & person & 0,53 & hoc \\
\hline 0,71 & subject & 0,52 & instruct \\
\hline 0,67 & hypermedia & 0,51 & compil \\
\hline 0,65 & hypertext & 0,50 & transmiss \\
\hline 0,65 & post & 0,50 & hypermedia \\
\hline 0,65 & wireless & 0,49 & embed \\
\hline 0,62 & microarchitectur & 0,48 & architectur \\
\hline 0,61 & profit & 0,47 & embed_system \\
\hline 0,61 & categori & 0,47 & web \\
\hline 0,59 & compil & 0,46 & memori \\
\hline 0,59 & digit & 0,45 & navig \\
\hline 0,58 & keyword & 0,45 & cach \\
\hline 0,57 & infocom & 0,45 & benchmark \\
\hline 0,57 & notic & 0,43 & dataset \\
\hline 0,56 & chip & 0,43 & microarchitectur \\
\hline 0,55 & hardwar & 0,42 & mine \\
\hline 0,53 & instruct & 0,42 & data mine \\
\hline 0,51 & execut & 0,41 & chip \\
\hline 0,51 & multihop & 0,40 & hop \\
\hline 0,49 & multiprocessor & 0,40 & $c m p$ \\
\hline 0,47 & cach & 0,39 & cyci \\
\hline 0,47 & hard & 0,38 & hyperlink \\
\hline 0,47 & hoc & 0,38 & transmit \\
\hline 0,47 & copi & 0,37 & folksonomi \\
\hline 0,47 & sigplan & 0,37 & text \\
\hline 0,47 & microprocessor & 0,37 & transistor \\
\hline 0,46 & $c m p$ & 0,37 & network toler \\
\hline 0,46 & micro & 0,37 & node_transmit \\
\hline 0,45 & pipelin & 0,37 & infocom \\
\hline 0,45 & kdd & 0,37 & hop multi \\
\hline 0,45 & server & 0,37 & code size \\
\hline 0,44 & mobi & 0,36 & hardwar \\
\hline 0,44 & keckler & 0,36 & site web \\
\hline 0,44 & manet & 0,36 & deploy \\
\hline 0,44 & sigkdd & 0,36 & hoc wireless \\
\hline 0,43 & $\mathrm{icml}$ & 0,35 & program \\
\hline 0,43 & navig & 0,35 & regist \\
\hline 0,43 & ipc & 0,35 & assign tag \\
\hline 0,42 & transmiss & 0,35 & crawl \\
\hline 0,42 & burger & 0,35 & rang transmiss \\
\hline 0,42 & ammp & 0,35 & retriev \\
\hline 0,42 & commerci & 0,35 & relai \\
\hline 0,41 & regist & 0,35 & $\mathrm{vpr}$ \\
\hline 0,41 & icdm & 0,34 & pipelin \\
\hline 0,41 & buffer & 0,34 & specul \\
\hline
\end{tabular}

Aut. Yule's Q $\bar{x}$ e 0,63 utilizando a representação bag-of-words. Para a coleção ACM-8, o atributo "wireless" apresenta um valor de 0,75 utilizando a representação [Jan. 5 Aut. Yule's Q $\bar{x}$ e e 0,65 utilizando a representação bag-of-words. Isso se dá pelo fato que palavras como "graphic" podem podem aparecer em documentos de várias categorias utilizando a representação bag-of-words, mas só irá aparecer na representação bag-of-related-words se for frequente em um documento. Portanto, há uma grande chance do atributo "graphic" ser extraído pela bag-of-related-words se este estiver em um documento sobre computação gráfica.

Para a coleção Reuters-21578, a representação bag-of-related-words se mostrou adequada uma vez que todas as representações propostas obtiveram uma taxa de erro menor que a bag-of-words. Na Tabela 4.22 são apresentados as 50 primeiras posições do ranking segundo a medida gain ratio para a Reuters-21578 utilizando as representações bagof-words e [Jan. 5. Aut. Yule's Q $\bar{x}$ ]. Estão marcados em itálico os atributos que são comuns aos dois rankings e em negrito os atributos considerados importantes e que aparecem somente no ranking da representação [Jan. 5. Aut. Yule's Q $\bar{x}$ ]. Ao todo 24 dos 50 atributos melhores ranqueados são comuns em ambas as representações. Novamente, muitos atributos compostos por mais de uma palavra aparecem bem ranqueados. Esses atributos também são significativos e relacionados às classes como "buffer_stock", "consum_price", "gold_ounce", "rule_stock", "cocoa_member", "gold_ton", "consum_produc", 
"sugar_white", e "sugar_tonn".

Tabela 4.22: Ranking da medida Gain Ratio para a coleção Reuters 21578 utilizando as representações bag-of-words e [Jan. 5. Aut. Yule's Q $\bar{x}$.

\begin{tabular}{|c|c|c|c|}
\hline \multicolumn{2}{|c|}{ Bag-of-words } & \multicolumn{2}{|c|}{ [Jan. 5. Aut. Yule's Q $\bar{x}$ ] } \\
\hline Valor & Atributo & Valor & Atributo \\
\hline 0,83 & $\operatorname{cocoa}$ & 0,85 & sugar \\
\hline 0,81 & $i c c o$ & 0,85 & $\operatorname{cocoa}$ \\
\hline 0,81 & coffe & 0,82 & coffe \\
\hline 0,80 & sugar & 0,77 & $i c c o$ \\
\hline 0,74 & buffer & 0,75 & gold \\
\hline 0,73 & $i \mathrm{CO}$ & 0,74 & buffer \\
\hline 0,71 & ounc & 0,73 & buffer stock \\
\hline 0,62 & kobena & 0,70 & ounc \\
\hline 0,62 & erbynn & 0,68 & $i c O$ \\
\hline 0,58 & kanon & 0,65 & grain \\
\hline 0,58 & bra & 0,60 & consum price \\
\hline 0,58 & barrel & 0,60 & gold ounc \\
\hline 0,58 & $g d p$ & 0,60 & oil \\
\hline 0,58 & assai & 0,59 & rule stock \\
\hline 0,56 & vessel & 0,58 & cocoāintern \\
\hline 0,55 & dauster & 0,58 & cocoa member \\
\hline 0,55 & intersect & 0,57 & ounc ton \\
\hline 0,54 & raw & 0,56 & gold_ton \\
\hline 0,54 & $c t$ & 0,55 & $g d p$ \\
\hline 0,53 & bag & 0,55 & assai \\
\hline 0,52 & cane & 0,54 & ton \\
\hline 0,51 & grain & 0,54 & vessel \\
\hline 0,51 & managua & 0,54 & kanon \\
\hline 0,51 & $\mathrm{ibc}$ & 0,54 & bra \\
\hline 0,50 & rebat & 0,53 & gold_ounc_ton \\
\hline 0,50 & width & 0,53 & grade ounc \\
\hline 0,50 & minework & 0,52 & bra kanon \\
\hline 0,50 & beet & 0,52 & origin \\
\hline 0,50 & index & 0,50 & dauster \\
\hline 0,49 & shipown & 0,50 & coin \\
\hline 0,49 & underground & 0,50 & ship \\
\hline 0,48 & bpd & 0,49 & mine \\
\hline 0,48 & lt & 0,49 & consum produc \\
\hline 0,48 & $g n p$ & 0,49 & bag \\
\hline 0,48 & roaster & 0,48 & $c t$ \\
\hline 0,48 & shr & 0,48 & compromis \\
\hline 0,47 & shipbuild & 0,48 & $g n p$ \\
\hline 0,47 & czarnikow & 0,48 & beet \\
\hline 0,47 & sugarcan & 0,48 & cane \\
\hline 0,47 & $\mathrm{~kg}$ & 0,48 & raw \\
\hline 0,47 & reintroduct & 0,48 & barrel \\
\hline 0,47 & nicaraguan & 0,47 & strike \\
\hline 0,47 & solubl & 0,47 & sugar white \\
\hline 0,47 & roast & 0,47 & sugar tonn \\
\hline 0,47 & robusta & 0,47 & seamen \\
\hline 0,47 & arango & 0,47 & board execut \\
\hline 0,46 & ivorian & 0,47 & managua \\
\hline 0,46 & navig & 0,47 & export_registr \\
\hline 0,46 & ton & 0,47 & coffe intern \\
\hline 0,46 & bullion & 0,46 & deleg \\
\hline 0,46 & oil & 0,46 & registr \\
\hline
\end{tabular}

Muitos dos atributos compostos por uma palavra e relacionados às classes da coleção Reuters-21578 aparecem na ranking da representação [Jan. 5. Aut. Yule's Q $\bar{x}$ ] e não apareceram no ranking dos atributos da representação bag-of-words. Por exemplo, os atributos "gold", "coin", "ship", "mine", e "strike" só aparecem no ranking da representação [Jan. 5. Aut. Yule's Q $\bar{x}$. Além disso, alguns atributos formados por palavras simples obtém uma maior pontuação para a medida gain ratio utilizando a representação bag-of-related-words do que bag-of-words. Por exemplo, as palavras sugar e oil obtém respectivamente as pontuações 0,85 e 0,60 utilizando a representação [Jan. 5 Aut. Yule's $\mathrm{Q} \bar{x}$, enquanto que utilizando a representação bag-of-words as pontuações obtidas são 0,80 e 0,43 respectivamente.

Apesar de em algumas situações a representação bag-of-related-words obter resultados inferiores devido à algumas características das bases utilizadas, os resultados obtidos mostraram que a forma de representação proposta é viável para a utilização do algoritmo de classificação J48. Para a coleção Reuters-21578, todas as representações bag-of-relatedwords geradas obtiveram resultados melhores que a representação bag-of-words. Vale ressaltar que a maioria das representações bag-of-related-words utilizadas geraram um número de atributos menor que a representação bag-of-words. Para a as coleções da 
ACM, as representações bag-of-related-words foram melhores que a representação bag-ofrelated-words em algumas situações e geraram regras de mais fácil entendimento.

SMO

Nesta seção são apresentados alguns dos resultados obtidos pelo método de classificação SMO (Sequential Minimal Optimization), que é um algoritmo para resolver problemas de otimização durante o treinamento das máquinas de vetor de suporte, utilizando as representações bag-of-related-words e bag-of-words. Na Tabela 4.23 são apresentados os resultados da representação bag-of-words e das representações bag-of-related-words com diferentes formas de mapeamento que obtiveram a menor taxa de erro para ao menos uma das coleções da ACM. Foram considerados apenas os itemsets frequentes como atributos das representações bag-of-related-words e foram obtidas as menores taxas de erro de classificação em 2 das 8 coleções (ACM-3, ACM-7).

Tabela 4.23: SMO - taxas de erro da representação bag-of-words e das representações bag-of-related-words com itemsets frequentes como atributos que obtiveram a menor taxa de erro para as coleções da ACM.

\begin{tabular}{|c|c|c|c|c|c|c|c|c|}
\hline & \multicolumn{8}{|c|}{ Taxa de Erro } \\
\hline Representação & ACM-1 & ACM-2 & ACM-3 & ACM-4 & ACM-5 & ACM-6 & ACM-7 & ACM-8 \\
\hline Bag-of-words & $\begin{array}{l}\boldsymbol{*} \mathbf{3 , 2 6} \\
\pm 0,32\end{array}$ & $\begin{array}{l}\boldsymbol{*}_{\mathbf{2}, \mathbf{2 0}} \\
\pm 0,32\end{array}$ & $\begin{array}{c}3,54 \\
\pm 0,32\end{array}$ & $\begin{array}{l}\boldsymbol{*}^{\mathbf{0}, \mathbf{2 5}} \\
\pm 0,32\end{array}$ & $\begin{array}{l}\boldsymbol{*}_{\mathbf{2}} \mathbf{2 , 1 2} \\
\pm 0,32\end{array}$ & $\begin{array}{l}\boldsymbol{*} \mathbf{1 , 1 4} \\
\pm 0,32\end{array}$ & $\begin{array}{c}3,84 \\
\pm 0,32\end{array}$ & $\begin{array}{r}\boldsymbol{*} \mathbf{4 , 0 4} \\
\pm 0,32\end{array}$ \\
\hline Jan. $50,6 \%$ & $\begin{array}{c}5,76 \\
\pm 0,32\end{array}$ & $\begin{array}{c}3,41 \\
\pm 0,32\end{array}$ & $\begin{array}{l}\boldsymbol{*} \mathbf{2 , 8 8} \\
\pm 0,32\end{array}$ & $\begin{array}{c}1,27 \\
\pm 0,32\end{array}$ & $\begin{array}{c}3,61 \\
\pm 0,32\end{array}$ & $\begin{array}{c}1,60 \\
\pm 0,32\end{array}$ & $\begin{array}{c}4,05 \\
\pm 0,32\end{array}$ & $\begin{array}{l}6,87 \\
\pm 0,32\end{array}$ \\
\hline Jan. $50,8 \%$ & $\begin{array}{c}6,02 \\
\pm 0,32\end{array}$ & $\begin{array}{c}2,93 \\
\pm 0,32\end{array}$ & $\begin{array}{l}\boldsymbol{*} \mathbf{2 , 8 8} \\
\pm 0,32\end{array}$ & $\begin{array}{c}1,27 \\
\pm 0,32\end{array}$ & $\begin{array}{c}3,61 \\
\pm 0,32\end{array}$ & $\begin{array}{c}2,29 \\
\pm 0,32\end{array}$ & $\begin{array}{c}3,41 \\
\pm 0,32\end{array}$ & $\begin{array}{l}7,88 \\
\pm 0,32\end{array}$ \\
\hline Jan. $52 \%$ & $\begin{array}{l}10,78 \\
\pm 0,32\end{array}$ & $\begin{array}{c}2,93 \\
\pm 0,32\end{array}$ & $\begin{array}{c}4,33 \\
\pm 0,32\end{array}$ & $\begin{array}{c}1,27 \\
\pm 0,32\end{array}$ & $\begin{array}{c}9,34 \\
\pm 0,32\end{array}$ & $\begin{array}{c}5,26 \\
\pm 0,32\end{array}$ & $\begin{array}{l}\boldsymbol{*} \mathbf{2 , 7 7} \\
\pm 0,32\end{array}$ & $\begin{array}{l}9,90 \\
\pm 0,32\end{array}$ \\
\hline
\end{tabular}

O mapeamento de janela 5 obteve os melhores resultados para a representação bag-ofrelated-words novamente. As representações [Jan. 5 0,6\%] e [Jan. 5 0,8\%] obtiveram os melhores resultados para a coleção ACM-3, e a representação [Jan. $52 \%$ ] obteve o melhor resultado para a coleção ACM-7.

Para verificar se a variação do suporte mínimo nas diversas formas de mapeamento afetou as taxas de erro obtidas pelo método $S M O$, foi aplicado o teste de Friedman considerando as 8 coleções da ACM para cada tipo de mapeamento. Na Tabela 4.24 são apresentados os resultados dos testes estatísticos. Pode-se notar que houve diferenças estatisticamente significantes para todas as variações do suporte mínimo quando foram utilizadas sentenças e parágrafos como transações. Quando foram utilizadas janelas, em geral, houve diferença do menor para o maior valor de suporte mínimo.

Para verificar qual o melhor tipo de mapeamento e comparar com a bag-of-words, foram escolhidos os melhores valores de suporte mínimo para cada tipo de mapeamento: [Sent. 2\%], [Par. 10\%], [Jan. 5 0,6\%], [Jan. 10 2\%], [Jan. 20 6\%], [Jan. 30 11\%]. Na Tabela 4.25 são apresentados os resultados dos testes estatísticos. Pode-se notar que quase todas as representações bag-of-related-words utilizadas para comparação com a representação bag-of-words não apresentaram diferenças estatisticamente significantes. Somente o mapeamento de parágrafos foi inferior com diferenças estatisticamente significantes em relação às outras representações.

Na Figura 4.9 é apresentada uma comparação gráfica das taxas de erro obtidas pelas melhores representações de cada tipo de mapeamento e pela representação bag-of-words. Analisando o gráfico da Figura 4.9(a), pode-se notar que todas as variações da representação bag-of-related-words têm um comportamento similar em relação à taxa de erro de classificação. Observa-se no gráfico que, em algumas situações, a abordagem proposta é próxima ou melhor do que a bag-of-words, e os tipos de mapeamento têm comportamento parecido em relação à taxa de erro. Pela Figura 4.9(b), observam-se várias situações em 
Tabela 4.24: SMO - resultado do teste estatístico para avaliar o impacto na taxa de erro de classificação causado pela variação do suporte mínimo para as diferentes formas de mapeamento nas coleções da ACM.

\begin{tabular}{|c|c|c|c|c|c|}
\multicolumn{1}{c|}{ Sentenças } \\
\cline { 2 - 6 } \multicolumn{1}{c|}{} & $2 \%$ & $3 \%$ & $4 \%$ & $5 \%$ & $6 \%$ \\
\hline $2 \%$ & - & $\boldsymbol{\Delta}$ & $\boldsymbol{\Delta}$ & $\boldsymbol{\Delta}$ & $\boldsymbol{\Delta}$ \\
\hline $3 \%$ & $\mathbf{\nabla}$ & - & $\boldsymbol{\Delta}$ & $\boldsymbol{\Delta}$ & $\boldsymbol{\Delta}$ \\
\hline $4 \%$ & $\mathbf{\nabla}$ & $\mathbf{\nabla}$ & - & $\boldsymbol{\Delta}$ & $\boldsymbol{\Delta}$ \\
\hline $5 \%$ & $\mathbf{\nabla}$ & $\mathbf{\nabla}$ & $\mathbf{\nabla}$ & - & $\boldsymbol{\Delta}$ \\
\hline $6 \%$ & $\mathbf{\nabla}$ & $\mathbf{\nabla}$ & $\mathbf{\nabla}$ & $\mathbf{\nabla}$ & - \\
\hline
\end{tabular}

\begin{tabular}{|c|c|c|c|c|c|}
\multicolumn{1}{c|}{} & $10 \%$ & $11 \%$ & $12 \%$ & $13 \%$ & $14 \%$ \\
\hline $10 \%$ & - & $\boldsymbol{\Delta}$ & $\boldsymbol{\Delta}$ & $\boldsymbol{\Delta}$ & $\boldsymbol{\Delta}$ \\
\hline $11 \%$ & $\mathbf{V}$ & - & $\boldsymbol{\Delta}$ & $\mathbf{\Delta}$ & $\boldsymbol{\Delta}$ \\
\hline $12 \%$ & $\mathbf{\nabla}$ & $\mathbf{\nabla}$ & - & $\boldsymbol{\Delta}$ & $\boldsymbol{\Delta}$ \\
\hline $13 \%$ & $\mathbf{\nabla}$ & $\mathbf{\nabla}$ & $\mathbf{\nabla}$ & - & $\boldsymbol{\Delta}$ \\
\hline $14 \%$ & $\mathbf{\nabla}$ & $\mathbf{\nabla}$ & $\mathbf{\nabla}$ & $\mathbf{\nabla}$ & - \\
\hline
\end{tabular}

\begin{tabular}{|c|c|c|c|c|c|}
\multicolumn{1}{c}{} & Janela 5 \\
\cline { 2 - 6 } \multicolumn{1}{c|}{} & $0,6 \%$ & $0,8 \%$ & $1 \%$ & $2 \%$ & $3 \%$ \\
\hline $0,6 \%$ & - & $\bullet$ & $\bullet$ & $\boldsymbol{\Delta}$ & $\boldsymbol{\Delta}$ \\
\hline $0,8 \%$ & $\bullet$ & - & $\bullet$ & $\boldsymbol{\Delta}$ & $\boldsymbol{\Delta}$ \\
\hline $1 \%$ & $\bullet$ & $\bullet$ & - & $\boldsymbol{\Delta}$ & $\boldsymbol{\Delta}$ \\
\hline $2 \%$ & $\mathbf{\nabla}$ & $\mathbf{\nabla}$ & $\mathbf{\nabla}$ & - & $\bullet$ \\
\hline $3 \%$ & $\mathbf{\nabla}$ & $\mathbf{\nabla}$ & $\mathbf{\nabla}$ & $\bullet$ & - \\
\hline
\end{tabular}

\begin{tabular}{|c|c|c|c|c|c|}
\cline { 2 - 6 } \multicolumn{1}{c|}{} & $2 \%$ & $3 \%$ & $4 \%$ & $5 \%$ & $6 \%$ \\
\hline $2 \%$ & - & $\bullet$ & $\bullet$ & $\Delta$ & $\Delta$ \\
\hline $3 \%$ & $\bullet$ & - & $\bullet$ & $\bullet$ & $\Delta$ \\
\hline $4 \%$ & $\bullet$ & $\bullet$ & - & $\bullet$ & $\Delta$ \\
\hline $5 \%$ & $\mathbf{\nabla}$ & $\bullet$ & $\bullet$ & - & $\bullet$ \\
\hline $6 \%$ & $\mathbf{\nabla}$ & $\mathbf{\nabla}$ & $\mathbf{\nabla}$ & $\bullet$ & - \\
\hline
\end{tabular}

\begin{tabular}{|c|c|c|c|c|c|}
\multicolumn{1}{c|}{ Janela 20} \\
\cline { 2 - 6 } \multicolumn{1}{c|}{} & $6 \%$ & $7 \%$ & $8 \%$ & $9 \%$ & $10 \%$ \\
\hline $6 \%$ & - & $\bullet$ & $\bullet$ & $\bullet$ & $\boldsymbol{\Delta}$ \\
\hline $7 \%$ & $\bullet$ & - & $\bullet$ & $\bullet$ & $\boldsymbol{\Delta}$ \\
\hline $8 \%$ & $\bullet$ & $\bullet$ & - & $\bullet$ & $\boldsymbol{\Delta}$ \\
\hline $9 \%$ & $\bullet$ & $\bullet$ & $\bullet$ & - & $\boldsymbol{\Delta}$ \\
\hline $10 \%$ & $\mathbf{\nabla}$ & $\mathbf{\nabla}$ & $\mathbf{\nabla}$ & $\mathbf{\nabla}$ & - \\
\hline
\end{tabular}

\begin{tabular}{|c|c|c|c|c|c|}
\cline { 2 - 6 } \multicolumn{1}{c|}{} & $10 \%$ & $11 \%$ & $12 \%$ & $13 \%$ & $14 \%$ \\
\hline $10 \%$ & - & $\bullet$ & $\bullet$ & $\bullet$ & $\Delta$ \\
\hline $11 \%$ & $\bullet$ & - & $\bullet$ & $\bullet$ & $\Delta$ \\
\hline $12 \%$ & $\bullet$ & $\bullet$ & - & $\bullet$ & $\Delta$ \\
\hline $13 \%$ & $\bullet$ & $\bullet$ & $\bullet$ & - & $\Delta$ \\
\hline $14 \%$ & $\mathbf{v}$ & $\mathbf{\nabla}$ & $\mathbf{\nabla}$ & $\mathbf{\nabla}$ & - \\
\hline
\end{tabular}

Tabela 4.25: SMO - resultado do teste estatístico para comparar a taxa de erro de classificação nas coleções ACM obtidas pela representação bag-of-words e pelas representações bag-of-related-words com diferentes formas de mapeamento.

\begin{tabular}{|c|c|c|c|c|c|c|c|}
\hline & Bag-of-words & Sent. $2 \%$ & Par. $10 \%$ & Jan. $50,6 \%$ & Jan. $102 \%$ & Jan. $206 \%$ & Jan. $3011 \%$ \\
\hline Bag-of-words & - & $\bullet$ & $\Delta$ & $\bullet$ & $\bullet$ & $\bullet$ & - \\
\hline Sent. $2 \%$ & $\bullet$ & - & $\bullet$ & $\bullet$ & $\bullet$ & $\bullet$ & $\bullet$ \\
\hline Par. $10 \%$ & $\nabla$ & $\boldsymbol{\nabla}$ & - & $\boldsymbol{\nabla}$ & $\boldsymbol{\nabla}$ & $\boldsymbol{\nabla}$ & $\boldsymbol{\nabla}$ \\
\hline Jan. $50,6 \%$ & $\bullet$ & $\bullet$ & $\Delta$ & - & $\bullet$ & $\bullet$ & $\bullet$ \\
\hline Jan. $102 \%$ & $\bullet$ & $\bullet$ & $\Delta$ & $\bullet$ & - & $\bullet$ & $\bullet$ \\
\hline Jan. $206 \%$ & $\bullet$ & $\bullet$ & $\boldsymbol{\Delta}$ & - & $\bullet$ & - & - \\
\hline Jan. $3011 \%$ & $\bullet$ & $\bullet$ & $\Delta$ & $\bullet$ & $\bullet$ & $\bullet$ & - \\
\hline
\end{tabular}

que há um aumento da taxa de erro obtido pelo mapeamento de parágrafos em relação ao mapeamento de sentenças, e um aumento da taxa de erro conforme o tamanho da janela deslizante aumenta.

Como as representações baseadas em janelas de tamanho 5 apresentaram os melhores resultados, foram executados experimentos utilizando o suporte automático neste tipo de mapeamento. Na Tabela 4.26 são apresentados os resultados das representações bag-ofrelated-words com mapeamento de janelas de tamanho 5 e da representação bag-of-words.

Na Tabela 4.27 são apresentados os resultados da representação bag-of-words e das representações bag-of-related-words com medidas de interesse objetivas que obtiveram a menor taxa de erro de classificação para ao menos uma das coleções da ACM. As representações com medidas de interesse objetivas apresentaram os melhores resultados em 1 das 8 coleções (ACM-7). O uso das medidas de interesse objetivas piorou os resultados para a coleção ACM-3, porém, em algumas situações melhorou os resultados das coleções ACM-1, ACM-2, ACM-4, ACM-6, ACM-7 e ACM-8.

Vale ressaltar que para algumas representações, como [Jan. 5 Aut. Conf. 0,50\%] e [Jan. 5 Aut. Corr. 0,50\%], a redução do número de atributos foi de aproximadamente $80 \%$ para a coleção ACM-7, e ainda assim foi obtida uma taxa de erro menor que a representação bag-of-words.

Para verificar se os limiares das medidas de interesse objetivas utilizadas produziram diferenças estatisticamente significantes na taxa de erro, foi aplicado o teste de Friedman 


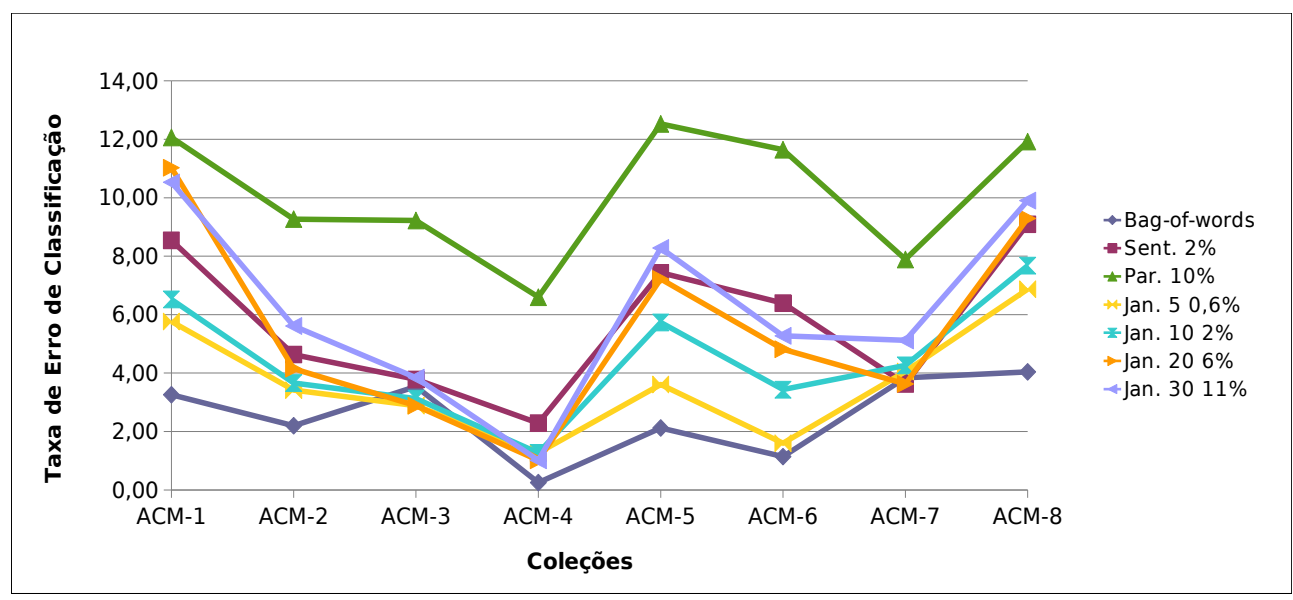

(a)

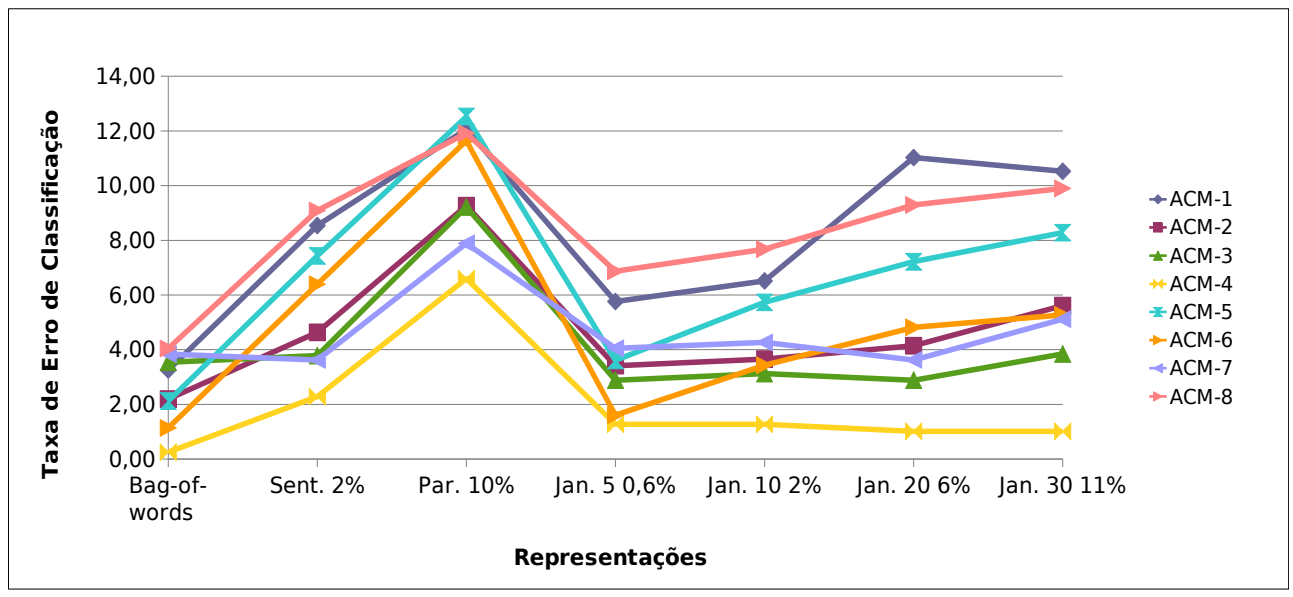

(b)

Figura 4.9: $S M O$ - (a) taxas de erro de classificação das representações bag-of-related-words com diferentes formas de mapeamento e da representação bag-of-words para as coleções da ACM; (b) taxas de erro de classificação das coleções da ACM para as representações bag-of-related-words com diferentes formas de mapeamento e a representação bag-of-words.

Tabela 4.26: $S M O$ - taxas de erro das representações bag-of-related-words com mapeamento de janela de tamanho 5 e da representação bag-of-words para as coleções da ACM.

\begin{tabular}{|c|c|c|c|c|c|c|c|c|}
\hline & \multicolumn{8}{|c|}{ Taxa de Erro } \\
\hline Representação & ACM-1 & ACM-2 & ACM-3 & ACM-4 & ACM-5 & ACM-6 & ACM-7 & ACM-8 \\
\hline Bag-of-words & $\begin{array}{l}* \mathbf{3 , 2 6} \\
\pm 0,32\end{array}$ & $\begin{array}{l}\boldsymbol{*}_{\mathbf{2}, \mathbf{2 0}} \\
\pm 0,32\end{array}$ & $\begin{array}{c}3,54 \\
\pm 0,32\end{array}$ & $\begin{array}{l}\boldsymbol{*} \mathbf{0 , 2 5} \\
\pm 0,32\end{array}$ & $\begin{array}{l}\boldsymbol{*}_{\mathbf{2}, \mathbf{1 2}} \\
\pm 0,32\end{array}$ & $\begin{array}{l}* \mathbf{1}, \mathbf{1 4} \\
\pm 0,32\end{array}$ & $\begin{array}{c}3,84 \\
\pm 0,32\end{array}$ & $\begin{array}{r}* \mathbf{4 , 0 4} \\
\pm 0,32\end{array}$ \\
\hline Jan. 5 Aut. & $\begin{array}{c}5,26 \\
\pm 0,32\end{array}$ & $\begin{array}{c}3,66 \\
\pm 0,31\end{array}$ & $\begin{array}{c}3,13 \\
\pm 0,31\end{array}$ & $\begin{array}{c}1,52 \\
\pm 0,31\end{array}$ & $\begin{array}{c}2,55 \\
\pm 0,31\end{array}$ & $\begin{array}{c}2,52 \\
\pm 0,31\end{array}$ & $\begin{array}{c}3,20 \\
\pm 0,31\end{array}$ & $\begin{array}{l}7,07 \\
\pm 0,32\end{array}$ \\
\hline Jan. $50,6 \%$ & $\begin{array}{c}5,76 \\
\pm 0,32\end{array}$ & $\begin{array}{c}3,41 \\
\pm 0,32\end{array}$ & $\begin{array}{l}\boldsymbol{*} \mathbf{2 , 8 8} \\
\pm 0,32\end{array}$ & $\begin{array}{c}1,27 \\
\pm 0,32\end{array}$ & $\begin{array}{c}3,61 \\
\pm 0,32\end{array}$ & $\begin{array}{c}1,60 \\
\pm 0,32\end{array}$ & $\begin{array}{c}4,05 \\
\pm 0,32\end{array}$ & $\begin{array}{l}6,87 \\
\pm 0,32\end{array}$ \\
\hline Jan. $50,8 \%$ & $\begin{array}{c}6,02 \\
\pm 0,32\end{array}$ & $\begin{array}{c}2,93 \\
\pm 0,32\end{array}$ & $\begin{array}{l}\boldsymbol{*}_{\mathbf{2}, \mathbf{8 8}} \\
\pm 0,32\end{array}$ & $\begin{array}{c}1,27 \\
\pm 0,32\end{array}$ & $\begin{array}{c}3,61 \\
\pm 0,32\end{array}$ & $\begin{array}{c}2,29 \\
\pm 0,32\end{array}$ & $\begin{array}{c}3,41 \\
\pm 0,32\end{array}$ & $\begin{array}{l}7,88 \\
\pm 0,32\end{array}$ \\
\hline Jan. $51 \%$ & $\begin{array}{c}6,27 \\
\pm 0,32\end{array}$ & $\begin{array}{c}2,93 \\
\pm 0,32\end{array}$ & $\begin{array}{c}3,13 \\
\pm 0,32\end{array}$ & $\begin{array}{c}1,52 \\
\pm 0,32\end{array}$ & $\begin{array}{c}5,31 \\
\pm 0,32\end{array}$ & $\begin{array}{c}2,75 \\
\pm 0,32\end{array}$ & $\begin{array}{c}3,41 \\
\pm 0,32\end{array}$ & $\begin{array}{c}6,87 \\
\pm 0,32 \\
\end{array}$ \\
\hline Jan. $52 \%$ & $\begin{array}{c}10,78 \\
\pm 0,32\end{array}$ & $\begin{array}{c}2,93 \\
\pm 0,32\end{array}$ & $\begin{array}{c}4,33 \\
\pm 0,32\end{array}$ & $\begin{array}{c}1,27 \\
\pm 0,32\end{array}$ & $\begin{array}{c}9,34 \\
\pm 0,32\end{array}$ & $\begin{array}{c}5,26 \\
\pm 0,32\end{array}$ & $\begin{array}{l}\boldsymbol{*}_{\mathbf{2}, \mathbf{7 7}} \\
\pm 0,32\end{array}$ & $\begin{array}{l}9,90 \\
\pm 0,32\end{array}$ \\
\hline Jan. $53 \%$ & $\begin{array}{l}12,53 \\
\pm 0,33\end{array}$ & $\begin{array}{c}5,12 \\
\pm 0,32\end{array}$ & $\begin{array}{c}4,09 \\
\pm 0,32\end{array}$ & $\begin{array}{c}3,05 \\
\pm 0,32\end{array}$ & $\begin{array}{c}9,34 \\
\pm 0,32\end{array}$ & $\begin{array}{c}3,66 \\
\pm 0,32\end{array}$ & $\begin{array}{c}3,84 \\
\pm 0,32\end{array}$ & $\begin{array}{l}11,11 \\
\pm 0,32\end{array}$ \\
\hline
\end{tabular}

considerando os resultados das 8 coleções da ACM. Não foi obtida nenhuma diferença estatisticamente significante para a variação dos limiares das medidas de interesse objetivas. Foram então comparadas as representações com diferentes medidas de interesse objetivas utilizando a média como limiar e a representação bag-of-words. Somente a representação 
Tabela 4.27: SMO - taxas de erro da representação bag-of-words e das representações bag-of-related-words com medidas de interesse objetivas que obtiveram a menor taxa de erro para as coleções da ACM.

\begin{tabular}{|c|c|c|c|c|c|c|c|c|}
\hline & \multicolumn{8}{|c|}{ Taxa de Erro } \\
\hline Representação & ACM-1 & ACM-2 & ACM-3 & ACM-4 & ACM-5 & ACM-6 & ACM-7 & ACM-8 \\
\hline \multirow{2}{*}{ Bag-of-words } & $* 3,26$ & $* 2,20$ & $* 3,54$ & $* 0,25$ & $* 2,12$ & $* 1,14$ & 3,84 & $* 4,04$ \\
\hline & $\pm 0,32$ & $\pm 0,32$ & $\pm 0,32$ & $\pm 0,32$ & $\pm 0,32$ & $\pm 0,32$ & $\pm 0,32$ & $\pm 0,32$ \\
\hline \multirow{2}{*}{ Jan. 5 Aut. Conf. 0,25 } & 5,26 & 3,41 & 4,09 & 1,52 & 3,40 & 2,29 & $* 2,77$ & 8,08 \\
\hline & $\pm 0,32$ & $\pm 0,32$ & $\pm 0,32$ & $\pm 0,32$ & $\pm 0,32$ & $\pm 0,32$ & $\pm 0,32$ & $\pm 0,32$ \\
\hline \multirow{2}{*}{ Jan. 5 Aut. Conf. 0,5 } & 5,01 & 4,39 & 4,33 & 1,52 & 3,18 & 2,06 & $* 2,77$ & 7,68 \\
\hline & $\pm 0,32$ & $\pm 0,32$ & $\pm 0,32$ & $\pm 0,32$ & $\pm 0,32$ & $\pm 0,32$ & $\pm 0,32$ & $\pm 0,32$ \\
\hline \multirow{2}{*}{ Jan. 5 Aut. Yule's Q ${ }^{\bar{x}}$} & 5,26 & 3,41 & 4,57 & 1,78 & 2,76 & 2,29 & $* 2,77$ & 7,07 \\
\hline & $\pm 0,32$ & $\pm 0,32$ & $\pm 0,32$ & $\pm 0,32$ & $\pm 0,32$ & $\pm 0,32$ & $\pm 0,32$ & $\pm 0,32$ \\
\hline \multirow{2}{*}{ Jan. 5 Aut. Corr. 0,50 } & 5,26 & 3,90 & 4,33 & 1,52 & 3,18 & 2,29 & $* 2,77$ & 7,68 \\
\hline & $\pm 0,32$ & $\pm 0,32$ & $\pm 0,32$ & $\pm 0,32$ & $\pm 0,32$ & $\pm 0,32$ & $\pm 0,32$ & $\pm 0,32$ \\
\hline \multirow{2}{*}{ Jan. 5 Aut. I.M. 0,005 } & 5,26 & 3,41 & 4,33 & 1,78 & 2,76 & 2,97 & $* 2,77$ & 6,67 \\
\hline & $\pm 0,32$ & $\pm 0,32$ & $\pm 0,32$ & $\pm 0,32$ & $\pm 0,32$ & $\pm 0,32$ & $\pm 0,32$ & $\pm 0,32$ \\
\hline
\end{tabular}

utilizando a medida objetiva Gini apresentou resultados estatisticamente inferiores à representação bag-of-words.

Na Figura 4.10 é apresentada uma comparação gráfica entre as representações bagof-related-words que utilizaram medidas de interesse objetivas com limiares baseados na média e a representação bag-of-words. Analisando os gráficos da Figura 4.10(a) pode-se observar que todas as medidas de interesse objetivas apresentaram um comportamento similar quanto à taxa de erro de classificação, e pela Figura 4.10(b) pode-se observar que nenhuma medida objetiva se sobressaiu em relação às demais.

Para a coleção Reuters-21578, 11 das 25 representações bag-of-related-words obtiveram uma taxa de erro menor que representação bag-of-words. A menor taxa de erro foi obtida pela representação [Jan. 5 Aut. Kappa 0,50\%]. O erro obtido foi de 22,90\%, sendo 1,0\% menor que o obtido pela representação bag-of-words e com uma quantidade de atributos aproximadamente $18 \%$ menor. Vale ressaltar que representações como [Jan. 5 Aut. Lift $\bar{x}$ ], [Jan. 5 Aut. I.M. $\bar{x}$ ], e [Jan. 5 Aut. Kappa 0,50\%] reduziram a quantidade de atributos em aproximadamente $20 \%$ e obtiveram uma taxa de erro menor que da representação bagof-words.

Tabela 4.28: SMO - taxas de erro da representação bag-of-words e das representações bag-of-related-words com medidas de interesse objetivas e limiares baseados na média para a coleção Reuters-21578.

\begin{tabular}{|l|r|}
\hline Representação & Taxa de Erro \\
\hline Bag-of-words & 23,32 \\
\hline Jan. 5 Aut. & 23,32 \\
\hline Jan. 5 Aut. Lift $\bar{x}$ & 23,21 \\
\hline Jan. 5 Aut. Conf. $\bar{x}$ & 24,05 \\
\hline Jan. 5 Aut. Yule's Q $\bar{x}$ & 23,53 \\
\hline Jan. 5 Aut. Corr. $\bar{x}$ & 23,63 \\
\hline Jan. 5 Aut. I.M. $\bar{x}$ & 23,21 \\
\hline Jan. 5 Aut. Gini $\bar{x}$ & 23,21 \\
\hline Jan. 5 Aut. Kappa $\bar{x}$ & 23,00 \\
\hline Jan. 5 Aut. J.M. $\bar{x}$ & 23,00 \\
\hline
\end{tabular}

De acordo com os resultados obtidos, a representação bag-of-related-words se mostrou adequada para a utilização do método de classificação $S M O$, uma vez que não houve evidências que a representação bag-of-words foi melhor que a bag-of-related-words para as coleções da ACM. Vale ressaltar que atributos como nomes de autores, locais e nomes de conferências podem ter influenciado os resultados à favor da representação bag-of-words novamente, um vez que os vetores de suporte utilizados podem conter esses atributos e com isso obter hiperplanos que separam melhor os documentos textuais. Já para a 


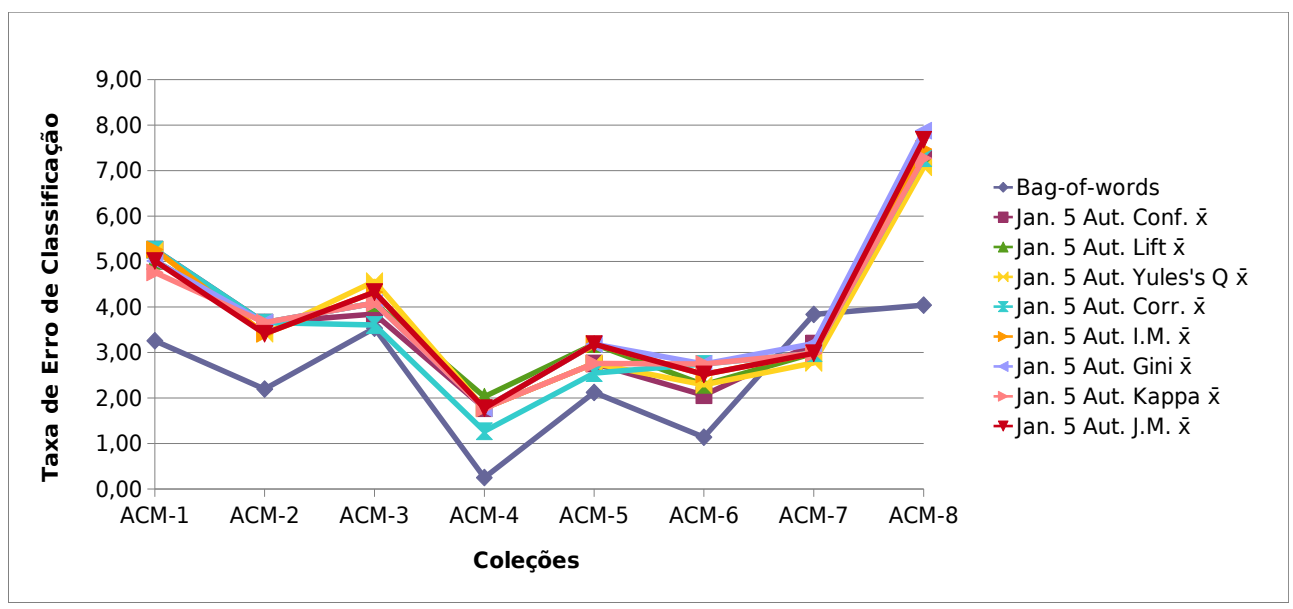

(a)

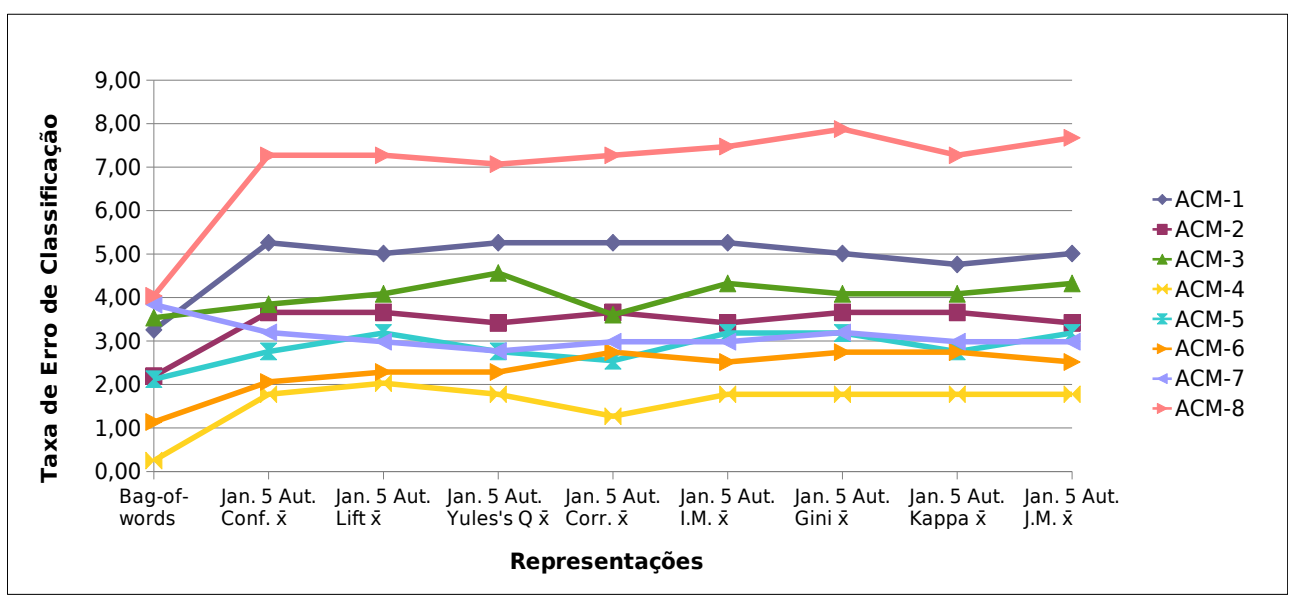

(b)

Figura 4.10: $S M O$ - (a) taxas de erro de classificação das representações bag-of-related-words com diferentes medidas de interesse objetivas e da representação bag-of-words para as coleções da ACM; (b) taxas de erro de classificação das coleções da ACM para as representações bag-of-related-words com diferentes medidas de interesse objetivas e a representação bag-of-words.

coleção Reuters-21578, novamente a abordagem proposta obteve a menor taxa de erro de classificação. O mapeamento por parágrafos não foi adequado para este método de classificação, enquanto que as janelas de tamanho 5 obtiveram os melhores resultados para a representação bag-of-related-words. O uso de medidas de interesse objetivas, apesar de aumentar a taxa de erro de classificação para uma coleção, conseguiu diminuir o erro e o número de atributos para a maioria das coleções.

\section{$K N N$}

Nesta seção são apresentados alguns dos resultados obtidos pelo algoritmo de classificação KNN (K-Nearest Neighbors) utilizando as representações bag-of-related-words e bag-of-words. Para este algoritmo foi implementada a distância cosseno, que é uma medida aconselhável para medir a similaridade de documentos representados no espaço vetorial, e o valor de $K$ foi definido em 7, seguindo as indicações de Furtado (2009).

Na Tabela 4.29 são apresentados os resultados da representação bag-of-words e das representações bag-of-related-words com diferentes formas de mapeamento que obtiveram a menor taxa de erro para ao menos uma das coleções da ACM. Foram considerados apenas os itemsets frequentes como atributos das representações bag-of-related-words. Foram 
obtidas a menor taxa de erro de classificação em 4 de 8 coleções (ACM-2, ACM-4, ACM$5, \mathrm{ACM}-7)$.

Tabela 4.29: KNN - taxas de erro da representação bag-of-words e das representações bag-of-related-words com itemsets frequentes como atributos que obtiveram a menor taxa de erro para as coleções da ACM.

\begin{tabular}{|c|c|c|c|c|c|c|c|c|}
\hline & \multicolumn{8}{|c|}{ Taxa de Erro } \\
\hline Representação & ACM-1 & ACM-2 & ACM-3 & ACM-4 & ACM-5 & ACM-6 & ACM-7 & ACM-8 \\
\hline Bag-of-words & $\begin{array}{c}\boldsymbol{*}_{\mathbf{1 0 , 0 2}} \\
\pm 0,06\end{array}$ & $\begin{array}{c}7,32 \\
\pm 0,04\end{array}$ & $\begin{array}{l}* \mathbf{4 , 9 6} \\
\pm 0,03\end{array}$ & $\begin{array}{c}2,04 \\
\pm 0,02\end{array}$ & $\begin{array}{c}5,74 \\
\pm 0,03\end{array}$ & $\begin{array}{l}* \mathbf{1 , 8 2} \\
\pm 0,03\end{array}$ & $\begin{array}{c}6,18 \\
\pm 0,03\end{array}$ & $\begin{array}{r}* \mathbf{4 , 4 4} \\
\pm 0,03\end{array}$ \\
\hline Jan. $50,8 \%$ & $\begin{array}{l}11,27 \\
\pm 0,05\end{array}$ & $\begin{array}{c}7,56 \\
\pm 0,03\end{array}$ & $\begin{array}{c}6,22 \\
\pm 0,05\end{array}$ & $\begin{array}{c}1,27 \\
\pm 0,01\end{array}$ & $\begin{array}{l}\boldsymbol{*}_{\mathbf{4}, \mathbf{8 9}} \\
\pm 0,04\end{array}$ & $\begin{array}{c}4,57 \\
\pm 0,03\end{array}$ & $\begin{array}{c}7,46 \\
\pm 0,04\end{array}$ & $\begin{array}{l}9,11 \\
\pm 0,03\end{array}$ \\
\hline Jan. $51 \%$ & $\begin{array}{l}11,53 \\
\pm 0,04\end{array}$ & $\begin{array}{c}7,80 \\
\pm 0,05\end{array}$ & $\begin{array}{c}5,77 \\
\pm 0,04\end{array}$ & $\begin{array}{l}\boldsymbol{*} \mathbf{1 , 0 1} \\
\pm 0,02\end{array}$ & $\begin{array}{c}5,52 \\
\pm 0,02\end{array}$ & $\begin{array}{c}3,44 \\
\pm 0,02\end{array}$ & $\begin{array}{c}7,03 \\
\pm 0,04\end{array}$ & $\begin{array}{l}9,88 \\
\pm 0,05\end{array}$ \\
\hline Jan. $52 \%$ & $\begin{array}{l}16,51 \\
\pm 0,08\end{array}$ & $\begin{array}{l}\boldsymbol{*} \mathbf{5 , 6 1} \\
\pm 0,03\end{array}$ & $\begin{array}{c}6,46 \\
\pm 0,04\end{array}$ & $\begin{array}{c}2,27 \\
\pm 0,02\end{array}$ & $\begin{array}{c}9,14 \\
\pm 0,05\end{array}$ & $\begin{array}{c}4,37 \\
\pm 0,03\end{array}$ & $\begin{array}{l}* \mathbf{4 , 9 0} \\
\pm 0,03\end{array}$ & $\begin{array}{l}12,76 \\
\pm 0,07\end{array}$ \\
\hline
\end{tabular}

As representações baseadas no mapeamento de janela deslizante de tamanho 5 obtiveram os melhores resultados em relação aos outros tipos de mapeamento analisados. A representação [Jan. 5 0,8\%] e [Jan. 5 1\%] obtiveram a menor taxa de erro para uma coleção cada (ACM-5 e ACM-4 respectivamente), e a representação [Jan. 5 2\%] obteve a menor taxa de erro para as coleções ACM-2 e ACM-7, com uma redução do número de atributos em relação à bag-of-words de $83 \%$ e $86 \%$ respectivamente.

Para verificar como a variação do suporte mínimo afetou as taxas de erro obtidas para os diversos tipos de mapeamento utilizados, foi aplicado o teste de Friedman para cada tipo de mapeamento considerando os resultados das 8 coleções da ACM. Na Tabela 4.30 são apresentados os resultados dos testes estatísticos. Pode-se notar que houve diferença com significância estatística nos resultados dos diverentes valores de suporte mínimo utilizados quando foram consideradas sentenças, parágrafos, e janelas de tamanho 5 e 10 . As diferenças foram obtidas dos menores para os maiores valores de suporte. Já as janelas de tamanho 20 e 30 não apresentaram diferenças estatísticas significantes para a variação do suporte mínimo.

Tabela 4.30: KNN - resultado do teste estatístico para avaliar o impacto na taxa de erro de classificação causado pela variação do suporte mínimo para as diferentes formas de mapeamento nas coleções da ACM.

\begin{tabular}{|c|c|c|c|c|c|}
\multicolumn{1}{c|}{ Sentenças } \\
\cline { 2 - 6 } \multicolumn{1}{c|}{} & $2 \%$ & $3 \%$ & $4 \%$ & $5 \%$ & $6 \%$ \\
\hline $2 \%$ & - & $\bullet$ & $\boldsymbol{\Delta}$ & $\boldsymbol{\Delta}$ & $\boldsymbol{\Delta}$ \\
\hline $3 \%$ & $\bullet$ & - & $\boldsymbol{\Delta}$ & $\boldsymbol{\Delta}$ & $\boldsymbol{\Delta}$ \\
\hline $4 \%$ & $\mathbf{\nabla}$ & $\mathbf{\nabla}$ & - & $\boldsymbol{\Delta}$ & $\boldsymbol{\Delta}$ \\
\hline $5 \%$ & $\mathbf{\nabla}$ & $\mathbf{\nabla}$ & $\mathbf{\nabla}$ & - & $\boldsymbol{\Delta}$ \\
\hline $6 \%$ & $\mathbf{\nabla}$ & $\mathbf{\nabla}$ & $\mathbf{\nabla}$ & $\mathbf{\nabla}$ & - \\
\hline
\end{tabular}

\begin{tabular}{|c|c|c|c|c|c|}
\multicolumn{1}{c}{} & Janela 5 \\
\cline { 2 - 6 } \multicolumn{1}{c|}{} & $0,6 \%$ & $0,8 \%$ & $1 \%$ & $2 \%$ & $3 \%$ \\
\hline $0,6 \%$ & - & $\bullet$ & $\bullet$ & $\bullet$ & $\boldsymbol{\Delta}$ \\
\hline $0,8 \%$ & $\bullet$ & - & $\bullet$ & $\bullet$ & $\boldsymbol{\Delta}$ \\
\hline $1 \%$ & $\bullet$ & $\bullet$ & - & $\bullet$ & $\boldsymbol{\Delta}$ \\
\hline $2 \%$ & $\bullet$ & $\bullet$ & $\bullet$ & - & $\bullet$ \\
\hline $3 \%$ & $\mathbf{\nabla}$ & $\mathbf{\nabla}$ & $\mathbf{\nabla}$ & $\bullet$ & - \\
\hline
\end{tabular}

\begin{tabular}{|c|c|c|c|c|c|}
\cline { 2 - 6 } \multicolumn{1}{c|}{} & $6 \%$ & $7 \%$ & $8 \%$ & $9 \%$ & $10 \%$ \\
\hline $6 \%$ & - & $\bullet$ & $\bullet$ & $\bullet$ & $\bullet$ \\
\hline $7 \%$ & $\bullet$ & - & $\bullet$ & $\bullet$ & $\bullet$ \\
\hline $8 \%$ & $\bullet$ & $\bullet$ & - & $\bullet$ & $\bullet$ \\
\hline $9 \%$ & $\bullet$ & $\bullet$ & $\bullet$ & - & $\bullet$ \\
\hline $10 \%$ & $\bullet$ & $\bullet$ & $\bullet$ & $\bullet$ & - \\
\hline
\end{tabular}

\begin{tabular}{|c|c|c|c|c|c|}
\cline { 2 - 6 } \multicolumn{1}{c|}{} & $10 \%$ & $11 \%$ & $12 \%$ & $13 \%$ & $14 \%$ \\
\hline $10 \%$ & - & $\bullet$ & $\bullet$ & $\Delta$ & $\Delta$ \\
\hline $11 \%$ & $\bullet$ & - & $\bullet$ & $\bullet$ & $\Delta$ \\
\hline $12 \%$ & $\bullet$ & $\bullet$ & - & $\bullet$ & $\Delta$ \\
\hline $13 \%$ & $\mathbf{\nabla}$ & $\bullet$ & $\bullet$ & - & $\bullet$ \\
\hline $14 \%$ & $\mathbf{\nabla}$ & $\mathbf{\nabla}$ & $\mathbf{\nabla}$ & $\bullet$ & - \\
\hline
\end{tabular}

\begin{tabular}{|c|c|c|c|c|c|}
\multicolumn{5}{c|}{ Janela 10} \\
\cline { 2 - 6 } \multicolumn{1}{c|}{} & $2 \%$ & $3 \%$ & $4 \%$ & $5 \%$ & $6 \%$ \\
\hline $2 \%$ & - & $\bullet$ & $\bullet$ & $\bullet$ & $\Delta$ \\
\hline $3 \%$ & $\bullet$ & - & $\bullet$ & $\bullet$ & $\Delta$ \\
\hline $4 \%$ & $\bullet$ & $\bullet$ & - & $\bullet$ & $\bullet$ \\
\hline $5 \%$ & $\bullet$ & $\bullet$ & $\bullet$ & - & $\bullet$ \\
\hline $6 \%$ & $\mathbf{V}$ & $\mathbf{\nabla}$ & $\bullet$ & $\bullet$ & - \\
\hline
\end{tabular}

\begin{tabular}{|c|c|c|c|c|c|}
\multicolumn{7}{c}{ Janela 30} \\
\cline { 2 - 6 } \multicolumn{1}{c|}{} & $10 \%$ & $11 \%$ & $12 \%$ & $13 \%$ & $14 \%$ \\
\hline $10 \%$ & - & $\bullet$ & $\bullet$ & $\bullet$ & $\bullet$ \\
\hline $11 \%$ & $\bullet$ & - & $\bullet$ & $\bullet$ & $\bullet$ \\
\hline $12 \%$ & $\bullet$ & $\bullet$ & - & $\bullet$ & $\bullet$ \\
\hline $13 \%$ & $\bullet$ & $\bullet$ & $\bullet$ & - & $\bullet$ \\
\hline $14 \%$ & $\bullet$ & $\bullet$ & $\bullet$ & $\bullet$ & - \\
\hline
\end{tabular}

Para analisar os resultados obtidos pelos diferentes tipos de mapeamento e comparar com a representação bag-of-words, foram escolhidos os melhores valores de suporte mín- 
imo para cada tipo de mapeamento: [Sent. 2\%], [Par. 10\%], [Jan. 5 1\%], [Jan. 10 2\%], [Jan. 20 7\%], [Jan. 30 10\%]. Na Tabela 4.31 são apresentados os resultados dos testes estatísticos utilizando estas representações. Pode-se notar que as representações [Jan. 5 1\%], [Jan. 10 2\%], e [Jan. 20 7\%] não apresentaram resultados com diferenças estatisticamente significantes em relação à representação bag-of-words. Entretanto, o uso de sentenças, parágrafos e a janela deslizante de tamanho 30 como transações apresentaram piores resultados com diferenças estatisticamente significantes.

Tabela 4.31: KNN - resultado do teste estatístico para comparar a taxa de erro de classificação nas coleções ACM obtidas pela representação bag-of-words e pelas representações bag-of-related-words com diferentes formas de mapeamento.

\begin{tabular}{|c|c|c|c|c|c|c|c|}
\hline & Bag-of-words & Sent. $2 \%$ & Par. $10 \%$ & Jan. $51 \%$ & Jan. $102 \%$ & Jan. $207 \%$ & Jan. $3010 \%$ \\
\hline Bag-of-words & - & $\Delta$ & $\Delta$ & $\bullet$ & $\bullet$ & $\bullet$ & $\Delta$ \\
\hline Sent. $2 \%$ & $\boldsymbol{\nabla}$ & - & - & $\bullet$ & $\bullet$ & - & $\bullet$ \\
\hline Par. $10 \%$ & $\nabla$ & 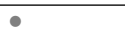 & - & $\nabla$ & $\boldsymbol{\nabla}$ & $\bullet$ & $\bullet$ \\
\hline Jan. $51 \%$ & - & $\bullet$ & $\Delta$ & - & $\bullet$ & $\bullet$ & $\bullet$ \\
\hline Jan. $102 \%$ & - & $\bullet$ & $\Delta$ & $\bullet$ & - & $\bullet$ & $\bullet$ \\
\hline Jan. $207 \%$ & $\bullet$ & $\bullet$ & • & $\bullet$ & $\bullet$ & - & $\bullet$ \\
\hline Jan. $3010 \%$ & $\boldsymbol{\nabla}$ & $\bullet$ & $\bullet$ & $\bullet$ & $\bullet$ & $\bullet$ & - \\
\hline
\end{tabular}

Na Figura 4.11 é apresentada uma comparação gráfica das taxas de erro obtidas pelas melhores representações bag-of-related-words com diferentes tipos de mapeamento e a representação bag-of-words. Analisando o gráfico da Figura 4.5(a), pode-se notar que todos os tipos de mapeamento utilizados tiveram um comportamento similar em relação à taxa de erro de classificação. Pela Figura 4.11(b), observam-se várias situações que há uma aumento da taxa de erro obtido pelo mapeamento de parágrafos em relação ao mapeamento de sentenças, e um aumento da taxa de erro conforme o tamanho da janela deslizante aumenta.

Como as representações baseadas em janelas de tamanho 5 apresentaram os melhores resultados também para o algoritmo de classificação $K N N$, foi gerada uma representação utilizando suporte automático para este tipo de mapeamento. Na Tabela 4.32 são apresentados os resultados das representações bag-of-related-words com mapeamento de janela 5 e da representação bag-of-words. Observam-se que os resultados obtidos utilizando o suporte automático foram tão bons quanto os obtidos utilizando valores de suporte mínimos definidos manualmente. Inclusive foram obtidas as menores taxas de erro de classificação para 3 coleções da ACM. Foram então utilizadas as medidas de interesse objetivas no mapeamento de janela deslizante de tamanho 5 com suporte mínimo automático para as coleções da ACM e Reuters-21578.

Tabela 4.32: KNN - taxas de erro das representações bag-of-related-words com mapeamento de janela de tamanho 5 e da representação bag-of-words para as coleções da ACM.

\begin{tabular}{|c|c|c|c|c|c|c|c|c|}
\hline & \multicolumn{8}{|c|}{ Taxa de Erro } \\
\hline Representação & ACM-1 & ACM-2 & ACM-3 & ACM-4 & ACM-5 & ACM-6 & ACM-7 & ACM-8 \\
\hline Bag-of-words & $\begin{array}{l}10,02 \\
\pm 0,06\end{array}$ & $\begin{array}{c}7,32 \\
\pm 0,04\end{array}$ & $\begin{array}{l}\boldsymbol{*}_{\mathbf{4}, \mathbf{9 6}} \\
\pm 0,03\end{array}$ & $\begin{array}{c}2,04 \\
\pm 0,02\end{array}$ & $\begin{array}{c}5,74 \\
\pm 0,03\end{array}$ & $\begin{array}{l}\boldsymbol{*}_{\mathbf{1}, \mathbf{8 2}} \\
\pm 0,03\end{array}$ & $\begin{array}{c}6,18 \\
\pm 0,03\end{array}$ & $\begin{array}{r}* \mathbf{4}, \mathbf{4 4} \\
\pm 0,03\end{array}$ \\
\hline Jan. 5 Aut. & $\begin{array}{c}* \mathbf{1 0 , 0 0} \\
\pm 0,05\end{array}$ & $\begin{array}{c}6,83 \\
\pm 0,03\end{array}$ & $\begin{array}{c}6,27 \\
\pm 0,05\end{array}$ & $\begin{array}{l}\boldsymbol{*}_{\mathbf{1}, \mathbf{0 1}} \\
\pm 0,01\end{array}$ & $\begin{array}{l}\boldsymbol{*}_{\mathbf{4}, \mathbf{2 4}} \\
\pm 0,03\end{array}$ & $\begin{array}{c}2,75 \\
\pm 0,03\end{array}$ & $\begin{array}{c}4,92 \\
\pm 0,03\end{array}$ & $\begin{array}{l}8,31 \\
\pm 0,06\end{array}$ \\
\hline Jan. $50,6 \%$ & $\begin{array}{l}14,04 \\
\pm 0,07\end{array}$ & $\begin{array}{c}9,76 \\
\pm 0,04\end{array}$ & $\begin{array}{c}5,06 \\
\pm 0,04\end{array}$ & $\begin{array}{c}1,02 \\
\pm 0,01\end{array}$ & $\begin{array}{c}5,94 \\
\pm 0,03\end{array}$ & $\begin{array}{c}5,95 \\
\pm 0,05\end{array}$ & $\begin{array}{c}6,83 \\
\pm 0,05\end{array}$ & $\begin{array}{l}8,89 \\
\pm 0,03\end{array}$ \\
\hline Jan. $50,8 \%$ & $\begin{array}{l}11,27 \\
\pm 0,05\end{array}$ & $\begin{array}{c}7,56 \\
\pm 0,03\end{array}$ & $\begin{array}{c}6,22 \\
\pm 0,05\end{array}$ & $\begin{array}{c}1,27 \\
\pm 0,01\end{array}$ & $\begin{array}{c}4,89 \\
\pm 0,04\end{array}$ & $\begin{array}{c}4,57 \\
\pm 0,03\end{array}$ & $\begin{array}{c}7,46 \\
\pm 0,04\end{array}$ & $\begin{array}{l}9,11 \\
\pm 0,03\end{array}$ \\
\hline Jan. $51 \%$ & $\begin{array}{l}11,53 \\
\pm 0,04\end{array}$ & $\begin{array}{c}7,80 \\
\pm 0,05\end{array}$ & $\begin{array}{c}5,77 \\
\pm 0,04\end{array}$ & $\begin{array}{l}\boldsymbol{*}_{\mathbf{1}, \mathbf{0 1}} \\
\pm 0,02\end{array}$ & $\begin{array}{c}5,52 \\
\pm 0,02\end{array}$ & $\begin{array}{c}3,44 \\
\pm 0,02\end{array}$ & $\begin{array}{c}7,03 \\
\pm 0,04\end{array}$ & $\begin{array}{l}9,88 \\
\pm 0,05\end{array}$ \\
\hline Jan. $52 \%$ & $\begin{array}{l}16,51 \\
\pm 0,08\end{array}$ & $\begin{array}{l}* \mathbf{5 , 6 1} \\
\pm 0,03\end{array}$ & $\begin{array}{c}6,46 \\
\pm 0,04\end{array}$ & $\begin{array}{c}2,27 \\
\pm 0,02\end{array}$ & $\begin{array}{c}9,14 \\
\pm 0,05\end{array}$ & $\begin{array}{c}4,37 \\
\pm 0,03\end{array}$ & $\begin{array}{l}\boldsymbol{*}_{\mathbf{4}, \mathbf{9 0}} \\
\pm 0,03\end{array}$ & $\begin{array}{l}12,76 \\
\pm 0,07\end{array}$ \\
\hline Jan. $53 \%$ & $\begin{array}{l}15,54 \\
\pm 0,03\end{array}$ & $\begin{array}{c}7,32 \\
\pm 0,04\end{array}$ & $\begin{array}{c}5,82 \\
\pm 0,05\end{array}$ & $\begin{array}{c}1,79 \\
\pm 0,02\end{array}$ & $\begin{array}{l}12,32 \\
\pm 0,04\end{array}$ & $\begin{array}{c}7,54 \\
\pm 0,04\end{array}$ & $\begin{array}{c}6,19 \\
\pm 0,03\end{array}$ & $\begin{array}{l}12,74 \\
\pm 0,03\end{array}$ \\
\hline
\end{tabular}

Na Tabela 4.33 são apresentados os resultados da representação bag-of-words e das 


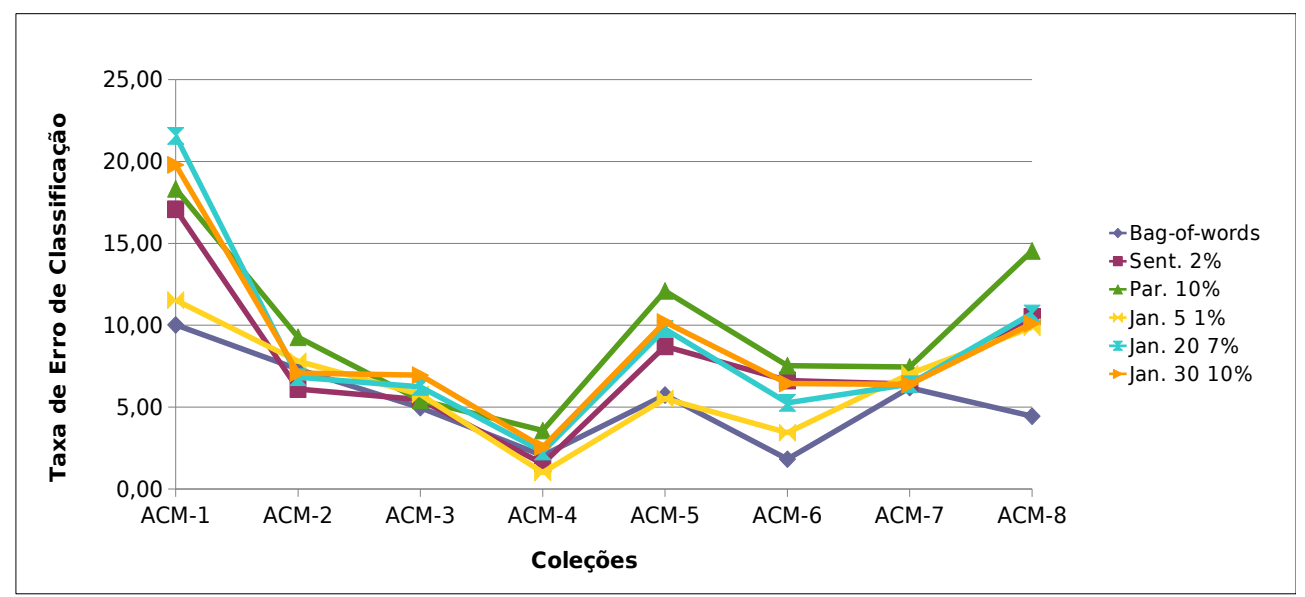

(a)

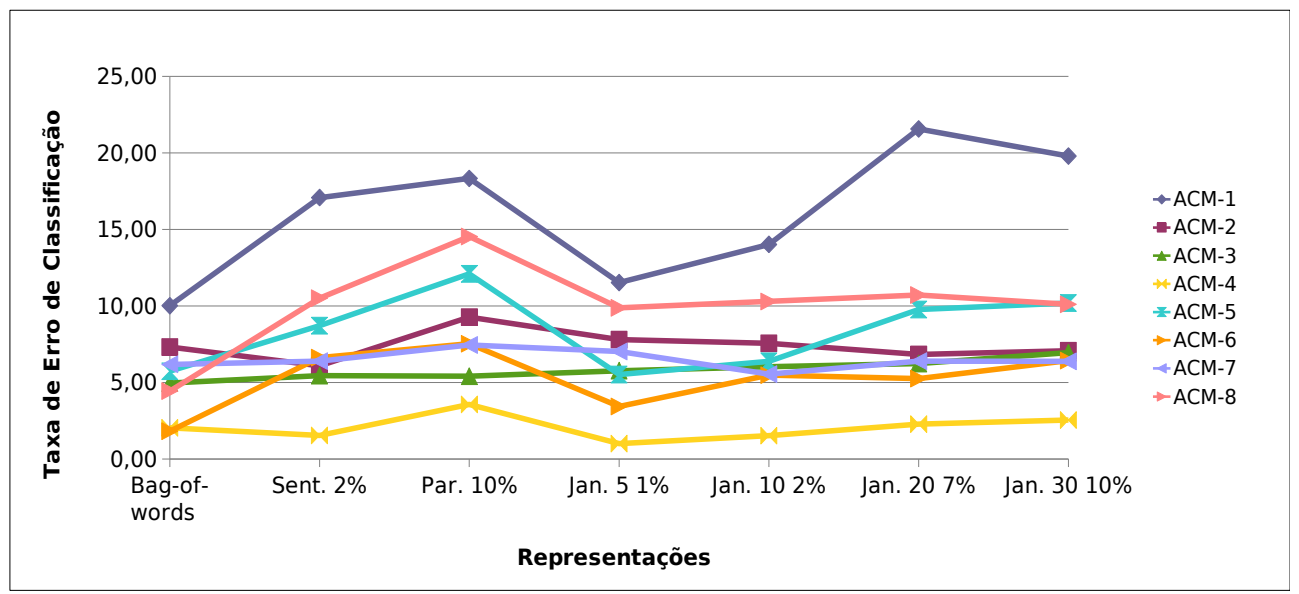

(b)

Figura 4.11: KNN - (a) taxas de erro de classificação das representações bag-of-related-words com diferentes formas de mapeamento e da representação bag-of-words para as coleções da ACM; (b) taxas de erro de classificação das coleções da ACM para as representações bag-of-related-words com diferentes formas de mapeamento e a representação bag-of-words.

representações bag-of-related-words com medidas de interesse objetivas que obtiveram a menor taxa de erro de classificação para ao menos uma das coleções da ACM. As representações utilizando medidas de interesse objetivas obtiveram a menor taxa de erro para 5 das 8 coleções (ACM-1, ACM-2, ACM-3, ACM-4 e ACM-5). O uso de medidas de interesse objetivas melhorou os resultados em relação ao uso somente do suporte para as coleções ACM-1, ACM-3, ACM-4, ACM-5 e ACM-7, inclusive obtendo a menor taxa de erro de classificação para a coleção ACM-1, a qual era obtida pela representação bag-of-words quando eram utilizados somente os itemsets frequentes como atributos das representações bag-of-related-words.

Vale ressaltar que o uso das medidas de interesse objetivas melhorou os resultados e reduziu o número de atributos para a maioria das coleções. Por exemplo, para a coleção ACM-1, o número de atributos em comparação com a bag-of-words foi reduzido em aproximadamente $76 \%$ com a representação [Jan. 5 Aut. Corr. 0,5$]$ e $63 \%$ para a coleção ACM-4 com a representação [Jan. 5 Aut. J.M. $\bar{x}]$.

Para verificar se os limiares das medidas de interesse objetivas utilizadas causaram diferenças significativas nas taxas de erro do algoritmo $K N N$, foi aplicado o teste de Friedman para cada medida objetiva considerando as 8 coleções da ACM. Houve diferença estatisticamente significante somente dos limiares da medida objetiva Kappa. Neste 
Tabela 4.33: KNN - taxas de erro da representação bag-of-words e das representações bag-of-related-words com medidas de interesse objetivas que obtiveram a menor taxa de erro para as coleções da ACM.

\begin{tabular}{|c|c|c|c|c|c|c|c|c|}
\hline \multirow[b]{2}{*}{ Representação } & \multicolumn{8}{|c|}{ Taxa de Erro } \\
\hline & ACM-1 & ACM-2 & ACM-3 & ACM-4 & ACM-5 & ACM-6 & ACM-7 & ACM-8 \\
\hline \multirow{2}{*}{ Bag-of-words } & 10,02 & 7,32 & 4,96 & 2,04 & 5,74 & $* 1,82$ & $* 6,18$ & $* 4,44$ \\
\hline & $\pm 0,06$ & $\pm 0,04$ & $\pm 0,03$ & $\pm 0,02$ & $\pm 0,03$ & $\pm 0,03$ & $\pm 0,03$ & $\pm 0,03$ \\
\hline \multirow{2}{*}{ Jan. 5 Aut. Yule's Q ${ }^{0,5}$} & 11,01 & 8,78 & 6,48 & 0,76 & $* 3,18$ & 3,66 & 6,61 & 8,47 \\
\hline & $\pm 0,06$ & $\pm 0,07$ & $\pm 0,04$ & $\pm 0,01$ & $\pm 0,02$ & $\pm 0,03$ & $\pm 0,02$ & $\pm 0,04$ \\
\hline \multirow{2}{*}{ Jan. 5 Aut. Corr. 0,5 } & $* 8,78$ & 10,49 & 5,49 & 1,27 & 4,65 & 4,13 & 7,25 & 8,69 \\
\hline & $\pm 0,04$ & $\pm 0,04$ & $\pm 0,04$ & $\pm 0,01$ & $\pm 0,04$ & $\pm 0,03$ & $\pm 0,02$ & $\pm 0,04$ \\
\hline \multirow{2}{*}{ Jan. 5 Aut. Corr. $\bar{x}$} & 9,26 & $* 6,83$ & 5,55 & 1,01 & 4,04 & 2,98 & 6,40 & 8,07 \\
\hline & $\pm 0,05$ & $\pm 0,04$ & $\pm 0,04$ & $\pm 0,02$ & $\pm 0,03$ & $\pm 0,02$ & $\pm 0,03$ & $\pm 0,05$ \\
\hline \multirow{2}{*}{ Jan. 5 Aut. J.M. $\bar{x}$} & 11,52 & 8,78 & $* 4,81$ & $* 0,50$ & 4,02 & 4,13 & 7,46 & 9,08 \\
\hline & $\pm 0,04$ & $\pm 0,04$ & $\pm 0,03$ & $\pm 0,02$ & $\pm 0,03$ & $\pm 0,03$ & $\pm 0,03$ & $\pm 0,02$ \\
\hline
\end{tabular}

caso, o limiar obtido utilizando a média apresentou melhores resultados com diferença estatística em relação aos limiares 0,15 e 0,20.

Uma vez que não foram apresentados resultados com diferença estatística dos limiares definidos manualmente em relação ao limiar baseado na média, foram utilizadas as representações com medidas de interesse objetivas e limiares baseados na média para realizar a comparação com a representação bag-of-words. Ao aplicar o teste de Friedman para estas representações, não foram verificadas diferenças estatisticamente significantes.

Na Figura 4.12 é apresentada uma comparação gráfica das taxas de erro obtidas pelas representações bag-of-related-words com medidas de interesse objetivas selecionadas para a comparação com a representação bag-of-words. De acordo com o gráfico da Figura 4.12(a), todas as medidas apresentaram comportamento semelhante quanto à taxa de erro, com exceção da medida objetiva Lift na coleção ACM-2, e da medida Confiança na coleção ACM-8. Pela Figura 4.12(b) observa-se que a medida Lift obteve a maior taxa de erro dentre as medidas de interesse objetivas para a maioria das coleções, enquanto que as medidas de interesse objetivas Correlação e Kappa obtiveram as menores taxas de erro para a maioria das coleções.

Na Tabela 4.34 são apresentados os resultados das representações bag-of-related-words com medidas de interesse objetivas e com limiares baseado na média para a coleção Reuters-21578. Todas as taxas de erro obtidas pelas representações bag-of-related-words foram superiores em relação à representação bag-of-words. A menor taxa de erro da abordagem proposta foi 17,58\%, obtido pela representação [Jan. 5 Aut. Conf. 0,50\%], sendo $2,56 \%$ maior em relação à representação bag-of-words.

Tabela 4.34: KNN - taxas de erro da representação bag-of-words e das representações bag-of-related-words com medidas de interesse objetivas e limiares baseados na média para a coleção Reuters-21578.

\begin{tabular}{|l|r|}
\hline Representação & Taxa de Erro \\
\hline Bag-of-words & $\mathbf{* 1 5 , 0 2}$ \\
\hline Jan. 5 Aut. & 18,29 \\
\hline Jan. 5 Aut. Lift $\bar{x}$ & 18,41 \\
\hline Jan. 5 Aut. Conf. $\bar{x}$ & 18,41 \\
\hline Jan. 5 Aut. Yule's Q $\bar{x}$ & 18,49 \\
\hline Jan. 5 Aut. Corr. $\bar{x}$ & 18,09 \\
\hline Jan. 5 Aut. I.M. $\bar{x}$ & 18,72 \\
\hline Jan. 5 Aut. Gini $\bar{x}$ & 18,09 \\
\hline Jan. 5 Aut. Kappa $\bar{x}$ & 18,84 \\
\hline Jan. 5 Aut. J.M. $\bar{x}$ & 18,41 \\
\hline
\end{tabular}

Ao contrário dos outros algoritmos de classificação utilizados, a abordagem proposta não obteve a menor taxa de classificação para a coleção Reuters-21578. Porém, para as 


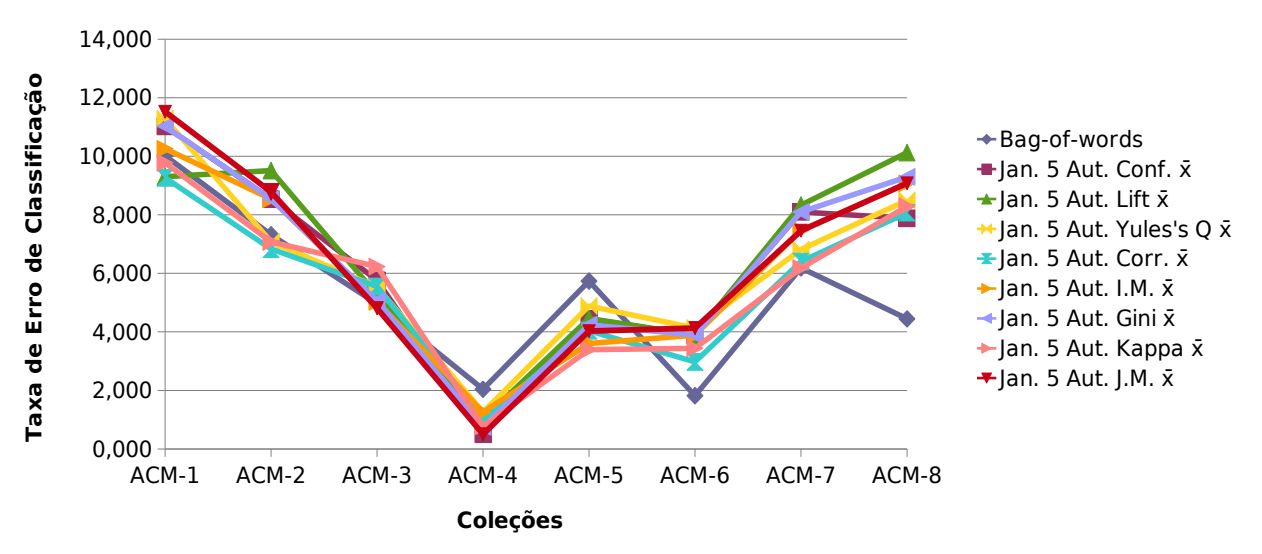

(a)

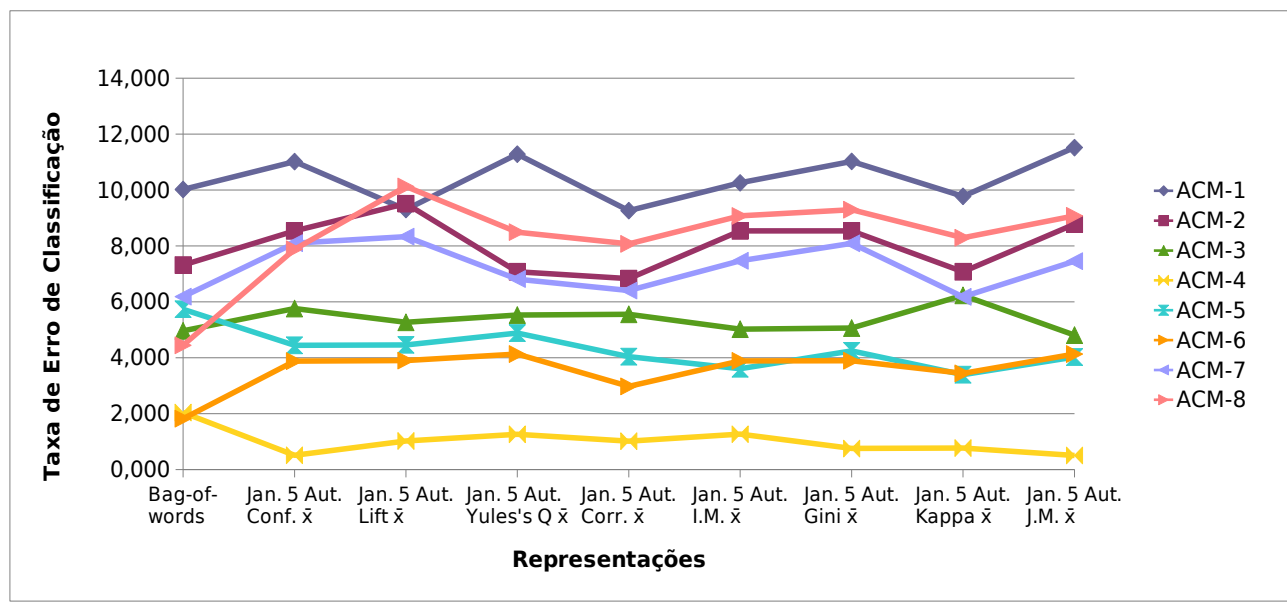

(b)

Figura 4.12: KNN - (a) taxas de erro de classificação das representações bag-of-related-words com diferentes medidas de interesse objetivas e da representação bag-of-words para as coleções da ACM; (b) taxas de erro de classificação das coleções da ACM para as representações bag-of-related-words com diferentes medidas de interesse objetivas e a representação bag-of-words.

coleções da ACM foram obtidas as menores taxas de erro para a maioria das coleções. Novamente não houve indícios que comprovaram que algum tipo de representação de coleções de documento textuais utilizada nos experimentos foi melhor que a outra.

\subsubsection{Avaliação da Viabilidade da Representação Bag-of-Related-Words para o Agrupamento de Coleções de Documentos Textuais}

Para verificar a adequação da representação bag-of-related-words para a tarefa de agrupamento de documentos textuais, foram realizados experimentos utilizando o algoritmo UPGMA (Unweighted Pair Group Method with Arithmetic Mean), que é um algoritmo de agrupamento hierárquico aglomerativo do tipo average-link. Este algoritmo obtém os melhores resultados para o agrupamento de documentos textuais juntamente com o algoritmo bisecting-k-means. Porém, os resultados do algoritmo bisecting-k-means dependem das escolhas inicias das sementes utilizadas para particionar os grupos, e por isso optou-se neste projeto utilizar o algoritmo UPGMA. Para avaliar a qualidade dos agrupamentos obtidos nos experimentos foi utilizada a medida FScore.

Por simplicidade, para as coleções ACM são apresentados somente os resultados das representações que obtiveram o maior valor para a media FScore para ao menos uma das 
coleções. Para a coleção Reuters-21578 são apresentados os resultados das representações com limiares obtidos automaticamente e a representação bag-of-words. No Apêndice D são apresentados todos os resultados da medida FScore para as representações bag-ofrelated-words e bag-of-words utilizando o algoritmo UPGMA.

Na Tabela 4.35 são apresentados os resultados da representação bag-of-words e das representações bag-of-related-words com diferentes formas de mapeamento que obtiveram o maior valor da medida FScore para ao menos uma das coleções da ACM. Foram considerados apenas os itemsets frequentes como atributos das representações bag-of-related-words. Foram obtidos os maiores valores da FScore para 7 das 8 coleções da ACM (ACM-1, ACM-2, ACM-3, ACM-4, ACM-5, ACM-6 e ACM-7). A diferença dos resultados obtidos pelas representações bag-of-related-words em relação à bag-of-words foi considerável em algumas coleções, como a ACM-2, em que a diferença foi de 0,111, e ACM-7, na qual a diferença foi de 0,130 .

Tabela 4.35: UPGMA - resultados da representação bag-of-words e das representações bag-of-relatedwords com itemsets frequentes como atributos que obtiveram a maior pontuação da medida FScore para as coleções da ACM.

\begin{tabular}{|c|c|c|c|c|c|c|c|c|}
\hline & \multicolumn{8}{|c|}{ FScore } \\
\hline Representação & ACM-1 & ACM-2 & ACM-3 & ACM-4 & ACM-5 & ACM-6 & ACM-7 & ACM-8 \\
\hline Bag-of-words & 0,779 & 0,818 & 0,821 & 0,854 & 0,842 & 0,892 & 0,800 & $*_{0,867}$ \\
\hline Jan. $50,06 \%$ & 0,771 & 0,820 & 0,863 & 0,917 & 0,868 & $* 0,910$ & 0,812 & 0,792 \\
\hline Jan. $50,08 \%$ & 0,788 & 0,845 & 0,891 & 0,900 & $* 0,881$ & 0,893 & 0,803 & 0,813 \\
\hline Jan. $52 \%$ & 0,806 & 0,912 & 0,843 & 0,909 & 0,829 & 0,880 & $* 0,930$ & 0,795 \\
\hline Jan. $53 \%$ & $* 0,813$ & 0,915 & 0,804 & 0,886 & 0,822 & 0,841 & 0,897 & 0,749 \\
\hline Jan. $105 \%$ & 0,761 & 0,924 & $*_{0,904}$ & 0,891 & 0,816 & 0,868 & 0,904 & 0,817 \\
\hline Jan. $207 \%$ & 0,765 & 0,874 & 0,877 & $* 0,921$ & 0,833 & 0,849 & 0,895 & 0,768 \\
\hline Jan. $3011 \%$ & 0,752 & $* 0,929$ & 0,893 & 0,889 & 0,814 & 0,872 & 0,919 & 0,764 \\
\hline
\end{tabular}

Assim como na classificação, as representações que utilizaram uma janela deslizante de tamanho 5 como mapeamento obtiveram os melhores resultados para o agrupamento de documentos textuais. Vale ressaltar que, em alguns casos, como das coleções ACM1 e ACM-3, os melhores resultados foram obtidos pelas configurações [Jan. 5 3\%] e [Jan. 10 5\%], com uma redução do número de atributos de aproximadamente $91 \%$ e $80 \%$ respectivamente em relação à bag-of-words.

Para verificar como a variação do valor de suporte mínimo afetou os resultados obtidos para as diversas formas de mapeamento, foi aplicado o teste de Friedman considerando os resultados das 8 coleções da ACM. Na Tabela 4.36 são apresentados os resultados do teste estatístico. Somente houve diferença estatisticamente significante nos resultados obtidos pelo mapeamento de sentença, em que os resultados dos limiares de $2 \%$ e $3 \%$ foram melhores com diferença estatística significante em relação ao limiar de $6 \%$.

Para comparar as diversas formas de mapeamento propostas e a representação bagof-words, foram selecionados os melhores valores de suporte mínimo para cada tipo de mapeamento: [Sent. 2\%], [Par. 10\%], [Jan. 5 2\%], [Jan. 10 5\%], [Jan. 20 8\%] e [Jan. 30 11\%]. Na Tabela 4.37 são apresentados os resultados do teste de Friedman considerando os resultados das 8 coleções da ACM. Pode-se notar que nenhuma das representações selecionadas apresentou diferenças estatisticamente significantes em relação às demais. Porém, vale ressaltar que a configuração [Jan. 5 2\%] reduziu mais de $80 \%$ do número de atributos e produziu melhores resultados que a bag-of-words em 5 das 8 coleções da ACM.

Na Figura 4.13 é apresentada uma comparação gráfica dos valores da FScore para as melhores representações bag-of-related-words com diferentes tipos de mapeamento e a representação bag-of-words. Na Figura 4.13(a) pode-se notar um comportamento similar em relação ao valor da medida FScore nos diversos tipos de mapeamento propostos, com exceção do mapeamento de sentenças na coleção ACM-7, e das janelas de tamanho 10, 20 e 30 na coleção ACM-4. Pela Figura 4.13(b) pode-se observar que para a maioria das 
Tabela 4.36: UPGMA - resultados do teste estatístico para avaliar o impacto na pontuação da medida FScore causado pela variação do suporte mínimo para as diferentes formas de mapeamento nas coleções ACM.

\begin{tabular}{|c|c|c|c|c|c|}
\multicolumn{1}{c|}{ Sentenças } \\
\cline { 2 - 6 } \multicolumn{1}{c|}{} & $2 \%$ & $3 \%$ & $4 \%$ & $5 \%$ & $6 \%$ \\
\hline $2 \%$ & - & $\bullet$ & $\bullet$ & $\bullet$ & $\Delta$ \\
\hline $3 \%$ & $\bullet$ & - & $\bullet$ & $\bullet$ & $\Delta$ \\
\hline $4 \%$ & $\bullet$ & $\bullet$ & - & $\bullet$ & $\bullet$ \\
\hline $5 \%$ & $\bullet$ & $\bullet$ & $\bullet$ & - & $\bullet$ \\
\hline $6 \%$ & $\mathbf{\nabla}$ & $\mathbf{\nabla}$ & $\bullet$ & $\bullet$ & - \\
\hline
\end{tabular}

Janela 5

\begin{tabular}{|c|c|c|c|c|c|}
\multicolumn{1}{c|}{} & \multicolumn{6}{c}{ Janela 5} \\
\cline { 2 - 6 } \multicolumn{1}{c|}{} & $0,6 \%$ & $0,8 \%$ & $1 \%$ & $2 \%$ & $3 \%$ \\
\hline $0,6 \%$ & - & $\bullet$ & $\bullet$ & $\bullet$ & $\bullet$ \\
\hline $0,8 \%$ & $\bullet$ & - & $\bullet$ & $\bullet$ & $\bullet$ \\
\hline $1 \%$ & $\bullet$ & $\bullet$ & - & $\bullet$ & $\bullet$ \\
\hline $2 \%$ & $\bullet$ & $\bullet$ & $\bullet$ & - & $\bullet$ \\
\hline $3 \%$ & $\bullet$ & $\bullet$ & $\bullet$ & $\bullet$ & - \\
\hline
\end{tabular}

\begin{tabular}{|c|c|c|c|c|c|}
\multicolumn{7}{c}{} & Janela 20 \\
\cline { 2 - 6 } \multicolumn{1}{c|}{} & $6 \%$ & $7 \%$ & $8 \%$ & $9 \%$ & $10 \%$ \\
\hline $6 \%$ & - & $\bullet$ & $\bullet$ & $\bullet$ & $\bullet$ \\
\hline $7 \%$ & $\bullet$ & - & $\bullet$ & $\bullet$ & $\bullet$ \\
\hline $8 \%$ & $\bullet$ & $\bullet$ & - & $\bullet$ & $\bullet$ \\
\hline $9 \%$ & $\bullet$ & $\bullet$ & $\bullet$ & - & $\bullet$ \\
\hline $10 \%$ & $\bullet$ & $\bullet$ & $\bullet$ & $\bullet$ & - \\
\hline
\end{tabular}

\begin{tabular}{|c|c|c|c|c|c|}
\cline { 2 - 6 } \multicolumn{1}{c|}{} & $10 \%$ & $11 \%$ & $12 \%$ & $13 \%$ & $14 \%$ \\
\hline $10 \%$ & - & $\bullet$ & $\bullet$ & $\bullet$ & $\bullet$ \\
\hline $11 \%$ & $\bullet$ & - & $\bullet$ & $\bullet$ & $\bullet$ \\
\hline $12 \%$ & $\bullet$ & $\bullet$ & - & $\bullet$ & $\bullet$ \\
\hline $13 \%$ & $\bullet$ & $\bullet$ & $\bullet$ & - & $\bullet$ \\
\hline $14 \%$ & $\bullet$ & $\bullet$ & $\bullet$ & $\bullet$ & - \\
\hline
\end{tabular}

\begin{tabular}{|c|c|c|c|c|c|}
\multicolumn{1}{c|}{} & \multicolumn{5}{c}{ Janela 10} \\
\cline { 2 - 6 } \multicolumn{1}{c|}{} & $2 \%$ & $3 \%$ & $4 \%$ & $5 \%$ & $6 \%$ \\
\hline $2 \%$ & - & $\bullet$ & $\bullet$ & $\bullet$ & $\bullet$ \\
\hline $3 \%$ & $\bullet$ & - & $\bullet$ & $\bullet$ & $\bullet$ \\
\hline $4 \%$ & $\bullet$ & $\bullet$ & - & $\bullet$ & $\bullet$ \\
\hline $5 \%$ & $\bullet$ & $\bullet$ & $\bullet$ & - & $\bullet$ \\
\hline $6 \%$ & $\bullet$ & $\bullet$ & $\bullet$ & $\bullet$ & - \\
\hline
\end{tabular}

\begin{tabular}{|c|c|c|c|c|c|}
\multicolumn{1}{c}{} & Janela 30 \\
\cline { 2 - 6 } \multicolumn{1}{c|}{} & $10 \%$ & $11 \%$ & $12 \%$ & $13 \%$ & $14 \%$ \\
\hline $10 \%$ & - & $\bullet$ & $\bullet$ & $\bullet$ & $\bullet$ \\
\hline $11 \%$ & $\bullet$ & - & $\bullet$ & $\bullet$ & $\bullet$ \\
\hline $12 \%$ & $\bullet$ & $\bullet$ & - & $\bullet$ & $\bullet$ \\
\hline $13 \%$ & $\bullet$ & $\bullet$ & $\bullet$ & - & $\bullet$ \\
\hline $14 \%$ & $\bullet$ & $\bullet$ & $\bullet$ & $\bullet$ & - \\
\hline
\end{tabular}

Tabela 4.37: UPGMA - resultados dos testes estatísticos para compara o valor da medida FScore nas coleções ACM obtidas pela representação bag-of-words e pelas representações bag-of-related-words com diferentes formas de mapeamento.

\begin{tabular}{|c|c|c|c|c|c|c|c|}
\hline & Bag-of-words & Sent. $2 \%$ & Par. $10 \%$ & Jan. $52 \%$ & Jan. $105 \%$ & Jan. $208 \%$ & Jan. $3011 \%$ \\
\hline Bag-of-words & - & $\bullet$ & $\bullet$ & $\bullet$ & $\bullet$ & $\bullet$ & $\bullet$ \\
\hline Sent. $3 \%$ & - & - & $\bullet$ & $\bullet$ & $\bullet$ & $\bullet$ & - \\
\hline Par. $11 \%$ & $\bullet$ & $\bullet$ & - & $\bullet$ & $\bullet$ & $\bullet$ & $\bullet$ \\
\hline Jan. $50,6 \%$ & - & - & - & - & $\bullet$ & $\bullet$ & $\bullet$ \\
\hline Jan. $102 \%$ & $\bullet$ & $\bullet$ & - & - & - & $\bullet$ & - \\
\hline Jan. $209 \%$ & $\bullet$ & 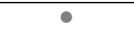 & - & - & $\bullet$ & - & 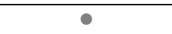 \\
\hline Jan. $3010 \%$ & $\bullet$ & $\bullet$ & - & - & $\bullet$ & $\bullet$ & - \\
\hline
\end{tabular}

coleções da ACM há uma queda de qualidade do mapeamento de parágrafos em relação ao de sentenças, e um aumento de qualidade das janelas de tamanho 5 em relação aos parágrafos. Diferente do que ocorreu com os algoritmos de classificação, o aumento do tamanho da janela não deteriorou a qualidade do agrupamento.

Como as representações baseadas em janelas deslizantes de tamanho 5 apresentaram os melhores resultados, foi analisado o uso do suporte automático para a tarefa de agrupamento de documentos textuais nesse tipo de mapeamento. Na Tabela 4.38 são apresentados os resultados das representações bag-of-related-words com mapeamento de janela 5 e da representação bag-of-words. Pode-se observar que os resultados obtidos utilizando o suporte automático foram tão bons quanto os obtidos utilizando os valores de suporte mínimos definidos manualmente. Foram então utilizadas as medidas de interesse objetivas no mapeamento de janela deslizante de tamanho 5 com suporte mínimo automático para as coleções da ACM e Reuters-21578.

Para as coleções da ACM, as representações bag-of-related-words com medidas de interesse objetivas foram melhores novamente em 7 das 8 coleções (ACM-1, ACM-2, ACM3, ACM-4, ACM-5, ACM-6 e ACM-7). Para as coleções ACM-1, ACM-2, ACM-3, ACM4, ACM-5, ACM-6 e ACM-8, as medidas de interesse objetivas reduziram o número de atributos e melhoram os resultados em relação à representação base utilizada ([Jan. 5 Aut.]) para a maioria das situações. Na Tabela 4.39 são apresentados os resultados em que as representações bag-of-related-words que utilizaram medidas de interesse objetivas e a representação bag-of-words obtiveram os melhores valores para a medida FScore. Vale 


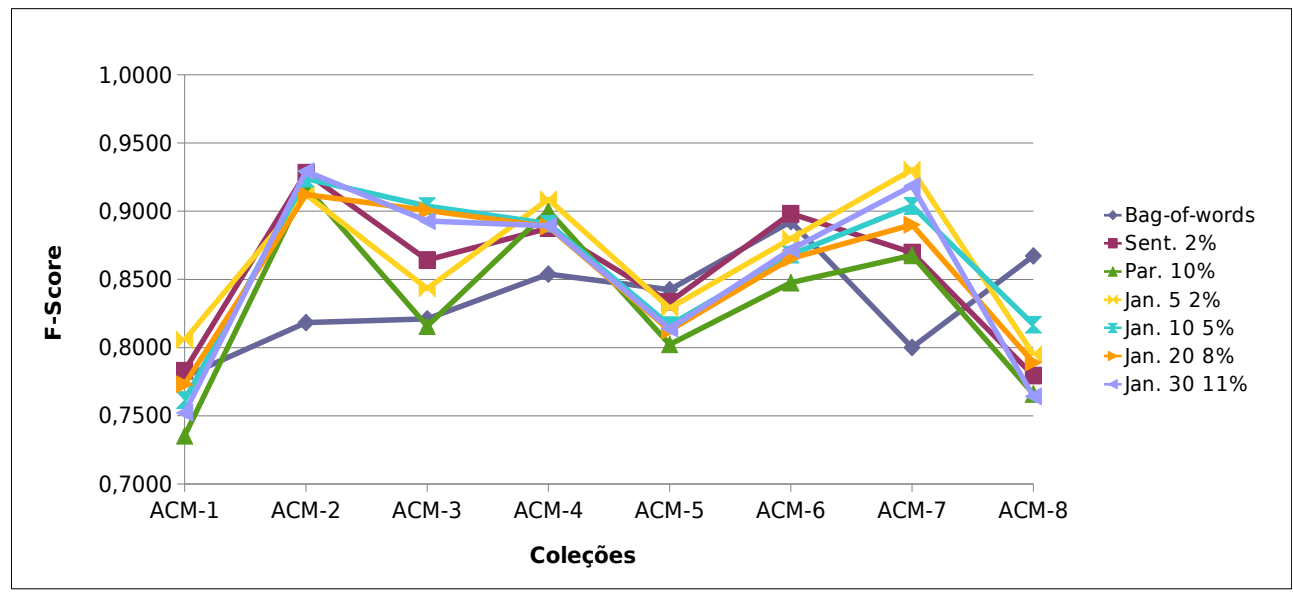

(a)

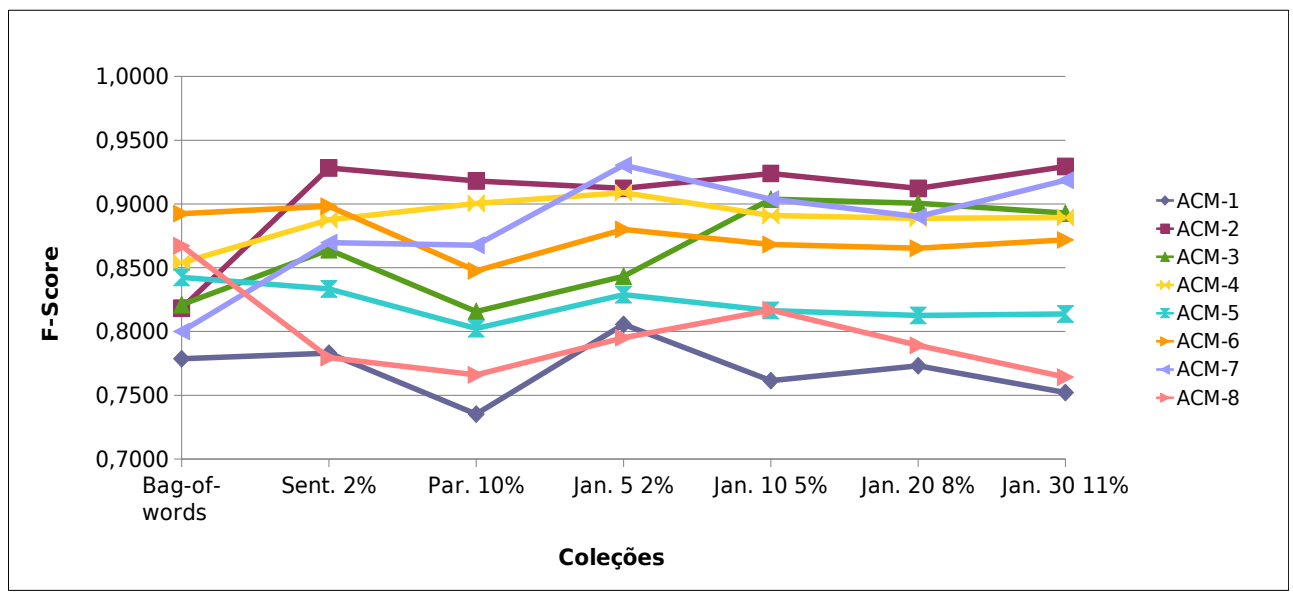

(b)

Figura 4.13: UPGMA - (A) valores da medida FScore obtida pelas melhores representações utilizando itemsets frequentes e pela representação bag-of-words para as coleções da ACM; (B) valores da medida FScore para as coleções da ACM obtidas pelas melhores representações utilizando itemsets frequentes e a representação bag-of-words.

Tabela 4.38: UPGMA - valores da medida FScore obtidos pelas representações bag-of-related-words com mapeamento de janela de tamanho 5 e da representação bag-of-words para as coleções da ACM.

\begin{tabular}{|l|r|r|r|r|r|r|r|r|}
\cline { 2 - 10 } \multicolumn{1}{c|}{} & \multicolumn{9}{c|}{ FScore } \\
\hline Representação & ACM-1 & ACM-2 & ACM-3 & ACM-4 & ACM-5 & ACM-6 & ACM-7 & ACM-8 \\
\hline Bag-of-words & 0,779 & 0,818 & 0,821 & 0,854 & 0,842 & 0,892 & 0,800 & ${ }^{*} \mathbf{0 , 8 6 7}$ \\
\hline Jan. 5 Aut. & 0.801 & 0.886 & 0.889 & $\boldsymbol{*}_{\mathbf{0 . 9 1 7}}$ & 0.868 & 0.890 & 0.822 & 0.820 \\
\hline Jan. 5 0,06\% & 0,771 & 0,820 & 0,863 & 0,917 & 0,868 & $\boldsymbol{*}_{\mathbf{0}} \mathbf{0 , 9 1 0}$ & 0,812 & 0,792 \\
\hline Jan. 5 0,08\% & 0,788 & 0,845 & 0,891 & 0,900 & $\boldsymbol{*} \mathbf{0 , 8 8 1}$ & 0,893 & 0,803 & 0,813 \\
\hline Jan. 5 1\% & 0,784 & 0,886 & $\boldsymbol{*} \mathbf{0 , 9 0 0}$ & 0,913 & 0,848 & 0,895 & 0,850 & 0,820 \\
\hline Jan. 5 2\% & 0,806 & 0,912 & 0,843 & 0,909 & 0,829 & 0,880 & $\boldsymbol{*}_{\mathbf{0}} \mathbf{0 3 3 0}$ & 0,795 \\
\hline Jan. 5 3\% & $\mathbf{*} \mathbf{0 , 8 1 3}$ & $\boldsymbol{*} \mathbf{0 , 9 1 5}$ & 0,804 & 0,886 & 0,822 & 0,841 & 0,897 & 0,749 \\
\hline
\end{tabular}

ressaltar que das configurações apresentadas na Tabela 4.39, a redução de atributos sempre foi maior que $26 \%$, havendo casos em que a redução chegou a $82 \%$.

Para verificar se os limiares das medidas de interesse objetivas utilizadas causaram diferenças significativas nos valores da medida FScore, foi aplicado o teste de Friedman para cada medida objetiva considerando as 8 coleções da ACM. Houve diferença estatisticamente significante somente para a medida Kappa, em que o limiar baseado na média foi melhor em relação ao limiar 0,15 . Portanto, as variações de limiares da maioria das medidas de interesse objetivas, reduziram a quantidade de atributos e mantiveram a 
Tabela 4.39: UPGMA - valores da medida FScore obtidos pela representação bag-of-words e pelas representações bag-of-related-words com medidas de interesse objetivas que obtiveram o maior valor da medida FScore para as coleções da ACM.

\begin{tabular}{|l|r|r|r|r|r|r|r|r|}
\cline { 2 - 10 } \multicolumn{1}{c|}{} & \multicolumn{9}{c|}{ FScore } \\
\hline Representação & ACM-1 & ACM-2 & ACM-3 & ACM-4 & ACM-5 & ACM-6 & ACM-7 & ACM-8 \\
\hline Bag- -f-words & 0,779 & 0,818 & 0,821 & 0,854 & 0,842 & 0,892 & 0,800 & $* \mathbf{0 , 8 6 7}$ \\
\hline Jan. 5 Aut. Conf. 0,5 & $\boldsymbol{*} \mathbf{0 , 8 5 5}$ & 0,882 & 0,886 & 0,922 & 0,911 & 0,884 & 0,799 & 0,744 \\
\hline Jan. 5 Aut. Lift 0,1 & 0,799 & ${ }^{*} \mathbf{0 , 8 8 9}$ & 0,892 & 0,918 & 0,901 & 0,913 & 0,786 & 0,814 \\
\hline Jan. 5 Aut. Lift Aut & 0,799 & $\boldsymbol{*}^{\mathbf{0 , 8 8 9}}$ & 0,892 & 0,918 & 0,901 & 0,913 & 0,786 & 0,814 \\
\hline Jan. 5 Aut. Yule's Q 0,75 & 0,796 & 0,872 & 0,904 & $\boldsymbol{*} \mathbf{0 , 9 2 6}$ & 0,902 & 0,910 & 0,763 & 0,824 \\
\hline Jan. 5 Aut. Corr. 0,25 & 0,789 & 0,854 & 0,896 & 0,922 & ${ }^{*} 0,915$ & 0,883 & 0,783 & 0,801 \\
\hline Jan. 5 Aut. Corr. 0,50 & 0,831 & 0,877 & 0,883 & 0,922 & 0,909 & ${ }^{*} \mathbf{0 , 9 2 5}$ & 0,805 & 0,778 \\
\hline Jan. 5 Aut. I.M. 0,01 & 0,853 & 0,883 & $\boldsymbol{*}^{\mathbf{0 , 9 0 8}}$ & 0,920 & 0,904 & 0,923 & 0,814 & 0,765 \\
\hline Jan. 5 Aut. Kappa $\bar{x}$ & 0,778 & 0,875 & 0,872 & 0,918 & 0,905 & 0,897 & ${ }^{*} \mathbf{0 , 8 1 5}$ & 0,803 \\
\hline
\end{tabular}

qualidade dos resultados. Pode-se notar também que não houve evidências que o uso de limiares definidos pelo usuário foi melhor que os obtidos através da média. Inclusive no caso da medida Kappa, o limiar obtido pela média foi melhor do que os limiares definidos manualmente.

Como não houve diferença dos resultados utilizando o limiar baseado na média em relação aos demais limiares, foram comparadas as representações com medidas de interesse objetivas utilizando a média como limiar e a representação bag-of-words. Novamente foi aplicado o teste de Friedman e não foi verificada diferença estatisticamente significante entre as representações considerando a medida FScore. Na Figura 4.14 é apresentada uma comparação gráfica das representações com medidas de interesse objetivas utilizadas na comparação com a representação bag-of-words. Na Figura 4.14(a) pode-se notar um comportamento semelhante das representações com medidas de interesse objetivas, com exceção de algumas medidas para as coleções ACM-4 (Lift, Yule's Q, e Correlação) e ACM-7 (Lift e Correlação). Pela Figura 4.14(b) pode-se observar que não houve destaque para nenhuma representação com medida objetiva, uma vez que houve oscilações dos resultados para as diversas representações.

Na Tabela 4.40 são apresentados os resultados das representações com medidas de interesse objetivas com limiares baseados na média para a coleção Reuters-21578. Todos os valores da medida FScore obtidos pelas representações propostas foram inferiores aos da representação bag-of-words. O melhor resultado da abordagem proposta foi obtido pela representação [Jan. 5 Aut. J.M. 0,05\%] com um valor de 0,6778, tendo uma diferença de 0,022 para a representação bag-of-words.

Tabela 4.40: UPGMA - valores da medida FScore obtidos pela representação bag-of-words e pelas representações bag-of-related-words com medidas de interesse objetivas e limiares baseados na média para a coleção Reuters-21578.

\begin{tabular}{|l|r|}
\hline Representação & \multicolumn{1}{|c|}{$\boldsymbol{*} \mathbf{0 c o r e}$} \\
\hline Bag-of-words & $\mathbf{0 , 7 0 0 2}$ \\
\hline Jan. 5 Aut. & 0,6626 \\
\hline Jan. 5 Aut. Conf. $\bar{x}$ Aut & 0,6491 \\
\hline Jan. 5 Aut. Lift $\bar{x}$ & 0,6579 \\
\hline Jan. 5 Aut. Yule's Q $\bar{x}$ & 0,6446 \\
\hline Jan. 5 Aut. Corr. $\bar{x}$ & 0,6662 \\
\hline Jan. 5 Aut. I.M. $\bar{x}$ & 0,6599 \\
\hline Jan. 5 Aut. Gini $\bar{x}$ & 0,6513 \\
\hline Jan. 5 Aut. Kappa $\bar{x}$ & 0,6610 \\
\hline Jan. 5 Aut. J.M. $\bar{x}$ & 0,6741 \\
\hline
\end{tabular}

De acordo com os resultados, a abordagem bag-of-related-words pode ser utilizada na tarefa de agrupamento de documentos textuais, principalmente em coleções de textos que possibilitam o mapeamento de uma grande quantidade de transações. Foram obtidos os 


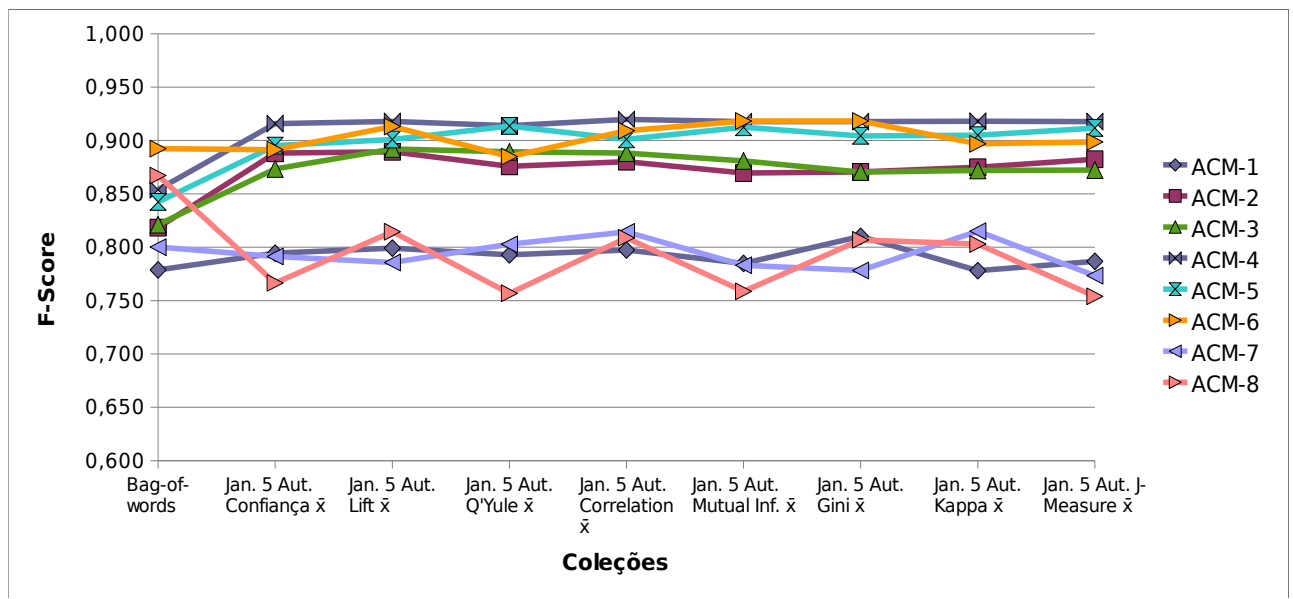

(a)

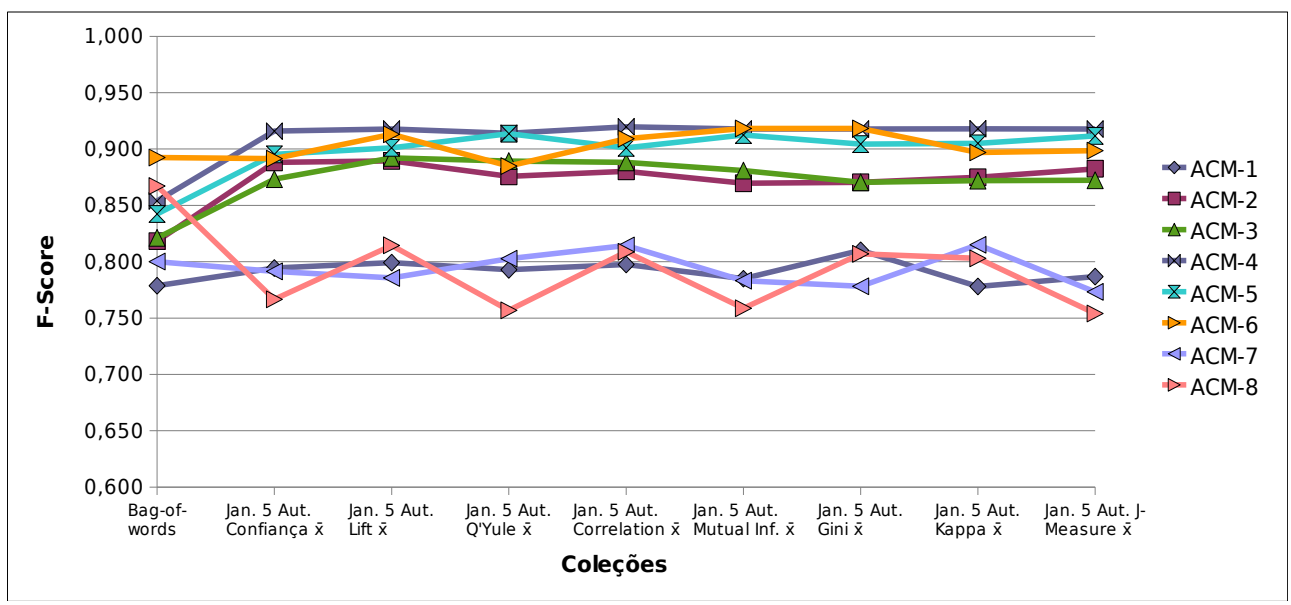

(b)

Figura 4.14: UPGMA - (A) valores da medida FScore obtidas pelas melhores representações utilizando medidas de interesse objetivas para extrair atributos e pela representação bag-of-words para as coleções da ACM; (B) valores da medida FScore para as coleções da ACM obtidas pelas melhores representações utilizando medidas de interesse objetivas e a representação bag-of-words.

melhores valores da medida FScore para a maioria das coleções da ACM com diferenças que chegaram a mais de um décimo. Pode-se observar que todas as formas de mapeamento e medidas de interesse objetivas utilizadas foram adequadas para as coleções da ACM, uma vez que não houve evidências que os resultados da representação bag-of-words foram significantes em relação aos resultados dos mapeamentos propostos. Já para a coleção Reuters-21578, as representação propostas foram inferiores à representação bag-of-words. Porém, as diferenças dos resultados nesta coleção chegaram à 0,022. Vale ressaltar que as medidas de interesse objetivas mais uma vez cumpriram o propósito de reduzir o número de atributos e manter a qualidade dos resultados.

\subsubsection{Avaliação de Hierarquias de Tópicos Construídas Utilizando a Represen- tação Bag-of-Related-Words}

Para avaliar a viabilidade da representação bag-of-related-words para a construção automática de uma hierarquia de tópicos, foi realizada uma avaliação subjetiva com 8 especialistas da área de ciências da computação. Foram construídas hierarquias de tópicos utilizando as coleções ACM-3, ACM-4 e ACM-8. Na Tabela 4.41 são apresentados os eventos dos quais os documentos textuais se referem. Essas coleções foram representadas 
pela bag-of-related-words [Jan. 5 Aut. Correlação $\bar{x}$ ] e por uma bag-of-words.

Tabela 4.41: Descrição das classes das coleções textuais da ACM-3, ACM-4, e ACM-8.

\begin{tabular}{|l|l|}
\hline Coleção & Classe \\
\hline \hline \multirow{4}{*}{ ACM-3 } & Workshop on Computer Architecture Education \\
\cline { 2 - 2 } & Symposium on Architecture for Networking And Communications Systems \\
\cline { 2 - 2 } & Workshop on Privacy in the Electronic Society \\
\cline { 2 - 2 } & Workshop on Software and Performance \\
\cline { 2 - 2 } & Workshop on Web Information and Data Management \\
\hline \hline \multirow{4}{*}{ ACM-4 } & Conference on Embedded Networked Sensor Systems \\
\cline { 2 - 2 } & Annual ACM Conference on Research and Development in Information Retrieval \\
\cline { 2 - 2 } & ACM Symposium on Parallel Algorithms and Architectures \\
\cline { 2 - 2 } & Symposium on Volume Visualization \\
\cline { 2 - 2 } & International Cross-Disciplinary Conference on Web Accessibility \\
\hline \hline \multirow{5}{*}{ ACM-8 } & International Symposium on Mobile Ad Hoc Networking \& Computing \\
\cline { 2 - 2 } & International Conference on Knowledge Discovery and Data Mining \\
\cline { 2 - 2 } & Language, Compiler and Tool Support for Embedded Systems \\
\cline { 2 - 2 } & Conference on Hypertext and Hypermedia \\
\cline { 2 - 2 } & International Symposium on Microarchitecture \\
\hline
\end{tabular}

A ferramenta Torch (Marcacini e Rezende, 2010) foi utilizada para construir as hierarquias de tópicos. Foi utilizado o algoritmo 5-secting-k-means para construir a representação hierárquica. Este algoritmo foi utilizado para que o primeiro nível da árvore contivesse 5 ramos, que correspondem às 5 categorias dos documentos, e para diminuir o número de ramos da hierarquia.

Na fase de seleção de descritores dos grupos da hierarquia, para cada grupo/nó $(G)$ da hierarquia foram selecionados os melhores atributos $t \in T$ do centroide $(C)$ do grupo $G$ como descritores. Para obter os melhores atributos $t$ que descrevem um grupo $G$, é construída uma matriz de contingência para cada atributo $t \in T$. Para construir essa matriz, recupera-se todos os documentos que contenham $t(R(t))$. Com o conjunto de documentos $R(t)$ e o grupo de documentos $G$ é possível construir uma matriz de contingência do atributo $t$, como apresentado na Tabela 4.42 (Manning et al., 2008; Chu, 2003).

Tabela 4.42: Matriz de contingência do atributo $t$

\begin{tabular}{|c|c|c|c|}
\cline { 3 - 4 } \multicolumn{2}{c|}{} & \multicolumn{2}{c|}{ Grupo $\boldsymbol{G}$} \\
\cline { 3 - 4 } \multicolumn{2}{c|}{$\boldsymbol{R}(t)$} & Relevante & Não Relevante \\
\cline { 2 - 4 } & Não Relevante & acertos & ruídos \\
\hline
\end{tabular}

Os significados dos items da Tabela 4.42 são definidos à seguir:

- Acertos: número de documentos recuperados por $R(t)$ que pertencem a $G$;

- Perdas: número de documentos em $G$ que não foram recuperados por $R(t)$;

- Ruídos: número de documentos recuperados por $R(t)$ que não pertencem a $G$; e

- Rejeitados: número de documentos que não pertencem a $G$ e que também não foram recuperados por $R(t)$.

A partir desses items, pode-se derivar diversos critérios para avaliar o poder de descrição atributo $t$ para o grupo $G$. Esses critérios podem ser a precisão (Equação 4.1), revocação (Equação 4.2) e a medida $F_{1}$ (Equação 4.3) (Chu, 2003). 


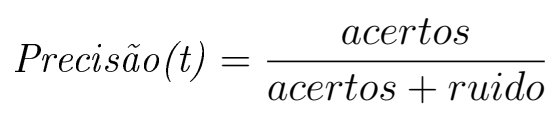

$$
\begin{aligned}
& \text { Revocação }(t)=\frac{\text { acertos }}{\text { acertos }+ \text { perda }} \\
& F_{1}(t)=\frac{2 * \operatorname{Precis} \tilde{a} o(t) * \operatorname{Revocaç\tilde {a}o(t)}}{\operatorname{Precis} \tilde{a} o(t)+\operatorname{Revocaç\tilde {a}o(t)}}
\end{aligned}
$$

Nos experimentos foi utilizada a medida $F_{1}$ como critério de avaliação do poder descritivo dos atributos. O valor da medida $F_{1}$ varia no intervalo [0,1], e quanto mais próximo de 1 melhor o poder descritivo do atributo. Todos os atributos $t \in T$ são avaliados, e um ranking é obtido em ordem decrescente dos valores da medida $F_{1}$. Desta forma, os descritores do grupo $G$ são formados pelos $j$ atributos melhores ranqueados. Nos experimentos realizados o valor de $j$ foi definido em 3 .

Para a avaliação dos especialistas, foram apresentadas duas hierarquias construídas utilizando as representações bag-of-related-words e bag-of-words. A representações utilizadas para a construção das hierarquias de tópicos não foram informadas aos especialistas.

Como critérios de avaliação, foram considerados os seguintes quesitos:

1) É possível identificar claramente os tópicos das coleções baseados em suas respectivas categorias?

2) A navegação pela hierarquia de tópicos conduziu a um conjunto de documentos desejado?

Para ambas as avaliações as notas foram definidas como:

0: Nada;

1: Pouco;

2: Razoável;

3: Bom;

4: Excelente.

Para facilitar a interpretação das hierarquias de tópicos por parte dos especialistas, as palavras radicalizadas foram substituídas pela palavra mais frequente na coleção que originou o radical. Na Tabela 4.43 são apresentadas as notas dadas para o primeiro quesito e na Tabela 4.44 são apresentadas as notas dadas para o segundo quesito. Pode-se notar que a média das notas da avaliação para todas as coleções foi maior para a representação bag-of-related-words do que a da representação bag-of-words.

Tabela 4.43: Notas dadas pelos especialistas para o primeiro quesito da avaliação subjetiva.

\begin{tabular}{|c|c|c|c|c|c|c|}
\cline { 2 - 7 } \multicolumn{1}{c|}{} & \multicolumn{2}{c}{ ACM-3 } & \multicolumn{2}{c|}{ ACtas } \\
\cline { 2 - 8 } \multicolumn{1}{c|}{} & \multicolumn{2}{c|}{ ACM-8 } & \multicolumn{2}{c|}{ ACM-8 } \\
\hline Especialistas & $\boldsymbol{B O} \boldsymbol{W}$ & $\boldsymbol{B O R} \boldsymbol{W}$ & $\boldsymbol{B O} \boldsymbol{W}$ & $\boldsymbol{B O R} \boldsymbol{W}$ & $\boldsymbol{B O} \boldsymbol{W}$ & $\boldsymbol{B O \boldsymbol { O } \boldsymbol { W }}$ \\
\hline Especialista 1 & 1 & 2 & 1 & 3 & 2 & 3 \\
\hline Especialista 2 & 2 & 3 & 1 & 3 & 2 & 3 \\
\hline Especialista 3 & 2 & 3 & 2 & 3 & 3 & 3 \\
\hline Especialista 4 & 2 & 4 & 2 & 2 & 2 & 3 \\
\hline Especialista 5 & 2 & 3 & 2 & 3 & 2 & 3 \\
\hline Especialista 6 & 3 & 2 & 3 & 1 & 4 & 2 \\
\hline Especialista 7 & 1 & 3 & 2 & 3 & 2 & 3 \\
\hline Especialista 8 & 0 & 3 & 0 & 3 & 3 & 2 \\
\hline Média & 1,62 & 2,87 & 1,62 & 2,62 & 2,5 & 2,75 \\
\hline
\end{tabular}

Nas Figuras 4.15, 4.16 e 4.17 são apresentados o $1^{\circ}$ e $2^{\circ}$ níveis das hierarquias de tópicos das coleções ACM-3, ACM-4 e ACM-8 que foram apresentadas aos especialistas de domínio. Pode-se notar que sempre que foi utilizada a representação bag-of-words 
Tabela 4.44: Notas dadas pelos especialistas para o segunda quesito da avaliação subjetiva.

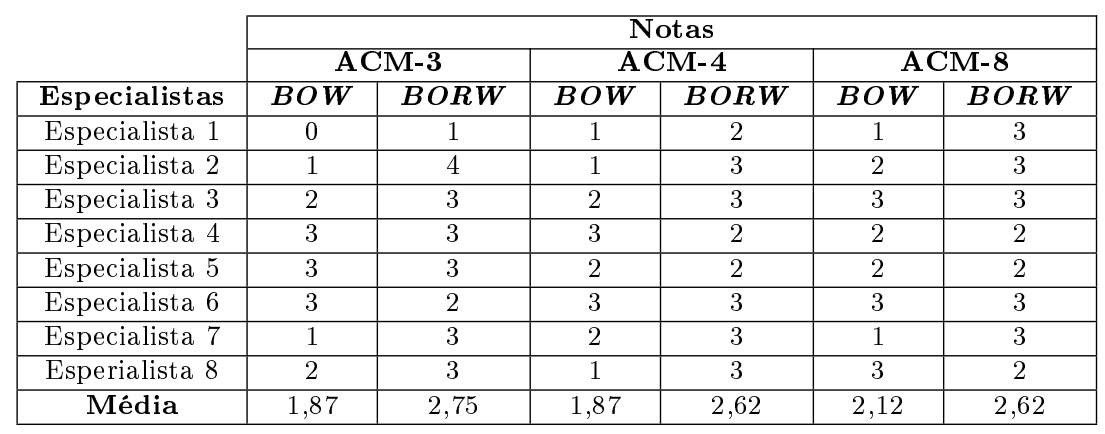

para construir a hierarquia de tópicos, nomes de autores e conferências apareceram nos descritores dos nós das hierarquias. Pode-se notar também que quando utilizada a representação bag-of-related-words para construir a hierarquia de tópicos, muitos dos descritores compostos por mais de uma palavra foram de fundamental importância para o entendimento da coleção de documentos. Por exemplo, para a coleção ACM-3 apareceram descritores como "key_public", "architecture_computer", e "engineering_search". Para a coleção ACM-4 apareceram descritores como "rendering_volume", "accessibility_web", e "information retrieval". Para a coleção ACM-8 apareceram os descritores "network_wireless", "frequent_itemset", e "language_program".

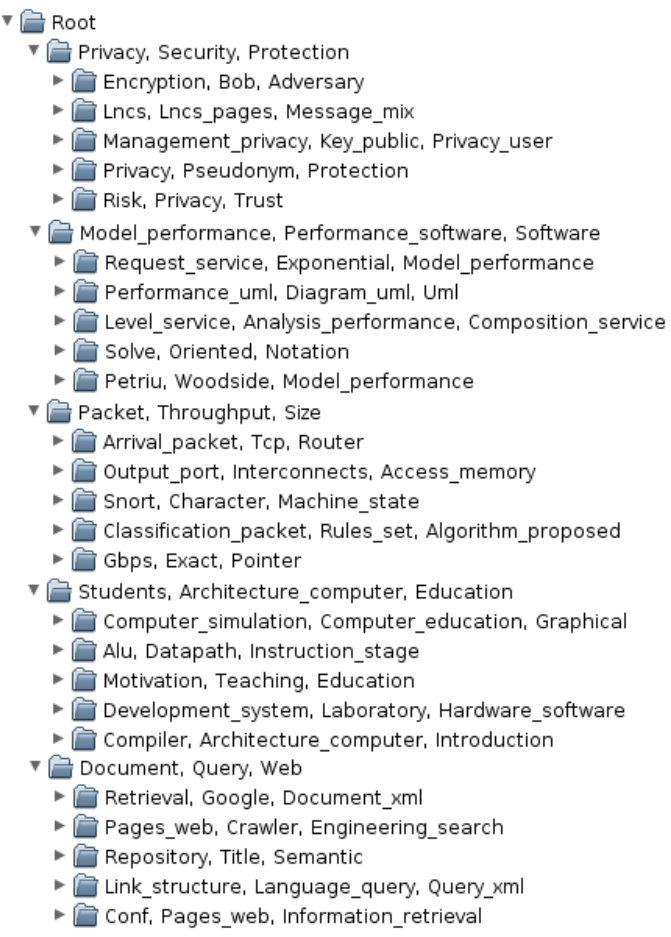

(a) Bag-of-related-words

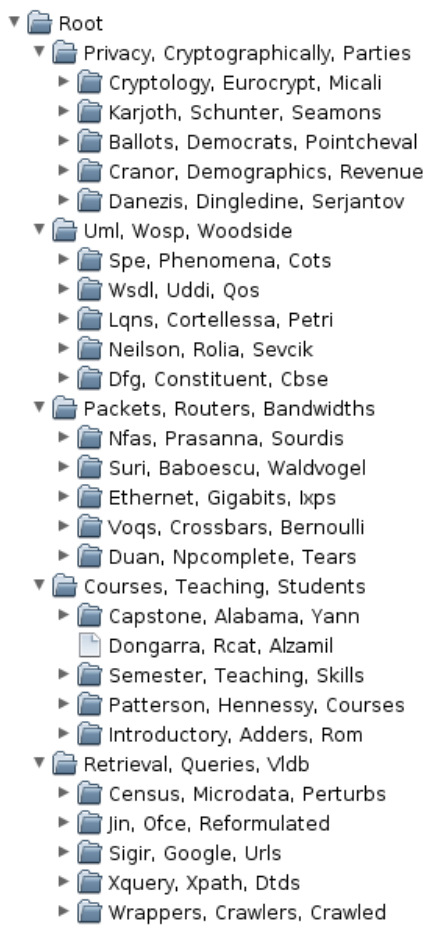

(b) Bag-of-words.

Figura 4.15: Segundo nível da hierarquia de tópicos para a coleção ACM-3 utilizando a representação bag-of-related-words (a) e a representação bag-of-words (b). 


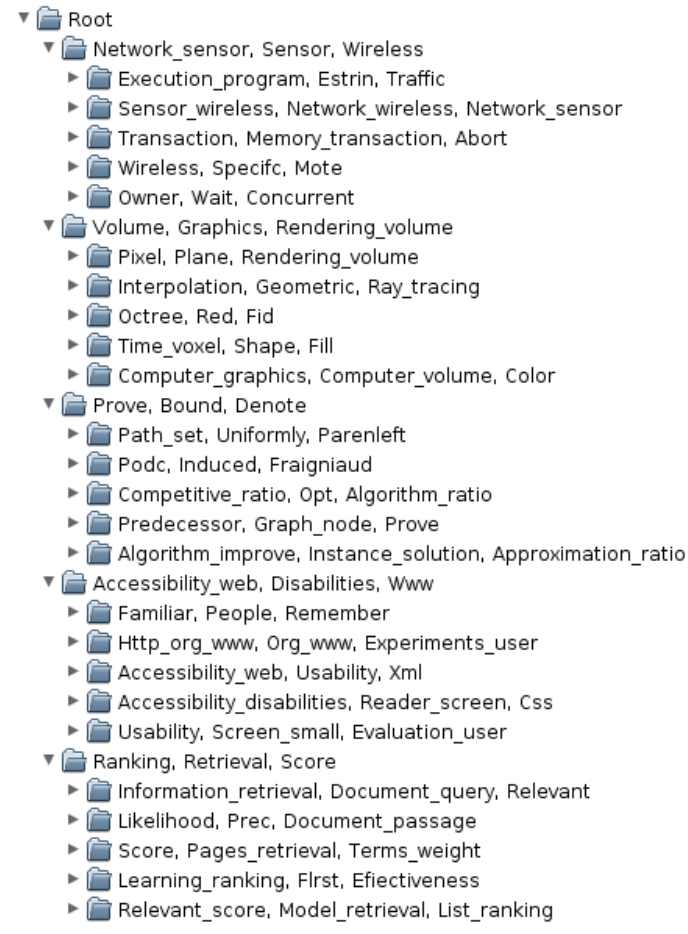

(a) Bag-of-related-words

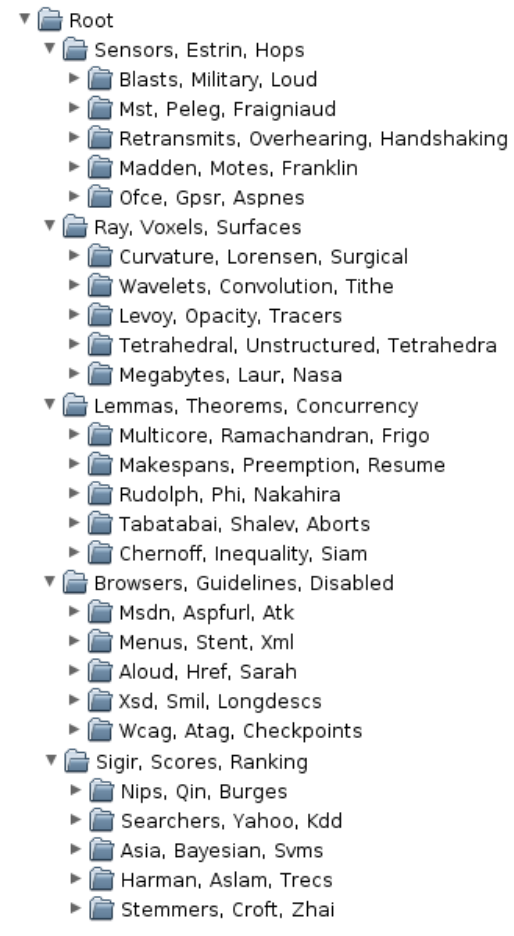

(b) Bag-of-words

Figura 4.16: Segundo nível da hierarquia de tópicos para a coleção ACM-4 utilizando a representação bag-of-related-words (a) e a representação bag-of-words (b).

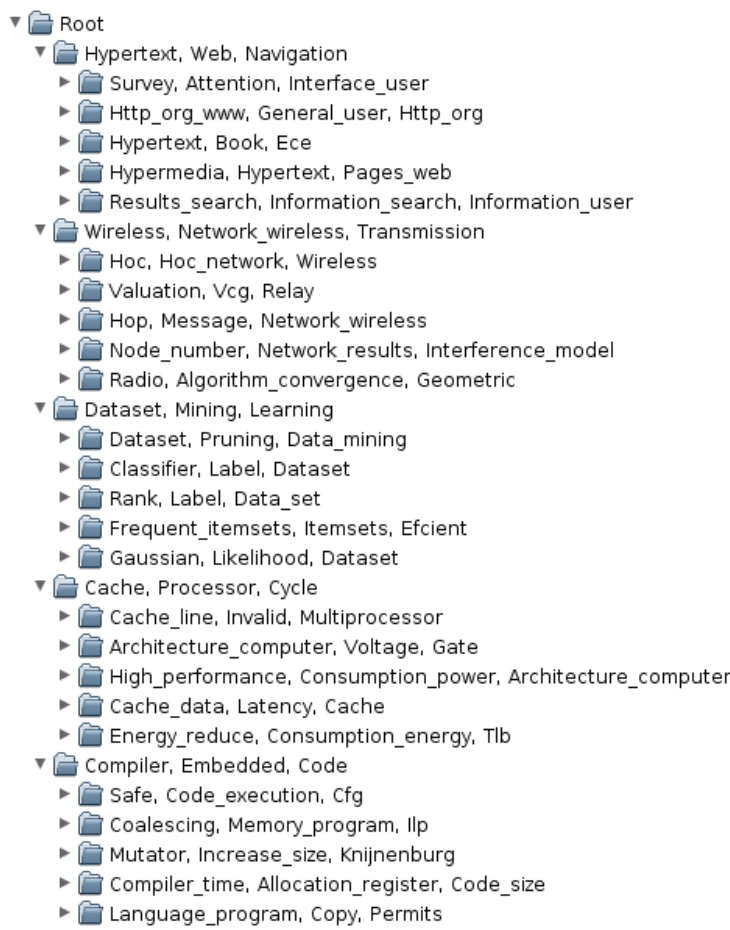

(a) Bag-of-related-words

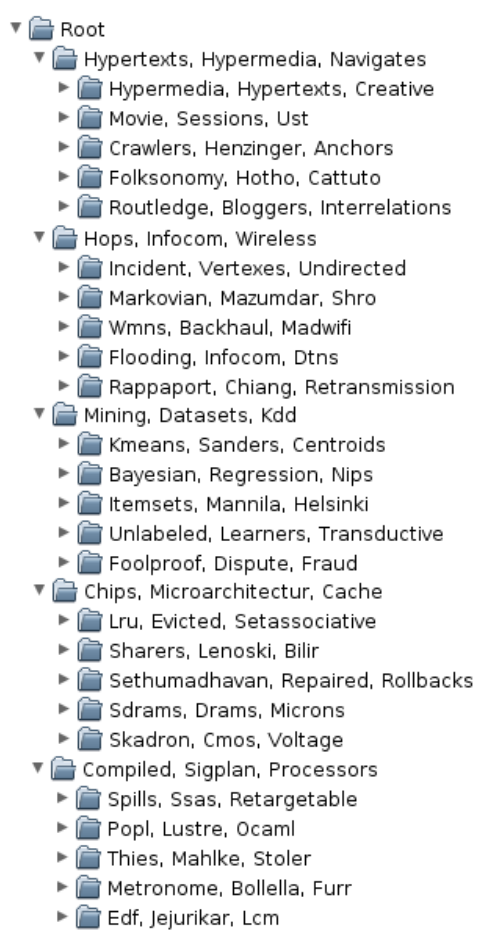

(b) Bag-of-words

Figura 4.17: Segundo nível da hierarquia de tópicos para a coleção ACM-8 utilizando a representação bag-of-related-words (a) e a representação bag-of-words (b). 


\subsection{Considerações Finais Sobre os Experimentos e Resultados Obti- dos}

Observa-se pelos resultados que a abordagem proposta para representação de coleções de documentos textuais pode ser utilizada nas tarefas de classificação, agrupamento e construção automática de hierarquia de tópicos para coleções de documentos textuais. De maneira geral, as representações que utilizaram janelas de tamanho 5 obtiveram os melhores resultados.

Observa-se ainda que para coleções de documentos que possuem textos nos quais se possam extrair uma grande quantidade de transações, a abordagem proposta é melhor para algoritmos de classificação que considerem todos os atributos, como o algoritmo Nä̈ve Bayes, ou os atributos em comum, como o algoritmo KNN. No caso da coleção ACM, que possui nomes de autores, locais e nomes de conferências, algoritmos que fazem seleção de atributos embarcada, como o algoritmo J48, ou quando utilizam apenas vetores que contenham esses atributos para criar hiperplanos de separação, como é o caso do método de classificação SMO, foram melhores utilizando a representação bag-of-words. Também quando são utilizados textos com uma grande quantidade de transações, a abordagem proposta proporciona bons resultados para a tarefa de agrupamento de documentos.

Ao utilizar textos curtos, a abordagem proposta não é adequada para tarefas que utilizam medidas de similaridade para gerar os padrões, como é o caso do algoritmo de classificação KNN, e o algoritmo de agrupamento hierárquico UPGMA. Isso se dá pelo fato de que palavras importantes para o cálculo da similaridade em textos curtos podem não ser frequentes, fazendo com que não sejam extraídas pela representação bag-of-relatedwords.

De maneira geral, apesar de em algumas situações a representação bag-of-words obter melhores resultados que a representação bag-of-related-words, não foram verificadas diferenças significativas, e os resultados obtidos pela representação bag-of-related-words auxiliaram a interpretação do conhecimento extraído. Ressalta-se também que a dimensionalidade das representações bag-of-related-words utilizadas foram em sua maioria menores que a da representação bag-of-words. Vale ressaltar também que os valores de limiares de medidas objetivas obtidos automaticamente obtiveram resultados tão bons quanto os definidos manualmente, isentando assim o usuário da definição de parâmetros. 

CAPÍTULO 5

\section{Conclusões}

Técnicas de Mineração de Textos têm-se tornado cada vez mais fundamentais para a organização e extração de conhecimentos devido à grande quantidade de documentos textuais disponíveis. Porém, os documentos textuais geralmente encontram-se em um formato não estruturado ou semi-estruturado, ou seja, não estão em um formato apropriado para a extração de padrões. Portanto, é necessária a estruturação dos documentos textuais de uma coleção para que as técnicas de Mineração de Textos possam ser aplicadas.

A maneira mais comum de representar os documentos textuais de uma coleção é por meio de uma bag-of-words. Neste tipo de representação, todas as palavras da coleção podem ser consideradas como atributos. Essa representação apresenta uma alta dimensionalidade, e não mantém a ordem das palavras ou quais palavras estão relacionadas em um documento textual.

Com isso, o objetivo proposto neste projeto de mestrado foi de desenvolver uma representação de documentos textuais que tenha uma dimensionalidade menor que a representação bag-of-words, que mantenha a relação entre as palavras de um documento textual, e que obtenha resultados para as tarefas de Mineração de Textos tão bons e de mais fácil entendimento que os obtidos pela representação bag-of-words. Para que estes requisitos sejam atendidos, são extraídas regras de associação de cada documento de uma coleção, considerando como transações as sentenças, parágrafos ou janelas deslizantes, e considerando como itens das transações as próprias palavras do documento.

A representação proposta neste projeto de mestrado, nomeada bag-of-related-words, evita alguns dos problemas encontrados pelas abordagens que geram atributos compostos por mais de uma palavra. Dentre eles, pode-se mencionar os seguintes:

- Evita-se a análise de toda a representação de documentos para gerar os atributos, uma vez que são consideradas somente as palavras presentes em um documento e não na coleção de documentos;

- Independe do balanceamento do vocabulário da coleção de documentos, uma vez serão gerados atributos de documentos mesmo que o vocabulário contido neste não seja frequente na coleção de documentos;

- Independe de língua e conhecimento externo, uma vez que não é necessário nenhum conhecimento a respeito da língua ou de um especialista para criar uma base de conhecimento para a geração dos atributos; 
- Os atributos compostos por mais de uma palavra não são adicionados à representação bag-of-words, evitando assim aumentar ainda mais a dimensionalidade da representação dos documentos textuais;

- Evita-se a geração de atributos não significativos para o usuário do processo de Mineração de Textos, uma vez que são gerados atributos compostos por palavras que estão relacionadas e que se repetem ao longo de um documento textual.

Para avaliar o quanto a representação bag-of-related-words é útil para as tarefas de Mineração de Textos em geral, mas principalmente na organização e busca exploratória em grandes coleções de documentos textuais, foram realizados 3 grupos de experimentos:

1. Classificação de documentos textuais para avaliar o quão bom são os atributos da representação bag-of-related-words para distinguir as categorias dos documentos textuais;

2. Agrupamento de documentos textuais para avaliar o quão bom é a estrutura de uma hierarquia de tópicos obtida utilizando a representação bag-of-related-words;

3. Construção automática de hierarquias de tópicos para avaliar o quanto a representação bag-of-related-words auxilia na organização e busca exploratória em coleções de documentos textuais.

Para todos os experimentos realizados, os resultados mostraram que os atributos da representação bag-of-related-words possuem um bom poder preditivo e permitem a construção de agrupamentos de documentos textuais tão bons quanto utilizando a representação bag-of-words. Na avaliação das hierarquias de tópicos por especialistas de domínio, a utilização da representação bag-of-related-words apresentou melhores resultados em todos os quesitos analisados.

Vale ressaltar que mesmo contendo atributos compostos por mais de uma palavra, a dimensionalidade da representação bag-of-related-words foi menor na maioria dos casos e com resultados tão bons quanto a representação bag-of-words. Além disso, ao analisar os resultados obtidos por um algoritmo simbólico de classificação, ou os rótulos de uma hierarquia de tópicos, pode-se perceber que os resultados obtidos utilizando a representação bag-of-related-words são de mais fácil entendimento e trazem mais conhecimento do que os obtidos utilizando a bag-of-words.

Verificou-se também que o mapeamento de janelas deslizantes de tamanho 5 proporcionou a geração de atributos que obtiveram os melhores resultados para as tarefas de classificação e agrupamento de documentos textuais. O uso de medidas de interesse objetivas, na maioria dos casos reduziram o número de atributos e mantiveram a qualidade dos resultados. As diferentes medidas de interesse objetivas demonstraram ser equivalentes na maioria das situações. Os limiares das medidas objetivas também demonstraram ser equivalentes para a maioria das situações. Inclusive o uso dos limiares obtidos automaticamente obteve resultados tão bons quanto os limiares definidos manualmente.

\subsection{Principais Resultados e Contribuições}

A principal contribuição deste projeto de mestrado é a abordagem proposta para representação de documentos textuais bag-of-related-words, que é mais compacta que a representação bag-of-words, gera atributos que contribuem positivamente para o processo de Mineração de Textos, e são mais significativos ao usuário. 
Foram avaliadas quais maneiras de mapear um documento em transações, e quais medidas de interesse objetivas produziram melhores resultados para o processo de Mineração de Textos. Foi verificado que as janelas deslizantes de tamanho 5 obtiveram melhores resultados para as tarefas de classificação e agrupamento de documentos textuais.

Também foi avaliado o uso de medidas de interesse objetivas, além de suporte e confiança, nas regras extraídas dos documentos textuais. Verificou-se que para a grande maioria das situações, as medidas objetivas diminuíram o número de atributos e mantiveram a qualidade dos resultados. Além disso, as medidas objetivas obtiveram resultados semelhantes para as tarefas de classificação e agrupamento de documentos textuais.

Uma das grandes dificuldades ao se trabalhar com regras de associação é a definição de limiares para as medidas objetivas. Verificou-se que os limiares de medidas objetivas definidos manualmente, em sua maioria, não causaram diferenças nos resultados com significância estatística. Foram também desenvolvidos métodos para calcular os limiares tanto do suporte quanto das demais medidas de interesse objetivas utilizadas neste projeto. Verificou-se que os limiares definidos automaticamente obtiveram resultados tão bons quanto os definidos manualmente, ou seja, é possível gerar uma representação bag-ofrelated-words sem que haja a necessidade de definição de limiares.

Foi desenvolvido uma ferramenta computacional para instanciação da representação bag-of-related-words denominada FEATuRE. A ferramenta FEATuRE também foi utilizada em um trabalho em parceria com o laboratório Intermedia (ICMC-USP) para a extração de padrões de ações de usuários em uma página web por meio da análise de arquivos de logs.

Algumas das contribuições tiveram seus resultados publicados em congressos científicos da área de Inteligência Artificial e Mineração de Textos. Foram três publicações relacionadas diretamente a este projeto de mestrado: i) em (Rossi e Rezende, 2010) foi analisado o impacto das diversas formas de mapeamento na tarefa de classificação; ii) em (Rossi e Rezende, 2011b) foi analisado o impacto do uso de diferentes medidas de interesse objetivas na tarefa de classificação; e iii) em (Rossi e Rezende, 2011a) foi analisado o impacto dos diferentes tipos de mapeamento e medidas de interesse objetivas nas tarefas de agrupamento e construção automática de hierarquias de tópicos. O resultado do uso da ferramenta FEATuRE para apoiar a análise das ações dos usuários em uma página web está disponível em (Neto et al., 2010).

Ainda estão sendo escritos um relatório técnico sobre a ferramenta FEATuRE e um artigo que será submetido à revista Information Processing \& Management.

\subsection{Limitações}

Embora os objetivos desse projeto de mestrado tenham sido cumpridos, algumas limitações foram observadas. A primeira refere-se às coleções de documentos textuais utilizadas. Foram utilizados apenas dois domínios de coleções de documentos textuais: artigos científicos e notícias. Outros domínios devem ser estudados para verificar a aplicabilidade da representação bag-of-related-words para documentos textuais de qualquer tipo de domínio.

Outra limitação refere-se à comparação da abordagem proposta neste projeto de mestrado com outros métodos de geração de atributos compostos por mais de uma palavra. Mesmo que o objetivo da representação bag-of-related-words é ser mais compacta e obter melhores resultados que a representação bag-of-words, seria interessante a comparação direta com outras abordagem para a geração de atributos compostos por mais de uma palavra. Entretanto, como foi visto na literatura, esses métodos geram uma dimensional- 
idade muito maior do que as utilizadas neste projeto de mestrado, e os recursos computacionais disponíveis para este projeto não seriam suficientes para gerar e extrair padrões das representações de coleções de documentos textuais utilizadas.

Por fim, foram submetidas hierarquias de tópicos aos especialistas de domínio considerando apenas a representação bag-of-related-words [Jan. 5 Aut. Correlação $\bar{x}]$. Seria interessante a submissão de hierarquias de tópicos construídas com diferentes tipos de representações bag-of-words-related para verificar qual produz um melhor entendimento da coleção de documentos ao usuário. Entretanto, como o processo de avaliação demanda muito tempo do especialista, não foi possível a submissão de hierarquias de tópicos construídas com diferentes representações bag-of-related-words.

\subsection{Trabalhos Futuros}

As primeiras propostas para trabalhos futuros referem-se à eliminação de redundância. Pode-se eliminar as regras redundantes de cada documento, ou eliminar os atributos redundantes da coleção de documentos. Por exemplo, se uma regra rede $\Rightarrow$ neural, possui suporte igual a $10 \%$ e a regra rede $\Rightarrow$ neural, artificial também possui suporte de $10 \%$, poderia-se por exemplo eliminar a regra rede $\Rightarrow$ neural uma vez que toda a sua informação está contida na regra rede $\Rightarrow$ neural, artificial. Processo semelhante pode ser feito com a matriz atributo-valor caso tenha-se um atributo "rede_neural" que apareça nos mesmos documentos em que o atributo "rede_neural_artificial".

Outras medidas de interesse objetivas também podem ser estudadas para verificar se há alguma que produz melhores resultados com diferenças estatisticamente significantes em relação às medidas avaliadas neste projeto de mestrado.

Foram utilizados somente pesos binários nos experimentos. Outros pesos para os atributos podem ser utilizados, como a frequência, tf-idf (Salton, 1989), ou o próprio suporte da regra ou valor de uma medida de interesse objetiva.

Também é interessante que se estudem outras formas da obtenção dos limiares automáticos, uma vez que neste projeto foram apenas analisadas formas simples para o cálculo dos limiares.

Por fim, pretende-se utilizar a forma de obtenção de relações entre palavras proposta neste projeto de mestrado para modelar relações entre nós do tipo termo em uma rede heterogênea para representação de coleções de documentos textuais. 


\section{Referências Bibliográficas}

Adamo, J.-M. (2001). Data mining for association rules and sequential patterns - sequential and parallel algorithms. Springer. Citado na página 12.

Agrawal, R., Imielinski, T., e Swami, A. N. (1993). Mining association rules between sets of items in large databases. In SIGMOD'93: Proceedings of the International Conference on Management of Data, páginas 207-216, Washington, D.C. ACM. Citado na página 13.

Agrawal, R., Mannila, H., Srikant, R., Toivonen, H., e Verkamo, A. I. (1996). Fast discovery of association rules. In Advances in Knowledge Discovery and Data Mining, páginas 307-328. AAAI/MIT Press. Citado na página 25.

Agrawal, R. e Srikant, R. (1994). Fast algorithms for mining association rules in large databases. In VLDB'94: Proceedings of the 20th International Conference on Very Large Data Bases, páginas 487-499, San Francisco, CA, USA. Morgan Kaufmann Publishers Inc. Citado nas páginas 3, 12, e 25.

Ahonen-Myka, H., Heinonen, O., Klemettinen, M., e Verkamo, A. I. (1999). Finding co-occurring text phrases by combining sequence and frequent set discovery. In Proceedings of the Workshop on Text Mining: Foundations, Techniques and Applications. Em conjunto com o IJCAI'99., páginas 1-9. Citado nas páginas 2, 27, 29, 30, e 48.

Antonie, M.-L. e Zaïane, O. R. (2002). Text document categorization by term association. In ICDM'02: Proceedings of the International Conference on Data Mining, página 19, Washington, DC, USA. IEEE Computer Society. Citado na página 14.

Ashrafi, M. Z., Taniar, D., e Smith, K. A. (2004). A new approach of eliminating redundant association rules. In DEXA'04: Proceeding of the International Conference on Database and Expert Systems Applications, páginas 465-474. Springer. Citado na página 14.

Bae, E., Vasudevan, B. G., e Balakrishnan, R. (2008). Acorn: Towards automating domain specific ontology construction process. In APWeb'08: Proceeding of the Asia-Pacific Web Conference, páginas 487-498. Citado na página 34.

Beil, F., Ester, M., e Xu, X. (2002). Frequent term-based text clustering. In SIGKDD'02: Proceedings of the International Conference on Knowledge Discovery and Data Mining, páginas 436-442. ACM. Citado nas páginas 11, 22, 26, 27, e 28.

Bekkerman, R. e Allan, J. (2004). Using bigrams in text categorization. Relatório Técnico IR-408, Center of Intelligent Information Retrieval, UMass Amherst. Citado nas páginas 2, 24, 28, 35, e 49. 
Blanchard, J., Guillet, F., Gras, R., e Briand, H. (2005). Using information-theoretic measures to assess association rule interestingness. In ICDM'05: Proceedings of the International Conference on Data Mining, páginas 66-73. Citado na página 45.

Borgelt, C. (2004). Implementação do algoritmo apriori (versão 4.27) http://www.borgelt.net/apriori.html. Citado na página 50.

Caropreso, M. F., Matwin, S., e Sebastiani, F. (2001). A learner-independent evaluation of the usefulness of statistical phrases for automated text categorization. Text databases \& document management: theory \& practice, páginas 78-102. Citado nas páginas 23, 25 , e 49 .

Carvalho, A. L. C., Moura, E. S., e Calado, P. (2010). Using statistical features to find phrasal terms in text collections. Journal of Information and Data Management, 1(3):583-597. Citado nas páginas 2 e 26.

Carvalho, V. R. e Cohen, W. W. (2006). Improving "email speech acts" analysis via n-gram selection. In ACTS '09: Proceedings of the Workshop on Analyzing Conversations in Text and Speech, páginas 35-41, Morristown, NJ, USA. Association for Computational Linguistics. Citado nas páginas 2, 10, e 26.

Cherfi, H., Napoli, A., e Toussaint, Y. (2006). Towards a text mining methodology using association rule extraction. Soft Computing, 10(5):431-441. Citado na página 14.

Chu, H. (2003). Information Representation and Retrieval in the Digital Age. Information Today. Citado na página 91.

Cohen, W. W., Carvalho, V. R., e Mitchell, T. (2004). Learning to classify email into "speech acts". In CMNLP'04: Proceeding of the Conference on Empirical Methods in Natural Language Processing, páginas 309-316. Citado na página 26.

Conrado, M. S. (2009). O efeito do uso de diferentes formas de extração de termos na compreensibilidade e representatividade dos termos em coleções textuais na língua portuguesa. Dissertação de mestrado, ICMC-USP, São Carlos - SP. Citado na página 9.

Doucet, A. e Ahonen-Myka, H. (2004). Non-contiguous word sequences for information retrieval. In $M W E^{\prime} 04:$ Proceedings of the Workshop on Multiword Expressions, páginas 88-95. Citado na página 29.

Ebecken, N. F. F., Lopes, M. C. S., e Costa, M. C. A. (2003). Mineração de Textos. In Rezende, S. O., editor, Sistemas Inteligentes: Fundamentos e Aplicações, capítulo 13, páginas 337-370. Manole, $1^{\mathrm{a}}$ edição. Citado nas páginas 1 e 7.

Fagan, J. (1989). The effectiveness of a nonsyntactic approach to automatic phrase indexing for document retrieval. Journal of the American Society for Information Science, 40(2):115-132. Citado nas páginas 2, 11, 23, 24, e 48.

Feldman, R., Aumann, Y., Amir, A., Zilberstein, A., e Klösgen, W. (1997). Maximal association rules: A new tool for mining for keyword co-occurrences in document collections. In KDD'97: Proceedings of the International Conference on Knowledge Discovery and Data Mining, páginas 167-170. Citado na página 14.

Feldman, R. e Sanger, J. (2006). The Text Mining Handbook: Advanced Approaches in Analyzing Unstructured Data. Cambridge University Press. Citado nas páginas 1, 12, 14,16 , e 20 . 
Fellbaum, C., editor (1998). WordNet: An Electronic Lexical Database (Language, Speech, and Communication). The MIT Press. Citado na página 26.

Fung, B. C. M., Wang, K., e Ester, M. (2003). Hierarchical document clustering using frequent itemsets. In SIAM SDM'03: Proceedings of the International Conference on Data Mining, páginas 59-70. Citado nas páginas 11, 22, 26, 28, e 48.

Furtado, G. E. A. B. D. S. (2009). How k-nearest neighbor parameters affect its performance. In ASAI'09: Proceedings of the Argentine Symposium on Artificial Intelligence, páginas 1-12. Citado na página 80.

Fürnkranz, J. (1998). A study using n-gram features for text categorization. Relatório Técnico OEFAI-TR-98-30, Austrian Research Institute for Artificial Intelligence. Citado nas páginas $2,10,25,48$, e 49 .

Gantz, J. F. e Reinsel, D. (2010). The digital universe decade - are you ready? External Publication of IDC (Analyse the Future) Information and Data, páginas 1-16. Citado na página 1.

Geng, L. e Hamilton, H. J. (2006). Interestingness measures for data mining: A survey. ACM Computing Surveys, 38(3):9. Citado nas páginas 14 e 45.

Guillet, F. e Hamilton, H. J., editors (2007). Quality Measures in Data Mining, volume 43 of Studies in Computational Intelligence. Springer. Citado nas páginas 14 e 45.

Gupta, V. e Lehal, G. (2009). A survey of text mining techniques and applications. Journal of Emerging Technologies in Web Intelligence, 1(1):60 - 76. Citado na página 1.

Holt, J. D. e Chung, S. M. (2001). Multipass algorithms for mining association rules in text databases. Knowledge and Information Systems, 3(2):168-183. Citado na página 14.

Holt, J. D. e Chung, S. M. (2007). Parallel mining of association rules from text databases. The Journal of Supercomputing, 39(3):273-299. Citado na página 14.

Ienco, D. e Meo, R. (2008). Towards the automatic construction of conceptual taxonomies. In Data Warehousing and Knowledge Discovery, páginas 327-336. Springer. Citado na página 35 .

Jaroszewicz, S. e Simovici, D. A. (2002). Pruning redundant association rules using maximum entropy principle. In PAKDD'02: Proceeding of the Pacific-Asia Conference on Knowledge Discovery and Data Mining, páginas 135-147. Springer. Citado na página 14.

Kanji, G. K. (2006). 100 Statistical Tests. SAGE Publications, $3^{\text {a }}$ edição. Citado na página 55.

Kashyap, V., Ramakrishnan, C., Thomas, C., e Sheth, A. P. (2005). Taxaminer: an experimentation framework for automated taxonomy bootstrapping. International Journal of Web and Grid Services, 1(2):240-266. Citado nas páginas 34 e 35.

Kongthon, A., Haruechaiyasak, C., e Thaiprayoon, S. (2008). Construction term thesaurus using text association rule mining. In CON'08: Proceeding of 6th International Conference on Electrical Engineering/Electronics, Computer, Telecommunications, and Information Technology, páginas 137-140. IEEE. Citado na página 14. 
Koster, C. e Seutter, M. (2003). Taming wild phrases. In ECIR'09: Proceedings of the European Conference on Information Retrieval, páginas 161-176. Citado na página 11.

Larsen, B. e Aone, C. (1999). Fast and effective text mining using linear-time document clustering. In SIGKDD'9: Proceeding of the International Conference on Knowledge Discovery and Data Mining, páginas 16-22. Citado nas páginas 22, 35, e 54.

Lenca, P., Vaillant, B., Meyer, P., e Lallich, S. (2007). Association rule interestingness measures: Experimental and theoretical studies. páginas 51-76. Citado na página 46.

Li, Y., Chung, S. M., e Holt, J. D. (2008). Text document clustering based on frequent word meaning sequences. Data $\&$ Knowledge Engineering, 64(1):381-404. Citado nas páginas 26 e 48.

Lie, Y., Loh, H. T., e Lu, W. G. (2007). Deriving taxonomy from documents at sentence level. In Do Prado, H. A. e Ferneda, E., editors, Emerging Technologies of Text Mining: Techniques and Applications, capítulo 5, páginas 99-119. Information Science Reference, $1^{\mathrm{a}}$ edição. Citado na página 30 .

Liu, B., Hsu, W., e Ma, Y. (1999). Pruning and summarizing the discovered associations. In SIGKDD'99: Proceedings of the International Conferenceon Knowledge Discovery and Data Mining, páginas 125-134. Citado na página 14.

Liu, G., Chang, E., e Han, S. (2005a). Powerful tool to expand business intelligence: Text mining. World Academy of Science, Engineering and Technology, 8:334-337. Citado na página 12.

Liu, N., Zhang, B., Yan, J., Chen, Z., Liu, W., Bai, F., e Chien, L. (2005b). Text representation: from vector to tensor. In ICDM'05: Proceedings of the International Conference on Data Mining, páginas 725 - 728. Citado na página 33.

Liu, S. e Hu, H. (2007). Text classification using sentential frequent itemsets. Journal of Computer Science and Technology, 22(2):334-337. Citado na página 14.

Lopes, A. A., Pinho, R., Paulovich, F. V., e Minghim, R. (2007). Visual text mining using association rules. Computers \& Graphics, 31(3):316-326. Citado na página 14.

Manning, C. D., Raghavan, P., e Schütze, H. (2008). An Introduction to Information Retrieval. Cambridge University Press. Citado na página 91.

Marcacini, R. M., Moura, M. F., e Rezende, S. O. (2007). Biblioteca digital do IFM: uma aplicação para a organização da informação por meio de agrupamentos hierárquicos. In WDL'0\%: Proceeding of the Workshop on Digital Libraries, volume CD-ROM of WDL, páginas 1-16. Citado na página 12.

Marcacini, R. M. e Rezende, S. O. (2008). Técnicas de visualização de informação para análise de taxonomias de tópicos. In II Assembléia Geral do IFM, volume 1, páginas 1-248. Instituto Fábrica do Milênio, Campinas - SP. Citado na página 53.

Marcacini, R. M. e Rezende, S. O. (2010). Torch: a tool for building topic hierarchies from growing text collection. In WFA'2010: IX Workshop de Ferramentas e Aplicações. Em conjunto com o XVI Simpósio Brasileiro de Sistemas Multimídia e Web (Webmedia), páginas 1-3. Citado nas páginas 53 e 91. 
McNicholas, P. D., Murphy, T. B., e O'Regan, M. (2008). Standardising the lift of an association rule. Computational Statistics \& Data Analysis, 52(10):4712-4721. Citado na página 45 .

Mitra, M., Buckley, C., Singhal, A., e Cardie, C. (1997). An analysis of statistical and syntactic phrases. In RIAO'97: International Conference on Computer-Assisted Information Retrieval, páginas 200-217. Citado nas páginas 11, 23, 24, e 29.

Mladenic, D. e Grobelnik, M. (1998). Word sequences as features in text-learning. In ERK'98: Proceeding of the Electrotechnical and Computer Science Conference, páginas 145-148. Citado nas páginas 2, 11, 24, 25, e 49.

Moura, M. F. (2009). Contribuições para a construção de taxonomias de tópicos em dominios restritos utilizando aprendizado estatistico. Tese de Doutorado, Instituto de Ciências Matemáticas e Computação - USP. Citado nas páginas 10, 34, e 35.

Neto, A. T., Fortes, R. P., Rossi, R. G., e Rezende, S. O. (2010). Mmwa-ae: boosting knowledge from multimodal interface design, reuse and usability evaluation. In SEKE'2010: Proceedings of the International Conference on Software Engineering and Knowledge Engineering, páginas 355-360. KSI - Knowledge Systems Institute. Citado na página 99.

Piatetsky-Shapiro, G. (1991). Discovery, analysis and presentation of strong rules. In Piatetsky-Shapiro, G. e Frawley, W. J., editors, Knowledge Discovery in Databases, páginas 229-248. AAAI Press. Citado na página 46.

Porter, M. F. (1980). An algorithm for suffix stripping. Readings in Information Retrieval, 14(3):130-137. Citado nas páginas 49 e 55.

Rezende, S. O., editor (2003). Sistemas Inteligentes - Fundamentos e Aplicações. Manole, Barueri, SP, Brasil. Citado nas páginas ix e 8.

Rezende, S. O., Pugliesi, J. B., Melanda, E. A., e Paula, M. F. (2003). Mineração de dados. In Rezende, S. O., editor, Sistemas Inteligentes - Fundamentos e Aplicações, capítulo 12, páginas 307-335. Manole, $1^{\text {a }}$ edição. Citado na página 8.

Rossi, R. G. e Rezende, S. O. (2010). The use of frequent itemsets extracted from textual documents for the classification task. In WTI'2010: III International Workshop on Web and Text Intelligence. Em conjunto com Joint Conference 2010 (SBIA, SBRN, JRI). Citado na página 99.

Rossi, R. G. e Rezende, S. O. (2011a). Building a topic hierarchy using the bag-ofrelated-words representation. In ACM DOCENG'2011: ACM Symposium on Document Engineering. Citado na página 99.

Rossi, R. G. e Rezende, S. O. (2011b). Generating features from textual documents through association rules. In ENIA'2011: Encontro Nacional de Inteligência Artificial. Citado na página 99.

Salton, G. (1989). Automatic text processing: the transformation, analysis, and retrieval of information by computer. Addison-Wesley Longman Publishing Co., Inc., Boston, MA, USA. Citado nas páginas 1, 9, 10, e 100. 
Schenker, A., Last, M., Bunke, H., e Kandel, A. (2003). Classification of web documents using a graph model. In ICDAR'03: Proceedings of the International Conference on Document Analysis and Recognition, página 240, Washington, DC, USA. IEEE Computer Society. Citado na página 1.

Scott, S. e Matwin, S. (1999). Feature engineering for text classification. In ICML'99: Proceedings of the International Conference on Machine Learning, páginas 379-388, San Francisco, CA, USA. Morgan Kaufmann Publishers Inc. Citado na página 2.

Sebastiani, F. (2002). Machine learning in automated text categorization. ACM Computing Surveys, 34(1):1-47. Citado nas páginas 15 e 16.

Silberschatz, A. e Tuzhilin, A. (1995). On subjective measures of interestingness in knowledge discovery. In KDD'95: Proceeding of the Conference on Knowledge Discovery and Data Mining, páginas 275-281. Citado na página 12.

Soares, M. V. B., Prati, R. C., e Monard, M. C. (2008). PReTexT II: Descrição da reestruturação da ferramenta de pré-processamento de textos. Relatório Técnico 333, ICMC-USP. http://www.icmc.usp.br/ biblio/BIBLIOTECA/rel_tec/RT_333.pdf. Citado nas páginas 53 e 55.

Solé, R. V., Corominas, B., Valverde, S., e Steels, L. (2010). Language networks: their structure, function and evolution. Complexity, 15(6):20-26. Citado na página 33.

Song, M. e fang Brook Wu, Y. (2008). Handbook of Research on Text and Web Mining Technologies. Information Science Reference, illustrated edition ${ }^{a}$ edição. Citado na página 1.

Souza, M. I. F., Santos, A. D., Moura, M. F., e Alves, M. D. R. (2006). Agência de informação embrapa: uma aplicação para a organização da informação e gestão do conhecimento. In WDL'06: Proceeding of the Workshop de Bibliotecas Digitais, páginas 51-56, Florianópolis, SC. Sociedade Brasileira de Computação. Citado na página 12.

Steinbach, M., Karypis, G., e Kumar, V. (2000). A comparison of document clustering techniques. In Grobelnik, M., Mladenic, D., e Milic-Frayling, N., editors, KDD-2000 Workshop on Text Mining, páginas 109-111, Boston, MA. Citado na página 54.

Tan, C.-M., Wang, Y.-F., e Lee, C.-D. (2002a). The use of bigrams to enhance text categorization. Information Processing and Management, 38(4):529-546. Citado nas páginas 10, 25, e 49 .

Tan, P.-N., Kumar, V., e Srivastava, J. (2002b). Selecting the right interestingness measure for association patterns. In SIGKDD'2002: Proceedings of the International Conferenceon Knowledge Discovery and Data Mining, páginas 32-41. ACM. Citado nas páginas 14, 45, e 46.

Tan, P.-N., Steinbach, M., e Kumar, V. (2005). Introduction to Data Mining. AddisonWesley. Citado nas páginas 18 e 19.

Tesar, R., Strnad, V., Jezek, K., e Poesio, M. (2006). Extending the single words-based document model: a comparison of bigrams and 2-itemsets. In DocEng'06: Symposium on Document Engineering, páginas 138-146. Citado nas páginas 2, 10, 29, e 48.

Witten, I. H. e Frank, E. (2005). Data Mining: Practical machine learning tools and techniques. Morgan Kaufmann, $2^{\mathrm{a}}$ edição. Citado nas páginas 4, 51, e 53. 
Wu, J., Xiong, H., e Chen, J. (2009). Adapting the right measures for k-means clustering. In SIGKDD'09: Proceeding of the International Conference on Knowledge Discovery and Data Mining, páginas 877-886. ACM. Citado nas páginas 2 e 46.

Yang, Z., Zhang, L., Yan, J., e Li, Z. (2003). Using association features to enhance the performance of naïve bayes text classifier. In ICCIMA '03: Proceeding of the International Conference on Computational Intelligence and Multimedia Applications, página 336. IEEE Computer Society. Citado nas páginas 2, 27, 28, 48, e 49.

Yu, L. e Liu, H. (2004). Efficient feature selection via analysis of relevance and redundancy. Journal of Machine Learning Research, 5:1205 - 1224. Citado na página 10.

Zamir, O. e Etzioni, O. (1998). Web document clustering: a feasibility demonstration. In SIGIR'98: Proceedings of the International Conference on Research and Development in Information Retrieval, páginas 46-54, New York, NY, USA. ACM. Citado na página 33.

Zhang, C., Wang, H., Liu, Y., e Xu, H. (2009). Document clustering description extraction and its application. In ICCPOL'09: Proceeding of the International Conference on the Computer Processing of Oriental Languages, páginas 370-377. Springer. Citado na página 35.

Zhang, C. e Zhang, S. (2002). Association Rule Mining, Models and Algorithms, volume 2307 of Lecture Notes in Computer Science. Springer, $1^{\mathrm{a}}$ edição. Citado na página 13.

Zhang, D. e Lee, W. S. (2003). Question classification using support vector machines. In SIGIR'03: Proceedings of the International Conference on Research and Development in Informaion Retrieval, páginas 26-32, New York, NY, USA. ACM. Citado na página 25.

Zhang, X. e Zhu, X. (2007). A new type of feature - loose n-gram feature in text categorization. In IbPRIA'0\%: Proceeding of the Iberian Conference on Pattern Recognition and Image Analysis, páginas 378-385. Springer. Citado nas páginas 2, 29, e 49.

Zhao, Y. e Karypis, G. (2002). Evaluation of hierarchical clustering algorithms for document datasets. In CIKM '02: Proceedings of the International Conference on Information and Knowledge Management, páginas 515-524. ACM Press. Citado nas páginas 20, 21, e 22 . 



\section{APÊNDICE}

A

\section{Pseudocódigos para a geração da representação bag-of-related-words}

Neste apêndice são apresentados os pseudocódigos dos passos para a obtenção da representação bag-of-related-words apresentados no Capítulo 3.

No Algoritmo 1 são apresentados os passos gerais para a geração dos atributos de cada documento $d_{i}$ da coleção de documentos $D$, e após esse processo, a construção da representação bag-of-related-words. As funções das linhas 2, 3, 4, 5 e 8 são apresentadas nos Algoritmos 2, 3, 4, 5 e 6 respectivamente. Na linha 7 é criado o vocabulário da coleção de documentos, que corresponde a união dos atributos de todos os documentos da coleção textual.

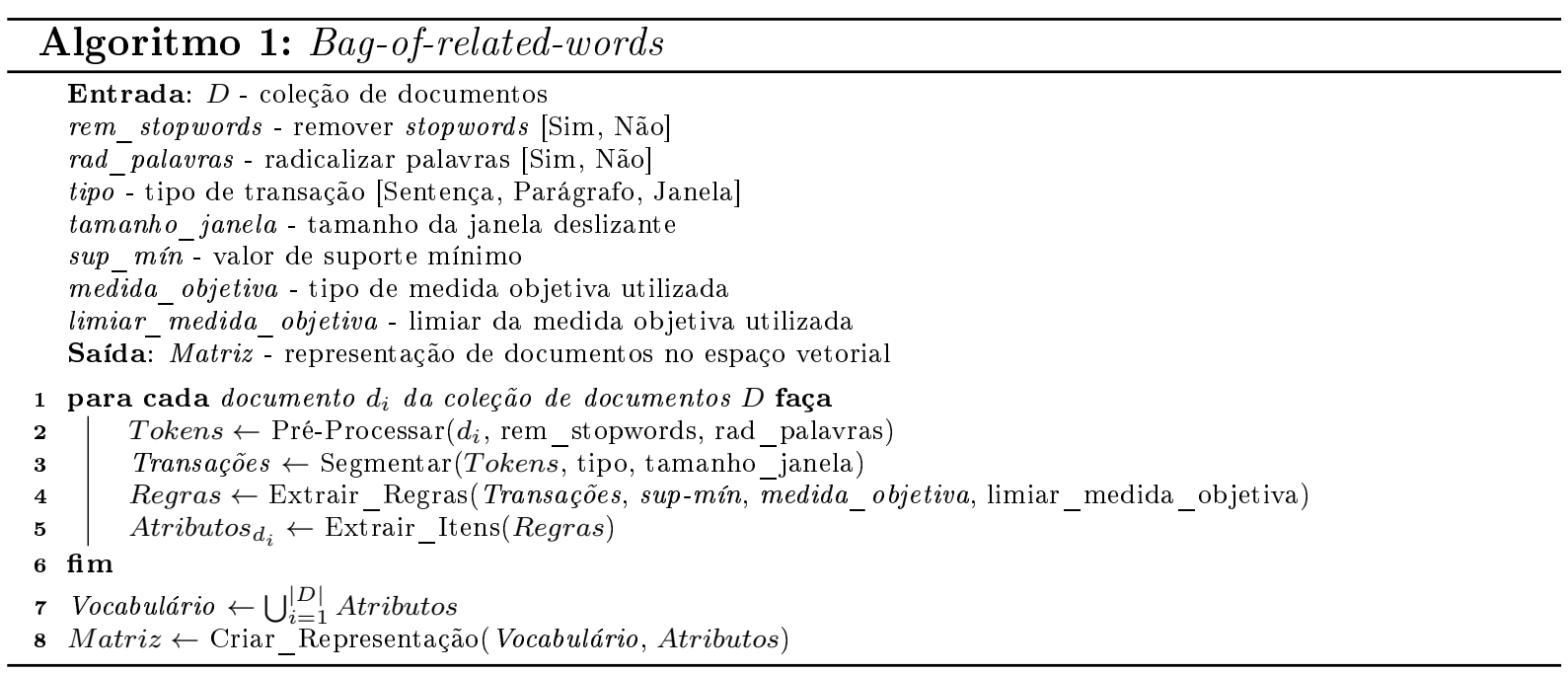

No Algoritmo 2 é realizado o pré-processamento de cada documento $d_{i}$ da coleção $D$. Neste algoritmo são realizadas a remoção de stopwords e a radicalização de palavras, caso seja a opção definida pelo usuário, e a saída é uma lista dos tokens, armazenada na variável Tokens, que contém as palavras após o pré-processamento e os sinais de pontuação.

No Algoritmo 3 é realizado o mapeamento do documento textual em transações. O algoritmo recebe como entrada uma lista de tokens, armazenado na variável Tokens, obtida pelo Algoritmo 2. São consideradas como sentenças todas as sequências de tokens entre os sinais de pontuação “.", "!", ou "?". Como parágrafos são considerados todas as 


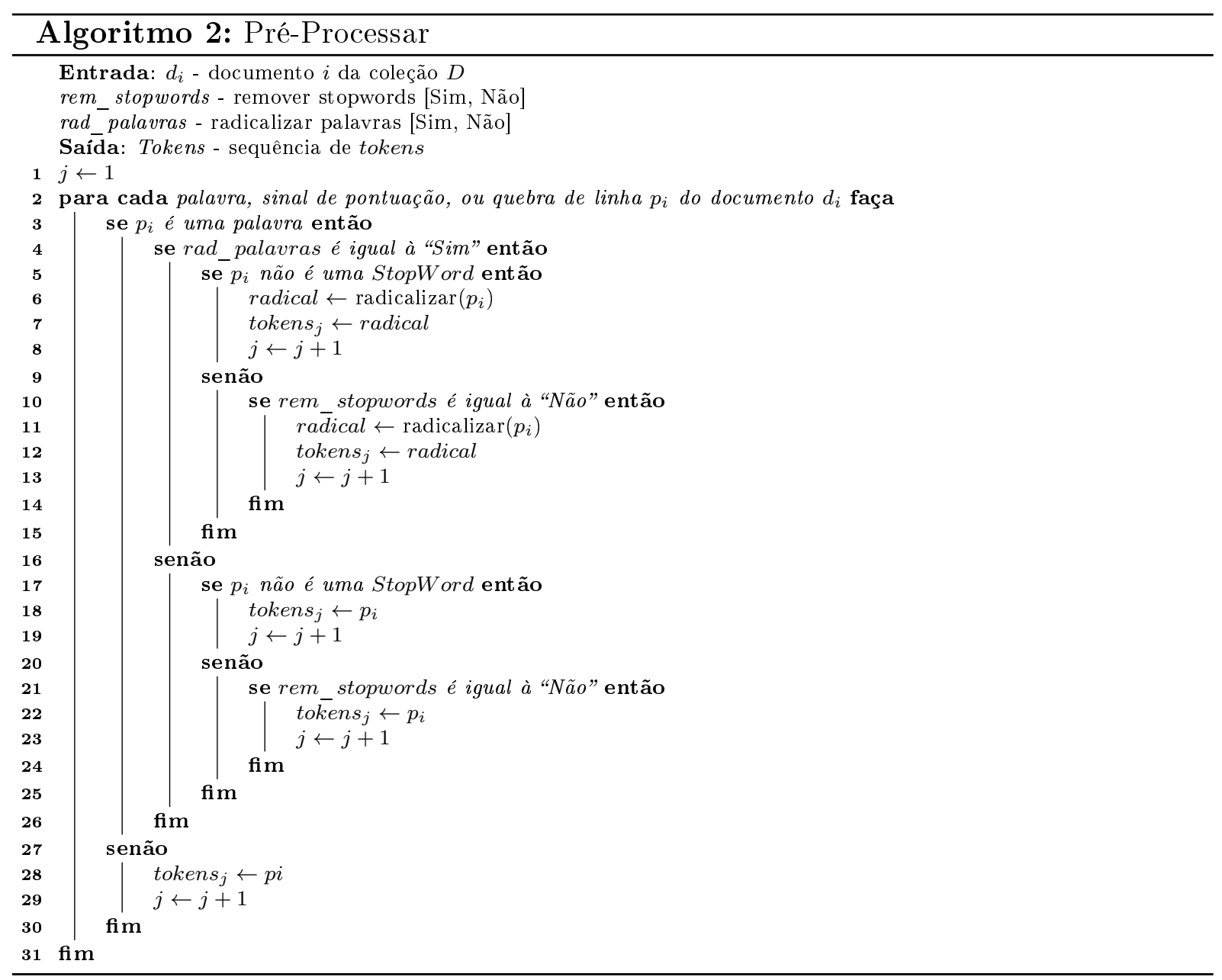

sequências de tokens entre os sinais de pontuação ".", "!", ou "?" que são seguidos por uma quebra de linha. Como janelas são consideradas as sequências de tokens de tamanho pré-determinado. Para isso são desconsiderados os sinais de pontuação como tokens. Vale ressaltar que as primeiras e as últimas transações possuem um número de tokens menor que o tamanho da janela, como apresentado na Seção 3.1.1.

No Algoritmo 4 são extraídas as regras de associação para cada documento $d_{i}$ da coleção de documentos $D$. Inicialmente são extraídas as regras de associação utilizando apenas o suporte mínimo.

No Algoritmo 5 são extraídos os itens das regras de associação de cada documento $d_{i}$ da coleção $D$ para utilizá-los como atributos. Nesta faze são utilizadas as medidas de interesse objetivas para podar as regras de associação extraídas para o documento $d_{i}$. Os itens das regras são ordenados lexicograficamente ou por algum tipo de ordem definida, por exemplo, a ordem em que as palavras aparecem nos documentos. Os itens ordenados são concatenados e adicionados ao conjunto de atributos do documento $d_{i}$.

No Algoritmo 6 é apresentado o pseudocódigo para criar a representação bag-of-relatedwords após a extração dos atributos da coleção de documentos. Utilizando a lista de atributos completa da coleção de documentos, armazenada na variável Vocabulário, são analisados os atributos de cada documento $d_{i}$ da coleção $D$. Para cada atributo do documento $d_{i}$ é verificada a sua posição na lista Vocabulário. De acordo com a posição, o atributo com seu respectivo peso é adicionado na matriz que representa o espaço vetorial. 


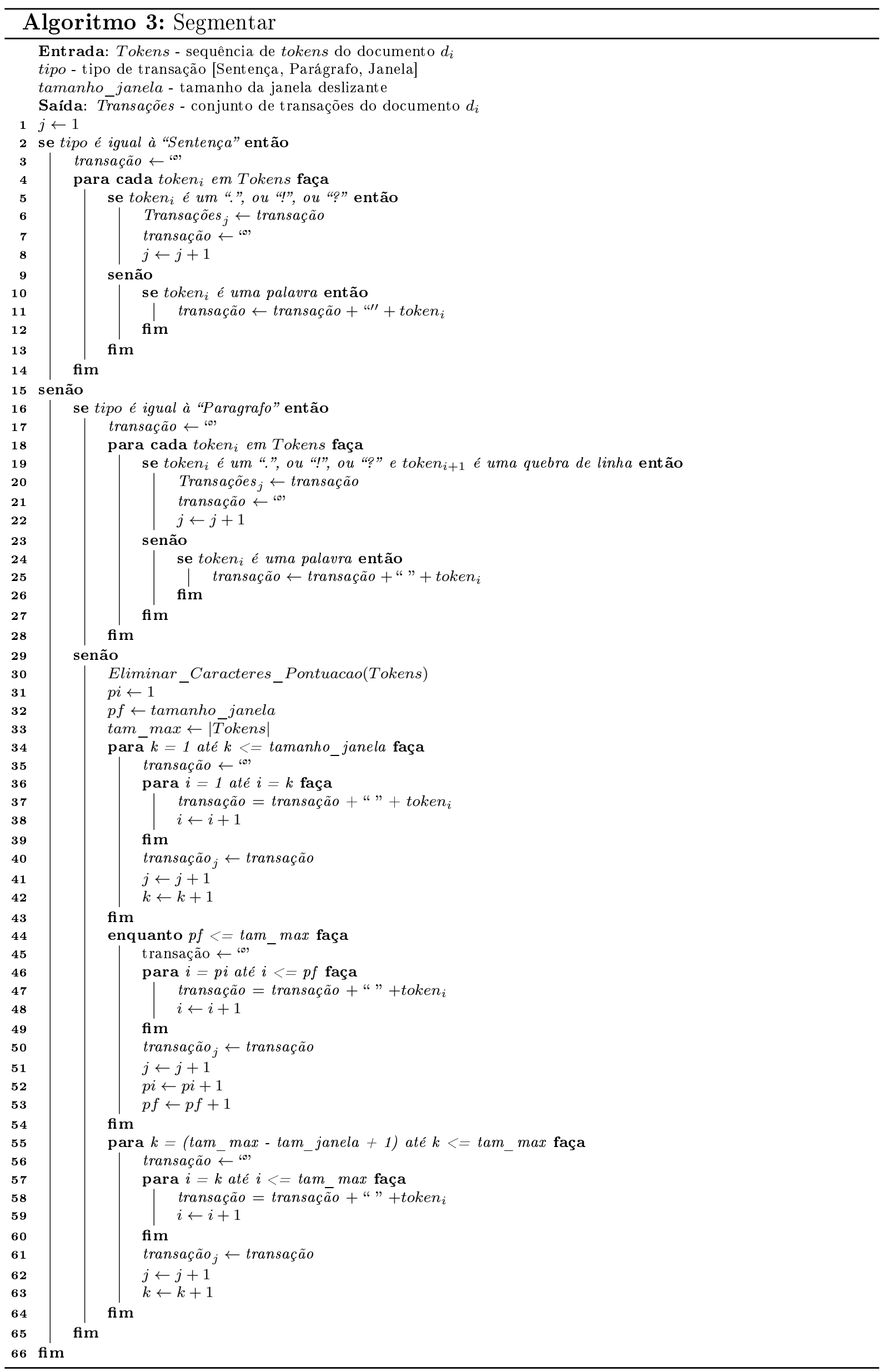



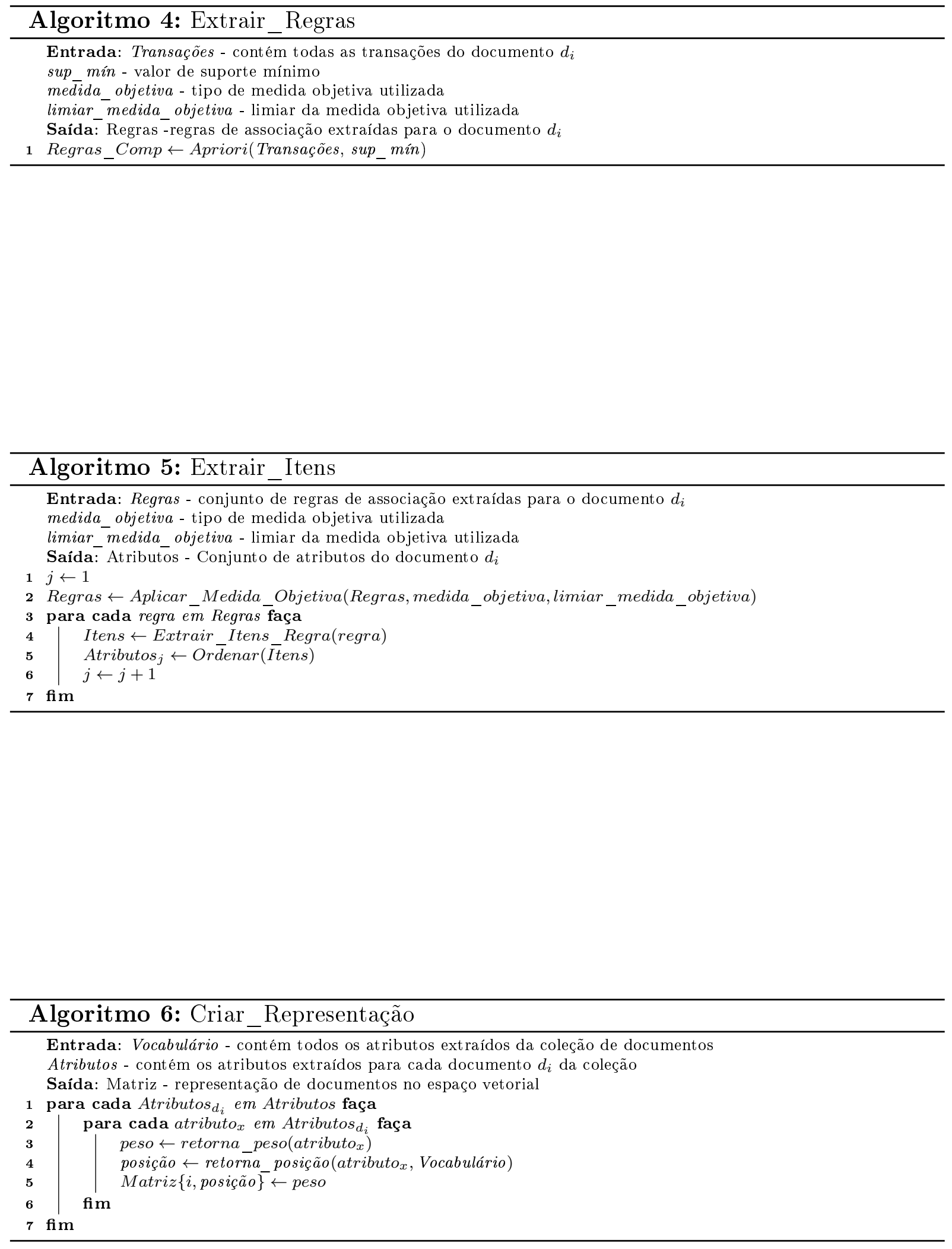


\section{Tabelas com o Número de Atributos das Coleções Textuais}

Neste apêndice são apresentadas as tabelas contendo o número de atributos gerados pelas representações bag-of-related-words e pela representação bag-of-words para as coleções utilizadas neste trabalho. Na Tabela B.1 é apresentado o número de atributos das representações bag-of-related-words que utilizaram os itemsets frequentes como atributos para as coleções da ACM. Na Tabela B.2 é apresentado o número de atributos das representações bag-of-related-words que utilizaram medidas de interesse objetivas para gerar os atributos para as coleções da ACM. Na Tabela B.3 é apresentado o número de atributos para a coleção Reuters-21578 obtido pelas representações bag-of-related-words que utilizaram medidas de interesse objetivas para gerar os atributos. 
Tabela B.1: Número de atributos das coleções da ACM obtidos pela representação bag-of-words e pelas representações bag-of-related-words que utilizaram itemsets frequentes como atributos.

\begin{tabular}{|c|c|c|c|c|c|c|c|c|}
\hline & \multicolumn{8}{|c|}{$\mathrm{N}^{\circ}$ de Atributos } \\
\hline Representação & ACM-1 & ACM-2 & ACM-3 & ACM-4 & ACM-5 & ACM-6 & ACM-7 & ACM-8 \\
\hline Bag-of-words & 38352 & 43844 & 37498 & 47830 & 36688 & 52198 & 50732 & 45886 \\
\hline Sent. $2 \%$ & 42324 & 45624 & 51532 & 37077 & 47814 & 37521 & 37309 & 45975 \\
\hline Sent. $3 \%$ & 16105 & 17007 & 20260 & 14883 & 17549 & 15337 & 14798 & 18546 \\
\hline Sent. $4 \%$ & 8251 & 8762 & 10494 & 7777 & 8984 & 8072 & 7791 & 9780 \\
\hline Sent. $5 \%$ & 4995 & 5406 & 5970 & 4677 & 5537 & 5075 & 4841 & 6012 \\
\hline Sent. $6 \%$ & 3396 & 3580 & 3927 & 3119 & 3756 & 3576 & 3256 & 4077 \\
\hline Par. 9\% & 52975 & 60702 & 70405 & 108554 & 80594 & 58487 & 40381 & 50658 \\
\hline Par. $10 \%$ & 36542 & 37802 & 46299 & 34411 & 45511 & 32674 & 26664 & 35872 \\
\hline Par. $11 \%$ & 24814 & 25852 & 34730 & 21975 & 32538 & 23953 & 19137 & 25539 \\
\hline Par. $12 \%$ & 17848 & 18530 & 23420 & 16563 & 22093 & 18368 & 14061 & 18828 \\
\hline Par. $13 \%$ & 13507 & 13144 & 16003 & 12853 & 16421 & 12507 & 10634 & 14065 \\
\hline Jan. $50,6 \%$ & 54286 & 66359 & 58290 & 55279 & 62201 & 60790 & 55299 & 60046 \\
\hline Jan. $50,8 \%$ & 32000 & 36957 & 33803 & 31850 & 35142 & 35978 & 33254 & 35741 \\
\hline Jan. $51 \%$ & 19688 & 22761 & 20710 & 19586 & 21568 & 22215 & 20923 & 22522 \\
\hline Jan. $52 \%$ & 6465 & 7307 & 6659 & 6215 & 6978 & 7314 & 6953 & 7598 \\
\hline Jan. $53 \%$ & 3606 & 3934 & 3609 & 3392 & 3864 & 4024 & 3866 & 4191 \\
\hline Jan. 5 Aut. & 35340 & 32907 & 35008 & 34961 & 39073 & 41317 & 45475 & 49524 \\
\hline Jan. $102 \%$ & 44493 & 53240 & 49690 & 46415 & 49598 & 51215 & 47275 & 52526 \\
\hline Jan. $103 \%$ & 20236 & 23827 & 22299 & 20744 & 22503 & 23311 & 21982 & 24261 \\
\hline Jan. $104 \%$ & 10930 & 12900 & 12045 & 11261 & 12155 & 12779 & 11989 & 13382 \\
\hline Jan. $105 \%$ & 7272 & 8385 & 7835 & 7239 & 7959 & 8444 & 7846 & 8847 \\
\hline Jan. $106 \%$ & 5036 & 5804 & 5431 & 4999 & 5550 & 5973 & 5468 & 6157 \\
\hline Jan. $206 \%$ & 40015 & 49424 & 46988 & 42613 & 45592 & 46233 & 42575 & 48386 \\
\hline Jan. $207 \%$ & 27803 & 33497 & 32348 & 29193 & 31642 & 31807 & 29827 & 33656 \\
\hline Jan. $208 \%$ & 19647 & 23977 & 22758 & 21099 & 22653 & 22533 & 21163 & 23957 \\
\hline Jan. $209 \%$ & 14691 & 17681 & 16897 & 15682 & 16843 & 16666 & 15740 & 17709 \\
\hline Jan. $2010 \%$ & 12340 & 13572 & 12996 & 12021 & 12867 & 12726 & 12149 & 13678 \\
\hline Jan. $3010 \%$ & 46572 & 59747 & 56431 & 51480 & 55171 & 55567 & 47746 & 54164 \\
\hline Jan. $3011 \%$ & 35409 & 44654 & 42681 & 38549 & 41919 & 41792 & 36411 & 41180 \\
\hline Jan. $3012 \%$ & 27535 & 34367 & 32936 & 29812 & 32436 & 32170 & 28522 & 32007 \\
\hline Jan. $3013 \%$ & 21728 & 27149 & 26039 & 23724 & 25774 & 25388 & 22616 & 25637 \\
\hline Jan. $3014 \%$ & 17573 & 21805 & 20953 & 19032 & 20757 & 20282 & 18252 & 20638 \\
\hline
\end{tabular}

Tabela B.2: Número de atributos das coleções da ACM obtidas pelas representações bag-of-words e bag-of-related-words que utilizaram medidas de interesse objetivas para gerar os atributos.

\begin{tabular}{|c|c|c|c|c|c|c|c|c|}
\hline & \multicolumn{8}{|c|}{$\mathrm{N}^{\circ}$ de Atributos } \\
\hline Representação & ACM-1 & ACM-2 & ACM-3 & ACM-4 & ACM-5 & ACM-6 & ACM-7 & ACM-8 \\
\hline Bag-of-words & 38352 & 43844 & 37498 & 47830 & 36688 & 52198 & 50732 & 45886 \\
\hline Jan. 5 Aut. Conf. 0.25 & 14133 & 14245 & 13390 & 13760 & 14620 & 16273 & 16429 & 17175 \\
\hline Jan. 5 Aut. Conf. 0.5 & 9153 & 9445 & 8319 & 8946 & 9449 & 10198 & 10235 & 10292 \\
\hline Jan. 5 Aut. Conf. $\bar{x}$ & 17477 & 17137 & 17124 & 17506 & 18938 & 20351 & 21751 & 23269 \\
\hline Jan. 5 Aut. Lift 0.1 & 13738 & 13926 & 13184 & 13656 & 14733 & 15778 & 16570 & 16981 \\
\hline Jan. 5 Aut. Lift 0.2 & 8558 & 8997 & 7737 & 8371 & 8937 & 9544 & 9403 & 9346 \\
\hline Jan. 5 Aut. Lift $\bar{x}$ & 13739 & 13927 & 13185 & 13657 & 14774 & 15779 & 16571 & 16982 \\
\hline Jan. 5 Aut. Yule's Q 0.5 & 25785 & 24619 & 25030 & 25634 & 27643 & 30661 & 32688 & 34439 \\
\hline Jan. 5 Aut. Yule's Q 0.75 & 19926 & 19184 & 18902 & 19680 & 20973 & 23500 & 24756 & 25591 \\
\hline Jan. 5 Aut. Yule's Q $\bar{x}$ & 24022 & 23062 & 23734 & 24147 & 26349 & 28411 & 30982 & 32897 \\
\hline Jan. 5 Aut. Corr. 0.25 & 15319 & 15414 & 14375 & 14935 & 15920 & 17651 & 17839 & 18402 \\
\hline Jan. 5 Aut. Corr. 0.50 & 9272 & 9623 & 8387 & 9027 & 9631 & 10281 & 10263 & 10290 \\
\hline Jan. 5 Aut. Corr. $\bar{x}$ & 33069 & 31056 & 32671 & 32827 & 36303 & 38926 & 42510 & 45834 \\
\hline Jan. 5 Aut. I.M. 0.01 & 7509 & 7980 & 6731 & 7359 & 7853 & 8266 & 8361 & 8151 \\
\hline Jan. 5 Aut. I.M. 0.005 & 25371 & 24682 & 24795 & 24946 & 27214 & 29848 & 31230 & 33128 \\
\hline Jan. 5 Aut. I.M. $\bar{x}$ & 17159 & 16887 & 16582 & 17137 & 18502 & 19999 & 21227 & 22331 \\
\hline Jan. 5 Aut. Gini 0.01 & 14478 & 15007 & 13683 & 13836 & 14808 & 16221 & 16011 & 16755 \\
\hline Jan. 5 Aut. Gini 0.005 & 20389 & 20326 & 19854 & 19657 & 21174 & 23547 & 23906 & 25765 \\
\hline Jan. 5 Aut. Gini $\bar{x}$ & 17978 & 17582 & 17519 & 17990 & 19416 & 21015 & 22283 & 23699 \\
\hline Jan. 5 Aut. Kappa 0.2 & 14846 & 15399 & 15035 & 14322 & 16247 & 15832 & 16876 & 18828 \\
\hline Jan. 5 Aut. Kappa 0.15 & 20514 & 20600 & 20927 & 20002 & 22907 & 22713 & 24614 & 27226 \\
\hline Jan. 5 Aut. Kappa $\bar{x}$. & 21120 & 20111 & 20632 & 20583 & 23508 & 23998 & 26233 & 28472 \\
\hline Jan. 5 Aut. J.M. 0.01 & 22160 & 21781 & 21430 & 21531 & 23245 & 25906 & 26630 & 28378 \\
\hline Jan. 5 Aut. J.M. 0.02 & 16290 & 16573 & 15477 & 15560 & 16777 & 18625 & 18483 & 19468 \\
\hline Jan. 5 Aut. J.M. $\bar{x}$ & 17884 & 17607 & 17481 & 17898 & 19408 & 20981 & 22350 & 23590 \\
\hline
\end{tabular}


Tabela B.3: Número de atributos da coleção Reuters-21578 obtidas pela representação bag-of-words e pelas representações bag-of-related-words que utilizaram medidas interesse objetivas para gerar os atributos.

\begin{tabular}{|l|r|}
\hline Representação & N $^{\mathbf{O}}$ de atributos \\
\hline Bag & 11711 \\
\hline Jan. 5 Lift 0.1 & 13006 \\
\hline Jan. 5 Lift 0.2 & 10952 \\
\hline Jan. 5 Lift Aut. & 9288 \\
\hline Jan. 5 Aut. Conf. 0.25 & 13816 \\
\hline Jan. 5 Aut. Conf. 0.50 & 9836 \\
\hline Jan. 5 Aut. Conf. Aut. & 9804 \\
\hline Jan. 5 Aut. Yule's Q 0.50 & 13275 \\
\hline Jan. 5 Aut. Yule's Q 0.75 & 11483 \\
\hline Jan. 5 Aut. Yule's Q Aut. & 11155 \\
\hline Jan. 5 Aut. Corr. 0.25 & 12625 \\
\hline Jan. 5 Aut. Corr. 0.50 & 8951 \\
\hline Jan. 5 Aut. Corr. Aut. & 14835 \\
\hline Jan. 5 Aut. I.M. 0.05 & 11535 \\
\hline Jan. 5 Aut. I.M. 0.1 & 9688 \\
\hline Jan. 5 Aut. I.M. Aut. & 9488 \\
\hline Jan. 5 Aut. Gini 0.01 & 13928 \\
\hline Jan. 5 Aut. Gini 0.04 & 11657 \\
\hline Jan. 5 Aut. Gini Aut. & 10030 \\
\hline Jan. 5 Aut. Kappa 0.3 & 13739 \\
\hline Jan. 5 Aut. Kappa 0.5 & 9612 \\
\hline Jan. 5 Aut. Kappa Aut. & 10121 \\
\hline Jan. 5 Aut. J.M. 0.02 & 13447 \\
\hline Jan. 5 Aut. J.M. 0.05 & 11883 \\
\hline Jan. 5 Aut. J.M. Aut. & 9921 \\
\hline
\end{tabular}

Pode-se notar pela Tabela B.1 que somente o menor valor de suporte de cada tipo de mapeamento gerou uma dimensionalidade maior que a representação bag-of-words. A janela de tamanho 5 com suporte automático ([Jan. 5 Aut.]) apresentou maior dimensionalidade em relação à representação bag-of-words somente para a coleção ACM-6. Como as representações que utilizaram medidas objetivas tiveram como base a representação [Jan. 5 Aut.] e as medidas de interesse foram utilizadas para diminuir o número de atributos, todas as representações com medidas objetivas tiveram uma dimensionalidade menor em relação à bag-of-words para todas as coleções da ACM, como apresentado na Tabela B.2. Já para a coleção Reuters-21578, somente os menores limiares de medidas objetivas utilizadas geraram uma dimensionalidade maior que a representação bag-of-words. O limiar $\bar{x}$ gerou uma dimensionalidade menor para todas as medidas de interesse objetivas com exceção da medida Correlação. 



\section{Tabelas com os Resultados de Classificação}

Neste apêndice são apresentadas as tabelas contendo os resultados obtidos pelas representações bag-of-related-words e pela representação bag-of-words para 4 algoritmos de classificação: Naïve Bayes, J48, SMO, e KNN. Os resultados obtidos utilizando esses algoritmos de classificação são apresentados nas seções C.1, C.2, C.3, e C.4 respectivamente.

Para as coleções ACM foi utilizado o procedimento 10-fold-cross-validation para avaliar os modelos de classificação obtidos com as representações utilizadas. Os resultados para a coleção ACM são a média da taxa de erro dos 10 folds e o desvio padrão. Já para a coleção Reuters-21578, como foi utilizado o procedimento de divisão da coleção de documentos para gerar um modelo (conjunto de treinamento) e testar o modelo (conjunto de teste), o resultado é a taxa de erro de classificação. As menores taxas de erro obtidas para cada coleção estão assinaladas em negrito nas tabelas.

\section{C.1 Naïve Bayes}

Nesta seção são apresentadas as tabelas contendo os resultados obtidos pelas representações bag-of-related-words e pela representação bag-of-words utilizando o algoritmo de classificação Naïve Bayes. Na Tabela C.1 são apresentadas as taxas de erro de classificação e o desvio padrão para as coleções da ACM obtidas pelas representações bag-ofrelated-words que utilizaram os itemsets frequentes como atributos. Na Tabela C.2 são apresentadas as taxas de erro de classificação e o desvio padrão para as coleções da ACM obtidas pelas representações bag-of-related-words que utilizaram medidas de interesse objetivas para gerar os atributos. Na Tabela C.3 são apresentadas as taxas de erro para a coleção Reuters-21578 obtidas pelas representações bag-of-related-words que utilizaram medidas de interesse objetivas para gerar os atributos. 
Tabela C.1: Naïve Bayes - taxas de erro obtidas pelas representações bag-of-related-words que utilizaram itemsets frequentes como atributos e pela representação bag-of-words para as coleções da ACM.

\begin{tabular}{|c|c|c|c|c|c|c|c|c|}
\hline & \multicolumn{8}{|c|}{ Taxa de Erro } \\
\hline Representação & ACM-1 & ACM-2 & ACM-3 & ACM-4 & ACM-5 & ACM-6 & ACM-7 & ACM-8 \\
\hline Bag-of-words & $\begin{array}{l}* \mathbf{5 , 5 1} \\
\pm 0,14\end{array}$ & $\begin{array}{c}7,80 \\
\pm 0,10\end{array}$ & $\begin{array}{c}7,55 \\
\pm 0,14\end{array}$ & $\begin{array}{l}11,42 \\
\pm 0,08\end{array}$ & $\begin{array}{l}\boldsymbol{*}_{\mathbf{2}, \mathbf{7 6}} \\
\pm 0,09\end{array}$ & $\begin{array}{c}7,29 \\
\pm 0,10\end{array}$ & $\begin{array}{c}7,89 \\
\pm 0,10\end{array}$ & $\begin{array}{r}* \mathbf{5}, \mathbf{8 6} \\
\pm 0,14\end{array}$ \\
\hline Sent. $2 \%$ & $\begin{array}{l}10,55 \\
\pm 0,20\end{array}$ & $\begin{array}{c}5,12 \\
\pm 0,14\end{array}$ & $\begin{array}{c}5,91 \\
\pm 0,15\end{array}$ & $\begin{array}{c}2,03 \\
\pm 0,09\end{array}$ & $\begin{array}{c}6,79 \\
\pm 0,16\end{array}$ & $\begin{array}{c}4,34 \\
\pm 0,13\end{array}$ & $\begin{array}{c}6,61 \\
\pm 0,16\end{array}$ & $\begin{array}{l}8,69 \\
\pm 0,18\end{array}$ \\
\hline Sent. $3 \%$ & $\begin{array}{l}11,56 \\
\pm 0,21\end{array}$ & $\begin{array}{c}4,88 \\
\pm 0,14\end{array}$ & $\begin{array}{c}6,38 \\
\pm 0,15\end{array}$ & $\begin{array}{c}2,28 \\
\pm 0,10\end{array}$ & $\begin{array}{c}6,58 \\
\pm 0,16\end{array}$ & $\begin{array}{c}3,88 \\
\pm 0,12 \\
\end{array}$ & $\begin{array}{c}4,69 \\
\pm 0,14 \\
\end{array}$ & $\begin{array}{l}8,08 \\
\pm 0,18\end{array}$ \\
\hline Sent. $4 \%$ & $\begin{array}{l}12,81 \\
\pm 0,22\end{array}$ & $\begin{array}{c}4,88 \\
\pm 0,14\end{array}$ & $\begin{array}{c}6,86 \\
\pm 0,15\end{array}$ & $\begin{array}{c}2,79 \\
\pm 0,10\end{array}$ & $\begin{array}{c}7,22 \\
\pm 0,16\end{array}$ & $\begin{array}{c}4,79 \\
\pm 0,13\end{array}$ & $\begin{array}{c}6,82 \\
\pm 0,16\end{array}$ & $\begin{array}{l}9,49 \\
\pm 0,18\end{array}$ \\
\hline Sent. $5 \%$ & $\begin{array}{l}12,31 \\
\pm 0,21\end{array}$ & $\begin{array}{c}6,59 \\
\pm 0,15\end{array}$ & $\begin{array}{c}6,86 \\
\pm 0,15\end{array}$ & $\begin{array}{c}5,08 \\
\pm 0,12\end{array}$ & $\begin{array}{c}8,92 \\
\pm 0,18\end{array}$ & $\begin{array}{c}5,71 \\
\pm 0,14\end{array}$ & $\begin{array}{c}7,04 \\
\pm 0,16\end{array}$ & $\begin{array}{l}12,53 \\
\pm 0,21\end{array}$ \\
\hline Sent. $6 \%$ & $\begin{array}{c}13,82 \\
\pm 0,22\end{array}$ & $\begin{array}{c}8,78 \\
\pm 0,17\end{array}$ & $\begin{array}{c}7,80 \\
\pm 0,16\end{array}$ & $\begin{array}{c}4,82 \\
\pm 0,12\end{array}$ & $\begin{array}{c}14,01 \\
\pm 0,22\end{array}$ & $\begin{array}{c}6,85 \\
\pm 0,15\end{array}$ & $\begin{array}{c}9,17 \\
\pm 0,18\end{array}$ & $\begin{array}{l}14,55 \\
\pm 0,23\end{array}$ \\
\hline Par. $10 \%$ & $\begin{array}{l}12,56 \\
\pm 0,22\end{array}$ & $\begin{array}{c}5,12 \\
\pm 0,14\end{array}$ & $\begin{array}{c}7,33 \\
\pm 0,16\end{array}$ & $\begin{array}{c}4,57 \\
\pm 0,14\end{array}$ & $\begin{array}{c}9,55 \\
\pm 0,18\end{array}$ & $\begin{array}{c}6,39 \\
\pm 0,15\end{array}$ & $\begin{array}{c}7,25 \\
\pm 0,16\end{array}$ & $\begin{array}{l}9,70 \\
\pm 0,18\end{array}$ \\
\hline Par. $11 \%$ & $\begin{array}{l}12,06 \\
\pm 0,21\end{array}$ & $\begin{array}{c}5,61 \\
\pm 0,15\end{array}$ & $\begin{array}{c}7,09 \\
\pm 0,16\end{array}$ & $\begin{array}{c}5,33 \\
\pm 0,13\end{array}$ & $\begin{array}{c}8,07 \\
\pm 0,17\end{array}$ & $\begin{array}{c}5,71 \\
\pm 0,14\end{array}$ & $\begin{array}{c}7,25 \\
\pm 0,16 \\
\end{array}$ & $\begin{array}{l}9,90 \\
\pm 0,19\end{array}$ \\
\hline Par. $12 \%$ & $\begin{array}{c}13,07 \\
\pm 0,22\end{array}$ & $\begin{array}{c}5,61 \\
\pm 0,14\end{array}$ & $\begin{array}{c}6,86 \\
\pm 0,16\end{array}$ & $\begin{array}{c}5,33 \\
\pm 0,14\end{array}$ & $\begin{array}{c}8,92 \\
\pm 0,18\end{array}$ & $\begin{array}{c}6,16 \\
\pm 0,14\end{array}$ & $\begin{array}{c}7,04 \\
\pm 0,16\end{array}$ & $\begin{array}{l}11,72 \\
\pm 0,20\end{array}$ \\
\hline Par. $13 \%$ & $\begin{array}{l}13,82 \\
\pm 0,22\end{array}$ & $\begin{array}{c}6,10 \\
\pm 0,14\end{array}$ & $\begin{array}{c}6,86 \\
\pm 0,16\end{array}$ & $\begin{array}{c}5,33 \\
\pm 0,14\end{array}$ & $\begin{array}{c}9,13 \\
\pm 0,19\end{array}$ & $\begin{array}{c}6,85 \\
\pm 0,15\end{array}$ & $\begin{array}{c}7,68 \\
\pm 0,17\end{array}$ & $\begin{array}{l}15,15 \\
\pm 0,23\end{array}$ \\
\hline Par. $14 \%$ & $\begin{array}{c}14,82 \\
\pm 0,23\end{array}$ & $\begin{array}{c}6,59 \\
\pm 0,15\end{array}$ & $\begin{array}{c}7,33 \\
\pm 0,16\end{array}$ & $\begin{array}{c}5,33 \\
\pm 0,13\end{array}$ & $\begin{array}{l}11,25 \\
\pm 0,20\end{array}$ & $\begin{array}{c}7,76 \\
\pm 0,16\end{array}$ & $\begin{array}{c}9,17 \\
\pm 0,18\end{array}$ & $\begin{array}{l}14,75 \\
\pm 0,23\end{array}$ \\
\hline Jan. 5 Aut. & $\begin{array}{c}9,27 \\
\pm 0,18\end{array}$ & $\begin{array}{c}3,90 \\
\pm 0,12\end{array}$ & $\begin{array}{c}3,13 \\
\pm 0,11\end{array}$ & $\begin{array}{c}1,52 \\
\pm 0,07\end{array}$ & $\begin{array}{c}3,61 \\
\pm 0,11\end{array}$ & $\begin{array}{c}3,66 \\
\pm 0,12\end{array}$ & $\begin{array}{c}4,26 \\
\pm 0,12\end{array}$ & $\begin{array}{l}6,67 \\
\pm 0,16\end{array}$ \\
\hline Jan. $50,6 \%$ & $\begin{array}{c}8,27 \\
\pm 0,18\end{array}$ & $\begin{array}{c}3,66 \\
\pm 0,12\end{array}$ & $\begin{array}{c}4,09 \\
\pm 0,12\end{array}$ & $\begin{array}{l}* \mathbf{0 , 5 1} \\
\pm 0,05\end{array}$ & $\begin{array}{c}2,97 \\
\pm 0,11\end{array}$ & $\begin{array}{l}* \mathbf{2 , 5 2} \\
\pm 0,10\end{array}$ & $\begin{array}{c}\boldsymbol{*}_{\mathbf{2}, \mathbf{9 9}} \\
\pm 0,11\end{array}$ & $\begin{array}{l}7,47 \\
\pm 0,17\end{array}$ \\
\hline Jan. $50,8 \%$ & $\begin{array}{c}9,77 \\
\pm 0,19\end{array}$ & $\begin{array}{l}\boldsymbol{*} \mathbf{2 , 9 3} \\
\pm 0,11\end{array}$ & $\begin{array}{l}\boldsymbol{*} \mathbf{3}, \mathbf{3 7} \\
\pm 0,12\end{array}$ & $\begin{array}{c}0,76 \\
\pm 0,06\end{array}$ & $\begin{array}{c}5,31 \\
\pm 0,14\end{array}$ & $\begin{array}{c}2,97 \\
\pm 0,11\end{array}$ & $\begin{array}{c}4,90 \\
\pm 0,14\end{array}$ & $\begin{array}{l}6,46 \\
\pm 0,16\end{array}$ \\
\hline Jan. $51 \%$ & $\begin{array}{c}10,03 \\
\pm 0,19\end{array}$ & $\begin{array}{c}4,15 \\
\pm 0,13\end{array}$ & $\begin{array}{c}4,09 \\
\pm 0,13\end{array}$ & $\begin{array}{c}0,76 \\
\pm 0,06\end{array}$ & $\begin{array}{c}5,31 \\
\pm 0,14\end{array}$ & $\begin{array}{c}3,20 \\
\pm 0,11\end{array}$ & $\begin{array}{c}5,33 \\
\pm 0,14\end{array}$ & $\begin{array}{l}6,67 \\
\pm 0,16\end{array}$ \\
\hline Jan. $52 \%$ & $\begin{array}{c}9,77 \\
\pm 0,19\end{array}$ & $\begin{array}{c}5,37 \\
\pm 0,14\end{array}$ & $\begin{array}{c}4,33 \\
\pm 0,13\end{array}$ & $\begin{array}{c}1,27 \\
\pm 0,07\end{array}$ & $\begin{array}{c}7,01 \\
\pm 0,16\end{array}$ & $\begin{array}{c}3,43 \\
\pm 0,12\end{array}$ & $\begin{array}{c}5,33 \\
\pm 0,14\end{array}$ & $\begin{array}{l}11,31 \\
\pm 0,20\end{array}$ \\
\hline Jan. $53 \%$ & $\begin{array}{l}11,28 \\
\pm 0,20\end{array}$ & $\begin{array}{c}5,37 \\
\pm 0,14\end{array}$ & $\begin{array}{c}6,73 \\
\pm 0,15\end{array}$ & $\begin{array}{c}2,28 \\
\pm 0,09\end{array}$ & $\begin{array}{c}7,01 \\
\pm 0,16\end{array}$ & $\begin{array}{c}4,12 \\
\pm 0,12\end{array}$ & $\begin{array}{c}5,76 \\
\pm 0,15\end{array}$ & $\begin{array}{l}9,90 \\
\pm 0,19\end{array}$ \\
\hline Jan. $102 \%$ & $\begin{array}{c}9,27 \\
\pm 0,19\end{array}$ & $\begin{array}{c}3,90 \\
\pm 0,12\end{array}$ & $\begin{array}{c}3,85 \\
\pm 0,12\end{array}$ & $\begin{array}{c}1,27 \\
\pm 0,07\end{array}$ & $\begin{array}{c}6,16 \\
\pm 0,15\end{array}$ & $\begin{array}{c}3,20 \\
\pm 0,11\end{array}$ & $\begin{array}{c}4,48 \\
\pm 0,13\end{array}$ & $\begin{array}{l}7,88 \\
\pm 0,17\end{array}$ \\
\hline Jan. $103 \%$ & $\begin{array}{l}11,03 \\
\pm 0,21\end{array}$ & $\begin{array}{c}4,39 \\
\pm 0,13\end{array}$ & $\begin{array}{c}4,57 \\
\pm 0,13\end{array}$ & $\begin{array}{c}1,27 \\
\pm 0,07\end{array}$ & $\begin{array}{c}7,22 \\
\pm 0,16\end{array}$ & $\begin{array}{c}4,58 \\
\pm 0,13\end{array}$ & $\begin{array}{c}4,26 \\
\pm 0,13\end{array}$ & $\begin{array}{l}9,29 \\
\pm 0,19\end{array}$ \\
\hline Jan. $104 \%$ & $\begin{array}{c}10,03 \\
\pm 0,19\end{array}$ & $\begin{array}{c}4,39 \\
\pm 0,13\end{array}$ & $\begin{array}{c}3,85 \\
\pm 0,12\end{array}$ & $\begin{array}{c}1,27 \\
\pm 0,07\end{array}$ & $\begin{array}{c}5,73 \\
\pm 0,15\end{array}$ & $\begin{array}{c}4,12 \\
\pm 0,12\end{array}$ & $\begin{array}{c}4,69 \\
\pm 0,13\end{array}$ & $\begin{array}{l}9,49 \\
\pm 0,19\end{array}$ \\
\hline Jan. $105 \%$ & $\begin{array}{l}11,03 \\
\pm 0,20\end{array}$ & $\begin{array}{c}4,63 \\
\pm 0,13\end{array}$ & $\begin{array}{c}4,57 \\
\pm 0,13\end{array}$ & $\begin{array}{c}1,52 \\
\pm 0,07\end{array}$ & $\begin{array}{c}6,58 \\
\pm 0,15\end{array}$ & $\begin{array}{c}3,89 \\
\pm 0,12\end{array}$ & $\begin{array}{c}5,97 \\
\pm 0,15\end{array}$ & $\begin{array}{l}9,70 \\
\pm 0,19\end{array}$ \\
\hline Jan. $106 \%$ & $\begin{array}{c}10,78 \\
\pm 0,20\end{array}$ & $\begin{array}{c}5,85 \\
\pm 0,14\end{array}$ & $\begin{array}{c}6,01 \\
\pm 0,14\end{array}$ & $\begin{array}{c}2,54 \\
\pm 0,09\end{array}$ & $\begin{array}{c}7,22 \\
\pm 0,17\end{array}$ & $\begin{array}{c}4,12 \\
\pm 0,12\end{array}$ & $\begin{array}{c}5,97 \\
\pm 0,15\end{array}$ & $\begin{array}{l}10,71 \\
\pm 0,20\end{array}$ \\
\hline Jan. $206 \%$ & $\begin{array}{c}10,78 \\
\pm 0,20\end{array}$ & $\begin{array}{c}3,90 \\
\pm 0,12\end{array}$ & $\begin{array}{c}4,33 \\
\pm 0,13\end{array}$ & $\begin{array}{c}1,27 \\
\pm 0,07\end{array}$ & $\begin{array}{c}6,79 \\
\pm 0,16\end{array}$ & $\begin{array}{c}4,36 \\
\pm 0,13\end{array}$ & $\begin{array}{c}4,26 \\
\pm 0,13\end{array}$ & $\begin{array}{l}9,09 \\
\pm 0,18\end{array}$ \\
\hline Jan. $207 \%$ & $\begin{array}{c}10,78 \\
\pm 0,20\end{array}$ & $\begin{array}{c}5,12 \\
\pm 0,14\end{array}$ & $\begin{array}{c}4,09 \\
\pm 0,13\end{array}$ & $\begin{array}{c}1,52 \\
\pm 0,08\end{array}$ & $\begin{array}{c}6,58 \\
\pm 0,16\end{array}$ & $\begin{array}{c}3,67 \\
\pm 0,12\end{array}$ & $\begin{array}{c}4,26 \\
\pm 0,13\end{array}$ & $\begin{array}{l}9,70 \\
\pm 0,19\end{array}$ \\
\hline Jan. $208 \%$ & $\begin{array}{l}10,03 \\
\pm 0,20\end{array}$ & $\begin{array}{c}4,39 \\
\pm 0,13\end{array}$ & $\begin{array}{c}3,61 \\
\pm 0,12\end{array}$ & $\begin{array}{c}1,78 \\
\pm 0,08\end{array}$ & $\begin{array}{c}6,37 \\
\pm 0,15\end{array}$ & $\begin{array}{c}4,36 \\
\pm 0,12\end{array}$ & $\begin{array}{c}5,33 \\
\pm 0,14\end{array}$ & $\begin{array}{l}9,49 \\
\pm 0,19\end{array}$ \\
\hline Jan. $209 \%$ & $\begin{array}{c}9,77 \\
\pm 0,19\end{array}$ & $\begin{array}{c}3,90 \\
\pm 0,13\end{array}$ & $\begin{array}{c}4,81 \\
\pm 0,14\end{array}$ & $\begin{array}{c}1,78 \\
\pm 0,08\end{array}$ & $\begin{array}{c}5,73 \\
\pm 0,14\end{array}$ & $\begin{array}{c}4,13 \\
\pm 0,12\end{array}$ & $\begin{array}{c}5,76 \\
\pm 0,14\end{array}$ & $\begin{array}{l}9,29 \\
\pm 0,19\end{array}$ \\
\hline Jan. $2010 \%$ & $\begin{array}{c}10,78 \\
\pm 0,20\end{array}$ & $\begin{array}{c}4,39 \\
\pm 0,13\end{array}$ & $\begin{array}{c}4,81 \\
\pm 0,13\end{array}$ & $\begin{array}{c}1,78 \\
\pm 0,08\end{array}$ & $\begin{array}{c}6,58 \\
\pm 0,15\end{array}$ & $\begin{array}{c}4,59 \\
\pm 0,13\end{array}$ & $\begin{array}{c}5,76 \\
\pm 0,14\end{array}$ & $\begin{array}{l}10,30 \\
\pm 0,19\end{array}$ \\
\hline Jan. $3010 \%$ & $\begin{array}{l}10,03 \\
\pm 0,20\end{array}$ & $\begin{array}{c}4,88 \\
\pm 0,14\end{array}$ & $\begin{array}{c}4,09 \\
\pm 0,12\end{array}$ & $\begin{array}{c}1,52 \\
\pm 0,08\end{array}$ & $\begin{array}{c}6,58 \\
\pm 0,16\end{array}$ & $\begin{array}{c}4,36 \\
\pm 0,13\end{array}$ & $\begin{array}{c}4,48 \\
\pm 0,13\end{array}$ & $\begin{array}{l}9,49 \\
\pm 0,19\end{array}$ \\
\hline Jan. $3011 \%$ & $\begin{array}{l}11,28 \\
\pm 0,21\end{array}$ & $\begin{array}{c}4,63 \\
\pm 0,13\end{array}$ & $\begin{array}{c}5,05 \\
\pm 0,14\end{array}$ & $\begin{array}{c}1,78 \\
\pm 0,08\end{array}$ & $\begin{array}{c}7,22 \\
\pm 0,17\end{array}$ & $\begin{array}{c}4,59 \\
\pm 0,13\end{array}$ & $\begin{array}{c}4,90 \\
\pm 0,14\end{array}$ & $\begin{array}{l}9,29 \\
\pm 0,19\end{array}$ \\
\hline Jan. $3012 \%$ & $\begin{array}{l}10,03 \\
\pm 0,20\end{array}$ & $\begin{array}{c}4,63 \\
\pm 0,13\end{array}$ & $\begin{array}{c}5,05 \\
\pm 0,14\end{array}$ & $\begin{array}{c}1,52 \\
\pm 0,08\end{array}$ & $\begin{array}{c}6,16 \\
\pm 0,15\end{array}$ & $\begin{array}{c}4,36 \\
\pm 0,12\end{array}$ & $\begin{array}{c}4,69 \\
\pm 0,14\end{array}$ & $\begin{array}{l}10,51 \\
\pm 0,20\end{array}$ \\
\hline Jan. $3013 \%$ & $\begin{array}{l}10,78 \\
\pm 0,20\end{array}$ & $\begin{array}{c}4,39 \\
\pm 0,13\end{array}$ & $\begin{array}{c}6,01 \\
\pm 0,14\end{array}$ & $\begin{array}{c}2,28 \\
\pm 0,09\end{array}$ & $\begin{array}{c}6,37 \\
\pm 0,15\end{array}$ & $\begin{array}{c}4,59 \\
\pm 0,13\end{array}$ & $\begin{array}{c}4,26 \\
\pm 0,13\end{array}$ & $\begin{array}{l}9,29 \\
\pm 0,19\end{array}$ \\
\hline Jan. $3014 \%$ & $\begin{array}{l}11,28 \\
\pm 0,20\end{array}$ & $\begin{array}{c}4,63 \\
\pm 0,13\end{array}$ & $\begin{array}{c}4,33 \\
\pm 0,13\end{array}$ & $\begin{array}{c}2,03 \\
\pm 0,09 \\
\end{array}$ & $\begin{array}{c}7,01 \\
\pm 0,16 \\
\end{array}$ & $\begin{array}{c}4,82 \\
\pm 0,13 \\
\end{array}$ & $\begin{array}{c}5,33 \\
\pm 0,14 \\
\end{array}$ & $\begin{array}{l}10,30 \\
\pm 0,20\end{array}$ \\
\hline
\end{tabular}


Apêndice C. Tabelas com os Resultados de Classificação

Tabela C.2: Naïve Bayes - taxas de erro obtidas pelas representações bag-of-related-words que utilizaram medidas de interesse objetivas para gerar os atributos e pela representação bag-of-words para as coleções da ACM.

\begin{tabular}{|c|c|c|c|c|c|c|c|c|}
\hline \multirow[b]{2}{*}{ Representação } & \multicolumn{8}{|c|}{ Taxa de Erro } \\
\hline & ACM-1 & ACM-2 & ACM-3 & ACM-4 & ACM-5 & ACM-6 & ACM-7 & ACM-8 \\
\hline Bag-of-words & $\begin{array}{l}* \mathbf{5 , 5 1} \\
\pm 0,14\end{array}$ & $\begin{array}{c}7,80 \\
\pm 0,10\end{array}$ & $\begin{array}{c}7,55 \\
\pm 0,14\end{array}$ & $\begin{array}{l}11,42 \\
\pm 0,08\end{array}$ & $\begin{array}{l}* \mathbf{2 , 7 6} \\
\pm 0,09\end{array}$ & $\begin{array}{c}7,29 \\
\pm 0,10\end{array}$ & $\begin{array}{c}7,89 \\
\pm 0,10\end{array}$ & $\begin{array}{r}\boldsymbol{*}^{\mathbf{5}, \mathbf{8 6}} \\
\pm 0,14\end{array}$ \\
\hline Jan. 5 Aut. Conf. 0,25 & $\begin{array}{c}9,77 \\
\pm 0,20\end{array}$ & $\begin{array}{c}4,15 \\
\pm 0,13\end{array}$ & $\begin{array}{c}4,33 \\
\pm 0,13\end{array}$ & $\begin{array}{c}2,28 \\
\pm 0,10\end{array}$ & $\begin{array}{c}4,03 \\
\pm 0,12\end{array}$ & $\begin{array}{c}3,66 \\
\pm 0,12\end{array}$ & $\begin{array}{c}6,18 \\
\pm 0,15\end{array}$ & $\begin{array}{l}7,27 \\
\pm 0,17\end{array}$ \\
\hline Jan. 5 Aut. Conf. 0,5 & $\begin{array}{c}10,28 \\
\pm 0,20\end{array}$ & $\begin{array}{c}4,63 \\
\pm 0,13\end{array}$ & $\begin{array}{c}4,33 \\
\pm 0,13\end{array}$ & $\begin{array}{c}2,54 \\
\pm 0,10\end{array}$ & $\begin{array}{c}4,03 \\
\pm 0,13\end{array}$ & $\begin{array}{c}3,89 \\
\pm 0,12\end{array}$ & $\begin{array}{c}5,54 \\
\pm 0,14\end{array}$ & $\begin{array}{c}7,88 \\
\pm 0,17\end{array}$ \\
\hline Jan. 5 Aut. Conf. $\bar{x}$ & $\begin{array}{c}9,77 \\
\pm 0,20\end{array}$ & $\begin{array}{c}3,90 \\
\pm 0,12\end{array}$ & $\begin{array}{c}3,85 \\
\pm 0,12\end{array}$ & $\begin{array}{c}2,28 \\
\pm 0,10\end{array}$ & $\begin{array}{c}3,82 \\
\pm 0,12\end{array}$ & $\begin{array}{c}4,12 \\
\pm 0,12\end{array}$ & $\begin{array}{c}6,18 \\
\pm 0,15\end{array}$ & $\begin{array}{l}7,27 \\
\pm 0,17\end{array}$ \\
\hline Jan. 5 Aut. Lift 0,1 & $\begin{array}{c}9,52 \\
\pm 0,19\end{array}$ & $\begin{array}{c}3,90 \\
\pm 0,12\end{array}$ & $\begin{array}{c}4,57 \\
\pm 0,13\end{array}$ & $\begin{array}{c}2,54 \\
\pm 0,10\end{array}$ & $\begin{array}{c}4,03 \\
\pm 0,13\end{array}$ & $\begin{array}{c}3,89 \\
\pm 0,12\end{array}$ & $\begin{array}{c}6,18 \\
\pm 0,15\end{array}$ & $\begin{array}{l}7,27 \\
\pm 0,17\end{array}$ \\
\hline Jan. 5 Aut. Lift 0,2 & $\begin{array}{c}10,28 \\
\pm 0,20\end{array}$ & $\begin{array}{c}4,63 \\
\pm 0,13\end{array}$ & $\begin{array}{c}4,33 \\
\pm 0,13\end{array}$ & $\begin{array}{c}2,28 \\
\pm 0,10\end{array}$ & $\begin{array}{c}4,03 \\
\pm 0,13\end{array}$ & $\begin{array}{c}3,89 \\
\pm 0,12\end{array}$ & $\begin{array}{c}5,54 \\
\pm 0,14\end{array}$ & $\begin{array}{l}8,28 \\
\pm 0,18\end{array}$ \\
\hline Jan. 5 Aut. Lift $\bar{x}$ & $\begin{array}{c}9,52 \\
\pm 0,19\end{array}$ & $\begin{array}{c}3,90 \\
\pm 0,12\end{array}$ & $\begin{array}{c}4,57 \\
\pm 0,13\end{array}$ & $\begin{array}{c}2,54 \\
\pm 0,10\end{array}$ & $\begin{array}{c}4,03 \\
\pm 0,13\end{array}$ & $\begin{array}{c}3,89 \\
\pm 0,12\end{array}$ & $\begin{array}{c}6,18 \\
\pm 0,15\end{array}$ & $\begin{array}{l}7,27 \\
\pm 0,17\end{array}$ \\
\hline Jan. 5 Aut. Yule's Q 0,5 & $\begin{array}{c}9,27 \\
\pm 0,19\end{array}$ & $\begin{array}{c}3,90 \\
\pm 0,12\end{array}$ & $\begin{array}{c}3,61 \\
\pm 0,12\end{array}$ & $\begin{array}{c}2,03 \\
\pm 0,09\end{array}$ & $\begin{array}{c}3,61 \\
\pm 0,12\end{array}$ & $\begin{array}{c}3,66 \\
\pm 0,12\end{array}$ & $\begin{array}{c}5,76 \\
\pm 0,15\end{array}$ & $\begin{array}{l}6,87 \\
\pm 0,17\end{array}$ \\
\hline Jan. 5 Aut. Yule's Q 0,75 & $\begin{array}{c}9,77 \\
\pm 0,20\end{array}$ & $\begin{array}{c}3,90 \\
\pm 0,12\end{array}$ & $\begin{array}{c}3,85 \\
\pm 0,12\end{array}$ & $\begin{array}{c}2,28 \\
\pm 0,10\end{array}$ & $\begin{array}{c}3,61 \\
\pm 0,12\end{array}$ & $\begin{array}{c}3,66 \\
\pm 0,12\end{array}$ & $\begin{array}{c}5,97 \\
\pm 0,15\end{array}$ & $\begin{array}{l}7,27 \\
\pm 0,17\end{array}$ \\
\hline Jan. 5 Aut. Yule's Q $\bar{x}$ & $\begin{array}{c}9,52 \\
\pm 0,19\end{array}$ & $\begin{array}{c}3,90 \\
\pm 0,12\end{array}$ & $\begin{array}{c}3,61 \\
\pm 0,12\end{array}$ & $\begin{array}{c}2,03 \\
\pm 0,09\end{array}$ & $\begin{array}{c}3,61 \\
\pm 0,12\end{array}$ & $\begin{array}{c}3,66 \\
\pm 0,12\end{array}$ & $\begin{array}{c}5,54 \\
\pm 0,15\end{array}$ & $\begin{array}{c}7,07 \\
\pm 0,17\end{array}$ \\
\hline Jan. 5 Aut. Corr. 0,25 & $\begin{array}{c}9,77 \\
\pm 0,20\end{array}$ & $\begin{array}{c}4,15 \\
\pm 0,13\end{array}$ & $\begin{array}{c}3,85 \\
\pm 0,12\end{array}$ & $\begin{array}{c}2,28 \\
\pm 0,10\end{array}$ & $\begin{array}{c}4,03 \\
\pm 0,13\end{array}$ & $\begin{array}{c}3,89 \\
\pm 0,12\end{array}$ & $\begin{array}{c}6,18 \\
\pm 0,15\end{array}$ & $\begin{array}{l}7,47 \\
\pm 0,17\end{array}$ \\
\hline Jan. 5 Aut. Corr. 0,50 & $\begin{array}{l}10,28 \\
\pm 0,20\end{array}$ & $\begin{array}{c}4,15 \\
\pm 0,13\end{array}$ & $\begin{array}{c}4,33 \\
\pm 0,13\end{array}$ & $\begin{array}{c}2,54 \\
\pm 0,10\end{array}$ & $\begin{array}{c}4,03 \\
\pm 0,13\end{array}$ & $\begin{array}{c}3,89 \\
\pm 0,12\end{array}$ & $\begin{array}{c}5,33 \\
\pm 0,14\end{array}$ & $\begin{array}{l}7,47 \\
\pm 0,17\end{array}$ \\
\hline Jan. 5 Aut. Corr. $\bar{x}$ & $\begin{array}{c}9,27 \\
\pm 0,19\end{array}$ & $\begin{array}{l}\boldsymbol{*} \mathbf{3 , 6 6} \\
\pm 0,12\end{array}$ & $\begin{array}{c}* \mathbf{3}, \mathbf{1 3} \\
\pm 0,11\end{array}$ & $\begin{array}{c}1,78 \\
\pm 0,08\end{array}$ & $\begin{array}{c}3,40 \\
\pm 0,12\end{array}$ & $\begin{array}{c}3,66 \\
\pm 0,12\end{array}$ & $\begin{array}{c}4,48 \\
\pm 0,13\end{array}$ & $\begin{array}{l}6,46 \\
\pm 0,16\end{array}$ \\
\hline Jan. 5 Aut. I.M. 0,005 & $\begin{array}{c}9,27 \\
\pm 0,19\end{array}$ & $\begin{array}{c}3,90 \\
\pm 0,12\end{array}$ & $\begin{array}{c}3,37 \\
\pm 0,12\end{array}$ & $\begin{array}{l}* \mathbf{1 , 5 2} \\
\pm 0,08\end{array}$ & $\begin{array}{c}3,61 \\
\pm 0,12\end{array}$ & $\begin{array}{c}3,66 \\
\pm 0,12\end{array}$ & $\begin{array}{c}5,33 \\
\pm 0,14\end{array}$ & $\begin{array}{c}6,87 \\
\pm 0,17\end{array}$ \\
\hline Jan. 5 Aut. I.M. 0,01 & $\begin{array}{c}10,28 \\
\pm 0,20\end{array}$ & $\begin{array}{c}5,12 \\
\pm 0,14\end{array}$ & $\begin{array}{c}4,33 \\
\pm 0,13\end{array}$ & $\begin{array}{c}2,28 \\
\pm 0,10\end{array}$ & $\begin{array}{c}4,03 \\
\pm 0,13\end{array}$ & $\begin{array}{c}3,89 \\
\pm 0,12\end{array}$ & $\begin{array}{c}5,76 \\
\pm 0,14\end{array}$ & $\begin{array}{l}8,28 \\
\pm 0,18\end{array}$ \\
\hline Jan. 5 Aut. I.M. $\bar{x}$ & $\begin{array}{c}9,77 \\
\pm 0,20\end{array}$ & $\begin{array}{c}3,90 \\
\pm 0,12\end{array}$ & $\begin{array}{c}3,85 \\
\pm 0,12\end{array}$ & $\begin{array}{c}2,28 \\
\pm 0,10\end{array}$ & $\begin{array}{c}3,82 \\
\pm 0,12\end{array}$ & $\begin{array}{c}3,89 \\
\pm 0,12\end{array}$ & $\begin{array}{c}5,97 \\
\pm 0,15\end{array}$ & $\begin{array}{l}7,27 \\
\pm 0,17\end{array}$ \\
\hline Jan. 5 Aut. Gini 0,005 & $\begin{array}{c}9,77 \\
\pm 0,20\end{array}$ & $\begin{array}{c}3,90 \\
\pm 0,12\end{array}$ & $\begin{array}{c}3,61 \\
\pm 0,12\end{array}$ & $\begin{array}{c}2,03 \\
\pm 0,09\end{array}$ & $\begin{array}{c}3,61 \\
\pm 0,12\end{array}$ & $\begin{array}{c}3,66 \\
\pm 0,12\end{array}$ & $\begin{array}{c}5,54 \\
\pm 0,15\end{array}$ & $\begin{array}{c}7,07 \\
\pm 0,17\end{array}$ \\
\hline Jan. 5 Aut. Gini 0,01 & $\begin{array}{c}9,77 \\
\pm 0,20\end{array}$ & $\begin{array}{c}4,15 \\
\pm 0,13\end{array}$ & $\begin{array}{c}3,85 \\
\pm 0,12\end{array}$ & $\begin{array}{c}2,28 \\
\pm 0,10\end{array}$ & $\begin{array}{c}3,82 \\
\pm 0,12\end{array}$ & $\begin{array}{c}3,89 \\
\pm 0,12\end{array}$ & $\begin{array}{c}5,76 \\
\pm 0,15\end{array}$ & $\begin{array}{c}7,68 \\
\pm 0,17\end{array}$ \\
\hline Jan. 5 Aut. Gini $\bar{x}$ & $\begin{array}{c}10,03 \\
\pm 0,20\end{array}$ & $\begin{array}{c}3,90 \\
\pm 0,12\end{array}$ & $\begin{array}{c}3,85 \\
\pm 0,12\end{array}$ & $\begin{array}{c}2,28 \\
\pm 0,10\end{array}$ & $\begin{array}{c}3,61 \\
\pm 0,12\end{array}$ & $\begin{array}{c}3,66 \\
\pm 0,12\end{array}$ & $\begin{array}{c}5,76 \\
\pm 0,15\end{array}$ & $\begin{array}{c}7,27 \\
\pm 0,17\end{array}$ \\
\hline Jan. 5 Aut. Kappa 0,15 & $\begin{array}{c}9,77 \\
\pm 0,20\end{array}$ & $\begin{array}{c}4,39 \\
\pm 0,13\end{array}$ & $\begin{array}{c}3,85 \\
\pm 0,12\end{array}$ & $\begin{array}{l}* \mathbf{1 , 5 2} \\
\pm 0,08\end{array}$ & $\begin{array}{c}3,61 \\
\pm 0,12\end{array}$ & $\begin{array}{c}3,89 \\
\pm 0,12\end{array}$ & $\begin{array}{c}4,69 \\
\pm 0,13\end{array}$ & $\begin{array}{l}7,27 \\
\pm 0,17\end{array}$ \\
\hline Jan. 5 Aut. Kappa 0,2 & $\begin{array}{c}9,77 \\
\pm 0,20\end{array}$ & $\begin{array}{c}4,15 \\
\pm 0,13\end{array}$ & $\begin{array}{c}3,85 \\
\pm 0,12\end{array}$ & $\begin{array}{c}2,03 \\
\pm 0,09\end{array}$ & $\begin{array}{c}3,82 \\
\pm 0,02\end{array}$ & $\begin{array}{c}3,89 \\
\pm 0,12\end{array}$ & $\begin{array}{c}4,69 \\
\pm 0,13\end{array}$ & $\begin{array}{c}7,68 \\
\pm 0,17\end{array}$ \\
\hline Jan. 5 Aut. Kappa $\bar{x}$ & $\begin{array}{c}9,52 \\
\pm 0,20\end{array}$ & $\begin{array}{c}4,15 \\
\pm 0,13\end{array}$ & $\begin{array}{c}3,85 \\
\pm 0,12\end{array}$ & $\begin{array}{c}1,78 \\
\pm 0,08\end{array}$ & $\begin{array}{c}3,61 \\
\pm 0,12\end{array}$ & $\begin{array}{c}3,66 \\
\pm 0,12\end{array}$ & $\begin{array}{l}* \mathbf{4 , 0 5} \\
\pm 0,13\end{array}$ & $\begin{array}{c}7,47 \\
\pm 0,17\end{array}$ \\
\hline Jan. 5 Aut. J.M. 0,01 & $\begin{array}{c}9,77 \\
\pm 0,20\end{array}$ & $\begin{array}{c}3,90 \\
\pm 0,12\end{array}$ & $\begin{array}{c}3,61 \\
\pm 0,12\end{array}$ & $\begin{array}{c}2,03 \\
\pm 0,09\end{array}$ & $\begin{array}{c}3,61 \\
\pm 0,12\end{array}$ & $\begin{array}{c}3,66 \\
\pm 0,12\end{array}$ & $\begin{array}{c}5,97 \\
\pm 0,15\end{array}$ & $\begin{array}{c}7,27 \\
\pm 0,17\end{array}$ \\
\hline Jan. 5 Aut. J.M. 0,02 & $\begin{array}{c}9,77 \\
\pm 0,20\end{array}$ & $\begin{array}{c}4,15 \\
\pm 0,12\end{array}$ & $\begin{array}{c}3,85 \\
\pm 0,12\end{array}$ & $\begin{array}{c}2,28 \\
\pm 0,10\end{array}$ & $\begin{array}{c}3,61 \\
\pm 0,12\end{array}$ & $\begin{array}{r}* \mathbf{3}, \mathbf{4 3} \\
\pm 0,12\end{array}$ & $\begin{array}{c}5,76 \\
\pm 0,15\end{array}$ & $\begin{array}{l}7,47 \\
\pm 0,17\end{array}$ \\
\hline Jan. 5 Aut. J.M. $\bar{x}$ & $\begin{array}{c}9,77 \\
\pm 0,20\end{array}$ & $\begin{array}{c}3,90 \\
\pm 0,12\end{array}$ & $\begin{array}{c}3,85 \\
\pm 0,12\end{array}$ & $\begin{array}{c}2,28 \\
\pm 0,10\end{array}$ & $\begin{array}{c}3,82 \\
\pm 0,12\end{array}$ & $\begin{array}{c}3,89 \\
\pm 0,12\end{array}$ & $\begin{array}{c}5,76 \\
\pm 0,15\end{array}$ & $\begin{array}{c}7,07 \\
\pm 0,17\end{array}$ \\
\hline
\end{tabular}


Tabela C.3: Naïve Bayes - taxas de erro obtidas pelas representações bag-of-related-words que utilizaram medidas de interesse objetivas para gerar os atributos e pela representação bag-of-words para a coleção Reuters-21578.

\begin{tabular}{|l|r|}
\hline Representação & Taxa de Erro \\
\hline Bag-of-words & 27,94 \\
\hline Jan. 5 Aut. & 24,26 \\
\hline Jan. 5 Aut. Lift 0,1 & 24,47 \\
\hline Jan. 5 Aut. Lift 0,2 & 25,42 \\
\hline Jan. 5 Aut. Lift $\bar{x}$ & 24,90 \\
\hline Jan. 5 Aut. Conf. 0,25 & 24,58 \\
\hline Jan. 5 Aut. Conf. 0,5 & 25,11 \\
\hline Jan. 5 Aut. Conf. $\bar{x}$ & 25,00 \\
\hline Jan. 5 Aut. Yule's Q 0,50 & 24,79 \\
\hline Jan. 5 Aut. Yule's Q 0,75 & 24,79 \\
\hline Jan. 5 Aut. Yule's Q $\bar{x}$ & 24,79 \\
\hline Jan. 5 Aut. Corr. 0,25 & 25,00 \\
\hline Jan. 5 Aut. Corr. 0,50 & 24,90 \\
\hline Jan. 5 Aut. Corr. $\bar{x}$ & 24,26 \\
\hline Jan. 5 Aut. I.M. 0,05 & 25,11 \\
\hline Jan. 5 Aut. I.M. 0,1 & 25,21 \\
\hline Jan. 5 Aut. I.M. $\bar{x}$ & 24,90 \\
\hline Jan. 5 Aut. Gini 0,01 & 24,58 \\
\hline Jan. 5 Aut. Gini 0,04 & 24,90 \\
\hline Jan. 5 Aut. Gini $\bar{x}$ & 24,79 \\
\hline Jan. 5 Aut. Kappa 0,3 & 24,16 \\
\hline Jan. 5 Aut. Kappa 0,5 & 24,79 \\
\hline Jan. 5 Aut. Kappa $\bar{x}$ & 24,68 \\
\hline Jan. 5 Aut. J.M. 0,02 & 25,00 \\
\hline Jan. 5 Aut. J.M. 0,05 & \\
\hline Jan. 5 Aut. J.M. $\bar{x}$ & $\mathbf{2 4 0}$ \\
\hline
\end{tabular}

Nos resultados obtidos pelos diferentes tipos de mapeamento para as coleções da ACM, nas coleções em que o menor erro foi obtido por uma representação bag-of-related-words todas as variações de tipos de mapeamento e suporte foram melhores que a representação bag-of-words, com exceção da representação [Sent. 6\%] para as coleções ACM-2, ACM-3 e ACM-7, e a representação [Par. 14\%] para as coleções ACM-6 e ACM-7. Fato semelhante ocorre nas representações bag-of-related-words que utilizaram medidas de interesse objetivas. Todas as variações de medidas de interesse objetivas e limiares foram melhores que representação bag-of-words para as coleções ACM-2, ACM-3, ACM-4, ACM-6, e ACM-7. Já para a coleção Reuters, todas as representações utilizadas obtiveram uma taxa de erro de classificação menor que a representação bag-of-words.

\section{C. $2 \quad J 48$}

Nesta seção são apresentadas as tabelas contendo os resultados obtidos pelas representações bag-of-related-words e pela representação bag-of-words utilizando o algoritmo de classificação J48. Na Tabela C.4 são apresentadas as taxas de erro de classificação e o desvio padrão para as coleções da ACM obtidas pelas representações bag-of-related-words que utilizaram os itemsets frequentes como atributos. Na Tabela C.5 são apresentadas as taxas de erro de classificação e o desvio padrão para as coleções da ACM obtidas pelas representações bag-of-related-words que utilizaram medidas de interesse objetivas para gerar os atributos. Na Tabela C.6 são apresentadas as taxas de erro para a coleção Reuters-21578 obtidas pelas representações bag-of-related-words que utilizaram medidas 
Apêndice C. Tabelas com os Resultados de Classificação

de interesse objetivas para gerar os atributos.

Tabela C.4: J48 - taxas de erro obtidas pelas representações bag-of-related-words que utilizaram itemsets frequentes como atributos e pela representação bag-of-words para as coleções da ACM.

\begin{tabular}{|c|c|c|c|c|c|c|c|c|}
\hline & \multicolumn{8}{|c|}{ Taxa de Erro } \\
\hline Representação & ACM-1 & ACM-2 & ACM-3 & ACM-4 & ACM-5 & ACM-6 & ACM-7 & ACM-8 \\
\hline Bag-of-words & $\begin{array}{c}\boldsymbol{*}_{\mathbf{1 1}, \mathbf{5 3}} \\
\pm 0,22\end{array}$ & $\begin{array}{l}* \mathbf{7}, \mathbf{0 7} \\
\pm 0,19\end{array}$ & $\begin{array}{l}12,97 \\
\pm 0,22\end{array}$ & $\begin{array}{r}\boldsymbol{*}_{\mathbf{6}, \mathbf{0 9}} \\
\pm 0,13\end{array}$ & $\begin{array}{c}* \mathbf{1 4}, \mathbf{0 1} \\
\pm 0,22\end{array}$ & $\begin{array}{l}11,62 \\
\pm 0,20\end{array}$ & $\begin{array}{l}11,30 \\
\pm 0,20\end{array}$ & $\begin{array}{l}* \mathbf{1 0}, \mathbf{3 0} \\
\pm 0,20\end{array}$ \\
\hline Sent. $2 \%$ & $\begin{array}{l}21,11 \\
\pm 0,28\end{array}$ & $\begin{array}{l}11,46 \\
\pm 0,21\end{array}$ & $\begin{array}{c}14,18 \\
\pm 0,22\end{array}$ & $\begin{array}{c}9,14 \\
\pm 0,19\end{array}$ & $\begin{array}{c}19,11 \\
\pm 0,27\end{array}$ & $\begin{array}{c}14,38 \\
\pm 0,23\end{array}$ & $\begin{array}{c}9,38 \\
\pm 0,19\end{array}$ & $\begin{array}{l}22,42 \\
\pm 0,29\end{array}$ \\
\hline Sent. $3 \%$ & $\begin{array}{l}24,37 \\
\pm 0,30\end{array}$ & $\begin{array}{l}17,32 \\
\pm 0,25\end{array}$ & $\begin{array}{c}13,71 \\
\pm 0,23\end{array}$ & $\begin{array}{c}10,41 \\
\pm 0,19\end{array}$ & $\begin{array}{l}20,59 \\
\pm 0,27\end{array}$ & $\begin{array}{l}18,04 \\
\pm 0,25\end{array}$ & $\begin{array}{c}10,87 \\
\pm 0,20\end{array}$ & $\begin{array}{l}27,27 \\
\pm 0,31\end{array}$ \\
\hline Sent. $4 \%$ & $\begin{array}{l}21,86 \\
\pm 0,28\end{array}$ & $\begin{array}{c}17,32 \\
\pm 0,25\end{array}$ & $\begin{array}{c}16,78 \\
\pm 0,25\end{array}$ & $\begin{array}{c}12,44 \\
\pm 0,21\end{array}$ & $\begin{array}{c}25,69 \\
\pm 0,31\end{array}$ & $\begin{array}{c}17,12 \\
\pm 0,25\end{array}$ & $\begin{array}{l}12,79 \\
\pm 0,22\end{array}$ & $\begin{array}{l}29,09 \\
\pm 0,32\end{array}$ \\
\hline Sent. $5 \%$ & $\begin{array}{l}25,13 \\
\pm 0,30\end{array}$ & $\begin{array}{c}17,07 \\
\pm 0,25\end{array}$ & $\begin{array}{c}17,26 \\
\pm 0,25\end{array}$ & $\begin{array}{l}13,45 \\
\pm 0,22\end{array}$ & $\begin{array}{l}25,90 \\
\pm 0,30\end{array}$ & $\begin{array}{l}17,12 \\
\pm 0,25\end{array}$ & $\begin{array}{l}14,29 \\
\pm 0,22\end{array}$ & $\begin{array}{l}34,95 \\
\pm 0,35\end{array}$ \\
\hline Sent. $6 \%$ & $\begin{array}{l}30,65 \\
\pm 0,33\end{array}$ & $\begin{array}{c}18,29 \\
\pm 0,26\end{array}$ & $\begin{array}{c}19,62 \\
\pm 0,27\end{array}$ & $\begin{array}{c}16,24 \\
\pm 0,23\end{array}$ & $\begin{array}{l}24,84 \\
\pm 0,30\end{array}$ & $\begin{array}{l}18,72 \\
\pm 0,25\end{array}$ & $\begin{array}{l}13,01 \\
\pm 0,22\end{array}$ & $\begin{array}{c}33,33 \\
\pm 0,34\end{array}$ \\
\hline Par. $10 \%$ & $\begin{array}{l}22,86 \\
\pm 0,29\end{array}$ & $\begin{array}{c}16,10 \\
\pm 0,25\end{array}$ & $\begin{array}{c}16,78 \\
\pm 0,25\end{array}$ & $\begin{array}{l}12,94 \\
\pm 0,22\end{array}$ & $\begin{array}{l}20,81 \\
\pm 0,27\end{array}$ & $\begin{array}{l}16,90 \\
\pm 0,25\end{array}$ & $\begin{array}{c}13,01 \\
\pm 0,22\end{array}$ & $\begin{array}{l}30,10 \\
\pm 0,33\end{array}$ \\
\hline Par. $11 \%$ & $\begin{array}{l}25,88 \\
\pm 0,30\end{array}$ & $\begin{array}{r}16,83 \\
\pm 0,25\end{array}$ & $\begin{array}{c}17,02 \\
\pm 0,25\end{array}$ & $\begin{array}{c}14,47 \\
\pm 0,23\end{array}$ & $\begin{array}{l}23,35 \\
\pm 0,29\end{array}$ & $\begin{array}{l}18,26 \\
\pm 0,25\end{array}$ & $\begin{array}{l}11,09 \\
\pm 0,20\end{array}$ & $\begin{array}{l}29,49 \\
\pm 0,32\end{array}$ \\
\hline Par. $12 \%$ & $\begin{array}{l}28,64 \\
\pm 0,32\end{array}$ & $\begin{array}{l}17,07 \\
\pm 0,25\end{array}$ & $\begin{array}{c}18,91 \\
\pm 0,26\end{array}$ & $\begin{array}{l}14,47 \\
\pm 0,23\end{array}$ & $\begin{array}{l}24,20 \\
\pm 0,29\end{array}$ & $\begin{array}{l}18,49 \\
\pm 0,25\end{array}$ & $\begin{array}{l}11,30 \\
\pm 0,20\end{array}$ & $\begin{array}{l}31,52 \\
\pm 0,33\end{array}$ \\
\hline Par. $13 \%$ & $\begin{array}{l}28,39 \\
\pm 0,31\end{array}$ & $\begin{array}{l}16,34 \\
\pm 0,25\end{array}$ & $\begin{array}{l}18,68 \\
\pm 0,26\end{array}$ & $\begin{array}{c}14,21 \\
\pm 0,23\end{array}$ & $\begin{array}{l}23,35 \\
\pm 0,28\end{array}$ & $\begin{array}{l}20,09 \\
\pm 0,27\end{array}$ & $\begin{array}{l}12,58 \\
\pm 0,21\end{array}$ & $\begin{array}{l}33,33 \\
\pm 0,34\end{array}$ \\
\hline Par. $14 \%$ & $\begin{array}{c}3 \pm 0,40 \\
\pm 0,32\end{array}$ & $\begin{array}{c}15,61 \\
\pm 0,24\end{array}$ & $\begin{array}{l}19,62 \\
\pm 0,26\end{array}$ & $\begin{array}{c}14,97 \\
\pm 0,23\end{array}$ & $\begin{array}{l}24,42 \\
\pm 0,29\end{array}$ & $\begin{array}{l}19,18 \\
\pm 0,25\end{array}$ & $\begin{array}{l}15,57 \\
\pm 0,23\end{array}$ & $\begin{array}{l}34,95 \\
\pm 0,34\end{array}$ \\
\hline Jan. 5 Aut. & $\begin{array}{l}14,29 \\
\pm 0,23\end{array}$ & $\begin{array}{l}13,90 \\
\pm 0,22\end{array}$ & $\begin{array}{c}9,62 \\
\pm 0,18\end{array}$ & $\begin{array}{c}8,88 \\
\pm 0,18\end{array}$ & $\begin{array}{l}18,26 \\
\pm 0,26\end{array}$ & $\begin{array}{c}8,24 \\
\pm 0,17\end{array}$ & $\begin{array}{l}16,63 \\
\pm 0,24\end{array}$ & $\begin{array}{l}17,37 \\
\pm 0,25\end{array}$ \\
\hline Jan. $50,6 \%$ & $\begin{array}{c}14,79 \\
\pm 0,24\end{array}$ & $\begin{array}{c}14,88 \\
\pm 0,24\end{array}$ & $\begin{array}{l}* \mathbf{9 , 6 2} \\
\pm 0,19\end{array}$ & $\begin{array}{c}6,60 \\
\pm 0,16\end{array}$ & $\begin{array}{l}15,71 \\
\pm 0,25\end{array}$ & $\begin{array}{l}* \mathbf{7}, \mathbf{5 5} \\
\pm 0,17\end{array}$ & $\begin{array}{l}13,01 \\
\pm 0,22\end{array}$ & $\begin{array}{l}17,17 \\
\pm 0,26\end{array}$ \\
\hline Jan. $50,8 \%$ & $\begin{array}{l}17,04 \\
\pm 0,25\end{array}$ & $\begin{array}{c}10,24 \\
\pm 0,20\end{array}$ & $\begin{array}{c}10,34 \\
\pm 0,20\end{array}$ & $\begin{array}{c}7,61 \\
\pm 0,17\end{array}$ & $\begin{array}{l}20,17 \\
\pm 0,27\end{array}$ & $\begin{array}{l}11,90 \\
\pm 0,21\end{array}$ & $\begin{array}{l}13,86 \\
\pm 0,23\end{array}$ & $\begin{array}{l}20,00 \\
\pm 0,27\end{array}$ \\
\hline Jan. $51 \%$ & $\begin{array}{l}16,29 \\
\pm 0,25\end{array}$ & $\begin{array}{c}9,27 \\
\pm 0,19\end{array}$ & $\begin{array}{l}11,78 \\
\pm 0,21\end{array}$ & $\begin{array}{l}10,41 \\
\pm 0,20\end{array}$ & $\begin{array}{l}19,32 \\
\pm 0,27\end{array}$ & $\begin{array}{l}11,67 \\
\pm 0,21\end{array}$ & $\begin{array}{l}13,43 \\
\pm 0,22\end{array}$ & $\begin{array}{l}24,85 \\
\pm 0,30\end{array}$ \\
\hline Jan. $52 \%$ & $\begin{array}{l}21,80 \\
\pm 0,28\end{array}$ & $\begin{array}{c}12,44 \\
\pm 0,22\end{array}$ & $\begin{array}{c}14,18 \\
\pm 0,22\end{array}$ & $\begin{array}{c}8,63 \\
\pm 0,18\end{array}$ & $\begin{array}{l}19,53 \\
\pm 0,27\end{array}$ & $\begin{array}{c}14,87 \\
\pm 0,24\end{array}$ & $\begin{array}{l}11,30 \\
\pm 0,21\end{array}$ & $\begin{array}{l}27,88 \\
\pm 0,32\end{array}$ \\
\hline Jan. $53 \%$ & $\begin{array}{l}23,31 \\
\pm 0,29\end{array}$ & $\begin{array}{l}15,12 \\
\pm 0,23\end{array}$ & $\begin{array}{l}18,03 \\
\pm 0,25\end{array}$ & $\begin{array}{l}12,44 \\
\pm 0,21\end{array}$ & $\begin{array}{l}25,27 \\
\pm 0,30\end{array}$ & $\begin{array}{l}16,25 \\
\pm 0,25\end{array}$ & $\begin{array}{c}9,59 \\
\pm 0,19\end{array}$ & $\begin{array}{l}28,48 \\
\pm 0,32\end{array}$ \\
\hline Jan. $102 \%$ & $\begin{array}{l}17,29 \\
\pm 0,26\end{array}$ & $\begin{array}{c}9,27 \\
\pm 0,18\end{array}$ & $\begin{array}{l}11,06 \\
\pm 0,21\end{array}$ & $\begin{array}{c}8,38 \\
\pm 0,18\end{array}$ & $\begin{array}{l}19,11 \\
\pm 0,27\end{array}$ & $\begin{array}{l}10,53 \\
\pm 0,20\end{array}$ & $\begin{array}{l}13,01 \\
\pm 0,22\end{array}$ & $\begin{array}{l}22,02 \\
\pm 0,29\end{array}$ \\
\hline Jan. $103 \%$ & $\begin{array}{l}16,54 \\
\pm 0,25\end{array}$ & $\begin{array}{l}11,95 \\
\pm 0,21\end{array}$ & $\begin{array}{l}14,42 \\
\pm 0,23\end{array}$ & $\begin{array}{l}10,15 \\
\pm 0,20\end{array}$ & $\begin{array}{l}21,66 \\
\pm 0,28\end{array}$ & $\begin{array}{l}14,65 \\
\pm 0,24\end{array}$ & $\begin{array}{l}10,66 \\
\pm 0,19\end{array}$ & $\begin{array}{l}27,88 \\
\pm 0,32\end{array}$ \\
\hline Jan. $104 \%$ & $\begin{array}{l}21,30 \\
\pm 0,28\end{array}$ & $\begin{array}{r}12,44 \\
\pm 0,22\end{array}$ & $\begin{array}{l}13,94 \\
\pm 0,23\end{array}$ & $\begin{array}{l}10,66 \\
\pm 0,20\end{array}$ & $\begin{array}{l}20,38 \\
\pm 0,27\end{array}$ & $\begin{array}{c}15,33 \\
\pm 0,24\end{array}$ & $\begin{array}{l}12,58 \\
\pm 0,22\end{array}$ & $\begin{array}{l}27,47 \\
\pm 0,31\end{array}$ \\
\hline Jan. $105 \%$ & $\begin{array}{l}23,81 \\
\pm 0,29\end{array}$ & $\begin{array}{l}15,85 \\
\pm 0,25\end{array}$ & $\begin{array}{l}14,66 \\
\pm 0,23\end{array}$ & $\begin{array}{c}10,91 \\
\pm 0,20\end{array}$ & $\begin{array}{l}23,14 \\
\pm 0,29\end{array}$ & $\begin{array}{c}15,79 \\
\pm 0,24\end{array}$ & $\begin{array}{l}11,09 \\
\pm 0,20\end{array}$ & $\begin{array}{l}28,08 \\
\pm 0,32\end{array}$ \\
\hline Jan. $106 \%$ & $\begin{array}{l}24,31 \\
\pm 0,30\end{array}$ & $\begin{array}{l}15,85 \\
\pm 0,24\end{array}$ & $\begin{array}{l}17,31 \\
\pm 0,25\end{array}$ & $\begin{array}{l}10,66 \\
\pm 0,20\end{array}$ & $\begin{array}{l}29,51 \\
\pm 0,33\end{array}$ & $\begin{array}{l}18,31 \\
\pm 0,26\end{array}$ & $\begin{array}{l}12,58 \\
\pm 0,22\end{array}$ & $\begin{array}{l}30,51 \\
\pm 0,33\end{array}$ \\
\hline Jan. $206 \%$ & $\begin{array}{l}19,30 \\
\pm 0,27\end{array}$ & $\begin{array}{r}14,15 \\
\pm 0,23\end{array}$ & $\begin{array}{l}14,18 \\
\pm 0,23\end{array}$ & $\begin{array}{l}10,66 \\
\pm 0,20\end{array}$ & $\begin{array}{l}18,90 \\
\pm 0,27\end{array}$ & $\begin{array}{c}14,68 \\
\pm 0,24\end{array}$ & $\begin{array}{c}9,59 \\
\pm 0,19\end{array}$ & $\begin{array}{l}29,70 \\
\pm 0,33\end{array}$ \\
\hline Jan. $207 \%$ & $\begin{array}{l}20,30 \\
\pm 0,27\end{array}$ & $\begin{array}{l}11,71 \\
\pm 0,21\end{array}$ & $\begin{array}{l}13,46 \\
\pm 0,23\end{array}$ & $\begin{array}{l}11,68 \\
\pm 0,21\end{array}$ & $\begin{array}{l}19,75 \\
\pm 0,27\end{array}$ & $\begin{array}{l}17,20 \\
\pm 0,25\end{array}$ & $\begin{array}{l}11,51 \\
\pm 0,20\end{array}$ & $\begin{array}{l}21,62 \\
\pm 0,28\end{array}$ \\
\hline Jan. $208 \%$ & $\begin{array}{l}23,81 \\
\pm 0,30\end{array}$ & $\begin{array}{r}15,37 \\
\pm 0,24\end{array}$ & $\begin{array}{l}15,63 \\
\pm 0,24\end{array}$ & $\begin{array}{l}10,41 \\
\pm 0,19\end{array}$ & $\begin{array}{l}21,87 \\
\pm 0,28\end{array}$ & $\begin{array}{l}16,06 \\
\pm 0,25\end{array}$ & $\begin{array}{l}11,51 \\
\pm 0,21\end{array}$ & $\begin{array}{l}29,09 \\
\pm 0,32\end{array}$ \\
\hline Jan. $209 \%$ & $\begin{array}{l}22,31 \\
\pm 0,28\end{array}$ & $\begin{array}{c}16,10 \\
\pm 0,24\end{array}$ & $\begin{array}{l}17,31 \\
\pm 0,25\end{array}$ & $\begin{array}{c}9,64 \\
\pm 0,19\end{array}$ & $\begin{array}{l}22,72 \\
\pm 0,25\end{array}$ & $\begin{array}{l}16,51 \\
\pm 0,20\end{array}$ & $\begin{array}{l}11,30 \\
\pm 0,32\end{array}$ & $\begin{array}{l}29,49 \\
\pm 0,32\end{array}$ \\
\hline Jan. $2010 \%$ & $\begin{array}{l}22,56 \\
\pm 0,28\end{array}$ & $\begin{array}{c}14,63 \\
\pm 0,24\end{array}$ & $\begin{array}{c}18,27 \\
\pm 0,26\end{array}$ & $\begin{array}{l}11,68 \\
\pm 0,21\end{array}$ & $\begin{array}{l}24,63 \\
\pm 0,30\end{array}$ & $\begin{array}{l}16,97 \\
\pm 0,25\end{array}$ & $\begin{array}{l}12,37 \\
\pm 0,22\end{array}$ & $\begin{array}{l}30,30 \\
\pm 0,33\end{array}$ \\
\hline Jan. $3010 \%$ & $\begin{array}{c}19,80 \\
\pm 0,27\end{array}$ & $\begin{array}{c}13,17 \\
\pm 0,22\end{array}$ & $\begin{array}{c}14,42 \\
\pm 0,23\end{array}$ & $\begin{array}{l}10,41 \\
\pm 0,20\end{array}$ & $\begin{array}{l}20,17 \\
\pm 0,27\end{array}$ & $\begin{array}{l}18,12 \\
\pm 0,26\end{array}$ & $\begin{array}{l}* \mathbf{8 , 9 6} \\
\pm 0,18\end{array}$ & $\begin{array}{l}26,26 \\
\pm 0,31\end{array}$ \\
\hline Jan. $3011 \%$ & $\begin{array}{c}20,80 \\
\pm 0,28\end{array}$ & $\begin{array}{r}14,88 \\
\pm 0,24\end{array}$ & $\begin{array}{c}13,94 \\
\pm 0,23\end{array}$ & $\begin{array}{c}9,64 \\
\pm 0,19\end{array}$ & $\begin{array}{c}22,29 \\
\pm 0,28\end{array}$ & $\begin{array}{c}16,06 \\
\pm 0,25\end{array}$ & $\begin{array}{l}10,23 \\
\pm 0,20\end{array}$ & $\begin{array}{l}27,27 \\
\pm 0,31\end{array}$ \\
\hline Jan. $3012 \%$ & $\begin{array}{c}23,31 \\
\pm 0,29\end{array}$ & $\begin{array}{c}14,88 \\
\pm 0,24\end{array}$ & $\begin{array}{c}16,11 \\
\pm 0,25\end{array}$ & $\begin{array}{l}11,68 \\
\pm 0,21\end{array}$ & $\begin{array}{c}23,14 \\
\pm 0,29\end{array}$ & $\begin{array}{l}15,83 \\
\pm 0,24\end{array}$ & $\begin{array}{l}12,58 \\
\pm 0,21\end{array}$ & $\begin{array}{l}29,90 \\
\pm 0,33\end{array}$ \\
\hline Jan. $3013 \%$ & $\begin{array}{l}24,06 \\
\pm 0,29\end{array}$ & $\begin{array}{r}15,85 \\
\pm 0,24\end{array}$ & $\begin{array}{c}17,31 \\
\pm 0,25\end{array}$ & $\begin{array}{c}9,64 \\
\pm 0,19\end{array}$ & $\begin{array}{l}23,57 \\
\pm 0,29\end{array}$ & $\begin{array}{l}17,43 \\
\pm 0,25\end{array}$ & $\begin{array}{l}11,94 \\
\pm 0,21\end{array}$ & $\begin{array}{l}26,67 \\
\pm 0,30\end{array}$ \\
\hline Jan. $3014 \%$ & $\begin{array}{l}18,80 \\
\pm 0,26\end{array}$ & $\begin{array}{c}15,12 \\
\pm 0,24\end{array}$ & $\begin{array}{c}17,31 \\
\pm 0,25\end{array}$ & $\begin{array}{c}10,91 \\
\pm 0,20\end{array}$ & $\begin{array}{l}23,35 \\
\pm 0,29\end{array}$ & $\begin{array}{l}19,27 \\
\pm 0,26\end{array}$ & $\begin{array}{l}12,58 \\
\pm 0,22\end{array}$ & $\begin{array}{l}28,48 \\
\pm 0,32\end{array}$ \\
\hline
\end{tabular}


Tabela C.5: J48 - taxas de erro obtidas pelas representações bag-of-related-words que utilizaram medidas de interesse objetivas para gerar os atributos e pela representação bag-of-words para as coleções da ACM.

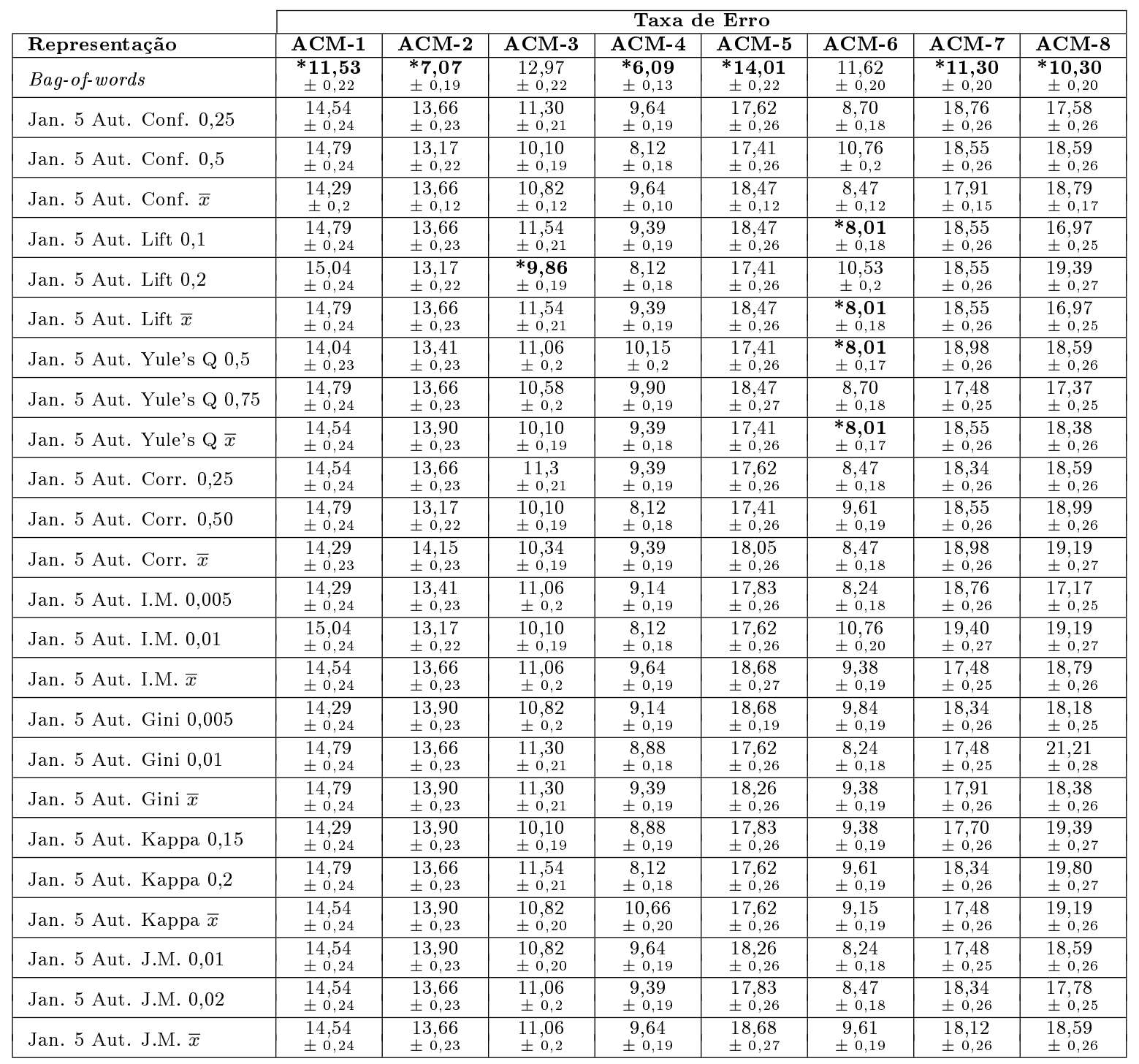


Tabela C.6: J48 - taxas de erro obtidas pelas representações bag-of-related-words que utilizaram medidas de interesse objetivas para gerar os atributos e pela representação bag-of-words para a coleção Reuters21578 .

\begin{tabular}{|l|r|}
\hline Representação & Taxa de Erro \\
\hline Bag-of-words & 31,72 \\
\hline Jan. 5 Aut. & 29,62 \\
\hline Jan. 5 Aut. Lift 0,1 & 29,83 \\
\hline Jan. 5 Aut. Lift 0,2 & 30,15 \\
\hline Jan. 5 Aut. Lift $\bar{x}$ & 30,04 \\
\hline Jan. 5 Aut. Conf. 0,25 & 29,20 \\
\hline Jan. 5 Aut. Conf. 0,50 & 30,36 \\
\hline Jan. 5 Aut. Conf. $\bar{x}$ & 30,36 \\
\hline Jan. 5 Aut. Yule's Q 0,50 & 29,31 \\
\hline Jan. 5 Aut. Yule's Q 0,75 & 30,25 \\
\hline Jan. 5 Aut. Yule's Q $\bar{x}$ & 29,52 \\
\hline Jan. 5 Aut. Corr. 0,25 & 29,94 \\
\hline Jan. 5 Aut. Corr. 0,50 & 29,73 \\
\hline Jan. 5 Aut. Corr. $\bar{x}$ & 29,62 \\
\hline Jan. 5 Aut. I.M. 0,05 & $\mathbf{2 8 , 9 9}$ \\
\hline Jan. 5 Aut. I.M. 0,1 & 29,52 \\
\hline Jan. 5 Aut. I.M. $\bar{x}$ & 30,04 \\
\hline Jan. 5 Aut. Gini 0,01 & $\mathbf{2 8 , 9 9}$ \\
\hline Jan. 5 Aut. Gini 0,04 & 29,94 \\
\hline Jan. 5 Aut. Gini $\bar{x}$ & 30,57 \\
\hline Jan. 5 Aut. Kappa 0,3 & 29,62 \\
\hline Jan. 5 Aut. Kappa 0,5 & 30,78 \\
\hline Jan. 5 Aut. Kappa $\bar{x}$ & 29,73 \\
\hline Jan. 5 Aut. J.M. 0,02 & $\boldsymbol{* 2 8 , 9 9}$ \\
\hline Jan. 5 Aut. J.M. 0,05 & 30,57 \\
\hline Jan. 5 Aut. J.M. $\bar{x}$ & 29,83 \\
\hline
\end{tabular}

Os resultados obtidos pelos diferentes tipos de mapeamento para as coleções da ACM utilizando o algoritmo J48 tiveram um comportamento diferente dos resultados obtidos utilizando o algoritmo Naïve Bayes. Nem todas as variações de mapeamento e suporte foram melhores que a representação bag-of-words nas coleções em que ao menos uma representação bag-of-related-words obteve a menor taxa de erro. Porém, quando foram utilizadas medidas de interesse objetivas, todas as variações de medidas e limiares foram melhores que a representação bag-of-words para as coleções ACM-3 e ACM-6. Para a coleção Reuters, todas as representações utilizadas obtiveram um taxa de erro de classificação menor que a representação bag-of-words.

\section{C.3 SMO}

Nesta seção são apresentadas as tabelas contendo os resultados obtidos pelas representações bag-of-related-words e pela representação bag-of-words utilizando o algoritmo de classificação $S M O$. Na Tabela C.7 são apresentadas as taxas de erro de classificação e o desvio padrão para as coleções da ACM obtidas pelas representações bag-of-related-words que utilizaram os itemsets frequentes como atributos. Na Tabela C.8 são apresentadas as taxas de erro de classificação e o desvio padrão para as coleções da ACM obtidas pelas representações bag-of-related-words que utilizaram medidas de interesse objetivas para gerar os atributos. Na Tabela C.9 são apresentadas as taxas de erro para a coleção Reuters-21578 obtidas pelas representações bag-of-related-words que utilizaram medidas de interesse objetivas para gerar os atributos. 
Tabela C.7: $S M O$ - taxas de erro obtidas pelas representações bag-of-related-words que utilizaram itemsets frequentes como atributos e pela representação bag-of-words para as coleções da ACM.

\begin{tabular}{|c|c|c|c|c|c|c|c|c|}
\hline \multirow[b]{2}{*}{ Represesentação } & \multicolumn{8}{|c|}{ Taxa de Erro } \\
\hline & ACM-1 & ACM-2 & ACM-3 & ACM-4 & ACM-5 & ACM-6 & ACM-7 & ACM-8 \\
\hline Bag-of-words & $\begin{array}{l}\boldsymbol{*} \mathbf{3 , 2 6} \\
\pm 0,32\end{array}$ & $\begin{array}{l}* \mathbf{2 , 2 0} \\
\pm 0,32\end{array}$ & $\begin{array}{c}3,54 \\
\pm 0,32\end{array}$ & $\begin{array}{l}* \mathbf{0 , 2 5} \\
\pm 0,32\end{array}$ & $\begin{array}{l}\mathbf{*} \mathbf{2 , 1 2} \\
\pm 0,32\end{array}$ & $\begin{array}{l}* \mathbf{1 , 1 4} \\
\pm 0,32\end{array}$ & $\begin{array}{c}3,84 \\
\pm 0,32\end{array}$ & $\begin{array}{c}\boldsymbol{*} \mathbf{4 , 0 4} \\
\pm 0,32\end{array}$ \\
\hline Sent. $2 \%$ & $\begin{array}{c}8,54 \\
\pm 0,32\end{array}$ & $\begin{array}{c}4,63 \\
\pm 0,32\end{array}$ & $\begin{array}{c}3,78 \\
\pm 0,32\end{array}$ & $\begin{array}{c}2,28 \\
\pm 0,32\end{array}$ & $\begin{array}{c}7,43 \\
\pm 0,32\end{array}$ & $\begin{array}{c}6,39 \\
\pm 0,32\end{array}$ & $\begin{array}{c}3,62 \\
\pm 0,32\end{array}$ & $\begin{array}{c}9,09 \\
\pm 0,32\end{array}$ \\
\hline Sent. $3 \%$ & $\begin{array}{l}11,06 \\
\pm 0,33\end{array}$ & $\begin{array}{c}6,59 \\
\pm 0,32\end{array}$ & $\begin{array}{c}3,78 \\
\pm 0,32\end{array}$ & $\begin{array}{c}3,81 \\
\pm 0,32\end{array}$ & $\begin{array}{c}9,34 \\
\pm 0,32\end{array}$ & $\begin{array}{c}6,39 \\
\pm 0,32\end{array}$ & $\begin{array}{c}3,62 \\
\pm 0,32\end{array}$ & $\begin{array}{l}10,30 \\
\pm 0,32\end{array}$ \\
\hline Sent. $4 \%$ & $\begin{array}{c}11,81 \\
\pm 0,33\end{array}$ & $\begin{array}{c}7,80 \\
\pm 0,32\end{array}$ & $\begin{array}{c}5,91 \\
\pm 0,32\end{array}$ & $\begin{array}{c}4,57 \\
\pm 0,32\end{array}$ & $\begin{array}{l}11,25 \\
\pm 0,33\end{array}$ & $\begin{array}{c}8,22 \\
\pm 0,32\end{array}$ & $\begin{array}{c}4,90 \\
\pm 0,32\end{array}$ & $\begin{array}{l}10,91 \\
\pm 0,32\end{array}$ \\
\hline Sent. $5 \%$ & $\begin{array}{l}12,31 \\
\pm 0,33\end{array}$ & $\begin{array}{c}9,02 \\
\pm 0,32\end{array}$ & $\begin{array}{c}8,51 \\
\pm 0,32\end{array}$ & $\begin{array}{c}6,85 \\
\pm 0,32\end{array}$ & $\begin{array}{l}14,65 \\
\pm 0,33\end{array}$ & $\begin{array}{c}9,13 \\
\pm 0,32\end{array}$ & $\begin{array}{c}6,82 \\
\pm 0,32\end{array}$ & $\begin{array}{l}13,13 \\
\pm 0,33\end{array}$ \\
\hline Sent. $6 \%$ & $\begin{array}{l}16,83 \\
\pm 0,33\end{array}$ & $\begin{array}{c}13,66 \\
\pm 0,33\end{array}$ & $\begin{array}{c}8,04 \\
\pm 0,32\end{array}$ & $\begin{array}{c}7,87 \\
\pm 0,32\end{array}$ & $\begin{array}{c}16,14 \\
\pm 0,33\end{array}$ & $\begin{array}{c}10,27 \\
\pm 0,33\end{array}$ & $\begin{array}{c}7,46 \\
\pm 0,32\end{array}$ & $\begin{array}{l}14,95 \\
\pm 0,33\end{array}$ \\
\hline Par. $10 \%$ & $\begin{array}{l}12,06 \\
\pm 0,33 \\
\end{array}$ & $\begin{array}{c}9,27 \\
\pm 0,32 \\
\end{array}$ & $\begin{array}{c}9,22 \\
\pm 0,32 \\
\end{array}$ & $\begin{array}{c}6,60 \\
\pm 0,32 \\
\end{array}$ & $\begin{array}{l}12,53 \\
\pm 0,33 \\
\end{array}$ & $\begin{array}{c}11,64 \\
\pm 0,33 \\
\end{array}$ & $\begin{array}{c}7,89 \\
\pm 0,32 \\
\end{array}$ & $\begin{array}{l}11,92 \\
\pm 0,32 \\
\end{array}$ \\
\hline Par. $11 \%$ & $\begin{array}{c}13,32 \\
\pm 0,33 \\
\end{array}$ & $\begin{array}{c}9,27 \\
\pm 0,33 \\
\end{array}$ & $\begin{array}{c}9,69 \\
\pm 0,33 \\
\end{array}$ & $\begin{array}{c}6,35 \\
\pm 0,32 \\
\end{array}$ & $\begin{array}{l}12,31 \\
\pm 0,33 \\
\end{array}$ & $\begin{array}{c}11,87 \\
\pm 0,33 \\
\end{array}$ & $\begin{array}{c}8,10 \\
\pm 0,32\end{array}$ & $\begin{array}{l}12,73 \\
\pm 0,33\end{array}$ \\
\hline Par. $12 \%$ & $\begin{array}{l}15,33 \\
\pm 0,33 \\
\end{array}$ & $\begin{array}{c}9,02 \\
\pm 0,33 \\
\end{array}$ & $\begin{array}{l}10,40 \\
\pm 0,33 \\
\end{array}$ & $\begin{array}{c}7,11 \\
\pm 0,32 \\
\end{array}$ & $\begin{array}{c}14,01 \\
\pm 0,33 \\
\end{array}$ & $\begin{array}{c}13,7 \\
\pm 0,33 \\
\end{array}$ & $\begin{array}{c}9,81 \\
\pm 0,33 \\
\end{array}$ & $\begin{array}{l}14,55 \\
\pm 0,33 \\
\end{array}$ \\
\hline Par. $13 \%$ & $\begin{array}{l}17,34 \\
\pm 0,33 \\
\end{array}$ & $\begin{array}{c}9,76 \\
\pm 0,33 \\
\end{array}$ & $\begin{array}{c}8,04 \\
\pm 0,32 \\
\end{array}$ & $\begin{array}{c}8,38 \\
\pm 0,32 \\
\end{array}$ & $\begin{array}{c}15,71 \\
\pm 0,33 \\
\end{array}$ & $\begin{array}{c}12,1 \\
\pm 0,33\end{array}$ & $\begin{array}{c}11,94 \\
\pm 0,33\end{array}$ & $\begin{array}{l}19,39 \\
\pm 0,33\end{array}$ \\
\hline Par. $14 \%$ & $\begin{array}{c}18,84 \\
\pm 0,33 \\
\end{array}$ & $\begin{array}{r}11,95 \\
\pm 0,33 \\
\end{array}$ & $\begin{array}{c}8,75 \\
\pm 0,33 \\
\end{array}$ & $\begin{array}{c}8,12 \\
\pm 0,32 \\
\end{array}$ & $\begin{array}{c}17,2 \\
\pm 0,33\end{array}$ & $\begin{array}{c}13,24 \\
\pm 0,33 \\
\end{array}$ & $\begin{array}{r}12,15 \\
\pm 0,33 \\
\end{array}$ & $\begin{array}{l}17,78 \\
\pm 0,33\end{array}$ \\
\hline Jan. 5 Aut. & $\begin{array}{c}5,26 \\
\pm 0,32 \\
\end{array}$ & $\begin{array}{c}3,66 \\
\pm 0,31 \\
\end{array}$ & $\begin{array}{c}3,13 \\
\pm 0,31 \\
\end{array}$ & $\begin{array}{c}1,52 \\
\pm 0,31 \\
\end{array}$ & $\begin{array}{c}2,55 \\
\pm 0,31\end{array}$ & $\begin{array}{c}2,52 \\
\pm 0,31 \\
\end{array}$ & $\begin{array}{c}3,20 \\
\pm 0,31\end{array}$ & $\begin{array}{l}7,07 \\
\pm 0,32 \\
\end{array}$ \\
\hline Jan. $50,6 \%$ & $\begin{array}{c}5,76 \\
\pm 0,32 \\
\end{array}$ & $\begin{array}{c}3,41 \\
\pm 0,32 \\
\end{array}$ & $\begin{array}{l}* \mathbf{2 , 8 8} \\
\pm 0,32 \\
\end{array}$ & $\begin{array}{c}1,27 \\
\pm 0,32 \\
\end{array}$ & $\begin{array}{c}3,61 \\
\pm 0,32 \\
\end{array}$ & $\begin{array}{c}1,60 \\
\pm 0,32 \\
\end{array}$ & $\begin{array}{c}4,05 \\
\pm 0,32 \\
\end{array}$ & $\begin{array}{l}6,87 \\
\pm 0,32 \\
\end{array}$ \\
\hline Jan. $50,8 \%$ & $\begin{array}{c}6,02 \\
\pm 0,32\end{array}$ & $\begin{array}{c}2,93 \\
\pm 0,32 \\
\end{array}$ & $\begin{array}{l}* \mathbf{2 , 8 8} \\
\pm 0,32\end{array}$ & $\begin{array}{c}1,27 \\
\pm 0,32\end{array}$ & $\begin{array}{c}3,61 \\
\pm 0,32\end{array}$ & $\begin{array}{c}2,29 \\
\pm 0,32\end{array}$ & $\begin{array}{c}3,41 \\
\pm 0,32\end{array}$ & $\begin{array}{l}7,88 \\
\pm 0,32\end{array}$ \\
\hline Jan. $51 \%$ & $\begin{array}{c}6,27 \\
\pm 0,32 \\
\end{array}$ & $\begin{array}{c}2,93 \\
\pm 0,32 \\
\end{array}$ & $\begin{array}{c}3,13 \\
\pm 0,32\end{array}$ & $\begin{array}{c}1,52 \\
\pm 0,32\end{array}$ & $\begin{array}{c}5,31 \\
\pm 0,32\end{array}$ & $\begin{array}{c}2,75 \\
\pm 0,32\end{array}$ & $\begin{array}{c}3,41 \\
\pm 0,32\end{array}$ & $\begin{array}{l}6,87 \\
\pm 0,32\end{array}$ \\
\hline Jan. $52 \%$ & $\begin{array}{l}10,78 \\
\pm 0,32\end{array}$ & $\begin{array}{c}2,93 \\
\pm 0,32\end{array}$ & $\begin{array}{c}4,33 \\
\pm 0,32\end{array}$ & $\begin{array}{c}1,27 \\
\pm 0,32\end{array}$ & $\begin{array}{c}9,34 \\
\pm 0,32\end{array}$ & $\begin{array}{c}5,26 \\
\pm 0,32\end{array}$ & $\begin{array}{l}\boldsymbol{*} \mathbf{2 , 7 7} \\
\pm 0,32\end{array}$ & $\begin{array}{l}9,90 \\
\pm 0,32\end{array}$ \\
\hline Jan. $53 \%$ & $\begin{array}{l}12,53 \\
\pm 0,33\end{array}$ & $\begin{array}{c}5,12 \\
\pm 0,32\end{array}$ & $\begin{array}{c}4,09 \\
\pm 0,32\end{array}$ & $\begin{array}{c}3,05 \\
\pm 0,32\end{array}$ & $\begin{array}{c}9,34 \\
\pm 0,32\end{array}$ & $\begin{array}{c}3,66 \\
\pm 0,32\end{array}$ & $\begin{array}{c}3,84 \\
\pm 0,32\end{array}$ & $\begin{array}{l}11,11 \\
\pm 0,32\end{array}$ \\
\hline Jan. $102 \%$ & $\begin{array}{c}6,52 \\
\pm 0,32\end{array}$ & $\begin{array}{c}3,66 \\
\pm 0,32\end{array}$ & $\begin{array}{c}3,13 \\
\pm 0,32\end{array}$ & $\begin{array}{c}1,27 \\
\pm 0,32\end{array}$ & $\begin{array}{c}5,73 \\
\pm 0,32\end{array}$ & $\begin{array}{c}3,43 \\
\pm 0,32\end{array}$ & $\begin{array}{c}4,26 \\
\pm 0,32\end{array}$ & $\begin{array}{l}7,68 \\
\pm 0,32\end{array}$ \\
\hline Jan. $103 \%$ & $\begin{array}{c}8,77 \\
\pm 0,32\end{array}$ & $\begin{array}{c}3,90 \\
\pm 0,32\end{array}$ & $\begin{array}{c}3,37 \\
\pm 0,32\end{array}$ & $\begin{array}{c}1,27 \\
\pm 0,32\end{array}$ & $\begin{array}{c}7,43 \\
\pm 0,32\end{array}$ & $\begin{array}{c}3,66 \\
\pm 0,32\end{array}$ & $\begin{array}{c}4,05 \\
\pm 0,32\end{array}$ & $\begin{array}{l}9,09 \\
\pm 0,32\end{array}$ \\
\hline Jan. $104 \%$ & $\begin{array}{c}9,52 \\
\pm 0,32\end{array}$ & $\begin{array}{c}4,39 \\
\pm 0,32\end{array}$ & $\begin{array}{c}3,85 \\
\pm 0,32\end{array}$ & $\begin{array}{c}1,02 \\
\pm 0,32\end{array}$ & $\begin{array}{c}8,28 \\
\pm 0,32\end{array}$ & $\begin{array}{c}5,03 \\
\pm 0,32\end{array}$ & $\begin{array}{c}3,41 \\
\pm 0,32\end{array}$ & $\begin{array}{l}10,3 \\
\pm 0,32\end{array}$ \\
\hline Jan. $105 \%$ & $\begin{array}{l}12,53 \\
\pm 0,33\end{array}$ & $\begin{array}{c}4,88 \\
\pm 0,32\end{array}$ & $\begin{array}{c}4,09 \\
\pm 0,32\end{array}$ & $\begin{array}{c}2,03 \\
\pm 0,32\end{array}$ & $\begin{array}{c}9,34 \\
\pm 0,32\end{array}$ & $\begin{array}{c}2,97 \\
\pm 0,32\end{array}$ & $\begin{array}{c}3,84 \\
\pm 0,32\end{array}$ & $\begin{array}{l}11,72 \\
\pm 0,32\end{array}$ \\
\hline Jan. $106 \%$ & $\begin{array}{l}12,53 \\
\pm 0,33\end{array}$ & $\begin{array}{c}5,85 \\
\pm 0,32\end{array}$ & $\begin{array}{c}3,13 \\
\pm 0,32\end{array}$ & $\begin{array}{c}3,3 \\
\pm 0,32\end{array}$ & $\begin{array}{l}10,62 \\
\pm 0,32\end{array}$ & $\begin{array}{c}6,18 \\
\pm 0,32\end{array}$ & $\begin{array}{c}4,90 \\
\pm 0,32\end{array}$ & $\begin{array}{l}11,92 \\
\pm 0,32\end{array}$ \\
\hline Jan. $206 \%$ & $\begin{array}{l}11,03 \\
\pm 0,33 \\
\end{array}$ & $\begin{array}{c}4,15 \\
\pm 0,32 \\
\end{array}$ & $\begin{array}{c}2,88 \\
\pm 0,32 \\
\end{array}$ & $\begin{array}{c}1,02 \\
\pm 0,32 \\
\end{array}$ & $\begin{array}{c}7,22 \\
\pm 0,32 \\
\end{array}$ & $\begin{array}{c}4,82 \\
\pm 0,32 \\
\end{array}$ & $\begin{array}{c}3,62 \\
\pm 0,32 \\
\end{array}$ & $\begin{array}{l}9,29 \\
\pm 0,32 \\
\end{array}$ \\
\hline Jan. $207 \%$ & $\begin{array}{c}9,77 \\
\pm 0,32 \\
\end{array}$ & $\begin{array}{c}4,63 \\
\pm 0,32 \\
\end{array}$ & $\begin{array}{c}4,33 \\
\pm 0,32 \\
\end{array}$ & $\begin{array}{c}1,27 \\
\pm 0,32 \\
\end{array}$ & $\begin{array}{c}7,86 \\
\pm 0,32 \\
\end{array}$ & $\begin{array}{c}5,73 \\
\pm 0,32 \\
\end{array}$ & $\begin{array}{c}4,26 \\
\pm 0,32 \\
\end{array}$ & $\begin{array}{l}9,49 \\
\pm 0,32 \\
\end{array}$ \\
\hline Jan. $208 \%$ & $\begin{array}{c}9,27 \\
\pm 0,32\end{array}$ & $\begin{array}{c}5,61 \\
\pm 0,32\end{array}$ & $\begin{array}{c}4,81 \\
\pm 0,32\end{array}$ & $\begin{array}{c}1,02 \\
\pm 0,32\end{array}$ & $\begin{array}{c}8,07 \\
\pm 0,32\end{array}$ & $\begin{array}{c}5,28 \\
\pm 0,32\end{array}$ & $\begin{array}{c}4,05 \\
\pm 0,32\end{array}$ & $\begin{array}{l}10,1 \\
\pm 0,32\end{array}$ \\
\hline Jan. $209 \%$ & $\begin{array}{l}12,03 \\
\pm 0,33 \\
\end{array}$ & $\begin{array}{c}5,12 \\
\pm 0,32 \\
\end{array}$ & $\begin{array}{c}4,33 \\
\pm 0,32 \\
\end{array}$ & $\begin{array}{c}1,78 \\
\pm 0,32 \\
\end{array}$ & $\begin{array}{c}7,01 \\
\pm 0,32 \\
\end{array}$ & $\begin{array}{c}4,59 \\
\pm 0,32 \\
\end{array}$ & $\begin{array}{c}4,26 \\
\pm 0,32 \\
\end{array}$ & $\begin{array}{l}11,11 \\
\pm 0,32 \\
\end{array}$ \\
\hline Jan. $2010 \%$ & $\begin{array}{r}11,28 \\
\pm 0,33 \\
\end{array}$ & $\begin{array}{c}6,83 \\
\pm 0,32 \\
\end{array}$ & $\begin{array}{c}3,85 \\
\pm 0,32 \\
\end{array}$ & $\begin{array}{c}3,05 \\
\pm 0,32 \\
\end{array}$ & $\begin{array}{c}9,55 \\
\pm 0,32 \\
\end{array}$ & $\begin{array}{c}5,96 \\
\pm 0,32 \\
\end{array}$ & $\begin{array}{c}4,48 \\
\pm 0,32 \\
\end{array}$ & $\begin{array}{l}12,32 \\
\pm 0,32 \\
\end{array}$ \\
\hline Jan. $3010 \%$ & $\begin{array}{r}11,03 \\
\pm 0,33 \\
\end{array}$ & $\begin{array}{c}4,88 \\
\pm 0,32 \\
\end{array}$ & $\begin{array}{c}3,85 \\
\pm 0,32 \\
\end{array}$ & $\begin{array}{c}1,52 \\
\pm 0,32 \\
\end{array}$ & $\begin{array}{c}8,92 \\
\pm 0,32 \\
\end{array}$ & $\begin{array}{c}5,50 \\
\pm 0,32 \\
\end{array}$ & $\begin{array}{c}5,12 \\
\pm 0,32 \\
\end{array}$ & $\begin{array}{c}10,1 \\
\pm 0,32\end{array}$ \\
\hline Jan. $3011 \%$ & $\begin{array}{l}10,53 \\
\pm 0,33 \\
\end{array}$ & $\begin{array}{c}5,61 \\
\pm 0,32\end{array}$ & $\begin{array}{c}3,85 \\
\pm 0,32\end{array}$ & $\begin{array}{c}1,02 \\
\pm 0,32\end{array}$ & $\begin{array}{c}8,28 \\
\pm 0,32\end{array}$ & $\begin{array}{c}5,28 \\
\pm 0,32\end{array}$ & $\begin{array}{c}5,12 \\
\pm 0,32\end{array}$ & $\begin{array}{c}9,9 \\
\pm 0,32\end{array}$ \\
\hline Jan. $3012 \%$ & $\begin{array}{l}10,78 \\
\pm 0,33\end{array}$ & $\begin{array}{c}5,61 \\
\pm 0,32\end{array}$ & $\begin{array}{c}4,33 \\
\pm 0,32\end{array}$ & $\begin{array}{c}1,78 \\
\pm 0,32\end{array}$ & $\begin{array}{c}9,34 \\
\pm 0,32\end{array}$ & $\begin{array}{c}4,59 \\
\pm 0,32\end{array}$ & $\begin{array}{c}4,48 \\
\pm 0,32\end{array}$ & $\begin{array}{l}11,11 \\
\pm 0,32\end{array}$ \\
\hline Jan. $3013 \%$ & $\begin{array}{l}10,78 \\
\pm 0,33\end{array}$ & $\begin{array}{c}6,10 \\
\pm 0,32\end{array}$ & $\begin{array}{c}3,85 \\
\pm 0,32\end{array}$ & $\begin{array}{c}2,28 \\
\pm 0,32\end{array}$ & $\begin{array}{c}8,92 \\
\pm 0,32\end{array}$ & $\begin{array}{c}5,50 \\
\pm 0,32\end{array}$ & $\begin{array}{c}5,12 \\
\pm 0,32\end{array}$ & $\begin{array}{l}10,91 \\
\pm 0,32\end{array}$ \\
\hline Jan. $3014 \%$ & $\begin{array}{l}11,78 \\
\pm 0,33 \\
\end{array}$ & $\begin{array}{c}7,07 \\
\pm 0,32 \\
\end{array}$ & $\begin{array}{c}3,61 \\
\pm 0,32 \\
\end{array}$ & $\begin{array}{c}3,55 \\
\pm 0,32 \\
\end{array}$ & $\begin{array}{c}9,13 \\
\pm 0,32 \\
\end{array}$ & $\begin{array}{c}6,19 \\
\pm 0,32 \\
\end{array}$ & $\begin{array}{c}5,33 \\
\pm 0,32 \\
\end{array}$ & $\begin{array}{l}12,73 \\
\pm 0,33 \\
\end{array}$ \\
\hline
\end{tabular}


Apêndice C. Tabelas com os Resultados de Classificação

Tabela C.8: $S M O$ - taxas de erro obtidas pelas representações bag-of-related-words que utilizaram medidas de interesse objetivas para gerar os atributos e pela representação bag-of-words para as coleções da ACM.

\begin{tabular}{|c|c|c|c|c|c|c|c|c|}
\hline \multirow[b]{2}{*}{ Representação } & \multicolumn{8}{|c|}{ Taxa de Erro } \\
\hline & ACM-1 & ACM-2 & ACM-3 & ACM-4 & ACM-5 & ACM-6 & ACM-7 & ACM-8 \\
\hline Bag-of-words & $\begin{array}{r}* \mathbf{3 . 2 6} \\
\pm 0,32\end{array}$ & $\begin{array}{r}* \mathbf{2 . 2 0} \\
\pm 0,32\end{array}$ & $\begin{array}{l}\boldsymbol{*} \mathbf{3 . 5 4} \\
\pm 0,32\end{array}$ & $\begin{array}{r}* \mathbf{0 . 2 5} \\
\pm 0,32\end{array}$ & $\begin{array}{l}\boldsymbol{*} \mathbf{2 . 1 2} \\
\pm 0,32\end{array}$ & $\begin{array}{l}* \mathbf{1 . 1 4} \\
\pm 0,32\end{array}$ & $\begin{array}{c}3.84 \\
\pm 0,32\end{array}$ & $\begin{array}{r}* \mathbf{4 . 0 4} \\
\pm 0,32\end{array}$ \\
\hline Jan. 5 Aut. Conf. 0,25 & $\begin{array}{c}5,26 \\
\pm 0,32\end{array}$ & $\begin{array}{c}3,41 \\
\pm 0,32\end{array}$ & $\begin{array}{c}4,09 \\
\pm 0,32\end{array}$ & $\begin{array}{c}1,52 \\
\pm 0,32\end{array}$ & $\begin{array}{c}3,40 \\
\pm 0,32\end{array}$ & $\begin{array}{c}2,29 \\
\pm 0,32\end{array}$ & $\begin{array}{l}* \mathbf{2 , 7 7} \\
\pm 0,32\end{array}$ & $\begin{array}{l}8,08 \\
\pm 0,32\end{array}$ \\
\hline Jan. 5 Aut. Conf. 0,5 & $\begin{array}{c}5,01 \\
\pm 0,32\end{array}$ & $\begin{array}{c}4,39 \\
\pm 0,32\end{array}$ & $\begin{array}{c}4,33 \\
\pm 0,32\end{array}$ & $\begin{array}{c}1,52 \\
\pm 0,32\end{array}$ & $\begin{array}{c}3,18 \\
\pm 0,32\end{array}$ & $\begin{array}{c}2,06 \\
\pm 0,32\end{array}$ & $\begin{array}{l}* \mathbf{2 , 7 7} \\
\pm 0,32\end{array}$ & $\begin{array}{c}7,68 \\
\pm 0,32\end{array}$ \\
\hline Jan. 5 Aut. Conf. $\bar{x}$ & $\begin{array}{c}5,26 \\
\pm 0,32\end{array}$ & $\begin{array}{c}3,66 \\
\pm 0,32\end{array}$ & $\begin{array}{c}3,85 \\
\pm 0,32\end{array}$ & $\begin{array}{c}1,78 \\
\pm 0,32\end{array}$ & $\begin{array}{c}2,76 \\
\pm 0,32\end{array}$ & $\begin{array}{c}2,06 \\
\pm 0,32\end{array}$ & $\begin{array}{c}3,20 \\
\pm 0,32\end{array}$ & $\begin{array}{l}7,27 \\
\pm 0,32\end{array}$ \\
\hline Jan. 5 Aut. Lift 0,1 & $\begin{array}{c}5,01 \\
\pm 0,32\end{array}$ & $\begin{array}{c}3,66 \\
\pm 0,32\end{array}$ & $\begin{array}{c}4,09 \\
\pm 0,32\end{array}$ & $\begin{array}{c}2,03 \\
\pm 0,32\end{array}$ & $\begin{array}{c}3,18 \\
\pm 0,32\end{array}$ & $\begin{array}{c}2,29 \\
\pm 0,32\end{array}$ & $\begin{array}{c}2,99 \\
\pm 0,32\end{array}$ & $\begin{array}{c}7,27 \\
\pm 0,32\end{array}$ \\
\hline Jan. 5 Aut. Lift 0,2 & $\begin{array}{c}5,26 \\
\pm 0,32\end{array}$ & $\begin{array}{c}4,15 \\
\pm 0,32\end{array}$ & $\begin{array}{c}4,33 \\
\pm 0,32\end{array}$ & $\begin{array}{c}1,52 \\
\pm 0,32\end{array}$ & $\begin{array}{c}3,18 \\
\pm 0,32\end{array}$ & $\begin{array}{c}2,06 \\
\pm 0,32\end{array}$ & $\begin{array}{c}2,99 \\
\pm 0,32\end{array}$ & $\begin{array}{c}7,68 \\
\pm 0,32\end{array}$ \\
\hline Jan. 5 Aut. Lift $\bar{x}$ & $\begin{array}{c}5,01 \\
\pm 0,32\end{array}$ & $\begin{array}{c}3,66 \\
\pm 0,32\end{array}$ & $\begin{array}{c}4,09 \\
\pm 0,32\end{array}$ & $\begin{array}{c}2,03 \\
\pm 0,32\end{array}$ & $\begin{array}{c}3,18 \\
\pm 0,32\end{array}$ & $\begin{array}{c}2,29 \\
\pm 0,32\end{array}$ & $\begin{array}{c}2,99 \\
\pm 0,32\end{array}$ & $\begin{array}{c}7,27 \\
\pm 0,32\end{array}$ \\
\hline Jan. 5 Aut. Yule's Q 0,5 & $\begin{array}{c}5,26 \\
\pm 0,32\end{array}$ & $\begin{array}{c}3,41 \\
\pm 0,32\end{array}$ & $\begin{array}{c}4,57 \\
\pm 0,32\end{array}$ & $\begin{array}{c}1,78 \\
\pm 0,32\end{array}$ & $\begin{array}{c}2,97 \\
\pm 0,32\end{array}$ & $\begin{array}{c}2,75 \\
\pm 0,32 \\
\end{array}$ & $\begin{array}{c}2,99 \\
\pm 0,32 \\
\end{array}$ & $\begin{array}{c}6,67 \\
\pm 0,32 \\
\end{array}$ \\
\hline Jan. 5 Aut. Yule's Q 0,75 & $\begin{array}{c}5,26 \\
\pm 0,32\end{array}$ & $\begin{array}{c}3,66 \\
\pm 0,32\end{array}$ & $\begin{array}{c}4,33 \\
\pm 0,32\end{array}$ & $\begin{array}{c}1,78 \\
\pm 0,32\end{array}$ & $\begin{array}{c}3,40 \\
\pm 0,32\end{array}$ & $\begin{array}{c}2,29 \\
\pm 0,32\end{array}$ & $\begin{array}{c}2,99 \\
\pm 0,32\end{array}$ & $\begin{array}{l}7,27 \\
\pm 0,32\end{array}$ \\
\hline Jan. 5 Aut. Yule's Q $\bar{x}$ & $\begin{array}{c}5,26 \\
\pm 0,32\end{array}$ & $\begin{array}{c}3,41 \\
\pm 0,32\end{array}$ & $\begin{array}{c}4,57 \\
\pm 0,32\end{array}$ & $\begin{array}{c}1,78 \\
\pm 0,32\end{array}$ & $\begin{array}{c}2,76 \\
\pm 0,32\end{array}$ & $\begin{array}{c}2,29 \\
\pm 0,32\end{array}$ & $\begin{array}{l}* \mathbf{2 , 7 7} \\
\pm 0,32\end{array}$ & $\begin{array}{l}7,07 \\
\pm 0,32\end{array}$ \\
\hline Jan. 5 Aut. Corr. 0,25 & $\begin{array}{c}5,26 \\
\pm 0,32\end{array}$ & $\begin{array}{c}3,66 \\
\pm 0,32\end{array}$ & $\begin{array}{c}4,09 \\
\pm 0,32\end{array}$ & $\begin{array}{c}1,78 \\
\pm 0,32\end{array}$ & $\begin{array}{c}3,40 \\
\pm 0,32\end{array}$ & $\begin{array}{c}2,52 \\
\pm 0,32\end{array}$ & $\begin{array}{c}3,20 \\
\pm 0,32\end{array}$ & $\begin{array}{l}7,47 \\
\pm 0,32\end{array}$ \\
\hline Jan. 5 Aut. Corr. 0,50 & $\begin{array}{c}5,26 \\
\pm 0,32\end{array}$ & $\begin{array}{c}3,90 \\
\pm 0,32\end{array}$ & $\begin{array}{c}4,33 \\
\pm 0,32\end{array}$ & $\begin{array}{c}1,52 \\
\pm 0,32\end{array}$ & $\begin{array}{c}3,18 \\
\pm 0,32\end{array}$ & $\begin{array}{c}2,29 \\
\pm 0,32\end{array}$ & $\begin{array}{l}* \mathbf{2 , 7 7} \\
\pm 0,32\end{array}$ & $\begin{array}{c}7,68 \\
\pm 0,32\end{array}$ \\
\hline Jan. 5 Aut. Corr. $\bar{x}$ & $\begin{array}{c}5,26 \\
\pm 0,32\end{array}$ & $\begin{array}{c}3,66 \\
\pm 0,32\end{array}$ & $\begin{array}{c}3,61 \\
\pm 0,32\end{array}$ & $\begin{array}{c}1,27 \\
\pm 0,32\end{array}$ & $\begin{array}{c}2,55 \\
\pm 0,32\end{array}$ & $\begin{array}{c}2,75 \\
\pm 0,32\end{array}$ & $\begin{array}{c}2,99 \\
\pm 0,32\end{array}$ & $\begin{array}{l}7,27 \\
\pm 0,32\end{array}$ \\
\hline Jan. 5 Aut. I.M. 0,005 & $\begin{array}{c}5,26 \\
\pm 0,32\end{array}$ & $\begin{array}{c}3,41 \\
\pm 0,32\end{array}$ & $\begin{array}{c}4,33 \\
\pm 0,32\end{array}$ & $\begin{array}{c}1,78 \\
\pm 0,32\end{array}$ & $\begin{array}{c}2,76 \\
\pm 0,32\end{array}$ & $\begin{array}{c}2,97 \\
\pm 0,32\end{array}$ & $\begin{array}{l}* \mathbf{2 , 7 7} \\
\pm 0,32\end{array}$ & $\begin{array}{l}6,67 \\
\pm 0,32\end{array}$ \\
\hline Jan. 5 Aut. I.M. 0,01 & $\begin{array}{c}5,26 \\
\pm 0,32\end{array}$ & $\begin{array}{c}4,15 \\
\pm 0,32\end{array}$ & $\begin{array}{c}4,33 \\
\pm 0,32\end{array}$ & $\begin{array}{c}1,52 \\
\pm 0,32\end{array}$ & $\begin{array}{c}3,18 \\
\pm 0,32\end{array}$ & $\begin{array}{c}2,52 \\
\pm 0,32\end{array}$ & $\begin{array}{c}2,99 \\
\pm 0,32\end{array}$ & $\begin{array}{c}7,88 \\
\pm 0,32\end{array}$ \\
\hline Jan. 5 Aut. I.M. $\bar{x}$ & $\begin{array}{c}5,26 \\
\pm 0,32\end{array}$ & $\begin{array}{c}3,41 \\
\pm 0,32\end{array}$ & $\begin{array}{c}4,33 \\
\pm 0,32\end{array}$ & $\begin{array}{c}1,78 \\
\pm 0,32\end{array}$ & $\begin{array}{c}3,18 \\
\pm 0,32\end{array}$ & $\begin{array}{c}2,52 \\
\pm 0,32\end{array}$ & $\begin{array}{c}2,99 \\
\pm 0,32\end{array}$ & $\begin{array}{c}7,47 \\
\pm 0,32\end{array}$ \\
\hline Jan. 5 Aut. Gini 0,005 & $\begin{array}{c}5,01 \\
\pm 0,32\end{array}$ & $\begin{array}{c}3,66 \\
\pm 0,32\end{array}$ & $\begin{array}{c}4,09 \\
\pm 0,32\end{array}$ & $\begin{array}{c}1,78 \\
\pm 0,32\end{array}$ & $\begin{array}{c}3,18 \\
\pm 0,32\end{array}$ & $\begin{array}{c}2,52 \\
\pm 0,32\end{array}$ & $\begin{array}{c}3,20 \\
\pm 0,32\end{array}$ & $\begin{array}{l}7,47 \\
\pm 0,32\end{array}$ \\
\hline Jan. 5 Aut. Gini 0,01 & $\begin{array}{c}5,51 \\
\pm 0,32\end{array}$ & $\begin{array}{c}3,66 \\
\pm 0,32\end{array}$ & $\begin{array}{c}4,09 \\
\pm 0,32\end{array}$ & $\begin{array}{c}1,78 \\
\pm 0,32\end{array}$ & $\begin{array}{c}3,40 \\
\pm 0,32\end{array}$ & $\begin{array}{c}2,29 \\
\pm 0,32\end{array}$ & $\begin{array}{c}2,99 \\
\pm 0,32\end{array}$ & $\begin{array}{l}7,47 \\
\pm 0,32\end{array}$ \\
\hline Jan. 5 Aut. Gini $\bar{x}$ & $\begin{array}{c}5,01 \\
\pm 0,32\end{array}$ & $\begin{array}{c}3,66 \\
\pm 0,32\end{array}$ & $\begin{array}{c}4,09 \\
\pm 0,32\end{array}$ & $\begin{array}{c}1,78 \\
\pm 0,32\end{array}$ & $\begin{array}{c}3,18 \\
\pm 0,32\end{array}$ & $\begin{array}{c}2,75 \\
\pm 0,32\end{array}$ & $\begin{array}{c}3,20 \\
\pm 0,32\end{array}$ & $\begin{array}{c}7,88 \\
\pm 0,32\end{array}$ \\
\hline Jan. 5 Aut. Kappa 0,15 & $\begin{array}{c}4,76 \\
\pm 0,32 \\
\end{array}$ & $\begin{array}{c}3,17 \\
\pm 0,32 \\
\end{array}$ & $\begin{array}{c}3,85 \\
\pm 0,32 \\
\end{array}$ & $\begin{array}{c}1,52 \\
\pm 0,32 \\
\end{array}$ & $\begin{array}{c}2,97 \\
\pm 0,32\end{array}$ & $\begin{array}{c}2,52 \\
\pm 0,32 \\
\end{array}$ & $\begin{array}{c}2,99 \\
\pm 0,32 \\
\end{array}$ & $\begin{array}{c}7,27 \\
\pm 0,32 \\
\end{array}$ \\
\hline Jan. 5 Aut. Kappa 0,2 & $\begin{array}{c}4,51 \\
\pm 0,32\end{array}$ & $\begin{array}{c}3,41 \\
\pm 0,32\end{array}$ & $\begin{array}{c}4,09 \\
\pm 0,32\end{array}$ & $\begin{array}{c}1,27 \\
\pm 0,32\end{array}$ & $\begin{array}{c}3,18 \\
\pm 0,32\end{array}$ & $\begin{array}{c}2,52 \\
\pm 0,32\end{array}$ & $\begin{array}{c}3,20 \\
\pm 0,32\end{array}$ & $\begin{array}{l}8,08 \\
\pm 0,32\end{array}$ \\
\hline Jan. 5 Aut. Kappa $\bar{x}$ & $\begin{array}{c}4,76 \\
\pm 0,32\end{array}$ & $\begin{array}{c}3,66 \\
\pm 0,32\end{array}$ & $\begin{array}{c}4,09 \\
\pm 0,32\end{array}$ & $\begin{array}{c}1,78 \\
\pm 0,32\end{array}$ & $\begin{array}{c}2,76 \\
\pm 0,32\end{array}$ & $\begin{array}{c}2,75 \\
\pm 0,32\end{array}$ & $\begin{array}{c}2,99 \\
\pm 0,32\end{array}$ & $\begin{array}{c}7,27 \\
\pm 0,32\end{array}$ \\
\hline Jan. 5 Aut. J.M. 0,01 & $\begin{array}{c}5,26 \\
\pm 0,32\end{array}$ & $\begin{array}{c}3,41 \\
\pm 0,32\end{array}$ & $\begin{array}{c}4,09 \\
\pm 0,32\end{array}$ & $\begin{array}{c}1,78 \\
\pm 0,32\end{array}$ & $\begin{array}{c}2,97 \\
\pm 0,32\end{array}$ & $\begin{array}{c}2,52 \\
\pm 0,32\end{array}$ & $\begin{array}{c}3,20 \\
\pm 0,32\end{array}$ & $\begin{array}{l}7,07 \\
\pm 0,32\end{array}$ \\
\hline Jan. 5 Aut. J.M. 0,02 & $\begin{array}{c}5,26 \\
\pm 0,32\end{array}$ & $\begin{array}{c}3,66 \\
\pm 0,32\end{array}$ & $\begin{array}{c}3,85 \\
\pm 0,32\end{array}$ & $\begin{array}{c}1,78 \\
\pm 0,32\end{array}$ & $\begin{array}{c}3,4 \\
\pm 0,32\end{array}$ & $\begin{array}{c}2,29 \\
\pm 0,32\end{array}$ & $\begin{array}{c}3,20 \\
\pm 0,32\end{array}$ & $\begin{array}{c}7,68 \\
\pm 0,32\end{array}$ \\
\hline Jan. 5 Aut. J.M. $\bar{x}$ & $\begin{array}{c}5,01 \\
\pm 0,32\end{array}$ & $\begin{array}{c}3,41 \\
\pm 0,32\end{array}$ & $\begin{array}{c}4,33 \\
\pm 0,32\end{array}$ & $\begin{array}{c}1,78 \\
\pm 0,32\end{array}$ & $\begin{array}{c}3,18 \\
\pm 0,32\end{array}$ & $\begin{array}{c}2,52 \\
\pm 0,32\end{array}$ & $\begin{array}{c}2,99 \\
\pm 0,32\end{array}$ & $\begin{array}{l}7,68 \\
\pm 0,32\end{array}$ \\
\hline
\end{tabular}


Tabela C.9: SMO - taxas de erro obtidas pelas representações bag-of-related-words que utilizaram medidas de interesse objetivas para gerar os atributos e pela representação bag-of-words para a coleção Reuters21578 .

\begin{tabular}{|l|r|}
\hline Representação & Taxa de Erro \\
\hline Bag-of-words & 23,32 \\
\hline Jan. 5 Aut. & 23,32 \\
\hline Jan. 5 Aut. Lift 0,1 & 23,11 \\
\hline Jan. 5 Aut. Lift 0,2 & 23,53 \\
\hline Jan. 5 Aut. Lift $\bar{x}$ & 23,21 \\
\hline Jan. 5 Aut. Conf. 0,25 & 23,63 \\
\hline Jan. 5 Aut. Conf. 0,50 & 24,58 \\
\hline Jan. 5 Aut. Conf. $\bar{x}$ & 24,05 \\
\hline Jan. 5 Aut. Yule's Q 0,50 & 23,53 \\
\hline Jan. 5 Aut. Yule's Q 0,75 & 23,53 \\
\hline Jan. 5 Aut. Yule's Q $\bar{x}$ & 23,53 \\
\hline Jan. 5 Aut. Corr. 0,25 & 23,32 \\
\hline Jan. 5 Aut. Corr. 0,50 & 24,58 \\
\hline Jan. 5 Aut. Corr. $\bar{x}$ & 23,63 \\
\hline Jan. 5 Aut. I.M. 0,05 & 23,32 \\
\hline Jan. 5 Aut. I.M. 0,1 & 23,74 \\
\hline Jan. 5 Aut. I.M. $\bar{x}$ & 23,21 \\
\hline Jan. 5 Aut. Gini 0,01 & 23,63 \\
\hline Jan. 5 Aut. Gini 0,04 & 23,11 \\
\hline Jan. 5 Aut. Gini $\bar{x}$ & 23,21 \\
\hline Jan. 5 Aut. Kappa 0,3 & 23,42 \\
\hline Jan. 5 Aut. Kappa 0,5 & *22,90 \\
\hline Jan. 5 Aut. Kappa $\bar{x}$ & 23,00 \\
\hline Jan. 5 Aut. J.M. 0,02 & 23,53 \\
\hline Jan. 5 Aut. J.M. 0,05 & 23,74 \\
\hline Jan. 5 Aut. J.M. $\bar{x}$ & 23,00 \\
\hline
\end{tabular}

Pode-se observar que o uso de medidas de interesse objetivas manteve ou diminuiu a taxa de erro de classificação para a maioria das coleções da ACM. Para a coleção Reuters, a representação utilizada como base para a utilização de medidas de interesse objetivas ([Jan. 5 Aut.]) obteve a mesma taxa de erro da representação bag-of-words. 11 das 24 representações utilizando medidas de interesse objetivas obtiveram melhores resultados que a representação [Jan. 5 Aut.]. As demais obtiveram uma taxa de erro bastante próxima em relação às representações bag-of-words e [Jan. 5 Aut.].

\section{C.4 KNN}

Nesta seção são apresentadas as tabelas contendo os resultados obtidos pelas representações bag-of-related-words e a representação bag-of-words utilizando o algoritmo de classificação $K N N$. Na Tabela C.10 são apresentadas as taxas de erro de classificação e o desvio padrão para as coleções da ACM obtidas pelas representações bag-of-related-words que utilizaram os itemsets frequentes como atributos. Na Tabela C.11 são apresentadas as taxas de erro de classificação e o desvio padrão para as coleções da ACM obtidas pelas representações bag-of-related-words que utilizaram medidas de interesse objetivas para gerar os atributos. Na Tabela C.12 são apresentadas as taxas de erro para a coleção Reuters-21578 obtidas pelas representações bag-of-related-words que utilizaram medidas de interesse objetivas para gerar os atributos. 
Apêndice C. Tabelas com os Resultados de Classificação

Tabela C.10: $K N N$ - taxas de erro obtidas pelas representações bag-of-related-words que utilizaram itemsets frequentes como atributos e pela representação bag-of-words para as coleções da ACM.

\begin{tabular}{|c|c|c|c|c|c|c|c|c|}
\hline & \multicolumn{8}{|c|}{ Taxa de Erro } \\
\hline Representação & ACM-1 & ACM-2 & ACM-3 & ACM-4 & ACM-5 & ACM-6 & ACM-7 & ACM-8 \\
\hline Bag-of-words & $\begin{array}{c}\boldsymbol{*}_{\mathbf{1 0}, \mathbf{0 2}} \\
\pm 0,06\end{array}$ & $\begin{array}{c}7,32 \\
\pm 0,04\end{array}$ & $\begin{array}{l}* \mathbf{4 , 9 6} \\
\pm 0,03\end{array}$ & $\begin{array}{c}2,04 \\
\pm 0,02\end{array}$ & $\begin{array}{c}5,74 \\
\pm 0,03\end{array}$ & $\begin{array}{l}* \mathbf{1 , 8 2} \\
\pm 0,03\end{array}$ & $\begin{array}{c}6,18 \\
\pm 0,03\end{array}$ & $\begin{array}{r}* \mathbf{4}, \mathbf{4 4} \\
\pm 0,03\end{array}$ \\
\hline Sent. $2 \%$ & $\begin{array}{l}17,08 \\
\pm 0,05\end{array}$ & $\begin{array}{c}6,10 \\
\pm 0,04\end{array}$ & $\begin{array}{c}5,45 \\
\pm 0,04\end{array}$ & $\begin{array}{c}1,54 \\
\pm 0,02\end{array}$ & $\begin{array}{c}8,71 \\
\pm 0,03\end{array}$ & $\begin{array}{c}6,62 \\
\pm 0,04\end{array}$ & $\begin{array}{c}6,40 \\
\pm 0,02\end{array}$ & $\begin{array}{l}10,51 \\
\pm 0,05\end{array}$ \\
\hline Sent. $3 \%$ & $\begin{array}{l}19,08 \\
\pm 0,07\end{array}$ & $\begin{array}{c}6,10 \\
\pm 0,04\end{array}$ & $\begin{array}{c}6,15 \\
\pm 0,04\end{array}$ & $\begin{array}{c}2,28 \\
\pm 0,03\end{array}$ & $\begin{array}{c}9,14 \\
\pm 0,05\end{array}$ & $\begin{array}{c}7,53 \\
\pm 0,05\end{array}$ & $\begin{array}{c}6,60 \\
\pm 0,04\end{array}$ & $\begin{array}{c}9,71 \\
\pm 0,03\end{array}$ \\
\hline Sent. $4 \%$ & $\begin{array}{c}17,59 \\
\pm 0,04\end{array}$ & $\begin{array}{c}8,29 \\
\pm 0,04\end{array}$ & $\begin{array}{c}7,12 \\
\pm 0,04\end{array}$ & $\begin{array}{c}4,06 \\
\pm 0,03\end{array}$ & $\begin{array}{c}9,76 \\
\pm 0,04\end{array}$ & $\begin{array}{c}8,46 \\
\pm 0,06\end{array}$ & $\begin{array}{c}7,68 \\
\pm 0,03\end{array}$ & $\begin{array}{l}13,11 \\
\pm 0,04\end{array}$ \\
\hline Sent. $5 \%$ & $\begin{array}{c}18,83 \\
\pm 0,06\end{array}$ & $\begin{array}{c}6,59 \\
\pm 0,03\end{array}$ & $\begin{array}{c}7,08 \\
\pm 0,03\end{array}$ & $\begin{array}{c}6,35 \\
\pm 0,03\end{array}$ & $\begin{array}{l}15,08 \\
\pm 0,06\end{array}$ & $\begin{array}{c}8,90 \\
\pm 0,03\end{array}$ & $\begin{array}{c}7,25 \\
\pm 0,03\end{array}$ & $\begin{array}{l}14,15 \\
\pm 0,04\end{array}$ \\
\hline Sent. $6 \%$ & $\begin{array}{c}18,34 \\
\pm 0,07\end{array}$ & $\begin{array}{c}10,49 \\
\pm 0,04\end{array}$ & $\begin{array}{c}8,97 \\
\pm 0,03\end{array}$ & $\begin{array}{c}7,33 \\
\pm 0,05\end{array}$ & $\begin{array}{c}16,99 \\
\pm 0,04\end{array}$ & $\begin{array}{l}12,09 \\
\pm 0,04\end{array}$ & $\begin{array}{c}10,87 \\
\pm 0,04\end{array}$ & $\begin{array}{l}18,77 \\
\pm 0,06\end{array}$ \\
\hline Par. $10 \%$ & $\begin{array}{l}18,33 \\
\pm 0,04\end{array}$ & $\begin{array}{c}9,27 \\
\pm 0,04\end{array}$ & $\begin{array}{c}5,42 \\
\pm 0,04\end{array}$ & $\begin{array}{c}3,56 \\
\pm 0,04\end{array}$ & $\begin{array}{l}12,10 \\
\pm 0,05\end{array}$ & $\begin{array}{c}7,53 \\
\pm 0,04\end{array}$ & $\begin{array}{c}7,45 \\
\pm 0,04\end{array}$ & $\begin{array}{l}14,54 \\
\pm 0,03\end{array}$ \\
\hline Par. $11 \%$ & $\begin{array}{l}19,56 \\
\pm 0,05\end{array}$ & $\begin{array}{c}8,54 \\
\pm 0,03\end{array}$ & $\begin{array}{c}5,68 \\
\pm 0,03 \\
\end{array}$ & $\begin{array}{c}4,81 \\
\pm 0,05\end{array}$ & $\begin{array}{c}10,59 \\
\pm 0,05\end{array}$ & $\begin{array}{c}9,38 \\
\pm 0,04\end{array}$ & $\begin{array}{c}8,53 \\
\pm 0,03 \\
\end{array}$ & $\begin{array}{l}14,54 \\
\pm 0,05\end{array}$ \\
\hline Par. $12 \%$ & $\begin{array}{c}19,31 \\
\pm 0,07\end{array}$ & $\begin{array}{c}10,24 \\
\pm 0,05\end{array}$ & $\begin{array}{c}8,52 \\
\pm 0,03\end{array}$ & $\begin{array}{c}7,36 \\
\pm 0,04\end{array}$ & $\begin{array}{l}12,96 \\
\pm 0,05\end{array}$ & $\begin{array}{c}9,13 \\
\pm 0,07\end{array}$ & $\begin{array}{c}9,60 \\
\pm 0,05\end{array}$ & $\begin{array}{l}15,77 \\
\pm 0,04\end{array}$ \\
\hline Par. $13 \%$ & $\begin{array}{l}19,60 \\
\pm 0,03\end{array}$ & $\begin{array}{l}10,49 \\
\pm 0,05\end{array}$ & $\begin{array}{c}9,21 \\
\pm 0,05\end{array}$ & $\begin{array}{c}6,84 \\
\pm 0,04\end{array}$ & $\begin{array}{l}12,73 \\
\pm 0,06\end{array}$ & $\begin{array}{c}10,69 \\
\pm 0,06\end{array}$ & $\begin{array}{c}8,75 \\
\pm 0,03\end{array}$ & $\begin{array}{l}19,01 \\
\pm 0,07\end{array}$ \\
\hline Jan. 5 Aut. & $\begin{array}{c}10,00 \\
\pm 0,05\end{array}$ & $\begin{array}{c}6,83 \\
\pm 0,03\end{array}$ & $\begin{array}{c}6,27 \\
\pm 0,05\end{array}$ & $\begin{array}{c}1,01 \\
\pm 0,01\end{array}$ & $\begin{array}{c}4,24 \\
\pm 0,03\end{array}$ & $\begin{array}{c}2,75 \\
\pm 0,03\end{array}$ & $\begin{array}{c}4,92 \\
\pm 0,03\end{array}$ & $\begin{array}{l}8,31 \\
\pm 0,06\end{array}$ \\
\hline Jan. $50,6 \%$ & $\begin{array}{c}14,04 \\
\pm 0,07\end{array}$ & $\begin{array}{c}9,76 \\
\pm 0,04 \\
\end{array}$ & $\begin{array}{c}5,06 \\
\pm 0,04 \\
\end{array}$ & $\begin{array}{c}1,02 \\
\pm 0,01\end{array}$ & $\begin{array}{c}5,94 \\
\pm 0,03\end{array}$ & $\begin{array}{c}5,95 \\
\pm 0,05\end{array}$ & $\begin{array}{c}6,83 \\
\pm 0,05\end{array}$ & $\begin{array}{l}8,89 \\
\pm 0,03\end{array}$ \\
\hline Jan. $50,8 \%$ & $\begin{array}{l}11,27 \\
\pm 0,05\end{array}$ & $\begin{array}{r}7,56 \\
\pm 0,03 \\
\end{array}$ & $\begin{array}{c}6,22 \\
\pm 0,05 \\
\end{array}$ & $\begin{array}{c}1,27 \\
\pm 0,01\end{array}$ & $\begin{array}{l}* \mathbf{4 , 8 9} \\
\pm 0,04 \\
\end{array}$ & $\begin{array}{c}4,57 \\
\pm 0,03 \\
\end{array}$ & $\begin{array}{c}7,46 \\
\pm 0,04 \\
\end{array}$ & $\begin{array}{l}9,11 \\
\pm 0,03\end{array}$ \\
\hline Jan. $51 \%$ & $\begin{array}{l}11,53 \\
\pm 0,04 \\
\end{array}$ & $\begin{array}{c}7,80 \\
\pm 0,05\end{array}$ & $\begin{array}{c}5,77 \\
\pm 0,04\end{array}$ & $\begin{array}{l}* \mathbf{1 , 0 1} \\
\pm 0,02\end{array}$ & $\begin{array}{c}5,52 \\
\pm 0,02\end{array}$ & $\begin{array}{c}3,44 \\
\pm 0,02\end{array}$ & $\begin{array}{c}7,03 \\
\pm 0,04\end{array}$ & $\begin{array}{l}9,88 \\
\pm 0,05\end{array}$ \\
\hline Jan. $52 \%$ & $\begin{array}{c}16,51 \\
\pm 0,08\end{array}$ & $\begin{array}{l}* \mathbf{5 , 6 1} \\
\pm 0,03\end{array}$ & $\begin{array}{c}6,46 \\
\pm 0,04\end{array}$ & $\begin{array}{c}2,27 \\
\pm 0,02\end{array}$ & $\begin{array}{c}9,14 \\
\pm 0,05\end{array}$ & $\begin{array}{c}4,37 \\
\pm 0,03\end{array}$ & $\begin{array}{l}\boldsymbol{*} \mathbf{4 , 9 0} \\
\pm 0,03\end{array}$ & $\begin{array}{l}12,76 \\
\pm 0,07\end{array}$ \\
\hline Jan. $53 \%$ & $\begin{array}{l}15,54 \\
\pm 0,03\end{array}$ & $\begin{array}{c}7,32 \\
\pm 0,04\end{array}$ & $\begin{array}{c}5,82 \\
\pm 0,05\end{array}$ & $\begin{array}{c}1,79 \\
\pm 0,02\end{array}$ & $\begin{array}{l}12,32 \\
\pm 0,04\end{array}$ & $\begin{array}{c}7,54 \\
\pm 0,04\end{array}$ & $\begin{array}{c}6,19 \\
\pm 0,03\end{array}$ & $\begin{array}{l}12,74 \\
\pm 0,03\end{array}$ \\
\hline Jan. $102 \%$ & $\begin{array}{l}14,03 \\
\pm 0,05\end{array}$ & $\begin{array}{c}7,56 \\
\pm 0,05\end{array}$ & $\begin{array}{c}6,03 \\
\pm 0,03\end{array}$ & $\begin{array}{c}1,53 \\
\pm 0,02\end{array}$ & $\begin{array}{c}6,38 \\
\pm 0,04\end{array}$ & $\begin{array}{c}5,48 \\
\pm 0,03\end{array}$ & $\begin{array}{c}5,55 \\
\pm 0,02\end{array}$ & $\begin{array}{l}10,30 \\
\pm 0,04\end{array}$ \\
\hline Jan. $103 \%$ & $\begin{array}{l}16,79 \\
\pm 0,06\end{array}$ & $\begin{array}{c}7,32 \\
\pm 0,03\end{array}$ & $\begin{array}{c}5,80 \\
\pm 0,03\end{array}$ & $\begin{array}{c}1,26 \\
\pm 0,02\end{array}$ & $\begin{array}{c}7,87 \\
\pm 0,04\end{array}$ & $\begin{array}{c}5,04 \\
\pm 0,03\end{array}$ & $\begin{array}{c}5,96 \\
\pm 0,03\end{array}$ & $\begin{array}{l}9,07 \\
\pm 0,05\end{array}$ \\
\hline Jan. $104 \%$ & $\begin{array}{l}16,78 \\
\pm 0,05\end{array}$ & $\begin{array}{c}7,80 \\
\pm 0,05\end{array}$ & $\begin{array}{c}7,24 \\
\pm 0,05\end{array}$ & $\begin{array}{c}2,04 \\
\pm 0,03\end{array}$ & $\begin{array}{c}9,55 \\
\pm 0,04\end{array}$ & $\begin{array}{c}5,94 \\
\pm 0,03\end{array}$ & $\begin{array}{c}6,82 \\
\pm 0,02\end{array}$ & $\begin{array}{l}11,51 \\
\pm 0,04\end{array}$ \\
\hline Jan. $105 \%$ & $\begin{array}{c}18,29 \\
\pm 0,04\end{array}$ & $\begin{array}{c}6,10 \\
\pm 0,03\end{array}$ & $\begin{array}{c}6,74 \\
\pm 0,03\end{array}$ & $\begin{array}{c}1,78 \\
\pm 0,02\end{array}$ & $\begin{array}{l}10,41 \\
\pm 0,04\end{array}$ & $\begin{array}{c}6,41 \\
\pm 0,05\end{array}$ & $\begin{array}{c}6,39 \\
\pm 0,04\end{array}$ & $\begin{array}{l}10,10 \\
\pm 0,05\end{array}$ \\
\hline Jan. $106 \%$ & $\begin{array}{l}15,55 \\
\pm 0,05\end{array}$ & $\begin{array}{c}6,34 \\
\pm 0,04\end{array}$ & $\begin{array}{c}6,95 \\
\pm 0,04\end{array}$ & $\begin{array}{c}3,04 \\
\pm 0,02\end{array}$ & $\begin{array}{c}9,55 \\
\pm 0,03\end{array}$ & $\begin{array}{c}7,79 \\
\pm 0,02\end{array}$ & $\begin{array}{c}7,68 \\
\pm 0,02\end{array}$ & $\begin{array}{l}13,15 \\
\pm 0,04\end{array}$ \\
\hline Jan. $206 \%$ & $\begin{array}{l}19,81 \\
\pm 0,06\end{array}$ & $\begin{array}{c}6,83 \\
\pm 0,06\end{array}$ & $\begin{array}{c}6,24 \\
\pm 0,04\end{array}$ & $\begin{array}{c}2,28 \\
\pm 0,02\end{array}$ & $\begin{array}{c}9,53 \\
\pm 0,04\end{array}$ & $\begin{array}{c}6,65 \\
\pm 0,03\end{array}$ & $\begin{array}{c}6,41 \\
\pm 0,02\end{array}$ & $\begin{array}{l}11,10 \\
\pm 0,02\end{array}$ \\
\hline Jan. $207 \%$ & $\begin{array}{l}21,56 \\
\pm 0,07\end{array}$ & $\begin{array}{c}6,83 \\
\pm 0,05\end{array}$ & $\begin{array}{c}6,24 \\
\pm 0,04\end{array}$ & $\begin{array}{c}2,28 \\
\pm 0,03\end{array}$ & $\begin{array}{c}9,77 \\
\pm 0,03\end{array}$ & $\begin{array}{c}5,26 \\
\pm 0,04\end{array}$ & $\begin{array}{c}6,39 \\
\pm 0,03\end{array}$ & $\begin{array}{l}10,71 \\
\pm 0,03\end{array}$ \\
\hline Jan. $208 \%$ & $\begin{array}{l}18,29 \\
\pm 0,07\end{array}$ & $\begin{array}{c}7,80 \\
\pm 0,04\end{array}$ & $\begin{array}{c}7,44 \\
\pm 0,06\end{array}$ & $\begin{array}{c}3,31 \\
\pm 0,02\end{array}$ & $\begin{array}{l}10,41 \\
\pm 0,06\end{array}$ & $\begin{array}{c}5,98 \\
\pm 0,03\end{array}$ & $\begin{array}{c}6,18 \\
\pm 0,04\end{array}$ & $\begin{array}{l}11,10 \\
\pm 0,05\end{array}$ \\
\hline Jan. $3010 \%$ & $\begin{array}{l}19,79 \\
\pm 0,06\end{array}$ & $\begin{array}{c}7,07 \\
\pm 0,03\end{array}$ & $\begin{array}{c}6,95 \\
\pm 0,05\end{array}$ & $\begin{array}{c}2,54 \\
\pm 0,02\end{array}$ & $\begin{array}{l}10,20 \\
\pm 0,05\end{array}$ & $\begin{array}{c}6,44 \\
\pm 0,03\end{array}$ & $\begin{array}{c}6,39 \\
\pm 0,03\end{array}$ & $\begin{array}{l}10,11 \\
\pm 0,03\end{array}$ \\
\hline Jan. $3011 \%$ & $\begin{array}{l}19,53 \\
\pm 0,04\end{array}$ & $\begin{array}{c}7,32 \\
\pm 0,03\end{array}$ & $\begin{array}{c}7,24 \\
\pm 0,05\end{array}$ & $\begin{array}{c}3,06 \\
\pm 0,03\end{array}$ & $\begin{array}{l}10,18 \\
\pm 0,04\end{array}$ & $\begin{array}{c}7,32 \\
\pm 0,04\end{array}$ & $\begin{array}{c}7,25 \\
\pm 0,03\end{array}$ & $\begin{array}{l}11,53 \\
\pm 0,04\end{array}$ \\
\hline Jan. $3012 \%$ & $\begin{array}{l}20,79 \\
\pm 0,07\end{array}$ & $\begin{array}{c}8,78 \\
\pm 0,05\end{array}$ & $\begin{array}{c}6,49 \\
\pm 0,04\end{array}$ & $\begin{array}{c}4,03 \\
\pm 0,04\end{array}$ & $\begin{array}{c}9,99 \\
\pm 0,04\end{array}$ & $\begin{array}{c}5,49 \\
\pm 0,03\end{array}$ & $\begin{array}{c}6,62 \\
\pm 0,03\end{array}$ & $\begin{array}{l}11,93 \\
\pm 0,04\end{array}$ \\
\hline Jan. $3013 \%$ & $\begin{array}{l}19,29 \\
\pm 0,05\end{array}$ & $\begin{array}{c}8,54 \\
\pm 0,04\end{array}$ & $\begin{array}{c}5,78 \\
\pm 0,04\end{array}$ & $\begin{array}{c}3,56 \\
\pm 0,03\end{array}$ & $\begin{array}{l}10,82 \\
\pm 0,04\end{array}$ & $\begin{array}{c}7,79 \\
\pm 0,02\end{array}$ & $\begin{array}{c}7,24 \\
\pm 0,04\end{array}$ & $\begin{array}{l}11,72 \\
\pm 0,03\end{array}$ \\
\hline Jan. $3014 \%$ & $\begin{array}{c}18,31 \\
\pm 0,07\end{array}$ & $\begin{array}{c}9,51 \\
\pm 0,05\end{array}$ & $\begin{array}{c}5,53 \\
\pm 0,05\end{array}$ & $\begin{array}{c}4,84 \\
\pm 0,03\end{array}$ & $\begin{array}{c}10,39 \\
\pm 0,04 \\
\end{array}$ & $\begin{array}{c}7,57 \\
\pm 0,04 \\
\end{array}$ & $\begin{array}{c}6,19 \\
\pm 0,03\end{array}$ & $\begin{array}{l}13,56 \\
\pm 0,04\end{array}$ \\
\hline
\end{tabular}


Tabela C.11: KNN - taxas de erro obtidas pelas representações bag-of-related-words que utilizaram medidas de interesse objetivas para gerar os atributos e pela representação bag-of-words para as coleções da ACM.

\begin{tabular}{|c|c|c|c|c|c|c|c|c|}
\hline & \multicolumn{8}{|c|}{ Taxa de Erro } \\
\hline Representação & ACM-1 & ACM-2 & ACM-3 & ACM-4 & ACM-5 & ACM-6 & ACM-7 & ACM-8 \\
\hline Bag-of-words & $\begin{array}{l}10,02 \\
\pm 0,06\end{array}$ & $\begin{array}{c}7,32 \\
\pm 0,04\end{array}$ & $\begin{array}{c}4,96 \\
\pm 0,03\end{array}$ & $\begin{array}{c}2,04 \\
\pm 0,02\end{array}$ & $\begin{array}{c}5,74 \\
\pm 0,03\end{array}$ & $\begin{array}{l}* \mathbf{1}, \mathbf{8 2} \\
\pm 0,03\end{array}$ & $\begin{array}{l}\boldsymbol{*}^{\mathbf{6}, \mathbf{1 8}} \\
\pm 0,03\end{array}$ & $\begin{array}{r}* 4,44 \\
\pm 0,03\end{array}$ \\
\hline Jan. 5 Aut. Conf. 0,25 & $\begin{array}{c}11,02 \\
\pm 0,06\end{array}$ & $\begin{array}{c}11,46 \\
\pm 0,06\end{array}$ & $\begin{array}{c}7,21 \\
\pm 0,03\end{array}$ & $\begin{array}{c}1,02 \\
\pm 0,01\end{array}$ & $\begin{array}{c}5,10 \\
\pm 0,03\end{array}$ & $\begin{array}{c}4,79 \\
\pm 0,04\end{array}$ & $\begin{array}{c}7,89 \\
\pm 0,04\end{array}$ & $\begin{array}{l}9,10 \\
\pm 0,04\end{array}$ \\
\hline Jan. 5 Aut. Conf. 0,5 & $\begin{array}{c}10,28 \\
\pm 0,32\end{array}$ & $\begin{array}{c}9,76 \\
\pm 0,32\end{array}$ & $\begin{array}{c}6,24 \\
\pm 0,32\end{array}$ & $\begin{array}{c}1,28 \\
\pm 0,32\end{array}$ & $\begin{array}{c}4,45 \\
\pm 0,32\end{array}$ & $\begin{array}{c}4,12 \\
\pm 0,32\end{array}$ & $\begin{array}{c}8,10 \\
\pm 0,32\end{array}$ & $\begin{array}{l}9,07 \\
\pm 0,32\end{array}$ \\
\hline Jan. 5 Aut. Conf. $\bar{x}$ & $\begin{array}{l}11,02 \\
\pm 0,05\end{array}$ & $\begin{array}{c}8,54 \\
\pm 0,04\end{array}$ & $\begin{array}{c}5,76 \\
\pm 0,03\end{array}$ & $\begin{array}{c}0,51 \\
\pm 0,01\end{array}$ & $\begin{array}{c}4,44 \\
\pm 0,04\end{array}$ & $\begin{array}{c}3,88 \\
\pm 0,04\end{array}$ & $\begin{array}{c}8,10 \\
\pm 0,05\end{array}$ & $\begin{array}{l}7,88 \\
\pm 0,04\end{array}$ \\
\hline Jan. 5 Aut. Lift 0,1 & $\begin{array}{c}10,28 \\
\pm 0,03\end{array}$ & $\begin{array}{c}8,29 \\
\pm 0,06\end{array}$ & $\begin{array}{c}6,01 \\
\pm 0,04\end{array}$ & $\begin{array}{c}1,26 \\
\pm 0,01\end{array}$ & $\begin{array}{c}4,46 \\
\pm 0,04\end{array}$ & $\begin{array}{c}4,12 \\
\pm 0,02\end{array}$ & $\begin{array}{c}7,26 \\
\pm 0,04\end{array}$ & $\begin{array}{l}8,29 \\
\pm 0,04\end{array}$ \\
\hline Jan. 5 Aut. Lift 0,2 & $\begin{array}{l}10,26 \\
\pm 0,06\end{array}$ & $\begin{array}{c}9,76 \\
\pm 0,06\end{array}$ & $\begin{array}{c}5,78 \\
\pm 0,04\end{array}$ & $\begin{array}{c}1,77 \\
\pm 0,01\end{array}$ & $\begin{array}{c}4,45 \\
\pm 0,03\end{array}$ & $\begin{array}{c}3,66 \\
\pm 0,04\end{array}$ & $\begin{array}{c}7,88 \\
\pm 0,05\end{array}$ & $\begin{array}{l}8,09 \\
\pm 0,02\end{array}$ \\
\hline Jan. 5 Aut. Lift $\bar{x}$ & $\begin{array}{c}9,30 \\
\pm 0,06\end{array}$ & $\begin{array}{c}9,51 \\
\pm 0,06\end{array}$ & $\begin{array}{c}5,27 \\
\pm 0,04\end{array}$ & $\begin{array}{c}1,02 \\
\pm 0,01\end{array}$ & $\begin{array}{c}4,46 \\
\pm 0,02\end{array}$ & $\begin{array}{c}3,90 \\
\pm 0,02\end{array}$ & $\begin{array}{c}8,33 \\
\pm 0,04\end{array}$ & $\begin{array}{l}10,13 \\
\pm 0,06\end{array}$ \\
\hline Jan. 5 Aut. Yule's Q 0,5 & $\begin{array}{l}11,01 \\
\pm 0,06\end{array}$ & $\begin{array}{c}8,78 \\
\pm 0,07\end{array}$ & $\begin{array}{c}6,48 \\
\pm 0,04\end{array}$ & $\begin{array}{c}0,76 \\
\pm 0,01\end{array}$ & $\begin{array}{l}* \mathbf{3}, \mathbf{1 8} \\
\pm 0,02\end{array}$ & $\begin{array}{c}3,66 \\
\pm 0,03\end{array}$ & $\begin{array}{c}6,61 \\
\pm 0,02\end{array}$ & $\begin{array}{l}8,47 \\
\pm 0,04\end{array}$ \\
\hline Jan. 5 Aut. Yule's Q 0,75 & $\begin{array}{r}12,53 \\
\pm 0,06\end{array}$ & $\begin{array}{c}10,73 \\
\pm 0,05\end{array}$ & $\begin{array}{c}6,00 \\
\pm 0,03 \\
\end{array}$ & $\begin{array}{c}1,26 \\
\pm 0,02\end{array}$ & $\begin{array}{c}4,24 \\
\pm 0,04\end{array}$ & $\begin{array}{c}4,58 \\
\pm 0,03\end{array}$ & $\begin{array}{c}6,41 \\
\pm 0,04 \\
\end{array}$ & $\begin{array}{l}8,87 \\
\pm 0,05 \\
\end{array}$ \\
\hline Jan. 5 Aut. Yule's Q $\bar{x}$ & $\begin{array}{l}11,28 \\
\pm 0,04\end{array}$ & $\begin{array}{c}7,07 \\
\pm 0,04\end{array}$ & $\begin{array}{c}5,53 \\
\pm 0,03\end{array}$ & $\begin{array}{c}1,26 \\
\pm 0,02\end{array}$ & $\begin{array}{c}4,88 \\
\pm 0,03\end{array}$ & $\begin{array}{c}4,13 \\
\pm 0,03\end{array}$ & $\begin{array}{c}6,81 \\
\pm 0,04\end{array}$ & $\begin{array}{l}8,49 \\
\pm 0,04\end{array}$ \\
\hline Jan. 5 Aut. Corr. 0,25 & $\begin{array}{c}9,04 \\
\pm 0,04\end{array}$ & $\begin{array}{l}10,49 \\
\pm 0,06\end{array}$ & $\begin{array}{c}6,27 \\
\pm 0,03\end{array}$ & $\begin{array}{c}1,02 \\
\pm 0,02\end{array}$ & $\begin{array}{c}5,32 \\
\pm 0,03\end{array}$ & $\begin{array}{c}4,79 \\
\pm 0,03\end{array}$ & $\begin{array}{c}7,25 \\
\pm 0,04\end{array}$ & $\begin{array}{l}8,68 \\
\pm 0,03\end{array}$ \\
\hline Jan. 5 Aut. Corr. 0,50 & $\begin{array}{l}* \mathbf{8 , 7 8} \\
\pm 0,04\end{array}$ & $\begin{array}{c}10,49 \\
\pm 0,04\end{array}$ & $\begin{array}{c}5,49 \\
\pm 0,04\end{array}$ & $\begin{array}{c}1,27 \\
\pm 0,01\end{array}$ & $\begin{array}{c}4,65 \\
\pm 0,04\end{array}$ & $\begin{array}{c}4,13 \\
\pm 0,03\end{array}$ & $\begin{array}{c}7,25 \\
\pm 0,02\end{array}$ & $\begin{array}{c}8,69 \\
\pm 0,04\end{array}$ \\
\hline Jan. 5 Aut. Corr. $\bar{x}$ & $\begin{array}{c}9,26 \\
\pm 0,05\end{array}$ & $\begin{array}{r}{ }^{*} \mathbf{6 , 8 3} \\
\pm 0,04\end{array}$ & $\begin{array}{c}5,55 \\
\pm 0,04\end{array}$ & $\begin{array}{c}1,01 \\
\pm 0,02\end{array}$ & $\begin{array}{c}4,04 \\
\pm 0,03\end{array}$ & $\begin{array}{c}2,98 \\
\pm 0,02\end{array}$ & $\begin{array}{c}6,40 \\
\pm 0,03\end{array}$ & $\begin{array}{l}8,07 \\
\pm 0,05\end{array}$ \\
\hline Jan. 5 Aut. I.M. 0,005 & $\begin{array}{l}10,77 \\
\pm 0,06\end{array}$ & $\begin{array}{c}8,29 \\
\pm 0,06\end{array}$ & $\begin{array}{c}6,50 \\
\pm 0,05\end{array}$ & $\begin{array}{c}0,77 \\
\pm 0,01\end{array}$ & $\begin{array}{c}3,82 \\
\pm 0,02\end{array}$ & $\begin{array}{c}5,02 \\
\pm 0,03\end{array}$ & $\begin{array}{c}7,90 \\
\pm 0,03\end{array}$ & $\begin{array}{l}8,88 \\
\pm 0,05\end{array}$ \\
\hline Jan. 5 Aut. I.M. 0,01 & $\begin{array}{c}9,78 \\
\pm 0,05\end{array}$ & $\begin{array}{c}9,51 \\
\pm 0,06\end{array}$ & $\begin{array}{c}5,75 \\
\pm 0,03\end{array}$ & $\begin{array}{c}1,28 \\
\pm 0,02\end{array}$ & $\begin{array}{c}5,74 \\
\pm 0,04\end{array}$ & $\begin{array}{c}4,56 \\
\pm 0,04\end{array}$ & $\begin{array}{c}6,18 \\
\pm 0,03\end{array}$ & $\begin{array}{l}8,06 \\
\pm 0,05\end{array}$ \\
\hline Jan. 5 Aut. I.M. $\bar{x}$ & $\begin{array}{l}10,26 \\
\pm 0,05\end{array}$ & $\begin{array}{c}8,54 \\
\pm 0,05\end{array}$ & $\begin{array}{c}5,02 \\
\pm 0,03\end{array}$ & $\begin{array}{c}1,26 \\
\pm 0,01\end{array}$ & $\begin{array}{c}3,60 \\
\pm 0,02\end{array}$ & $\begin{array}{c}3,88 \\
\pm 0,03\end{array}$ & $\begin{array}{c}7,47 \\
\pm 0,04\end{array}$ & $\begin{array}{l}9,07 \\
\pm 0,05\end{array}$ \\
\hline Jan. 5 Aut. Gini 0,005 & $\begin{array}{l}12,78 \\
\pm 0,06\end{array}$ & $\begin{array}{c}9,27 \\
\pm 0,04\end{array}$ & $\begin{array}{c}5,53 \\
\pm 0,04\end{array}$ & $\begin{array}{c}1,27 \\
\pm 0,02\end{array}$ & $\begin{array}{c}5,53 \\
\pm 0,03\end{array}$ & $\begin{array}{c}5,25 \\
\pm 0,04\end{array}$ & $\begin{array}{c}8,52 \\
\pm 0,04\end{array}$ & $\begin{array}{l}8,70 \\
\pm 0,05\end{array}$ \\
\hline Jan. 5 Aut. Gini 0,01 & $\begin{array}{l}10,77 \\
\pm 0,05\end{array}$ & $\begin{array}{c}10,49 \\
\pm 0,03\end{array}$ & $\begin{array}{c}6,03 \\
\pm 0,04\end{array}$ & $\begin{array}{c}1,27 \\
\pm 0,02\end{array}$ & $\begin{array}{c}4,88 \\
\pm 0,03\end{array}$ & $\begin{array}{c}5,25 \\
\pm 0,03\end{array}$ & $\begin{array}{c}8,73 \\
\pm 0,04\end{array}$ & $\begin{array}{l}9,07 \\
\pm 0,05\end{array}$ \\
\hline Jan. 5 Aut. Gini $\bar{x}$ & $\begin{array}{c}11,03 \\
\pm 0,04\end{array}$ & $\begin{array}{c}8,54 \\
\pm 0,04\end{array}$ & $\begin{array}{c}5,06 \\
\pm 0,04\end{array}$ & $\begin{array}{c}0,75 \\
\pm 0,02\end{array}$ & $\begin{array}{c}4,25 \\
\pm 0,02\end{array}$ & $\begin{array}{c}3,89 \\
\pm 0,04\end{array}$ & $\begin{array}{c}8,09 \\
\pm 0,05\end{array}$ & $\begin{array}{l}9,29 \\
\pm 0,04\end{array}$ \\
\hline Jan. 5 Aut. Kappa 0,15 & $\begin{array}{l}11,79 \\
\pm 0,05\end{array}$ & $\begin{array}{c}7,32 \\
\pm 0,04\end{array}$ & $\begin{array}{c}7,44 \\
\pm 0,03\end{array}$ & $\begin{array}{c}1,27 \\
\pm 0,02\end{array}$ & $\begin{array}{c}5,52 \\
\pm 0,03\end{array}$ & $\begin{array}{c}4,82 \\
\pm 0,02\end{array}$ & $\begin{array}{c}8,32 \\
\pm 0,03\end{array}$ & $\begin{array}{l}8,89 \\
\pm 0,03\end{array}$ \\
\hline Jan. 5 Aut. Kappa 0,2 & $\begin{array}{l}12,27 \\
\pm 0,05\end{array}$ & $\begin{array}{c}8,05 \\
\pm 0,04\end{array}$ & $\begin{array}{c}6,97 \\
\pm 0,04\end{array}$ & $\begin{array}{c}1,01 \\
\pm 0,02\end{array}$ & $\begin{array}{c}5,52 \\
\pm 0,02\end{array}$ & $\begin{array}{c}4,35 \\
\pm 0,03\end{array}$ & $\begin{array}{c}8,72 \\
\pm 0,04\end{array}$ & $\begin{array}{l}9,10 \\
\pm 0,04\end{array}$ \\
\hline Jan. 5 Aut. Kappa $\bar{x}$ & $\begin{array}{c}9,78 \\
\pm 0,02\end{array}$ & $\begin{array}{c}7,07 \\
\pm 0,04\end{array}$ & $\begin{array}{c}6,23 \\
\pm 0,03\end{array}$ & $\begin{array}{c}0,77 \\
\pm 0,02\end{array}$ & $\begin{array}{c}3,39 \\
\pm 0,02\end{array}$ & $\begin{array}{c}3,44 \\
\pm 0,03\end{array}$ & $\begin{array}{c}6,18 \\
\pm 0,03\end{array}$ & $\begin{array}{l}8,29 \\
\pm 0,04\end{array}$ \\
\hline Jan. 5 Aut. J.M. 0,01 & $\begin{array}{l}10,28 \\
\pm 0,04\end{array}$ & $\begin{array}{c}9,76 \\
\pm 0,03\end{array}$ & $\begin{array}{c}5,52 \\
\pm 0,03\end{array}$ & $\begin{array}{c}0,76 \\
\pm 0,01\end{array}$ & $\begin{array}{c}5,31 \\
\pm 0,04\end{array}$ & $\begin{array}{c}4,57 \\
\pm 0,02\end{array}$ & $\begin{array}{c}6,82 \\
\pm 0,03\end{array}$ & $\begin{array}{l}9,09 \\
\pm 0,03\end{array}$ \\
\hline Jan. 5 Aut. J.M. 0,02 & $\begin{array}{l}11,77 \\
\pm 0,04\end{array}$ & $\begin{array}{c}10,49 \\
\pm 0,03\end{array}$ & $\begin{array}{c}6,71 \\
\pm 0,04\end{array}$ & $\begin{array}{c}0,76 \\
\pm 0,01\end{array}$ & $\begin{array}{c}5,53 \\
\pm 0,04\end{array}$ & $\begin{array}{c}4,83 \\
\pm 0,03\end{array}$ & $\begin{array}{c}7,04 \\
\pm 0,04\end{array}$ & $\begin{array}{l}8,49 \\
\pm 0,04\end{array}$ \\
\hline Jan. 5 Aut. J.M. $\bar{x}$ & $\begin{array}{c}11,52 \\
\pm 0,04\end{array}$ & $\begin{array}{c}8,78 \\
\pm 0,04\end{array}$ & $\begin{array}{l}* \mathbf{4 , 8 1} \\
\pm 0,03\end{array}$ & $\begin{array}{l}* \mathbf{0 , 5 0} \\
\pm 0,02\end{array}$ & $\begin{array}{c}4,02 \\
\pm 0,03\end{array}$ & $\begin{array}{c}4,13 \\
\pm 0,03\end{array}$ & $\begin{array}{c}7,46 \\
\pm 0,03\end{array}$ & $\begin{array}{c}9,08 \\
\pm 0,02\end{array}$ \\
\hline
\end{tabular}


Tabela C.12: KNN - taxas de erro obtidas pelas representações bag-of-related-words que utilizaram medidas de interesse objetivas para gerar os atributos e pela representação bag-of-words para a coleção Reuters-21578.

\begin{tabular}{|l|r|}
\hline Representação & Taxa de Erro \\
\hline Bag-of-words & $\boldsymbol{* 1 5 , 0 2}$ \\
\hline Jan. 5 Aut. & 18,29 \\
\hline Jan. 5 Aut. Lift 0,1 & 18,21 \\
\hline Jan. 5 Aut. Lift 0,2 & 18,09 \\
\hline Jan. 5 Aut. Lift $\bar{x}$ & 18,41 \\
\hline Jan. 5 Aut. Conf. 0,25 & 18,25 \\
\hline Jan. 5 Aut. Conf. 0,50 & 17,58 \\
\hline Jan. 5 Aut. Conf. $\bar{x}$ & 18,41 \\
\hline Jan. 5 Aut. Yule's Q 0,50 & 19,04 \\
\hline Jan. 5 Aut. Yule's Q 0,75 & 18,33 \\
\hline Jan. 5 Aut. Yule's Q $\bar{x}$ & 18,49 \\
\hline Jan. 5 Aut. Corr. 0,25 & 18,57 \\
\hline Jan. 5 Aut. Corr. 0,50 & 18,45 \\
\hline Jan. 5 Aut. Corr. $\bar{x}$ & 18,09 \\
\hline Jan. 5 Aut. I.M. 0,05 & 19,16 \\
\hline Jan. 5 Aut. I.M. 0,1 & 19,24 \\
\hline Jan. 5 Aut. I.M. $\bar{x}$ & 18,72 \\
\hline Jan. 5 Aut. Gini 0,01 & 18,09 \\
\hline Jan. 5 Aut. Gini 0,04 & 18,49 \\
\hline Jan. 5 Aut. Gini $\bar{x}$ & 18,09 \\
\hline Jan. 5 Aut. Kappa 0,3 & 18,29 \\
\hline Jan. 5 Aut. Kappa 0,5 & 18,96 \\
\hline Jan. 5 Aut. Kappa $\bar{x}$ & 18,84 \\
\hline Jan. 5 Aut. J.M. 0,02 & 18,41 \\
\hline Jan. 5 Aut. J.M. 0,05 & 18,72 \\
\hline Jan. 5 Aut. J.M. $\bar{x}$ & 18,41 \\
\hline
\end{tabular}

Nos resultados obtidos pelo algoritmo de classificação $K N N$ para as coleções da ACM, pode-se notar que o uso das representações com medidas de interesse objetivas fez com que a representação bag-of-related-words obtivesse a menor taxa de erro de classificação para as coleções ACM-1 e ACM-3. Quando foram utilizadas representações bag-of-related-words com itemsets frequentes como atributos, a menor taxa de erro para essas coleções era obtida pela representação bag-of-words. Para a coleção Reuters, diferente do que ocorreu com os demais algoritmos de classificação utilizados neste projeto de doutorado, a menor taxa de erro de classificação não foi obtida pela representação bag-of-related-words. 



\section{Tabelas com os Resultados de Agrupamento}

Neste apêndice são apresentadas as tabelas contendo os resultados do algoritmo de agrupamento hierárquico aglomerativo UPGMA obtidos pela representação bag-of-words e pelas representações bag-of-related-words. A métrica utilizada para avaliar o agrupamento de documentos foi a medida FScore. Na Tabela D.1 são apresentados os resultados obtidos pelas representações bag-of-related-words que utilizaram itemsets frequentes como atributos para as coleções da ACM. Na Tabela D.2 são apresentados os resultados para as coleções da ACM obtidos pelas representação bag-of-related-words que utilizaram medidas objetivas para gerar os atributos. Na Tabela D.3 são apresentados os resultados para a coleção Reuters-21578 obtido pelas representações bag-of-related-words que utilizaram medidas de interesse objetivas para gerar os atributos. Os maiores valores da medida FScore para cada coleção estão assinaladas em negrito nas tabelas. 
Tabela D.1: UPGMA - valores da medida FScore para as coleções da ACM obtidas pelas representações bag-of-related-words que utilizam itemsets frequentes como atributos e pela representação bag-of-words.

\begin{tabular}{|c|c|c|c|c|c|c|c|c|}
\hline & \multicolumn{8}{|c|}{ FScore } \\
\hline Representação & ACM-1 & ACM-2 & ACM-3 & ACM-4 & ACM-5 & ACM-6 & ACM-7 & ACM-8 \\
\hline Bag-of-words & 0,779 & 0,818 & 0,821 & 0,854 & 0,842 & 0,892 & 0,800 & $* 0,867$ \\
\hline Sent. $2 \%$ & 0,783 & 0,928 & 0,864 & 0,888 & 0,833 & 0,898 & 0,870 & 0,779 \\
\hline Sent. 3\% & 0,780 & 0,869 & 0,870 & 0,897 & 0,831 & 0,861 & 0,921 & 0,777 \\
\hline Sent. $4 \%$ & 0,803 & 0,901 & 0,826 & 0,871 & 0,813 & 0,809 & 0,920 & 0,765 \\
\hline Sent. 5\% & 0,727 & 0,914 & 0,817 & 0,850 & 0,789 & 0,845 & 0,873 & 0,805 \\
\hline Sent. $6 \%$ & 0,702 & 0,854 & 0,822 & 0,845 & 0,774 & 0,825 & 0,831 & 0,725 \\
\hline Par. $10 \%$ & 0,735 & 0,918 & 0,816 & 0,900 & 0,802 & 0,848 & 0,868 & 0,766 \\
\hline Par. $11 \%$ & 0,741 & 0,893 & 0,811 & 0,903 & 0,775 & 0,854 & 0,887 & 0,758 \\
\hline Par. $12 \%$ & 0,770 & 0,912 & 0,828 & 0,848 & 0,782 & 0,816 & 0,846 & 0,746 \\
\hline Par. $13 \%$ & 0,747 & 0,902 & 0,796 & 0,857 & 0,765 & 0,813 & 0,857 & 0,739 \\
\hline Par. $14 \%$ & 0,719 & 0,912 & 0,787 & 0,842 & 0,781 & 0,852 & 0,847 & 0,729 \\
\hline Par. $15 \%$ & 0,725 & 0,896 & 0,777 & 0,839 & 0,750 & 0,846 & 0,866 & 0,696 \\
\hline Jan. 5 Aut. & 0.801 & 0.886 & 0.889 & 0.917 & 0.868 & 0.890 & 0.822 & 0.820 \\
\hline Jan. 5 0,06\% & 0,771 & 0,820 & 0,863 & 0,917 & 0,868 & $* 0,910$ & 0,812 & 0,792 \\
\hline Jan. $50,08 \%$ & 0,788 & 0,845 & 0,891 & 0,900 & $* 0,881$ & 0,893 & 0,803 & 0,813 \\
\hline Jan. $51 \%$ & 0,784 & 0,886 & 0,900 & 0,913 & 0,848 & 0,895 & 0,850 & 0,820 \\
\hline Jan. $52 \%$ & 0,806 & 0,912 & 0,843 & 0,909 & 0,829 & 0,880 & *0,930 & 0,795 \\
\hline Jan. $53 \%$ & $* 0,813$ & 0,915 & 0,804 & 0,886 & 0,822 & 0,841 & 0,897 & 0,749 \\
\hline Jan. $102 \%$ & 0,760 & 0,873 & 0,884 & 0,907 & 0,826 & 0,886 & 0,832 & 0,791 \\
\hline Jan. $103 \%$ & 0,744 & 0,864 & 0,877 & 0,912 & 0,843 & 0,875 & 0,895 & 0,797 \\
\hline Jan. $104 \%$ & 0,772 & 0,922 & 0,866 & 0,906 & 0,816 & 0,850 & 0,893 & 0,787 \\
\hline Jan. $105 \%$ & 0,761 & 0,924 & $* 0,904$ & 0,891 & 0,816 & 0,868 & 0,904 & 0,817 \\
\hline Jan. $106 \%$ & 0,788 & 0,913 & 0,797 & 0,881 & 0,810 & 0,871 & 0,894 & 0,815 \\
\hline Jan. $206 \%$ & 0,726 & 0,864 & 0,849 & 0,910 & 0,836 & 0,856 & 0,865 & 0,766 \\
\hline Jan. $207 \%$ & 0,765 & 0,874 & 0,877 & $* 0,921$ & 0,833 & 0,849 & 0,895 & 0,768 \\
\hline Jan. $208 \%$ & 0,773 & 0,912 & 0,901 & 0,889 & 0,813 & 0,865 & 0,890 & 0,789 \\
\hline Jan. $209 \%$ & 0,757 & 0,914 & 0,873 & 0,894 & 0,820 & 0,871 & 0,905 & 0,795 \\
\hline Jan. $2010 \%$ & 0,780 & 0,927 & 0,816 & 0,876 & 0,809 & 0,871 & 0,907 & 0,766 \\
\hline Jan. $3010 \%$ & 0,751 & 0,869 & 0,887 & 0,904 & 0,820 & 0,861 & 0,886 & 0,769 \\
\hline Jan. $3011 \%$ & 0,752 & $*^{*} 0,929$ & 0,893 & 0,889 & 0,814 & 0,872 & 0,919 & 0,764 \\
\hline Jan. $3012 \%$ & 0,730 & 0,921 & 0,875 & 0,904 & 0,804 & 0,849 & 0,908 & 0,782 \\
\hline Jan. $3013 \%$ & 0,749 & 0,915 & 0,791 & 0,887 & 0,803 & 0,861 & 0,900 & 0,767 \\
\hline Jan. $3014 \%$ & 0,768 & 0,921 & 0,845 & 0,890 & 0,811 & 0,853 & 0,900 & 0,781 \\
\hline
\end{tabular}

Tabela D.2: UPGMA - valores da medida FScore para as coleções da ACM obtidas pelas representações bag-of-related-words que utilizaram medidas de interesse objetivas para gerar os atributos e pela representação bag-of-words.

\begin{tabular}{|c|c|c|c|c|c|c|c|c|}
\hline & \multicolumn{8}{|c|}{ FScore } \\
\hline Representação & ACM-1 & ACM-2 & ACM-3 & ACM-4 & ACM-5 & ACM-6 & ACM-7 & ACM-8 \\
\hline Bag-of-words & 0.779 & 0.818 & 0.821 & 0.854 & 0.842 & 0.892 & 0.800 & $* 0.867$ \\
\hline Jan. 5 Aut. Conf. 0,25 & 0,817 & 0,875 & 0,861 & 0,916 & 0,896 & 0,900 & 0,762 & 0,758 \\
\hline Jan. 5 Aut. Conf. 0,5 & $* 0,855$ & 0,882 & 0,886 & 0,922 & 0,911 & 0,884 & 0,799 & 0,744 \\
\hline Jan. 5 Aut. Conf. $\bar{x}$ & 0,794 & 0,888 & 0,873 & 0,916 & 0,895 & 0,891 & 0,791 & 0,767 \\
\hline Jan. 5 Aut. Lift 0,1 & 0,799 & $* 0,889$ & 0,892 & 0,918 & 0,901 & 0,913 & 0,786 & 0,814 \\
\hline Jan. 5 Aut. Lift 0,2 & 0,827 & 0,880 & 0,896 & 0,922 & 0,904 & 0,891 & 0,791 & 0,753 \\
\hline Jan. 5 Aut. Lift $\bar{x}$ & 0,799 & $* 0,889$ & 0,892 & 0,918 & 0,901 & 0,913 & 0,786 & 0,814 \\
\hline Jan. 5 Aut. Yule's Q 0,5 & 0,797 & 0,848 & 0,888 & 0,910 & 0,902 & 0,889 & 0,787 & 0,829 \\
\hline Jan. 5 Aut. Yule's Q 0,75 & 0,796 & 0,872 & 0,904 & $* 0,926$ & 0,902 & 0,910 & 0,763 & 0,824 \\
\hline Jan. 5 Aut. Yule's Q $\bar{x}$ & 0,793 & 0,876 & 0,889 & 0,914 & 0,914 & 0,885 & 0,803 & 0,757 \\
\hline Jan. 5 Aut. Corr. 0,25 & 0,789 & 0,854 & 0,896 & 0,922 & $* 0,915$ & 0,883 & 0,783 & 0,801 \\
\hline Jan. 5 Aut. Corr. 0,50 & 0,831 & 0,877 & 0,883 & 0,922 & 0,909 & $* 0,925$ & 0,805 & 0,778 \\
\hline Jan. 5 Aut. Corr. $\bar{x}$ & 0,797 & 0,880 & 0,888 & 0,920 & 0,901 & 0,909 & 0,814 & 0,809 \\
\hline Jan. 5 Aut. I.M. 0,005 & 0,806 & 0,857 & 0,881 & 0,912 & 0,896 & 0,890 & 0,794 & 0,798 \\
\hline Jan. 5 Aut. I.M. 0,01 & 0,853 & 0,883 & $* 0,908$ & 0,920 & 0,904 & 0,923 & 0,814 & 0,765 \\
\hline Jan. 5 Aut. I.M. $\bar{x}$ & 0,785 & 0,870 & 0,881 & 0,918 & 0,912 & 0,918 & 0,783 & 0,759 \\
\hline Jan. 5 Aut. Gini 0,005 & 0,775 & 0,861 & 0,846 & 0,915 & 0,862 & 0,909 & 0,789 & 0,740 \\
\hline Jan. 5 Aut. Gini 0,01 & 0,792 & 0,885 & 0,868 & 0,918 & 0,909 & 0,895 & 0,781 & 0,735 \\
\hline Jan. 5 Aut. Gini $\bar{x}$ & 0,810 & 0,871 & 0,870 & 0,918 & 0,904 & 0,918 & 0,778 & 0,807 \\
\hline Jan. 5 Aut. Kappa 0,15 & 0,770 & 0,854 & 0,826 & 0,926 & 0,827 & 0,907 & 0,741 & 0,752 \\
\hline Jan. 5 Aut. Kappa 0,2 & 0,771 & 0,866 & 0,864 & 0,910 & 0,858 & 0,915 & 0,747 & 0,778 \\
\hline Jan. 5 Aut. Kappa $\bar{x}$ & 0,778 & 0,875 & 0,872 & 0,918 & 0,905 & 0,897 & $* 0,815$ & 0,803 \\
\hline Jan. 5 Aut. J.M. 0,01 & 0,783 & 0,847 & 0,869 & 0,916 & 0,905 & 0,919 & 0,798 & 0,828 \\
\hline Jan. 5 Aut. J.M. 0,02 & 0,771 & 0,880 & 0,885 & 0,912 & 0,903 & 0,881 & 0,778 & 0,745 \\
\hline Jan. 5 Aut. J.M. $\bar{x}$ & 0,787 & 0,882 & 0,872 & 0,918 & 0,912 & 0,899 & 0,773 & 0,754 \\
\hline
\end{tabular}


Tabela D.3: UPGMA - valores da medida FScore para a coleção Reuters-21578 obtidas pelas representações bag-of-related-words que utilizaram medidas de interesse objetivas para gerar os atributos e pela representação bag-of-words.

\begin{tabular}{|l|r|}
\hline Representação & F Score \\
\hline Bag-of-words & $\boldsymbol{* 0 , 7 0 0 2}^{\mathbf{0}}$ \\
\hline Jan. 5 Aut. & 0,6626 \\
\hline Jan. 5 Aut. Lift 0,1 & 0,6479 \\
\hline Jan. 5 Aut. Lift 0,2 & 0,6681 \\
\hline Jan. 5 Aut. Lift $\bar{x}$ & 0,6579 \\
\hline Jan. 5 Aut. Conf. 0,25 & 0,6597 \\
\hline Jan. 5 Aut. Conf. 0,5 & 0,6491 \\
\hline Jan. 5 Aut. Conf. $\bar{x}$ & 0,6491 \\
\hline Jan. 5 Aut. Yule's Q 0,50 & 0,6648 \\
\hline Jan. 5 Aut. Yule's Q 0,75 & 0,6680 \\
\hline Jan. 5 Aut. Yule's Q $\bar{x}$ & 0,6446 \\
\hline Jan. 5 Aut. Corr. 0,25 & 0,6644 \\
\hline Jan. 5 Aut. Corr. 0,50 & 0,6766 \\
\hline Jan. 5 Aut. Corr. $\bar{x}$ & 0,6662 \\
\hline Jan. 5 Aut. I.M. 0,05 & 0,6565 \\
\hline Jan. 5 Aut. I.M. 0,1 & 0,6618 \\
\hline Jan. 5 Aut. I.M. $\bar{x}$ & 0,6599 \\
\hline Jan. 5 Aut. Gini 0,01 & 0,6305 \\
\hline Jan. 5 Aut. Gini 0,04 & 0,6657 \\
\hline Jan. 5 Aut. Gini $\bar{x}$ & 0,6513 \\
\hline Jan. 5 Aut. Kappa 0,3 & 0,6636 \\
\hline Jan. 5 Aut. Kappa 0,5 & 0,6422 \\
\hline Jan. 5 Aut. Kappa $\bar{x}$ & 0,6610 \\
\hline Jan. 5 Aut. J.M. 0,02 & 0,6655 \\
\hline Jan. 5 Aut. J.M. 0,05 & 0,6778 \\
\hline Jan. 5 Aut. J.M. $\bar{x}$ & 0,6741 \\
\hline
\end{tabular}

Para as coleções da ACM, a representação bag-of-related-words obteve o maior valor da medida FScore para a maioria das coleções (7 de 8). O uso de medidas objetivas melhorou os resultados para a maioria das situações. Já para a coleção Reuters, assim como no algoritmo KNN que utiliza cálculo de similaridades entre objetos, o maior valor da FScore foi obtido pela representação bag-of-words. 